$\star^{\star \star \star \star} \star$ Co-funded by the

Cooperation for innovation and the exchange of good practices sub-programme

\title{
EVENT PROJECT
}

EUROPEAN AND VIETNAMESE COLLABORATION ON GRADUATE EMPLOYMENT

\section{VIETNAMESE GRADUATES' LABOUR MARKET ENTRY AND EMPLOYMENT: A TRACER STUDY}

Nguyen Van Thang José María Peiró Le Quang Canh Vicente González-Romá Vicente Martínez-Tur 



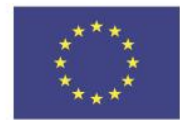

Co-funded by the

Erasmus+ Programme

of the European Union

Cooperation for innovation and the exchange of good practices sub-programme

EVENT PROJECT

EUROPEAN AND VIETNAMESE COLLABORATION

ON GRADUATE EMPLOYMENT

\title{
VIETNAMESE GRADUATES' \\ LABOUR MARKET ENTRY AND EMPLOYMENT: \\ A TRACER STUDY
}

\author{
Nguyen Van Thang \\ National Economics University \\ José María Peiró \\ University of Valencia and Ivie \\ Le Quang Canh \\ National Economics University \\ Vicente González-Romá \\ University of Valencia \\ Vicente Martínez-Tur \\ University of Valencia
}

April 2020 
Disclaimer: "The European Commission's support for the production of this publication does not constitute an endorsement of the contents, which reflect the views only of the authors, and the Commission cannot be held responsible for any use which may be made of the information contained therein.".

Suggested citation:

Van Thang, N., J. M. Peiró, L. Q. Canh, V. González-Romá and V. Martínez-Tur (2020). Vietnamese graduates' labour market entry and employment: A tracer study. Uppsala (Sweden): Uppsala University. DOI: 10.33063/diva-409987

ISBN: 978-91-506-2828-9

1st edition, April 2020

Uppsala University PO Box 256, SE-751 05 Uppsala, Sweden

(C) The authors

This work is published under the Creative Commons Attribution (CC BY 4.0) licence. Anyone may reproduce, distribute, translate and create derivative works of this article (for both commercial and non-commercial purposes), subject to full attribution to the original publication and authors. The full terms of this licence may be seen at http://creativecommons.org/licences/by/4.0/legalcode 


\section{PROLOGUE}

Students' labour market entry and employment after graduation is an important issue for education policy makers, University authorities and managers, employers, researchers, and graduates and their families. It is a critical challenge for all the actors involved to ensure that the human capital generated and developed in universities leads to proper jobs that can optimally contribute to the development of society and the country's economy. This objective implies that graduates are able to obtain high quality jobs that fit their education and level of qualifications. This is an important aspiration of students and their families, who invest in graduates' education and of the whole society, which also makes important contributions to their education.

In the context of a rapidly changing socio-economic context and labour market, a growing demand for university graduates, and increasing university enrolment, the creation of jobs for newly graduated students becomes more difficult and urgent. Enhancing the employability of students is an important objective of the employment and education agendas of each country. This book is written to increase the understanding of the employability of university graduates, in order to improve their employment capacity and bridge the gap between the university and the labour market.

This book is based on the Europe-Vietnam Collaborative on Graduates' Employment project, funded and supported by the European Union under the Erasmus + CBHE Program, EVENT, 573903-EPP-1-2016-1-SE-EPPKA2-CBHE-SP. The broader objective of the EVENT Project was to contribute to increasing the employability of university graduates in Vietnam. To achieve this central objective, the project carried out several actions whose outputs may be found in the web portal that was transferred to the Vietnamese Ministry of Education and Training (MOET) at the end of the project.

The project consortium consisted of nine universities from Europe and Vietnam: Uppsala University (Sweden-leader of the project), Royal Swedish Technical University (Sweden), University of Valencia (Spain), University of Groningen (Netherlands), National Economics University, Hanoi University of Industry, Hue University, Ho Chi Minh City University of Technical Education, and Ho Chi Minh City University of Technology. This book is a product of the project and led by the University of Valencia in collaboration with the National Economics University.

One key action of the project was the development of a tracer study to study the situation of the job market entry and labour status of the graduates of the five Vietnamese universities involved in the project. This tracer study aimed to fulfil, among others, the following functions:

- to provide feedback to the HEI to improve the redesigning of the curricula taught and better respond to the demands of the job market;

- to provide occupational information for young people and their families that is relevant for vocational orientation and guidance;

- to offer indicators to evaluate the effectiveness of the HEI in increasing graduates' employability and orientating and evaluating higher education policies; 
- to offer a tool for other Universities to use to perform tracer studies based on their specific needs and aims.

The context, aims, methods, and results of the tracer study, as well as a number of conclusions and recommendations, are presented in this book, which has also been published in Vietnamese. The study was developed by the authors, who are professors at the University of Valencia and the National Economics University. The university graduates' survey was conducted with significant support from Vietnamese partner universities under the overall management and coordination of Uppsala University and the project coordinators: Ms. Oddný Ósk Sverrisdóttir and Mr. Björn Nyström. The project coordinators helped to organise the necessary support activities to conduct the surveys and compile this book.

The authors would like to acknowledge and express their gratitude for the support and contributions of many officials and individuals in the preparation of this book: Mr. Hoang Cong Dung, Ms. Bui Lan Huong (Ministry of Education and Training); Mr. Pham Hong Chuong-Rector, Mr. Le Viet Thuy, Mr. Bui Trung Hai, (National Economics University); Mr. Le Viet Anh, Mr. Nguyen Van Thanh, Ms. Dinh Thi Hai Ha, Mr. Tran Viet Hoi (Hanoi University of Industry); Mr. Truong Quy Tung - Vice Rector, Mr. Hoang Huu Hanh, Mr. Hoang Kim Toan (Hue University); Mr. Bui Xuan Lam - Vice Rector, Ms. Nguyen Lan Huong, Mr. Huynh Thanh Tung (Ho Chi Minh City University of Technology); Do Van Dung - Rector, Mr. Nguyen Vu Lan (Ho Chi Minh City University of Technical Education).

The authors would also like to thank 1710 graduates from the five Vietnamese partner universities for their time and sincere comments when participating in the survey. Without their cooperation, this study would not have been possible, and their contributions have shed light on the complex and interesting reality of graduates' labour market and job insertion situation and processes.

Hanoi, 15th of April, 2020. 


\section{TABLE OF CONTENTS}

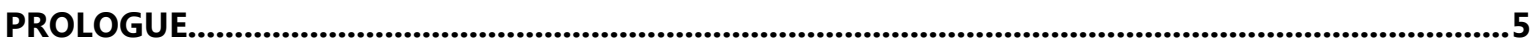

EXECUTIVE SUMMARY .....................................................................................................................15

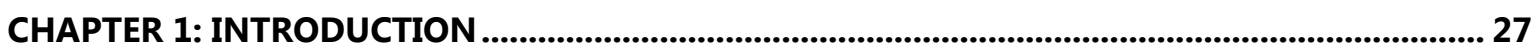

1.1. Higher education in Vietnam........................................................................................................ 28

1.2. Nation-wide and university surveys on graduate employability ...................................... 30

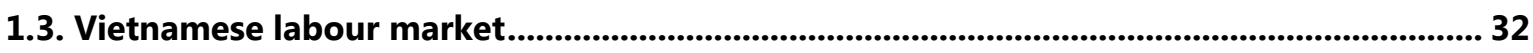

1.3.1. Labour force

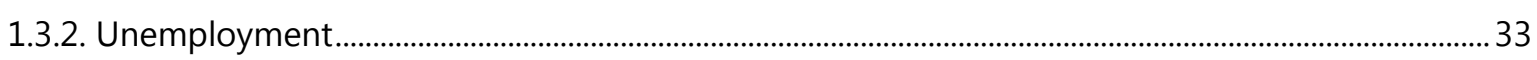

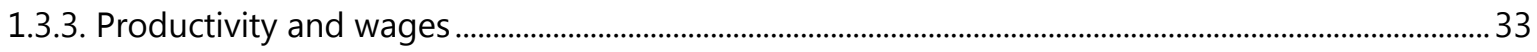

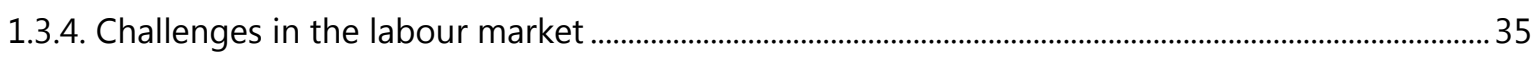

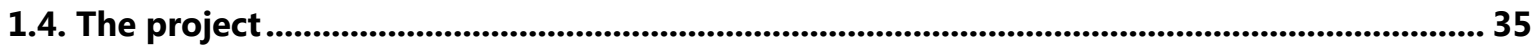

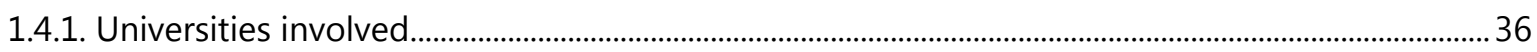

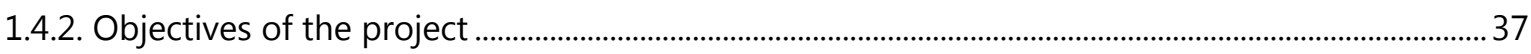

1.4.3. Connection to other parts of the project............................................................................................ 38

1.5. Contents and structure of the report ........................................................................................ 38

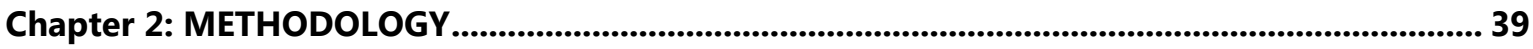

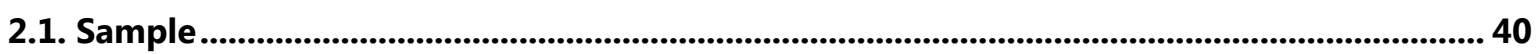

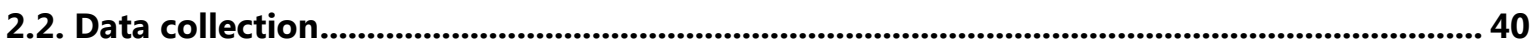

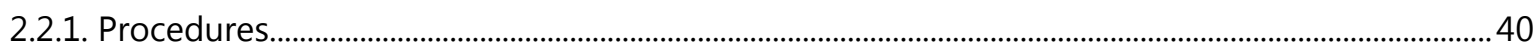

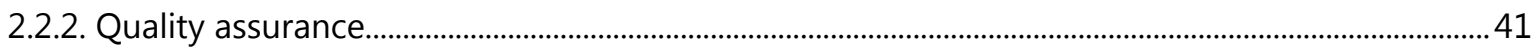

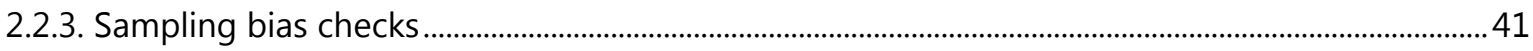

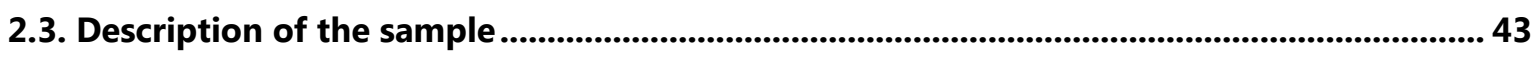

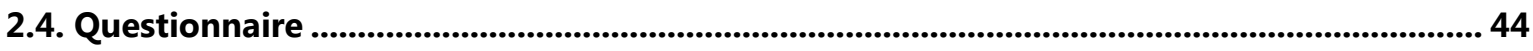

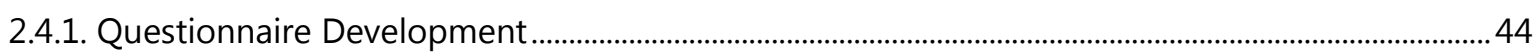

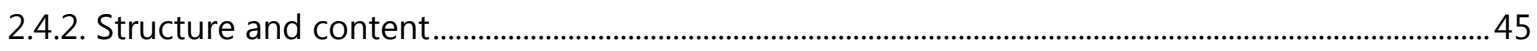

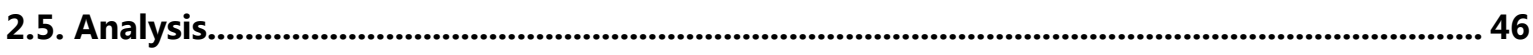

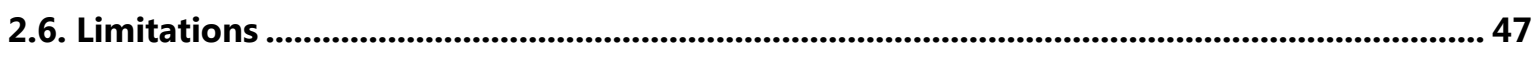

CHAPTER 3: SURVEY RESULTS FOR THE TOTAL SAMPLE OF GRADUATES .................................. 49

3.1. Graduates' employment status ...................................................................................... 50

3.1.1. Current employment situation …………………………………………………………………..... 50

3.1.2. Number of jobs since graduation .............................................................................................................. 51

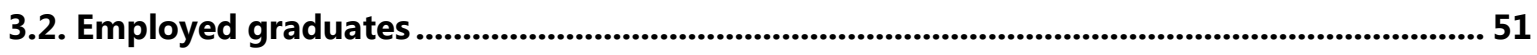

3.2.1. Time needed to find the first paid job after graduation .......................................................................... 51

3.2.2. Strategies to find first paid job after graduation ....................................................................................... 53

3.2.3. Strategies to find the current job after graduation............................................................................ 53

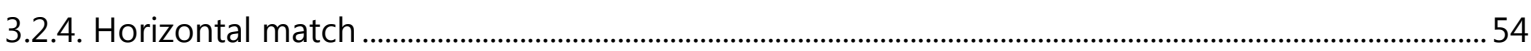


3.2.5. Level of education required for the current job ................................................................................. 54

3.2.6. Competences-job requirement match......................................................................................................... 55

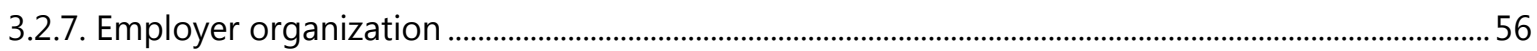

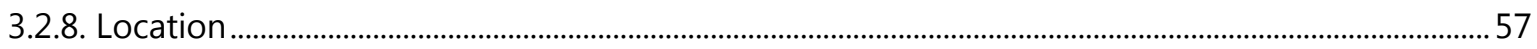

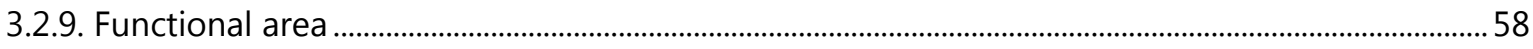

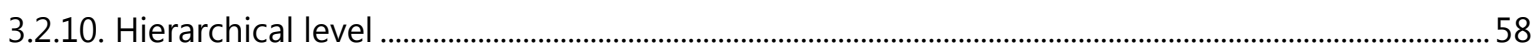

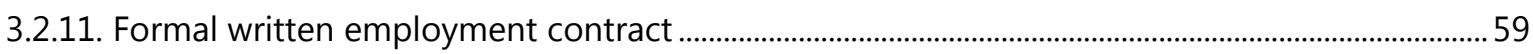

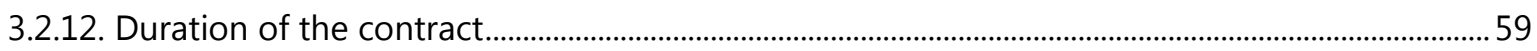

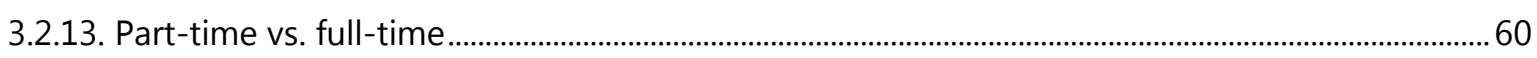

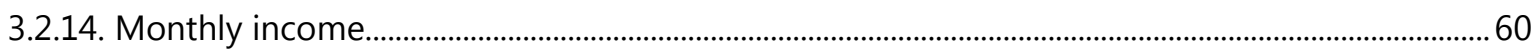

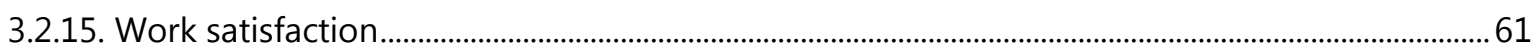

3.2.16. Importance of competencies for good performance ........................................................................ 62

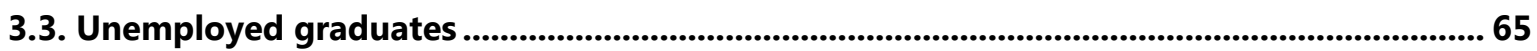

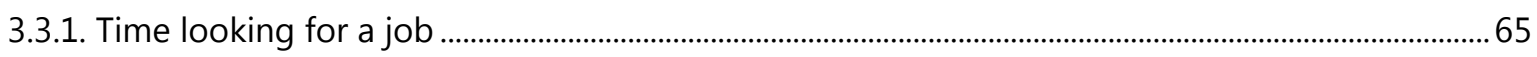

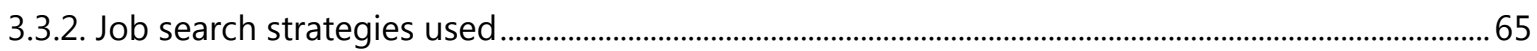

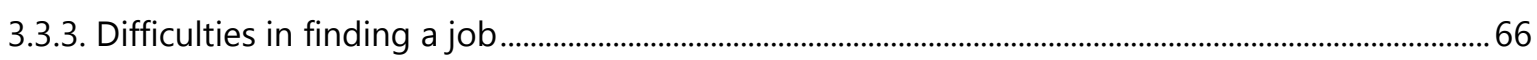

3.3.4. University career centre: demand and services ........................................................................................ 67

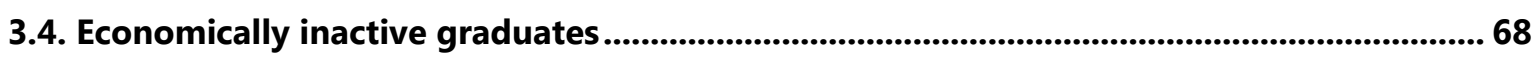

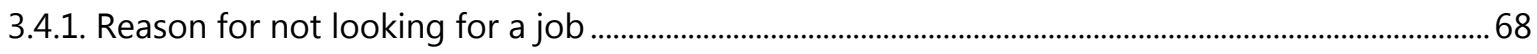

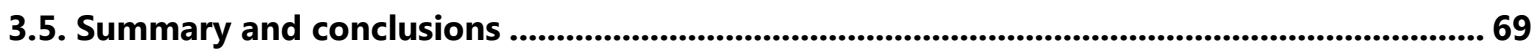

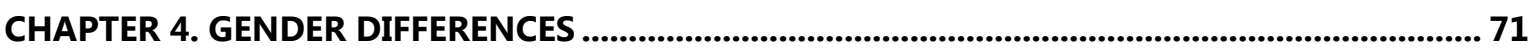

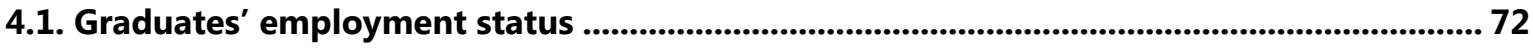

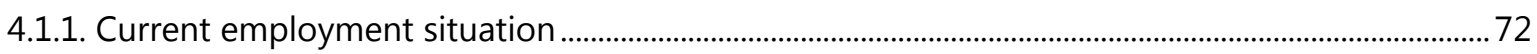

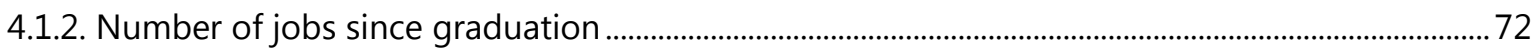

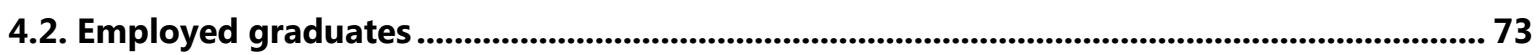

4.2.1. Time needed to find the first paid job after graduation ......................................................................... 73

4.2.2. Strategies to find first paid job after graduation ................................................................................ 74

4.2.3. Strategies to find the current job after graduation............................................................................. 75

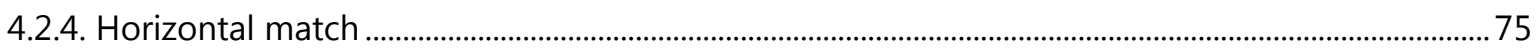

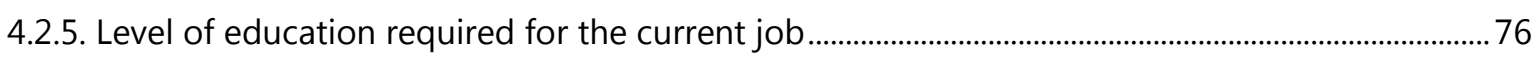

4.2.6. Competencies-job requirement match....................................................................................................

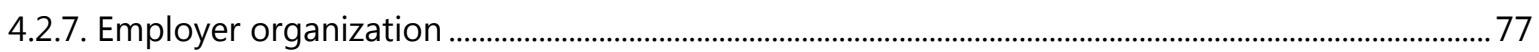

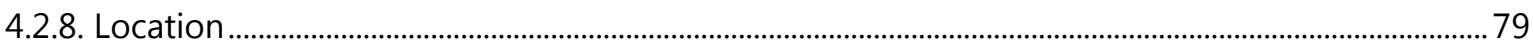

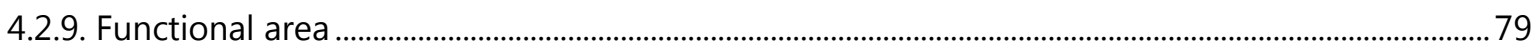

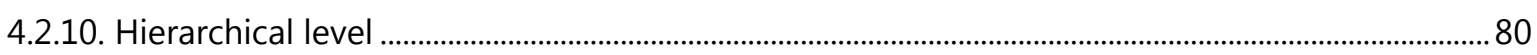

4.2.11. Formal written employment contract ............................................................................................... 81

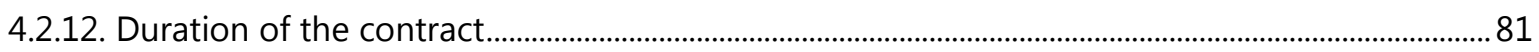

4.2.13. Part-time vs. full-time ................................................................................................................. 82

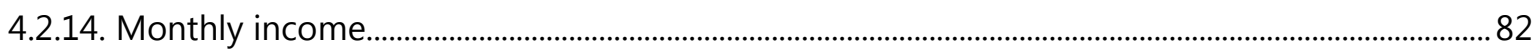

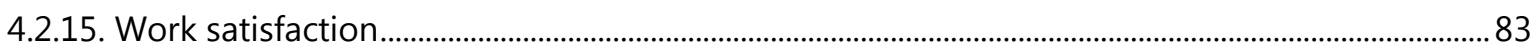

4.2.16. Importance of competencies for good performance .................................................................... 83 
4.3.1. Time spent looking for a job ....................................................................................................................... 87

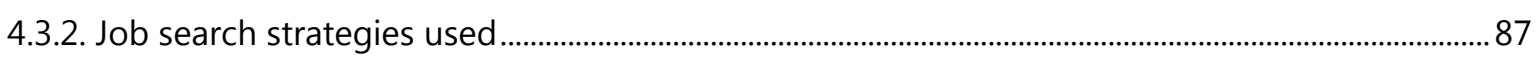

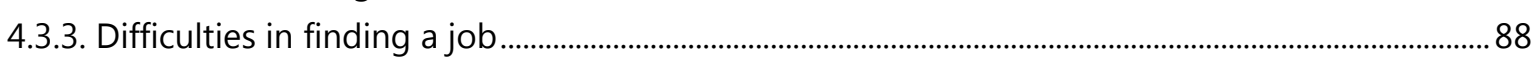

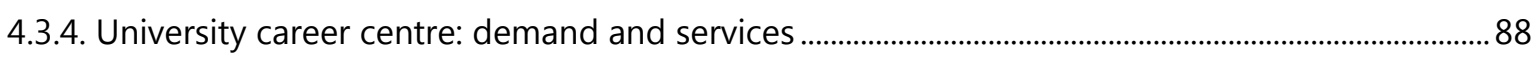

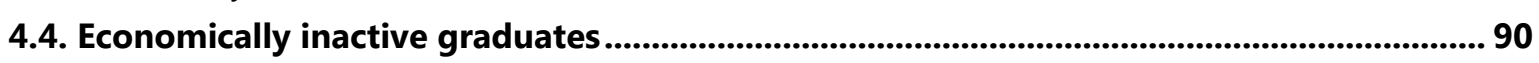

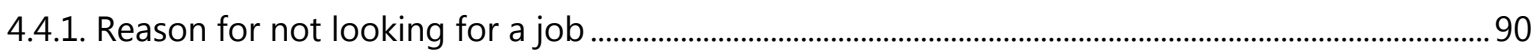

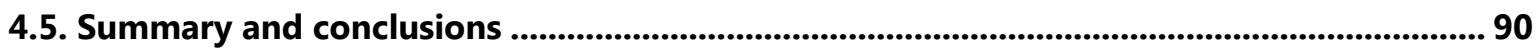

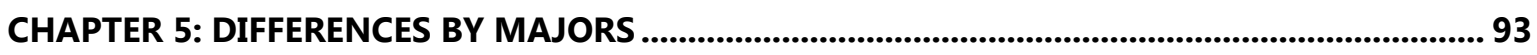

5.1. Graduates' employment status ...................................................................................................... 94

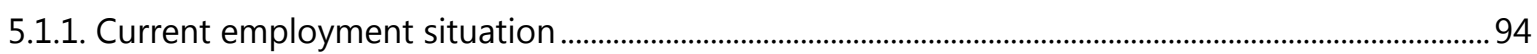

5.1.2. Number of jobs since graduation ........................................................................................................ 95

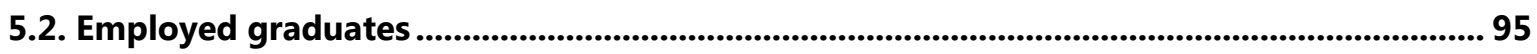

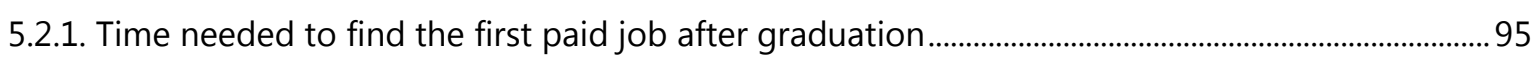

5.2.2. Strategies to find first paid job after graduation ................................................................................

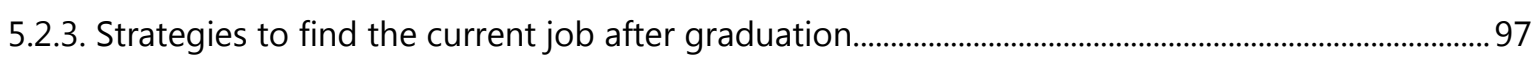

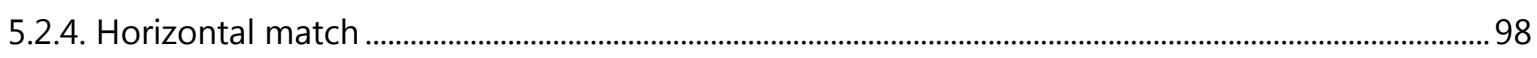

5.2.5. Level of education required for the current job................................................................................. 99

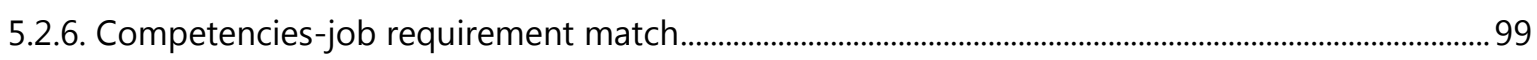

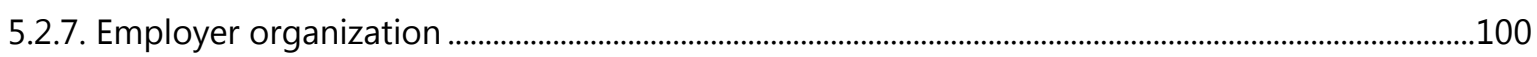

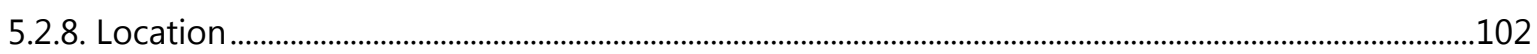

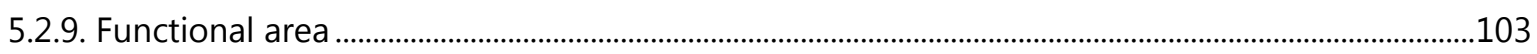

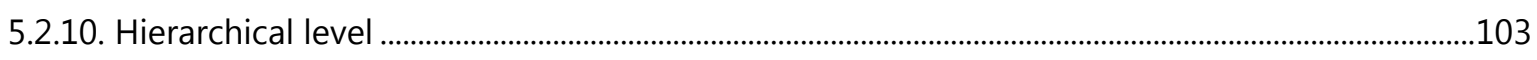

5.2.11. Formal written employment contract .................................................................................................104

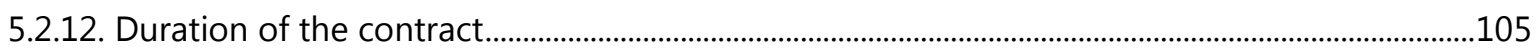

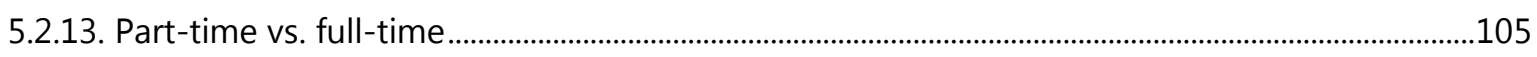

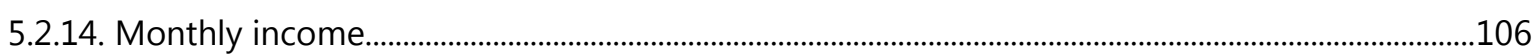

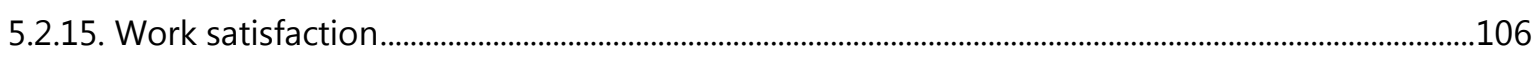

5.2.16. Importance of competences for good performance ...................................................................107

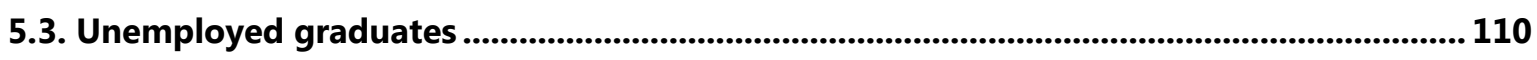

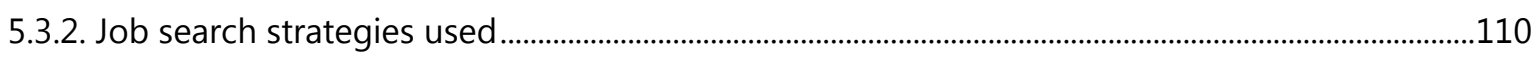

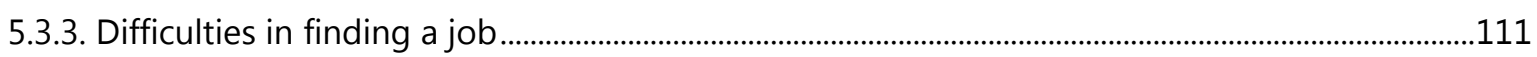

5.3.4. University career center: demand and services ................................................................................112

5.4. Economically inactive graduates ............................................................................................ 113

5.4.1. Reason for not looking for a job .......................................................................................................... 113

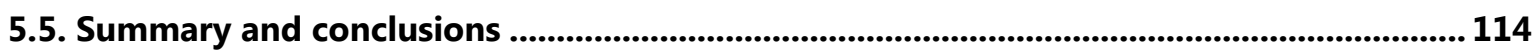

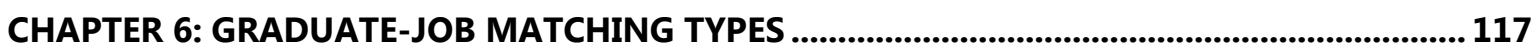

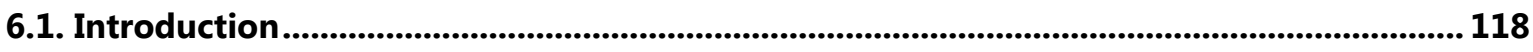

6.2. Distribution of graduates by groups according to the double matching.................................. 119

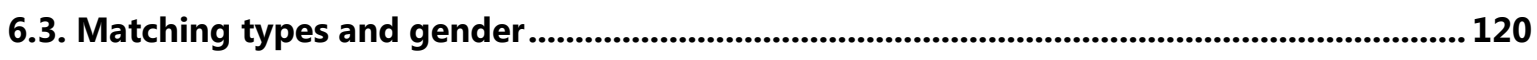

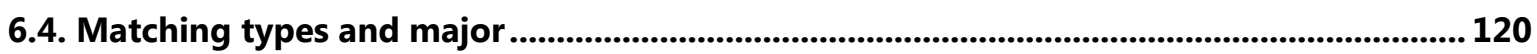


6.5. Matching types and job search strategies.

6.6. Matching types and employed vs self-employed .................................................................... 124

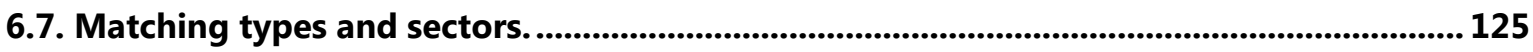

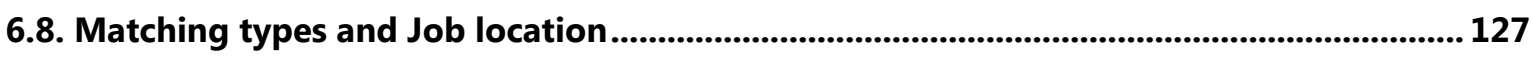

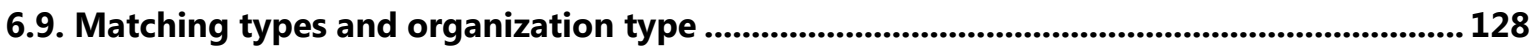

6.10. Matching types and organization size ............................................................................. 129

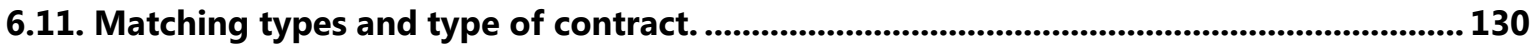

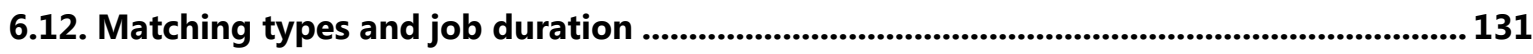

6.13. Matching types and full-time vs part-time job................................................................... 132

6.14. Matching types and hierarchical level.................................................................................... 133

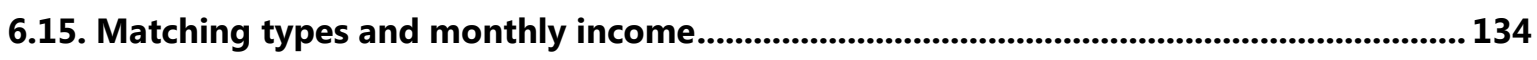

6.16. Matching types and work satisfaction ................................................................................. 135

6.17. Matching types and the match between competences and job requirements ............... 136

6.18. Matching types and competence importance.......................................................................... 137

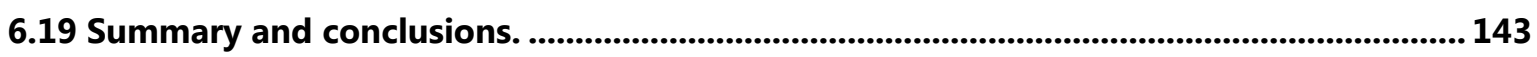

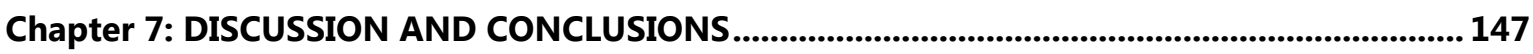

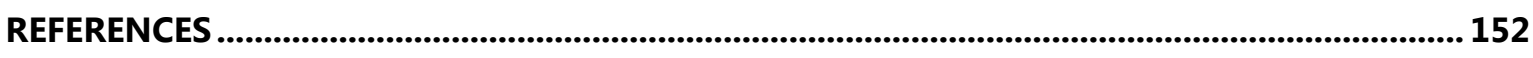

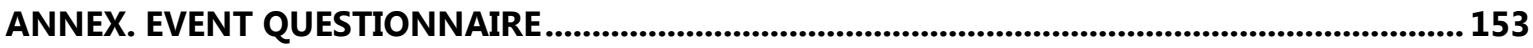




\section{LIST OF FIGURES}

Figure 1.1. The number of universities in Vietnam, 2000-2017

Figure 1.2: Faculty with doctoral degrees at universities and colleges during the period $2000-$ 2017

Figure 1.3. Probability distribution of universities by number of students enrolled .................................. 30

Figure 1.4. Shares of the employed labour force by sectors in 2017 ......................................................... 32

Figure 1.5. Unemployment rate in Vietnam, 2008-2018 ............................................................................

Figure 1.6. Labour productivity and salary, 2005-2017 ................................................................................. 34

Figure 2.1. Shares of university participation in the population and survey sample................................. 42

Figure 2.2. Shares of respondents by gender and major in the population and survey sample.......... 42

Figure 2.3. Numbers of respondents and response rates of member universities .................................... 43

Figure 2.4. Composition of the survey sample ...................................................................................................... 44

Figure 3.1. Current employment situation......................................................................................................... 50

Figure 3.2. Number of jobs since graduation................................................................................................ 51

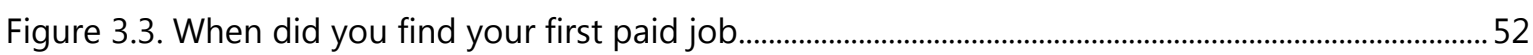

Figure 3.4. The average number of months to find the first paid job after graduation......................................... 52

Figure 3.5. Strategies to find your first paid job after graduation or the job you already had when

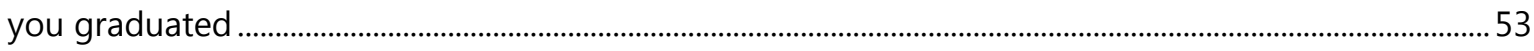

Figure 3.6. Strategies to find your current job after graduation ................................................................... 54

Figure 3.7. To what extent is the content of your current job related to the content of your

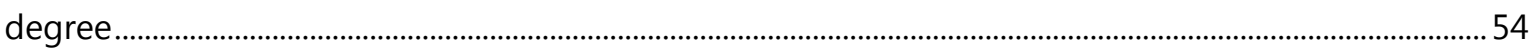

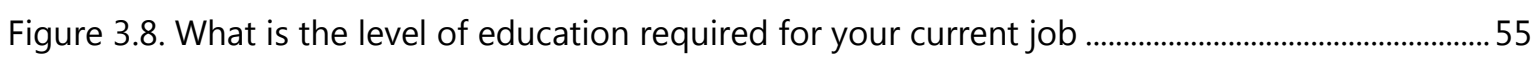

Figure 3.9. To what extent do your competences match the requirements of your job ....................................... 55

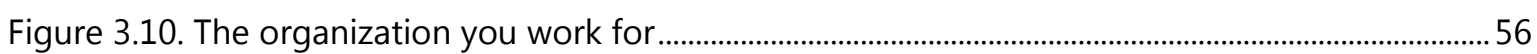

Figure 3.11. What is the sector of economic activity of your organization...................................................... 56

Figure 3.12. How many employees does your company have..........................................................................57

Figure 3.13. Where is your current job located ........................................................................................ 57

Figure 3.14. In what functional area of the company is your current job included .................................. 58

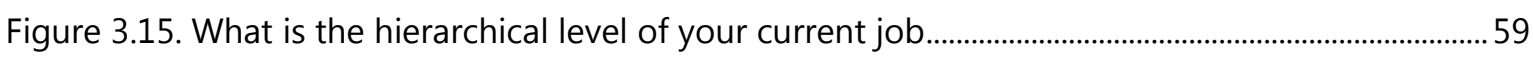

Figure 3.16. Did you sign a formal written employment contract for your current job....................................... 59

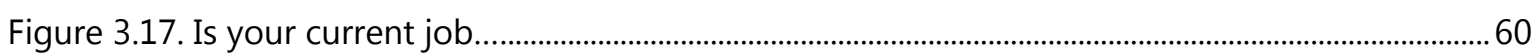

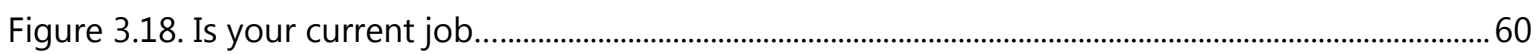

Figure 3.19. An estimation of your monthly income in your current job...................................................... 61

Figure 3.20. What is the degree of satisfaction or dissatisfaction produced by each of the following aspects of your job

Figure 3.21. Rate the importance of each of the following factors and competences for good performance in your current job: cognitive competences.

Figure 3.22. Rate the importance of each of the following factors and competences for good performance in your current job: management competences. 
Figure 3.23. Rate the importance of each of the following factors and competences for good performance in your current job: interpersonal competences

Figure 3.24. Rate the importance of each of the following factors and competences for good performance in your current job: instrumental competences.

Figure 3.25. Rate the importance of each of the following factors and competences for good performance in your current job: attitudinal competences

Figure 3.26. How many months have you been looking for a job................................................................. 65

Figure 3.27. What are the 3 job search strategies you have been using more frequently....................................... 66

Figure 3.28. Rate the degree of responsibility of each of the following factors in your difficulties in finding a job

Figure 3.29. Do you want the career centre of your university to support you in searching for a job.

Figure 3.30. If yes, what do you want the Career Centre to offer (multiple responses) ......................................... 68

Figure 3.31. Why aren't you looking for a job right now? (choose the most important reason) .........69

Figure 4.1. Current employment situation, by gender................................................................................ 72

Figure 4.2. Number of jobs since graduation, by gender.................................................................................. 73

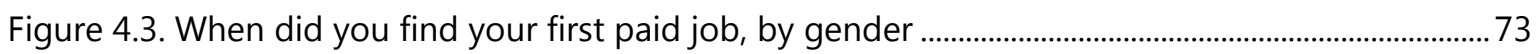

Figure 4.4. The average number of months to find the first paid job after graduation, by gender....74 Figure 4.5. Strategies to find your first paid job after graduation or the job you already had when you graduated, by gender.

Figure 4.6. Strategies to find your current job after graduation, by gender ................................................. 75

Figure 4.7. To what extent does the content of your current job relate to the content of your

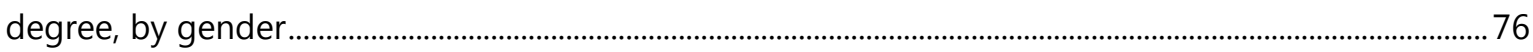

Figure 4.8. What is the level of education required for your current job, by gender ...............................76

Figure 4.9. To what extent do your competencies match the requirements of your job, by gender.77

Figure 4.11. Sector of economic activity of your organization, by gender .................................................. 78

Figure 4.12. How many employees does your company have, by gender .................................................... 79

Figure 4.13. Where is your current job located, by gender ............................................................................ 79

Figure 4.14. In what functional area of the company is your current job included, by gender .............80 80

Figure 4.15. What is the hierarchical level of your current job, by gender........................................... 80

Figure 4.16. Did you sign a formal written employment contract for your current job, by gender.... 81

Figure 4.17. Is your current job... by gender................................................................................................. 81

Figure 4.18. Is your current job... by gender................................................................................................ 82

Figure 4.19. An estimation of your monthly income in your current job, by gender................................. 82

Figure 4.20. What is the degree of satisfaction or dissatisfaction produced by each of the following aspects of your job, by gender

Figure 4.21. Rate the importance of each of the following factors and competences for good performance in your current job, by gender: cognitive competences

Figure 4.22. Rate the importance of each of the following factors and competences for good performance in your current job, by gender: management competences

Figure 4.23. Rate the importance of each of the following factors and competences for good performance in your current job, by gender: interpersonal competences 
Figure 4.24. Rate the importance of each of the following factors and competences for good performance in your current job, by gender: instrumental competences.

Figure 4.25. Rate the importance of each of the following factors and competences for good performance in your current job, by gender: attitudinal competences........................................................... 86

Figure 4.26. Average number of months that you have been looking for a job, by gender.................... 87

Figure 4.27. What are the 3 job search strategies you have been using more frequently, by gender

Figure 4.28. Rate the degree of responsibility of each of the following factors in your difficulties in finding a job, by gender.

Figure 4.29. Do you want the career centre of your university to support you in searching for a job, by gender.

Figure 4.30. If yes, what do you want the Career Centre to offer, by gender (multiple responses).... 89 Figure 4.31. Why aren't you looking for a job right now, by gender? (choose the most important reason)

Figure 5.1. Current employment situation, by major...

Figure 5.2. Number of jobs since graduation, by major ............................................................................. 95

Figure 5.3. When did you find your first paid job, by major ............................................................................ 96

Figure 5.4. The average numbers of months to find the first paid job after graduation, by major ....96

Figure 5.5. Strategies to find your first paid job after graduation or the job you already had when you graduated, by major.

Figure 5.6. Strategies to find your current job after graduation, by major

Figure 5.7. To what extent is the content of your current job related to the content of your

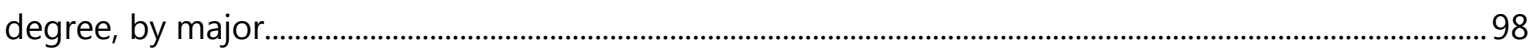

Figure 5.8. What is the level of education required for your current job, by major ................................. 99

Figure 5.9. To what extent do your competences match the requirements of your job, by major..... 99

Figure 5.11. What is the sector of economic activity of your organization, by major ..........................................101

Figure 5.12. How many employees does your company have, by major ...................................................102

Figure 5.13. Where is your current job located, by major ..............................................................................102

Figure 5.14. In what functional area of the company is your current job included, by major..............103

Figure 5.15. What is the hierarchical level of your current job, by major .................................................104

Figure 5.16.. Did you sign a formal written employment contract for your current job, by major....104

Figure 5.17. Is your current job... by major .................................................................................................

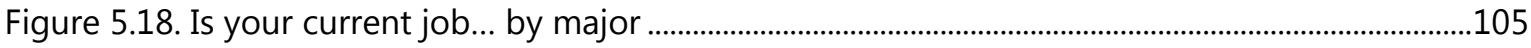

Figure 5.19. An estimation of your monthly income in your current job, by major .................................106

Figure 5.20. What is the degree of satisfaction or dissatisfaction produced by each of the following aspects of your job, by major

Figure 5.21. Rate the importance of each of the following factors and competences for good performance in your current job, by major: cognitive competences

Figure 5.22. Rate the importance of each of the following factors and competences for good performance in your current job, by major: management competences

Figure 5.23. Rate the importance of each of the following factors and competences for good performance in your current job, by major: interpersonal competences. 
Figure 5.24. Rate the importance of each of the following factors and competences for good performance in your current job, by major: instrumental competences

Figure 5.25. Rate the importance of each of the following factors and competences for good performance in your current job, by major: attitudinal competences ..........................................................109

Figure 5.26. Average number of months you have been looking for a job, by major .................................................110

Figure 5.27. What are the 3 job search strategies you have been using more frequently, by major111 Figure 5.28. Rate the degree of responsibility of each of the following factors in your difficulties in finding a job, by major.

Figure 5.29. Do you want the career centre of your university to support you in searching for a job, by major

Figure 5.30. If yes, what do you want the Career Centre to offer, by major (multiple responses).....113 Figure 5.31. Why aren't you looking for a job right now, by major? (choose the most important reason)

Figure 6.1. Double match: general results ..................................................................................................119

Figure 6.2. Matching types and gender ...................................................................................................120

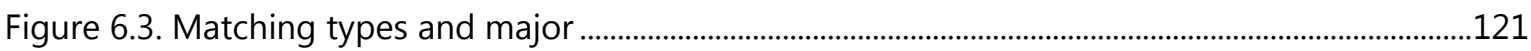

Figure 6.4a. Matching type (G1) and job search strategies .......................................................................122

Figure 6.4b. Matching type (G2) and job search strategies.................................................................122

Figure 6.4c. Matching type (G3) and job search strategies .......................................................................123

Figure 6.4d. Matching type (G4) and job search strategies.....................................................................123

Figure 6.5. Matching types and employed vs. self-employed ........................................................................125

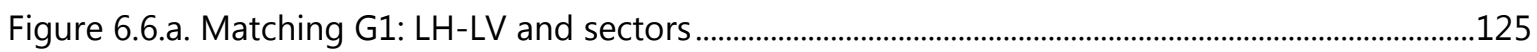

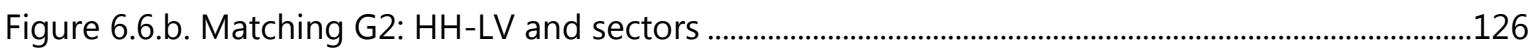

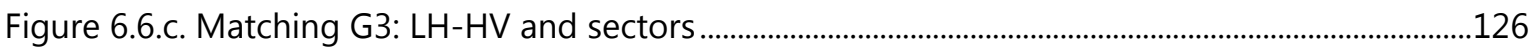

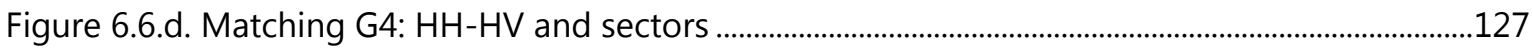

Figure 6.7. Matching types and job location ........................................................................................128

Figure 6.8. Matching types and organization type ..................................................................................129

Figure 6.9. Matching types and organization size ...................................................................................130

Figure 6.10. Matching types and formal contracts .....................................................................................131

Figure 6.11. Matching types and job duration .......................................................................................132

Figure 6.12. Matching types and full-time vs part-time job.............................................................................133

Figure 6.13. Matching types and hierarchical level ..........................................................................................134

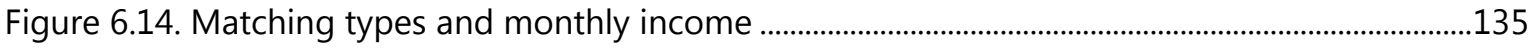

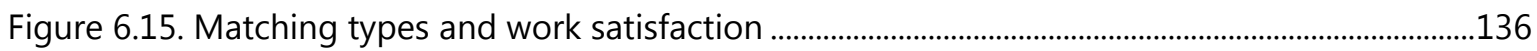

Figure 6.16. Matching types and competences-job requirements match....................................................137

Figure 6.10.a. Matching types and importance of cognitive competences ..............................................139

Figure 6.10.b. Matching types and importance of management competences ..................................................140

Figure 6.10.c. Matching types and importance of interpersonal competences ....................................................141

Figure 6.10.d. Matching types and importance of instrumental competences..................................................142

Figure 6.10.e. Matching types and importance of attitudinal competences ...........................................143 



\section{EXECUTIVE SUMMARY}

\section{Structure of the executive summary}

> The executive summary is structured in five main sections:

- Introduction: It presents the context, objectives, functions, and method of the study.

- Graduates' job search

- Graduates' job characteristics

- Graduates' job quality

- 'Soft' competencies and effective performance

\section{INTRODUCTION}

\section{Context}

\section{Objectives}

\section{Functions}

> This project responds to the needs of Vietnamese higher education institutions. Unemployment of university graduates in Vietnam may partly stem from a mismatch between the education offered and the demands of the labour market. The feedback from the labour market seems to support this, but employers also mention a lack of "soft" competencies in newly graduated job applicants. The responses from graduates suggest a lack of actors bridging the gap between universities and employers, whereas MOLISA has stated that there is a surplus of graduates recently, given the countries' current economy. Moreover, the available information on the true state of employment of university graduates is not sufficient for universities in developing their curriculums and for MOET and MOLISA in their management.

The broader objective of the project is to increase employability of university graduates in Vietnam. To reach the central objectives, the project attempts to work towards the following specific objectives:

- to identify the main characteristics of the labour-market insertion processes of University graduates through a survey study addressed to graduates from five Vietnamese Universities.

- to provide information about the employment status, working conditions, and characteristics of the graduates' jobs.

- to analyse the job search processes and strategies and their effectiveness in the different segments of the labour market.

- to provide indicators of the usefulness of their University education and the Degree obtained in getting a job, the job quality (in terms of fit to the Degree, job salary, job satisfaction, etc.), and their work performance.

- to provide information about unemployed and inactive graduates.

$>$ The tracer studies aim to fulfil, among others, the following functions:

- to provide feedback to the HEI to improve the redesigning of the curricula taught and better respond to the demands of the labour market;

- to provide occupational information for young people and their families that is relevant for vocational orientation and guidance,

- to offer indicators to evaluate the effectiveness of the HEI in increasing the graduates' employability, as well as the orientation and evaluation of higher education policies.

- To offer a tool for other Universities to use to perform tracer studies based on their needs and aims. 
$>$ The survey is conducted in five universities in Vietnam. The target group in the surveyed sample includes students who graduated in 2016. At the time of conducting the survey, these graduates had already been in the job market for a year.

- A multistage-sampling method was used. First, each university member decided on at least three majors to be surveyed. Second, based on proportions of graduates in each major, the number of students in the sample was determined, and they were randomly selected by applying the Proportionate Stratified Random Sampling Method. Third, replacements for the selected sample were also randomly prepared in advance.

- The final survey sample includes 1710 students covering two science fields: engineering and social sciences.

- An online survey was employed by using SurveyMonkey. An invitation letter, which was prepared in advance, was sent to the selected graduates via confirmed emails asking for their participation.

- Response rates of graduates from each university were relatively high compared to a common online survey, and the average response rate was $54.8 \%$ of the total number of emails sent out. - The survey sample covers graduates from 21 majors, of which 5 majors overlap across universities. These majors are finally categorized into two larger science fields: Engineering and Social Sciences. Then, the Vietnamese questionnaire was implemented on an on-line platform in order to collect a small sample of data that allowed us to conduct a pilot study.

\section{GRADUATES' JOB SEARCH}

\section{Most graduates declared that they had worked in one or two jobs since graduation}

$>42.1 \%$ of graduates reported that they had only worked in one job since graduation; whereas $36.4 \%$ of them declared that they had worked in two jobs

- Only 3.3\% of graduates declared they had not worked after graduation

\section{Of those graduates who found their first paid job after graduation, $73.6 \%$ took three months or less (after graduating) to find it}

$>53.5 \%$ of graduates found their first paid job after graduation, whereas $46.5 \%$ found it before graduating. Among those who found their first job after graduation, $35.4 \%$ took one month or less after graduation to find it; $23.5 \%$ took two months; and $14.7 \%$ took three months

- The average time to find the first paid job after graduation was 3.1 months

- Only $5.6 \%$ of graduates took 10 months or more, after graduation, to find their first paid job

- The percentage of men who found a job "before graduation" (49\%) was greater than the percentage of women (43.7\%)

- The percentage of Engineering and Science (ES) graduates who found a job "before graduation" (51.9\%) was greater than the percentage of Social Science (SS) graduates (42\%)

- The average number of months spent looking for the first paid job was higher for SS graduates (3.28 months) than for ES graduates (2.79) 


\section{Internet resources predominated among strategies used by graduates to find their first paid job}

$>$ Graduates used a wide range of strategies (they were asked to report the three most important) to find their first paid job. Internet resources predominated: "social and/or professional Internet networks" (30.6\%) and "Internet portals, company websites, and press ads." (29.2\%). Graduates also frequently used "Personal contacts" (25.2\%) and "contacting the employer on my own initiative" (24.6\%).

- Contacting "universities' employment services" (4.5\%) and "employment agencies" (1.9\%) were among the least frequently used strategies

- Women used "social and/or professional Internet networks" (40.1\%) and "Internet portals, company websites, and press ads." (36.3\%) more often than men (30.8\% and $31.6 \%$, respectively).

- Men used the "employment services of the university" (8.4\%) and were "contacted by the employer" (16\%) more often than women $(1.5 \%$ and $10 \%$, respectively).

- SS graduates used the following strategies more often than ES graduates: practices in companies or institutions; social and/or professional Internet networks; and self-employment. By contrast, ES graduates used the following strategies more often than SS graduates: personal contacts; contacts initiated by the employer; contacts with the employer initiated by the graduate; employment agencies; Internet portals, company websites, and press ads; and university employment services
Internet resources also predominated in the strategies used to find the current job after graduation

\author{
On average, \\ unemployed graduates \\ have already spent 6.4 \\ months looking for a \\ job
}

Graduates used a wide range of strategies (they were asked to report the three most important) to find their current job after graduation. Internet resources predominated again: "Internet portals, company websites, and press ads." (33.2\%) and "social and/or professional Internet networks" (29.9\%). Graduates also frequently used "Personal contacts" (27.2\%) and "contacting the employer on my own initiative" (25.5\%).

- Again, contacting "universities' employment services" (4.8\%) and "employment agencies" (2.8\%) were among the least frequently used strategies

- Women used "social and/or professional Internet networks" (39.3\%) more often than men (30.3\%).

- Men used the "employment services of the university" (9.1\%) and were "contacted by the employer" (17.8\%) more often than women (1.2\% and $11.4 \%$, respectively).

- SS graduates used the following strategies more often than ES graduates: internships in companies or institutions; social and/or professional Internet networks; and self-employment. By contrast, ES graduates used the following strategies more often than SS graduates: personal contacts; contacts initiated by the employer; contacts with the employer initiated by the graduate; employment agencies; and university employment services

29.34\% of unemployed graduates had been looking for a job for a month or less. By contrast, $12.01 \%$ had already spent 7 to 12 months looking for a job, and $16.01 \%$ had already spent more than 12 months. 


\section{Internet resources predominated among the strategies used by unemployed graduates to look for a job}

$>$ The two job search strategies most frequently used by unemployed graduates were related to Internet resources: "Internet portals, company websites, and press ads." (78\%) and "social and/or professional Internet networks" (65.3\%).

- A relevant group of unemployed graduates also used "personal contacts" (45.3\%). By contrast, more formal strategies such as "contacting employment agencies" (10.0\%) and using the "employment services of their own University" (3,3\%) were considered by a minority of the graduates searching for a job

- Women used "social and/or professional internet networks" (70\%) more often than men (61.3\%).

- Men used "Internet portals, company websites, and press ads." (82.5\%) and "personal contacts (relatives, friends, etc.)" (51.3\%) more often than women $(72.9 \%$ and $38.6 \%$, respectively).
Unemployed graduates perceive that the most important obstacle to find a job is "lack of, or insufficient, professional practice and experience"
Most unemployed

graduates $\mathbf{( 7 2 . 1 \% )}$ wanted the University Career Centres to support them in searching for a job
$>$ Using a measurement scale that ranged from 1 to 5 (higher scores indicate greater difficulties), "lack of, or insufficient, professional practice and experience" (mean $=3.6$ ) was unemployed graduates' most important obstacle to finding a job.

- Other obstacles were also scored with a value of 3 or higher: "lack of language skills" (3.3); "lack of knowledge about the labour market" (3.1); "saturation of the labour market" (3); and "The jobs you have been offered do not have an adequate wage" (3)

- SS and ES graduates partially differed in the importance attributed to obstacles. "Lack of or insufficient professional practice and experience" was the most important obstacle for both SS (3.7) and ES (3.6) graduates. The second and third most important obstacles for SS graduates were "lack of language skills" (3.4) and "lack of knowledge about the labour market" (3.1). By contrast, the second and third most important obstacles for ES graduates were "the jobs offered did not have an adequate wage" (3.2) and "saturation of the labour market" (3.1)

$>$ Among those unemployed graduates who wanted the University Career Centres to support them in searching for a job, $68.4 \%$ requested that these Centres "provide job opportunities for each major". 55.1\% of them also requested that these Centres "provide general information about the labour market and job opportunities"

- Other services were requested less: "hosting job fairs and other events with employers" (43.9\%); "job search consulting services" (40.8\%); "soft skills training services (38.8\%); "information about training opportunities (38.8\%); and "job hunting skills" (27.6\%).

- Men insisted more on the need for services related to "hosting job fairs and other events with employers" (51\%) and "soft skill training services" (42.9\%) than women (36.7\% and $34.7 \%$, respectively)

- SS graduates insisted more on the need for services related to "information about training opportunities" (27.4\%) than ES graduates (21.8\%). By contrast, ES graduates expected more services that would "provide more job opportunities for each major" (58.2\%) and "more jobhunting skills" (21.8\%) than SS graduates (36.8\% and $15.8 \%$, respectively) 
The main reason for inactive graduates not looking for a job was to continue studying
Only $2.3 \%$ of the surveyed graduates were inactive (neither working nor looking for a job)

- Among inactive graduates, the main reason for not looking for a job was to "keep on studying" (66.7\%). The other reasons represented far fewer graduates (e.g., "taking care of family and/or housework, 11.1\%)

\section{GRADUATES' JOB CHARACTERISTICS.}

\author{
The employment rate \\ was high (91.2\%) \\ among graduates
}

\section{$56.1 \%$ of graduates worked in private companies}

Most of the graduates were employed (82.6\%); whereas $6.2 \%$ were selfemployed

- Only $8.8 \%$ of the graduates were actively searching for a job

- Only $2.3 \%$ of the graduates were unemployed and not looking for a job (inactive graduates)

In addition to private companies, a relevant number of graduates worked in Foreign Direct Investment companies (23.7\%)

- $10.5 \%$ of graduates worked in public organizations, $3.6 \%$ in publicprivate ventures, $2 \%$ in foreign organizations, and only $0.3 \%$ in NGOs - Men worked in Foreign Direct Investment companies (27.6\%) more often than women (20.8\%)

- Women (62.4\%) worked in private companies more often than men (54.1\%)

- Graduates in Social Sciences (SS) worked in private companies (61.8\%) more often than graduates in Engineering and Science (ES) (53.5\%)

- ES graduates (30\%) worked in Foreign Direct Investment companies more often than SS graduates (19.6\%)

The two biggest groups of graduates worked in the "manufacturing" (17.2\%) and "banking, finance, and insurance" (10.7\%) sectors

- Other sectors where graduates worked were the following: "education and training" (6\%); "wholesale, retail, and repairs" (5.7\%); "professional, science, and technological activities" (5.6\%); "agriculture, forestry, fishery" (5.6\%); "construction" (5.6\%); "information and communication" (5.2\%). In general, other sectors each represented less than $5 \%$ of graduates

- Women and men differed in their profiles. Women were more present than men in "transportation and logistics", "food-accommodation services", "banking-finance-insurance", "administrative-supportive services", and "education and training". Men were more present than women in: "manufacturing", "electricity-fuel-gas (energy)", "construction", and "professional-science-technology"

- SS graduates and ES graduates also differed in their profiles. SS graduates worked in the following sectors more often than ES graduates: "banking, finance and insurance"; "food, accommodation services"; "transportation and logistics"; and "administration and supportive services". By contrast, ES graduates worked in the following sectors more often than SS graduates: "professional, science, and technological activities"; "electricity, fuel, oil, and gas"; "construction"; "agriculture, forestry, and fishery"; "information and communication"; and "education and training" 
Most graduates worked in large (more than 300 employees) or small (between 11 and 200 employees) companies
$43.8 \%$ of graduates worked in large companies, whereas 39.5\% worked in small companies

- $10.2 \%$ of graduates worked in micro-companies (up to 10 employees), whereas only $6.5 \%$ of graduates worked in medium-size companies (between 201 and 300 employees)

- Women worked in micro (11.6\%) and small companies (43.8\%) more than men (8.8\% and $35.5 \%$, respectively)

- Men worked in large companies (48\%) more than women (39.1\%)

- ES graduates worked in large companies (49.2\%) more than SS graduates $(39.2 \%)$

- SS graduates worked in small companies (44.5\%) more than ES graduates $(33.4 \%)$
$56.3 \%$ of the graduates worked in a different region from the one where their families live
Although working in a different region from the one where their families live predominated among graduates, another large group of graduates worked in the same town (13.4\%), province (18\%), or region (9.1\%) where their families live

- Only $3.3 \%$ of the graduates surveyed worked abroad

- Women worked more in places closer to cities where their families live (46.9\% in the same town, province, or region) than men (34.7\%)

- Men worked more in places in a different region from the one where their families live (60.2\%), or abroad (5.1\%), than women $(51.8 \%$ and $1.3 \%$, respectively)

- SS graduates worked more in places closer to cities where their families live $(43.8 \%$ in the same town, province, or region) than ES graduates (36.6\%)

- ES graduates worked more in places in a different region from the one where their families live (59.9\%) than SS graduates (53.2\%)

The two biggest groups of graduates worked in "production and/or provision of services" (20.9\%) and "sales and marketing" (18\%) functional areas

- Other functional areas where graduates worked were the following: "quality control" (10\%); "customer service" (8.6\%); "administration and finance" (7.8\%); "research, development, \& innovation" (6.9\%); "general management" (6.5\%); "computing" (5.9\%); and "education" (5.2\%). Other functional areas each represented less than $5 \%$ of graduates

- Women and men differed in their profiles. Women worked in "Administration and finance", "computing", "customer services", "education", and "logistics" more often than men. By contrast, men worked in "Production and/or provision of services", "quality control", and "Research, Development \& Innovation" more often than women - SS and ES graduates also differed in their profiles. SS graduates worked in "sales and marketing", "administration and finance", "customer services", "computing", and "logistics" more often than ES graduates. By contrast, ES graduates worked in "production and/or provision of services", "quality control", "education", and "research, development \& innovation" more often than SS graduates 


\section{GRADUATES' JOB QUALITY}

\author{
Job content matched \\ graduates' degree \\ content in $53 \%$ of \\ graduates
}

$>$ Regarding the horizontal match (i.e., the relationship between the content of the graduates' job and the content of their university degree), $53 \%$ of the graduates had a job with a high ("quite" or "a lot") horizontal match, whereas $47 \%$ had a job with a low ("little" or "none") horizontal match.

- Most male graduates (59\%) had jobs with a high horizontal match, whereas only $47 \%$ of female graduates had this type of job.

- Focusing on graduates' majors, most graduates in Engineering and Science (ES) (59\%) had jobs with a high horizontal match, whereas only $48 \%$ of graduates in Social Sciences (SS) had this type of job.

\section{The percentage of $\quad>$ Most of the graduates (85.7\%) indicated that the level of education over-educated required in their current job was a college or university degree. graduates was very low $\bullet 8.7 \%$ had jobs requiring a master's degree or a higher level.}

(5.7\%)

\author{
The percentage of \\ over-qualified \\ graduates was low \\ (18\%)
}

$>$ Regarding the vertical match (i.e., the degree to which graduates competences matched the requirements of their jobs), $71 \%$ of the graduates reported a good match.

- $11 \%$ of the graduates reported being under-qualified.

- More women (75\%) than men (68\%) reported a good vertical match.

- More men (14\%) than women (7\%) reported being under-qualified.
Half of the graduates (51\%) had jobs with both a horizontal and a vertical match
- Regarding a double match (i.e., the degree to which the surveyed graduates reported a horizontal and/or vertical match), 51\% reported having jobs with both a horizontal and a vertical match.

- $42 \%$ of the graduates reported having jobs with a vertical match, but a low horizontal match.

- More men (58\%) than women (42\%) reported having jobs with a double match.

- More graduates in SS (61\%) than in ES (39\%) had jobs with a low horizontal match and a high vertical match.
$83 \%$ of the graduates
surveyed were
entry-level employees
Regarding the hierarchical level, only $15 \%$ of the graduates occupied supervisory/managerial positions.

- More men (19\%) than women (11\%) occupied supervisory/managerial positions.

- More graduates in ES (19\%) than in SS (13\%) occupied

supervisory/managerial positions

Most graduates (87\%) > Only 13\% performed their jobs without a formal written employment signed a formal written contract.

employment contract - Men (89\%) had formal contracts more often than women (85\%).

- More graduates in ES (89\%) than in SS (85 \%) had formal contracts. 
$70 \%$ of the graduates had long-term jobs

Most of the graduates (97\%) had full-time jobs
$>$ Regarding contract duration, $11 \%$ had short-term jobs, and $17 \%$ had a job with an unidentified-term job.

- More graduates in ES (73\%) than in SS (67\%) had long-term jobs.

\author{
Almost two thirds of \\ the sample $(64 \%)$ had \\ monthly incomes of \\ between 5 and 10 \\ million Vietnamese \\ dongs
}

$>$ The percentages of part-time vs. full-time jobs were similar for men and women, and for ES and SS graduates.
The average level of work satisfaction was slightly above the intermediate point
In the case of monthly income, $11 \%$ had a monthly income below 5 million dongs, and $25 \%$ had a monthly income above 10 million.

- Men had a greater monthly income than women. 38\% of male graduates had a monthly income above 10 million dongs, whereas this percentage was $11 \%$ for female graduates.

- ES graduates had a greater monthly income than SS graduates. $34 \%$ of ES graduates had a monthly income above 10 million, whereas this percentage was $18 \%$ for SS graduates.

$>$ In terms of work satisfaction, the surveyed graduates were moderately satisfied with their work. The average score in the sample was 2.83 (response scale:

1. Very dissatisfied, 2. Dissatisfied, 3. Satisfied, 4. Very satisfied; intermediate point $=2.5$ ) .

- There were no relevant differences between the work satisfaction scores of male (2.85) and female (2.81) graduates, or between ES (2.87) and SS (2.80) graduates.

\section{SOFT COMPETENCIES AND EFFECTIVE PERFORMANCE}

\section{Cognitive competencies highly necessary for graduates in order to effectively perform their jobs.}

$>$ Participants in the study reported on the importance of cognitive competencies in their job performance. On a scale from 1 (none) to 5 (a lot), the ranking of importance as assessed by the total sample is as follows: Problem solving (4.26), continuous learning (4.20), systematic thinking (3.89), creativity (3.76), critical thinking (3.74), report writing (3.66), and transferring theory into practice (3.59).

- Graduates in ES score significantly higher on creativity (3.87) compared to SS graduates, whereas SS score higher on critical thinking (3.76) than graduates in Engineering and science.

- Moreover, males score significantly higher than women on Creativity (3.90), systematic thinking (3.78), and Report writing (3.73).

\section{Cognitive competencies are more necessary for graduates working in jobs that fit their Degree specialty and}

$>$ When data are split on the basis of the quality of the job in terms of the vertical and horizontal fit (vertical fit indicates that the job requires University studies, and horizontal fit indicates high correspondence between the discipline of the degree and the field of practice of the job), the graduates working in jobs with a high vertical fit and a high horizontal fit present significantly higher average scores than the other groups (see for comparison purposes the average scores after the slash in each 
require a university degree

competency). They declare that in order to perform their jobs effectively, it is extremely important to be competent in Problem solving (4.3/3.8), continuous learning (4.3/3.6), Systematic thinking (4.0/3.2), critical thinking (3.9/3.3) creativity (3.9/3.2), report writing $(3.8 / 2,7)$, and transferring theory into practice $(3.8 / 2.8)$.

> University-graduate employees often need to have management competencies in order to effectively perform their jobs. In fact, on a scale from 1 (none) to 5 (a lot), the ranking of importance of the management competencies considered is as follows: Planning (4.03), decision making (4.01), time management (4.01), motivating others (3.74), and leadership (3.69).

- Interestingly, the graduates in ES score significantly higher on decision making (4.09) compared to graduates from SS, whereas SS score higher on motivating others (3.82) and leadership (3.77) than ES graduates.

- Males score significantly higher than women on most management competencies: Planning (4.08), decision making (4.08), motivating others (3.81), and leadership (3.79).

\section{Management competencies are more necessary for graduates working in jobs that fit their Degree specialty and require a university degree.}

\section{Interpersonal competencies are also very important for graduates in order to effectively perform their jobs}

$>$ When data are desegregated based on the quality of their job in terms of vertical and horizontal fit (vertical fit indicates that the job requires University studies, and horizontal fit indicates high correspondence between the degree and the field of practice), the graduates working in jobs with a high vertical fit and a high horizontal fit present significantly higher average scores than the other groups on every competency (after the slash, see the figures for the low-low fit group, for comparison purposes). To effectively do their jobs, it is very important for them to be competent in Planning (4.20/3.5), decision making (4.20/3.5), time management (4.10/3.5), motivating others (3.9/3.1), and leadership (3.8/3.2).

$>$ University-graduate employees often perform jobs that require relating to others (mates, subordinates, customers, etc.) competently. According to the information provided by the total sample of graduates on the survey, the ranking of importance of these competencies is as follows: communication skills (4.29), team work (4.01), negotiation skills (4.01), customer relations skills (3.97), conflict solving (3.94) intercultural skills (3.89), and presentation skills (3.75).

- ES graduates score significantly higher on teamwork (4.10) compared to SS graduates. In turn, the SS graduates score higher on communication skills (4.32) and negotiation skills (4.05)

- Moreover, males score significantly higher than women on teamwork (4.10) and presentation skills (3.82), whereas women score significantly higher on customer relations skills (4.03).

\footnotetext{
Interpersonal

competencies are more important for graduates working in jobs that fit their
}

$>$ When we compare the average obtained for the group of graduates employed in jobs with high vertical and horizontal fit with the other three groups on the need for these competencies for effective job performance, they present significantly higher scores on every competency. We rank these competencies according to their scores in the high-high fit group, 
Degree specialty and require a university degree

\section{Instrumental competencies are important for graduates in order to effectively perform their jobs.}

and after the slash we provide the average score for the low-low group for comparison purposes: communication skills (4.40/4.0), teamwork (4.10/3.5), negotiation skills $(4.10 / 3,7)$, customer relations skills $(4.0 / 3,8)$, conflict solving (4.0/3.7) intercultural skills (4.0/3.5), and presentation skills (3.90/3.2).

> University-graduate employees often perform jobs that require instrumental competencies that are rather horizontal and relevant for many jobs. In our study, we have addressed office skills, computer skills, and foreign language skills. According to the information provided by the total sample of graduates on the survey, the ranking of importance of these competencies for their job performance is the following: computer skills (4.05), office skills (3.89), and foreign languages skills (3.84).

- ES graduates score significantly higher on foreign languages skills (3.95) compared to SS graduates. In turn, the SS graduates score higher on office skills (3.95).

- Regarding gender differences, males score significantly higher than women on office skills (3.98).

\section{Instrumental \\ competencies are more necessary for graduates working in jobs that fit their Degree specialty and require a university degree}

Attitudinal
competencies are very
important for
graduates in order to
perform effectively
their jobs

$>$ When we compare the average obtained for the employed graduates in jobs with high vertical and high horizontal fit with the other three groups (coming out from different fit conditions) in the need for instrumental competencies for effective job performance, the group with high-high fit presents significantly higher scores on every competency. We rank these competencies according to their scores in the high-high fit group, and after the slash, we provide the average score for the low-low fit group for comparison purposes: computer skills (4.17/3.0), foreign languages skills (3.98/3.08), and office skills (3.96/3.11)
The attitudes graduates show when performing their jobs influence their performance. Effective and excellent performance requires these horizontal competencies, which if not enacted, may hamper even good technical performance. This is clearly acknowledged by the participants in the survey. According to the information provided by the graduates, the ranking of importance of these competencies is as follows: accept responsibility (4.24), punctuality (4.15), adaptability (4.14), rule compliance (4.06), commitment (3.91), and entrepreneurship (3.54).

- ES graduates score significantly higher on commitment $(3,95)$ and entrepreneurship $(3,68)$ compared to SS graduates.

- Men score significantly higher than women on rule compliance (4.11), commitment (3.95), and entrepreneurship (3.68).

\author{
Attitudinal \\ competencies are more \\ necessary for \\ graduates working in \\ jobs that have a high \\ Degree-specialty fit \\ and require $a$ \\ university degree
}

When comparing the average of the group of graduates employed in jobs with high vertical and high horizontal fit with the other three groups, they present significantly higher scores on every attitudinal competency considered. We rank these competencies according to their scores in the high-high fit group, and after the slash, we provide the average score for the low-low group for comparison purposes: accept responsibility (4.3/3.9), punctuality (4.3/3.8), adaptability (4.2/3.9), rule compliance (4.2/3.6), commitment (4.0/3.7), and entrepreneurship (3.7/3.1). 



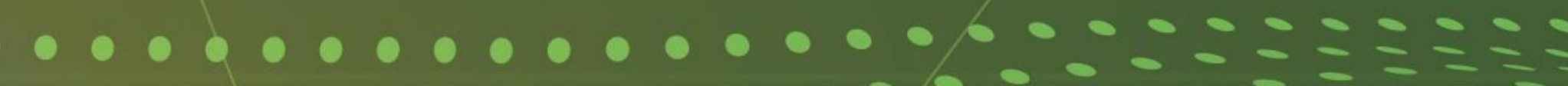

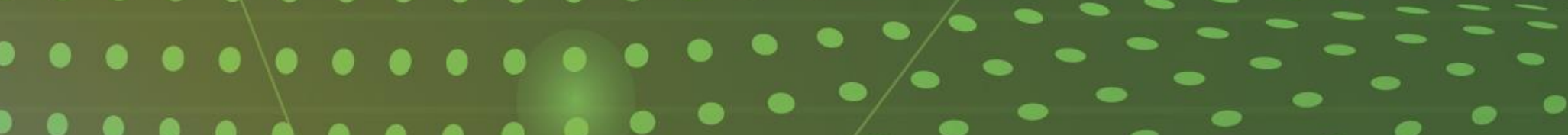

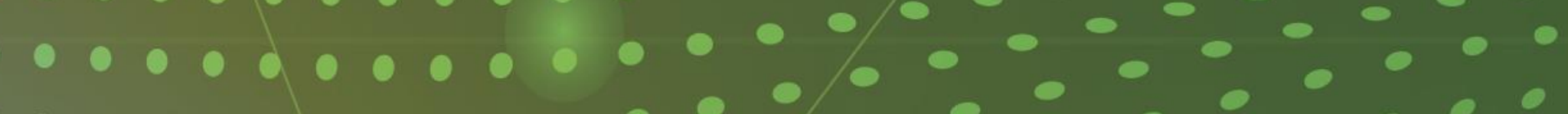

-

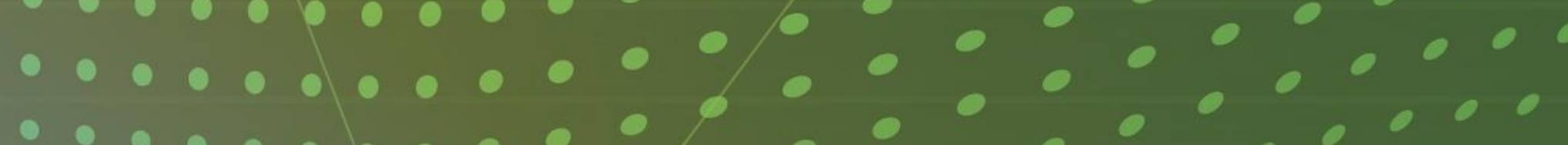
$\cdots \cdots$

CHAPTER 1: INTRODUCTION 


\section{CHAPTER 1: INTRODUCTION}

\subsection{Higher education in Vietnam}

The number of higher education institutions in Vietnam grew strongly from 2000 - 2012 and has tended to level off since 2012. By December 2017, there were a total of 235 (undergraduate) universities in Vietnam, excluding the military and police universities. Figure 1.1. presents the growth trend of universities and colleges (both public and private) in the period from 2000 to 2018. It shows that the total number of universities tripled in the period from 2000-2012 and then levelled-off. The demarcation between private and not-for-profit institutions remains vague because Vietnam mainly uses the term "private" to indicate only those not owned by the state. Universities are primarily administered by central ministries, most of which are under the management of the Ministry of Education and Training (MOET), as seen in Table 1.1.

Figure 1.1. The number of universities in Vietnam, 2000-2017

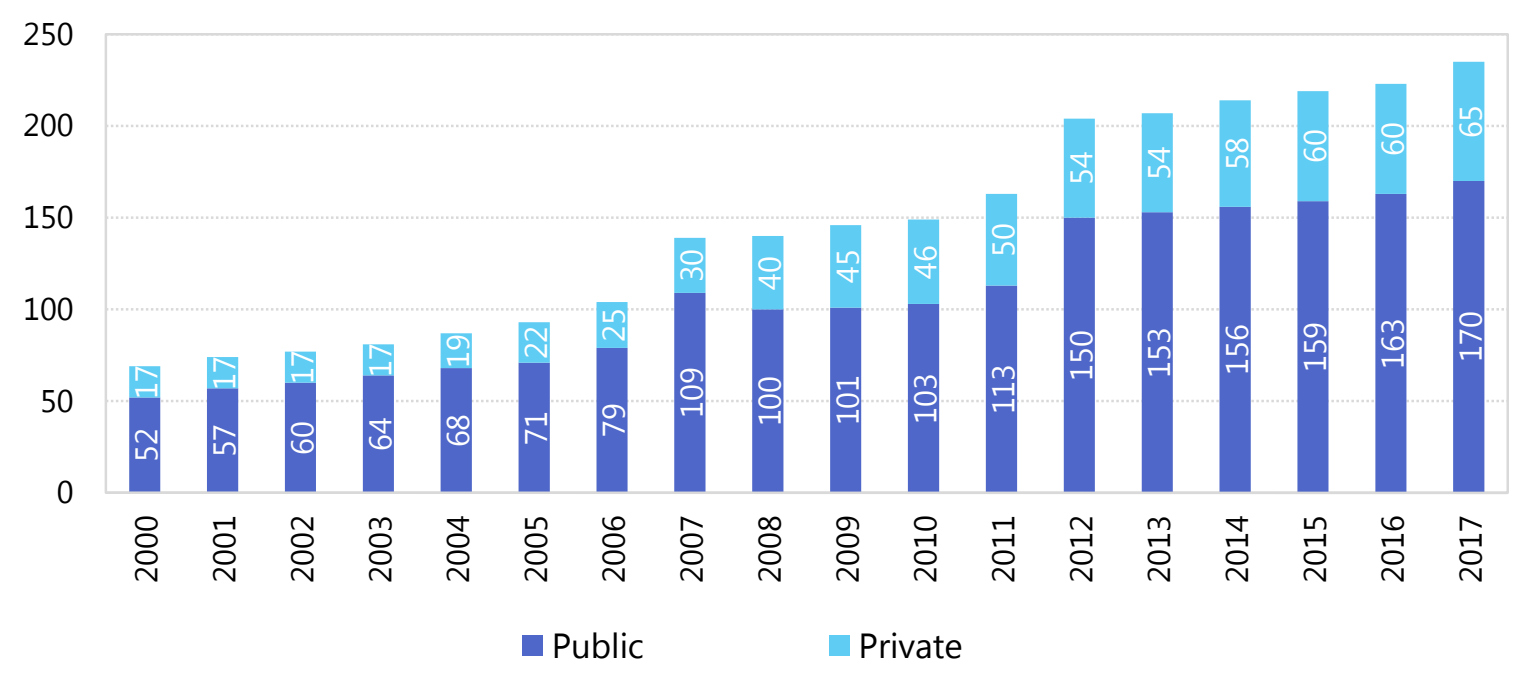

Source: Statistics from MOET

Table 1.1: Classification of universities by administrative agency (2017)

\begin{tabular}{lccc}
\hline & Number of universities & Of public universities (\%) & $\begin{array}{c}\text { Of total } \\
\text { universities (\%) }\end{array}$ \\
Public & $\mathbf{1 7 0}$ & & $\mathbf{7 2 . 3}$ \\
National university & 2 & 1.2 & 0.9 \\
MOET & 35 & 20.6 & 14.9 \\
Other Ministries & 91 & 53.5 & 38.7 \\
Local Authority & 42 & 24.7 & 17.9 \\
Private & $\mathbf{6 5}$ & & $\mathbf{2 7 . 7}$ \\
Total & 235 & & 100 \\
\hline
\end{tabular}

Source: Consolidated from MOET 2018 
The number of students rose significantly and faster than the number of universities, which has led to overcrowding in a few universities. The number of university students in Vietnam increased from 124,000 students in 1991 to 1,707,000 students in 2017. In other words, the number of students doubled in around 7 years, which means that the total number of students enrolled during this period increased to almost 14 times the original number. These increases, however, disproportionally occurred in a few well-known universities, causing these universities to be overwhelmed and struggle to meet the explosion in demand. Many newly established private universities still struggle to meet the enrolment threshold (Crawford and Tran, 2015). The number of faculties also faces a similar challenge. The proportion of students/faculty on average has been multiplied by four, having risen to over 50 students/faculty at some institutions. The quality of the teachers is generally still considered to be low compared to common international standards. The number of faculty members with doctoral degrees has remained relatively stable. As Figure 1.2 shows, during this 17-year period, the percentage of faculty members with doctoral degrees did not change. This suggests that the quality of training, reflected in competencies gained by graduates, may suffer.

Figure 1.2: Faculty with doctoral degrees at universities and colleges during the period $2000-2017$

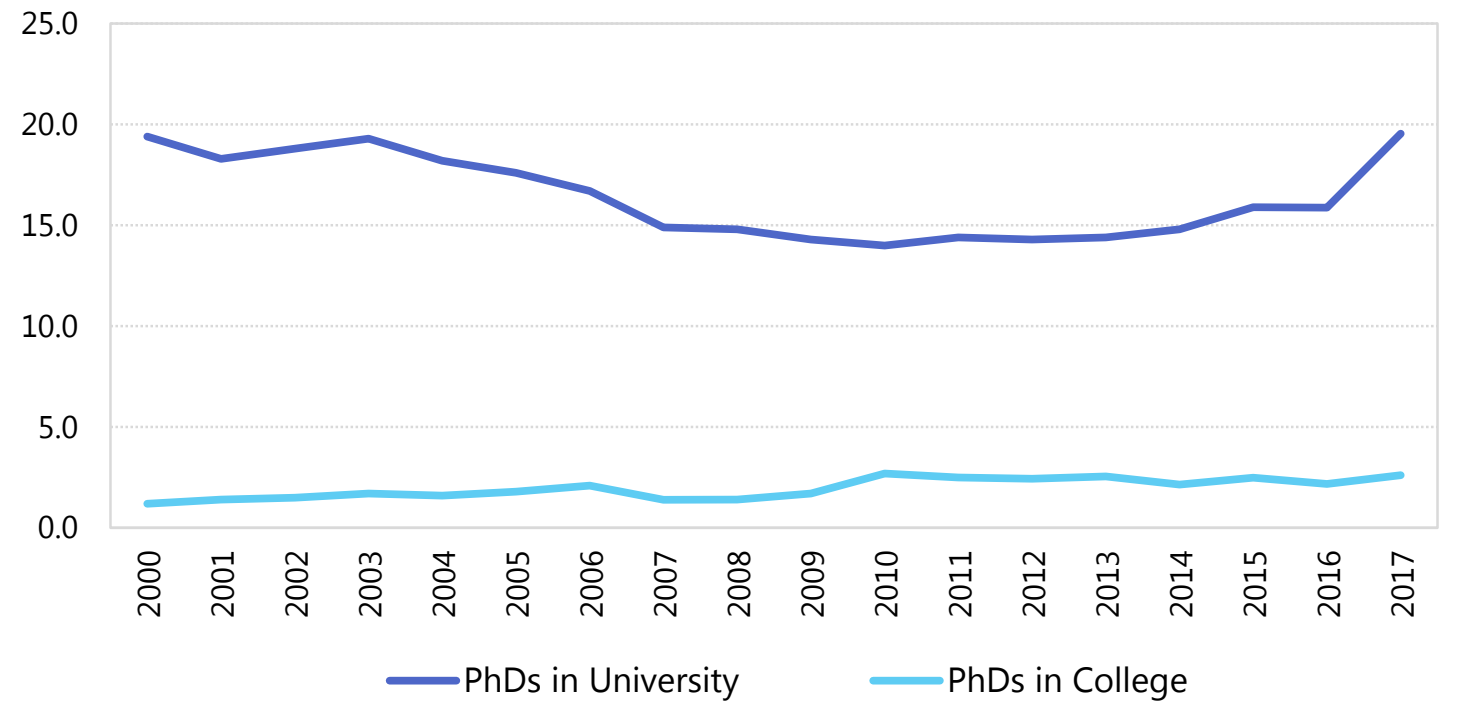

Source: MOET

Universities and colleges in Vietnam are quite different in size, with a few large universities coexisting with numerous small ones. Figure 1.3. shows a picture of land use of a representative sample of 42 universities, and their enrolment numbers in undergraduate and postgraduate programmes. This figure shows that a small number of large cases account for a large proportion of students, and institution sizes drop significantly towards the tail of the probability distribution. The distribution of enrolled students demonstrates that the group of 14 major universities as of 2012/2013 (accounting for about 5\% of institutions) attracts nearly one-third of undergraduate students and nearly two-thirds of graduate students. These 14 institutions (under the management of many different ministries) are called the "key universities" or "national key universities". 
Figure 1.3. Probability distribution of universities by student enrolment

\begin{tabular}{|c|c|c|c|c|c|}
\hline Size distribution by Land Area & & \multicolumn{4}{|c|}{ Number of students $2012-2013$ (students) } \\
\hline $4 \mathrm{e}+06-$ & & $\begin{array}{l}\text { Under- } \\
\text { graduate }\end{array}$ & $\%$ & $\begin{array}{c}\text { Post- } \\
\text { graduate }\end{array}$ & $\%$ \\
\hline 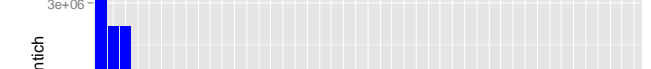 & National University (2) & 93,294 & 6.4 & 6,366 & 8.8 \\
\hline$\frac{\Phi}{2} 20+06$ & $\begin{array}{l}\text { The remaining } 12 \text { national } \\
\text { key universities }\end{array}$ & 378,499 & 26.0 & 37,714 & 51.9 \\
\hline & Other universities & 981,274 & 67.5 & 28,651 & 39.4 \\
\hline 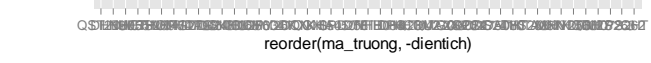 & Total & $1,453,067$ & 100 & 72,731 & 100 \\
\hline
\end{tabular}

Source: Description according to the MOET-CIEM survey (2012); table updated from Crawford and Tran (2015).

Note: The number of HEls refers to the school year 2012/2013

Most of the public universities in Vietnam are specialized training institutions, as reflected in their name, such as the National Economics University, Ho Chi Minh University of Technical Education, University of Transportation, University of Mining - Geology, National Academy of Public Administration, etc. This factor has important implications for universities' enrolment and employability, which are strongly influenced by market trends. Single-discipline universities have been seriously affected by short-term market demand, causing unstable enrolment and employability. Furthermore, graduates may lack certain competencies, especially the competencies that are not strengths of the universities, such as soft-skills in technically-oriented universities.

Thus, the overall picture of the development of Vietnam's higher education in the past decade shows that demand for university enrolment rose very sharply, but Vietnam's higher education system was not adequately prepared in terms of both human resources and management models.

\subsection{Nation-wide and university surveys on graduate employability}

As the number of universities and enrolment increased sharply, so did the concern about graduate employment. In the past ten years, quarterly reports by MOLISA consistently warned of graduate unemployment. For example, in MOLISA's 4th quarter in 2017, there were about 215,000 university graduates who were unemployed, whereas about 400,000 graduated yearly. ${ }^{1}$ Importantly, the report estimated that $60 \%$ of university graduates' current jobs are not related to their degrees.

\footnotetext{
${ }^{1}$ http://www.molisa.gov.vn/vi/Pages/ChiTiet.aspx?IDNews=27879
} 
MOET has also given priority to increasing graduate employability. Several measures have been introduced:

- Since 2016, universities are required to conduct graduate employment surveys and send reports to MOET (Resolution 97/NQ-CP, dated 04/11/2016 of the Government).

- Employability, based on universities' self-reports, has become a criterion for the enrolment quota given to each university (Circular 05/2017/TT-BGDĐT, dated 25/01/2017)

The most recent report from the Higher Education Department (MOET) (16/4/2018) reports several figures: ${ }^{2}$

- In 2015, there were 175,781 graduates, of which 141,381 participated in university employability surveys (80.4\%). Of the surveyed graduates, 112,694 graduates were employed (80\%), and 9091 graduates continued to study (6.4\%).

- In 2016, 233 universities conducted employability surveys. The reported results were that $82 \%$ of the graduates surveyed had jobs after 12 months (82\%). Fields with the highest unemployment rates include Education and Teacher Training (19\%), Social Services (19\%), Environmental Studies (17\%), and Legal Studies (17\%). Those with the lowest unemployment rates are Architecture (7\%), Health (7\%), and Technology (9\%).

Reports by MOLISA and MOET have provided some overall indicators of employability, i.e., overall employability ratios and the most employable fields. In these reports, there are gaps between the competencies required for jobs and those provided by universities. Furthermore, there is inconsistency in the methods used by different agencies in conducting the surveys.

Since 2016, universities are required to conduct surveys and report graduate employability 12 months after graduation. In 2017, 233 universities sent reports to MOET. Although the reports provide some indications of employability, there are reservations about using these results:

- Universities conducted employability surveys based on the administrative order from MOET, not necessarily on their own volition. Thus, commitment to conducting quality surveys is not guaranteed. In addition, the reported employability rates were used to decide on the enrolment quotas for the universities. This raises a potential conflict in conducting the survey and reporting the results.

- $\quad$ Although MOET gave some instructions about reported indicators, there have been no guidelines for survey methods and processes. The methods and processes could be vastly different across universities, raising concerns about the reliability of the results.

- Most universities have conducted employability surveys to fulfil administrative orders

\footnotetext{
2 Employability of university graduates in 2016 - a compilation from universities' self-reports. Department of Higher Education, Ministry of Education and Training, Hanoi, Vietnam, dated 16/4/2018.
} 
and/or have input for their public relations. The feedback has not been adequately used to improve curricula and/or academic offerings.

In this context, a carefully designed survey with the clear purpose of giving feedback to education programs would be helpful to Vietnamese universities. Hence, we have EVENT!

\subsection{Vietnamese labour market}

\subsubsection{Labour force}

Vietnam is a country with a young population and a labour force of 54.8 million people, accounting for 58.5 percent of the population in 2017. The labour force is continuously increasing over time. For example, the labour force of 38.5 million in 2000 increased to 54.8 million people in 2017, representing an annual growth of approximately 2.1 percent. The employed labour force working in state, foreign-invested, and non-state sectors accounted for 8.6, 7.8, and 83.6 percent, respectively. There is a downward trend in the share of the employed labour force in the agricultural sector and an upward trend in the share of the employed labour force in the industrial and service sectors. In 2017, employment in the agricultural sector was 40.2 percent, a sharp drop from the 55.1 percent in 2005; the industrial sector employs 25.7 percent of the working labour force, and the other 34.1 percent work in the services sector.

Figure 1.4. Shares of the employed labour force by sectors in 2017

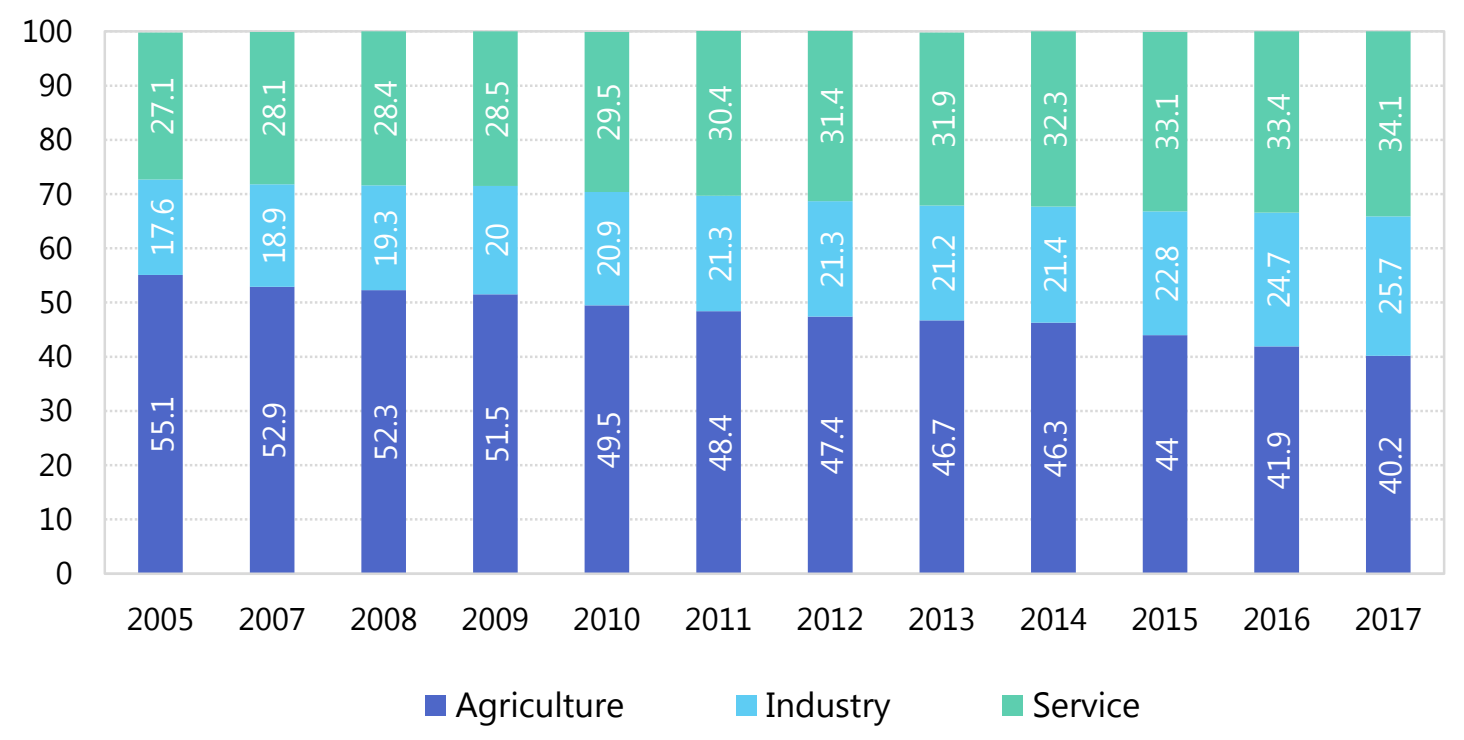

Source: Consolidated from GSO data

Urban areas accounted for around 32 percent of the employed labour force, whereas the rest were employed in rural areas. Male employees accounted for 52 percent of the Vietnamese workforce, which is slightly different from the female share. The workforce between the ages of 15 and 39 currently accounts for nearly half of the total labour force. The share of skilled workers of working age in 2017 was estimated at 21.5 percent, increasing slightly over time. 


\subsubsection{Unemployment}

Recently, unemployment and underemployment rates are relatively low in Vietnam. In 2018, the rate of unemployment in the working age group was 2.1 percent, of which rates for urban and rural areas were 3.1 and 1.7 percent, respectively. The underemployment rate of working age workers was 1.63 percent, of which rates for urban and rural areas were 0.86 and 2.1 percent, respectively.

Figure 1.5. Unemployment rate in Vietnam, 2008-2018

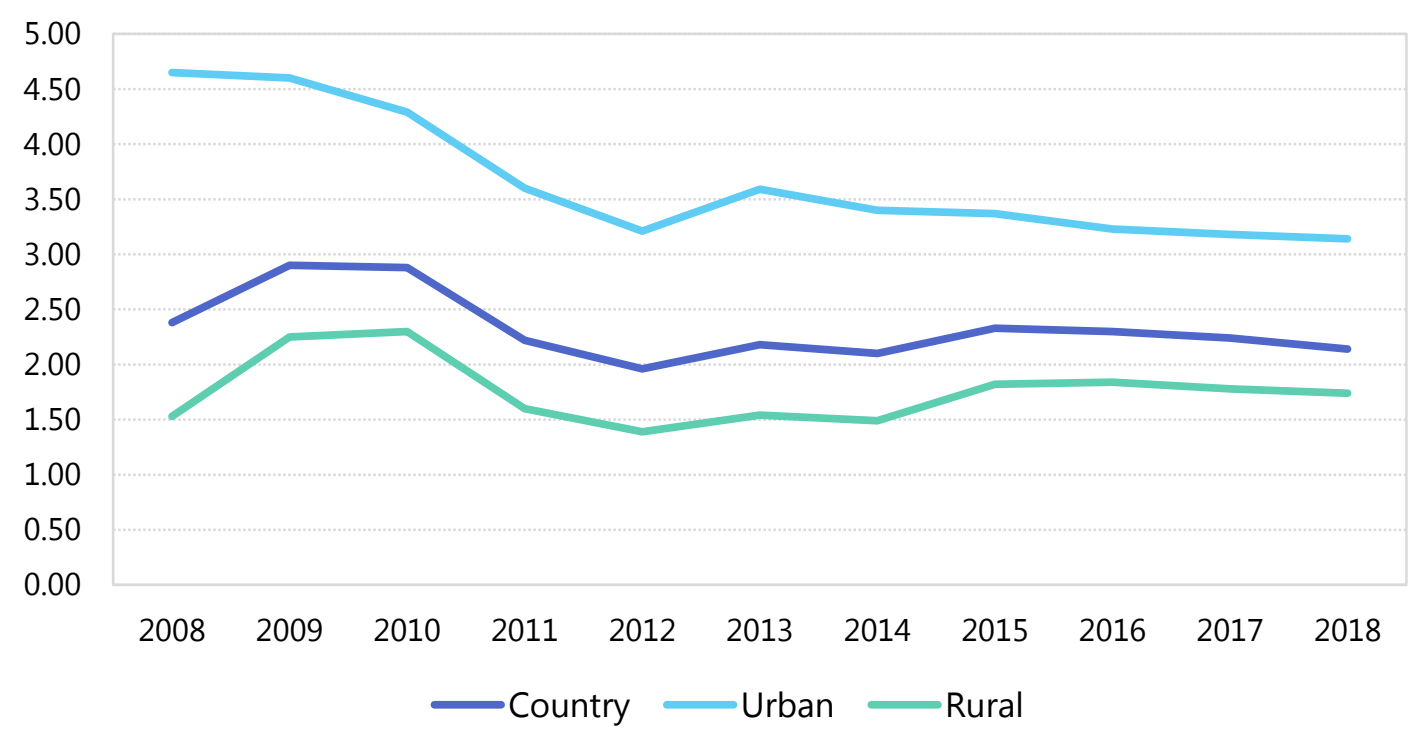

Source: Consolidated from GSO number

Despite low unemployment and underemployment rates, the number of unemployed workers with university degrees is relatively large. By the end of 2017, about 162,000 unemployed people held bachelor's degrees, accounting for 13.0 percent of unemployment. This raises a question about a mismatch between universities and the labour market.

\subsubsection{Productivity and wages}

Vietnam's labour productivity has improved significantly over the years. Its average growth rate was 11.3 percent from 2010-2017, and labour productivity doubles every five years. However, labour productivity is still low compared to other countries in the region, and the absolute distance is continuously increasing. Labour productivity in the Agricultural sector is low, equal to $38 \%$ of the average labour productivity for the whole economy, whereas labour productivity in industrial and service sectors is 20 and 6 times the productivity in the agricultural sector, respectively. From 2010 to 2017, the sectors with high labour productivity were mining, production and distribution of electricity and gas, finance, insurance, technological activities, real estate, and water supply. At the other extreme, the agricultural sector has the lowest labour productivity. Improving labour productivity in the agricultural sector should be a serious part of the government's agenda. 
Figure 1.6. Labour productivity and salary, 2005-2017

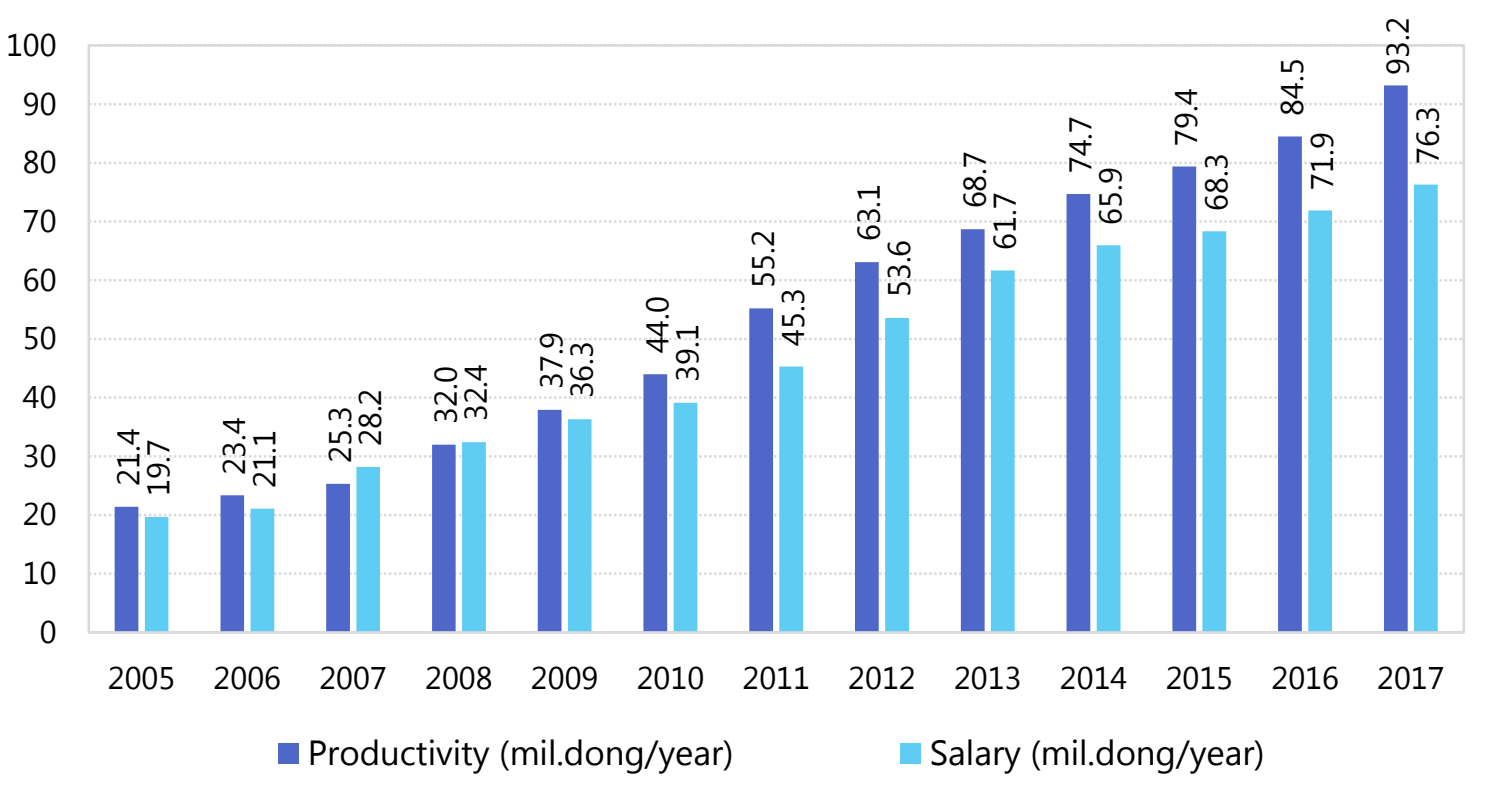

Source: Consolidated from GSO data

Wages and salaries in Vietnam are very dissimilar across occupations, and there is a stark contrast between urban and rural areas. The average annual salary per person in Vietnam is around VND 76.3 million dong (US\$3500), and it is differentiated by many factors, such as regions, industries, and ownership. From 2010-2017, the annual average growth rate of productivity was 11.3 percent, whereas it was 10 percent for the average wages. State-owned enterprises paid the highest average monthly wages, compared to FDI and private sector firms in 2017, about VND 11.01 million (US\$ 469) per month. The average monthly wage in FDI firms was VND 9.04 million (US\$ 386), and private firms paid their workers VND 7.37 million (US\$ 314) per month. Regions that have attracted the majority of the FDI in the past few years have the highest salaries in the country, such as Ba Ria-Vung Tau, Ho Chi Minh city, Hanoi, and Bac Ninh. Among all the economic sectors, services and industry had the highest average monthly income at VND 9.41 million (US\$ 402), whereas agriculture had the lowest average monthly wages in 2017 at VND 5.25 million (US\$225). 


\subsubsection{Challenges in the labour market}

The Vietnamese labour market is facing some major challenges, including lack of skilled labour, the impact of industry 4.0, and the need for labour reforms due to the upcoming free trade agreements (MOLISA and GSO, 2019; Das, 2018). ${ }^{3}$. First, lack of skilled labour is a chronic issue in the Vietnamese labour market. Although the Vietnamese government has taken steps to increase vocational and technical training in order to meet the requirements of the labour market, only 22.2 percent of the employed labour force were trained by universities granting degrees/certificates. Many FDI firms have been struggling to hire skilled labour in Vietnam, and around 40 percent of FDI firms in Vietnam find it difficult to recruit skilled employees (Das, 2018). Lack of skilled labour will slow down the economic transition from labour-intensive to high-tech production, which will reduce the country's competitiveness. Second, there are challenges due to the impact of industry 4.0. Global businesses are moving quickly towards Industry 4.0, which would impact current and future labourers because industry 4.0 will create totally new jobs and require high skills and competences. It is predicted that the youth unemployment rate will be higher, and as Industry 4.0 approaches, the shortage of skilled workers will become much more pronounced. If the Vietnamese government does not take steps to enhance human capital, it will have a significant impact on the economy. Third, there are challenges due to free trade agreements (FTA). Vietnam is an active country in signing free trade agreements with 12 signed FTAs, with four others in final discussions. When the Comprehensive and Progressive Agreement for Trans-Pacific Partnership (CPTPP) and the EUVietnam FTA come into effect, labour costs are predicted to be higher. These FTAs are beneficial because they improve market access for Vietnamese exporters, but the government needs to focus on labour reforms, skills, and governance to fully realize the benefits of the agreements. The FTAs require members to adopt and maintain the rights stated in the 1998 ILO Declaration, institutions, and practices because labour rights are among the key provisions. Although Vietnam has taken steps to meet the requirements through institutional and legal reforms, more needs to be done in terms of enforcement.

\subsection{The project}

This project responds to the needs of Vietnamese higher education institutions. Unemployed university graduates recently initiated a public debate and discussion about the government agenda. Officials from the Ministry of Education and Training (MOET) and the Ministry of Labour, Invalids and Social Affairs (MOLISA) have publicly commented that the unemployment of university graduates in Vietnam stems from a mismatch between the education offered and the demands of the labour market. The feedback from the labour market seems to highlight this, but employers also mention a lack of "soft" competencies in newly graduated job

\footnotetext{
${ }^{3}$ MOLISA and GSO (2019). Quarterly labor market update 2018, Hanoi.

Das, K. (2018). Labor market trends in Vietnam, Vietnamese Briefing
} 
applicants. Responses from graduates suggest that there is a lack of actors bridging the gap between universities and employers, whereas MOLISA has stated that there is a surplus of graduates recently, given the country's current economy. Moreover, the information on the real state of employment of university graduates is not sufficient for universities developing curricula or for MOET and MOLISA in their management duties. Performing a detailed tracer study would benefit all partners by designing a standard tracer study and providing evidence for curriculum development and management by related ministries. This study potentially identifies the areas where the academic education offered by our partner universities does not fit the demands of the labour market.

\subsubsection{Universities involved}

Three European and five Vietnamese universities were involved in this project. In this section, the role of each partner in the project is briefly described.

Uppsala University is a coordinator of the project, ensuring that all objectives are met, making sure all indicators are measured in the quality control of the project, and guaranteeing that activities are carried out as described in the proposal. The University of Valencia, one of the most outstanding Spanish universities in both national and international rankings, plays a significant role in the project. It contributes to the different packages designed in the project, and it leads the work package for the tracer studies. The University of Groningen is a research university with a global outlook, and it is currently in the top 100 on several influential ranking lists. The university contributes to the projects in different packages by developing tracer studies, teaching research methodology, and providing input to develop the career centres of Vietnamese university partners.

The five Vietnamese university partners include the National Economics University (NEU), Hanoi University of Industry (HaUI), University of Hue (HU), Ho Chi Minh city University of Technology and Education (HCMUTE), and Ho Chi Minh City University of Technology (HUTECH). The National Economics University is one of the leading universities in Economics, Management and Business Administration, with more than 45,000 students currently enrolled. It is the current chair of the network of more than 40 universities offering economics and business administration degrees in Vietnam. Participating in this project, the role of NEU involved conducting the tracer study, the career centre, and web-portal development. HaUI is the oldest technical university in Vietnam, offering many technical majors and training degrees. It currently has 27,000 students enrolled in different levels: college, university, and post-graduate. HaUI takes the lead in the work package on dissemination and exploitation of the project, it participates in all project activities, and it assists the coordinator in the management of the project. Hue University has been recognized as a key academic and scientific research hub for central Vietnam and the whole country. It has succeeded in building its position as a prestigious institution in the Vietnamese higher education system. Currently, it has 8 colleges under its 
umbrella, with 47,000 students currently enrolled ${ }^{4}$. With its previous experiences in Erasmus Mundus projects, HU participates in all the work packages of the project in order to further enhance the university's educational and academic roles in terms of support for student activities, especially the employability of graduated students. HCMUTE is the first university in Vietnam, educating and training technical teachers for the whole country. It offers quality technology-oriented programs delivered at various levels of training and in different modes of study. Current enrolment is 24,000 students, including both part-time and full-time training modes. The university mainly participates in the career centre, the tracer study, and project quality assurance. HUTECH has highly ranked and nationally recognized academic programs. It is a home for students who desire to study in an intimate, scholarly, and dynamic atmosphere and conduct their higher education in a trustworthy institution. The university assists the coordinating institution with the implementation of the project by leading a work package on the quality plan and by participating in all the other activities in the project.

\subsubsection{Objectives of the project}

The broad objective of the project is to increase the employability of university graduates in Vietnam. To reach the central objectives, the project attempts to work towards the following specific objectives:

Perform a detailed tracer study at partner universities. The data collected in this study would be fed back to the curricula designers and higher education managers. This could potentially help to identify the areas where the academic education offered by the partner universities does not meet the demands of the labour market. This tracer study offers its methodology to other universities in Vietnam, inviting them to do the same. This will potentially assist in bridging the gap in the mismatch between education and work.

Design and host intensive workshops for teachers and educators in our Vietnamese partner universities, raising awareness of the particular skills reportedly lacking in Vietnamese students. International experts who are currently implementing models for how to reach both students and university management stress the importance of raising awareness not only with university teachers but also at the level of university management and with the students. The project, therefore, aims to set up meetings with all the specified target groups, relying on data from the tracer study, in order to create a permanent place for soft skills development at our partner universities.

Develop a collaboration between partner universities and industry. A career centre plays a role in student employability by bringing together the university, students, and industries. By developing a web portal, it continues to gather information in line with the tracer study, adding to the data already collected.

\footnotetext{
${ }^{4}$ The eight colleges include Sciences, Education, Medicine, Agriculture \& Forestry, Economics, Foreign Languages, Arts, Law.
} 


\subsubsection{Connection to other parts of the project}

The tracer study is an important work package under the umbrella of the project. By counselling related stakeholders, this tracer study is conducted to respond to the need to understand the employability of university graduates and provide feedback on curriculum design and management. Results from the survey will reveal the real state of employment of newly graduated university students in Vietnam, the competences and/or knowledge students need to be trained in, and how to deliver this knowledge. The tracer study is closely associated with the career centre work package because it provides feedback to adjust curriculums, feedback on what competences the career centre should provide to meet labour market demands, and feedback on how to do this. The tracer study also provides input to design a web-portal offering appropriate services and a platform for collecting more regular data on the employment of university graduates.

\subsection{Contents and structure of the report}

This report offers the main results of the study. After this introductory chapter, Chapter 2 presents the methodology of the study, describing the study sample and the questionnaire used to collect the data. Chapter 3 offers the results obtained for the whole sample, distinguishing different groups according to their employment status: employed, unemployed, and inactive graduates. In chapter 4, we describe the results, disaggregating them by gender and comparing the information obtained from male and female graduates. Chapter 5 analyses the results of the different sections of the survey, splitting them by major category: Science and engineering vs. social sciences. In chapter 6 , we classify the graduates according to two types of matching: 1) a vertical match (which analyses the fit between the level of education required by the job and the highest level the graduate has achieved; and 2) horizontal matching (the fit or misfit between the occupational area of the job held by the graduate and the disciplinary content of the University degree with which s/he graduated. Finally, in chapter 7, a number of conclusions are drawn from the results of the study, and recommendations from those conclusions are presented for different stakeholders. The analyses of the data obtained from the graduates of each University participating in the tracer study are carried out and reported by the team from each University. 


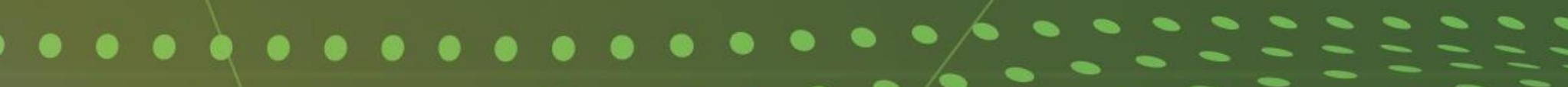

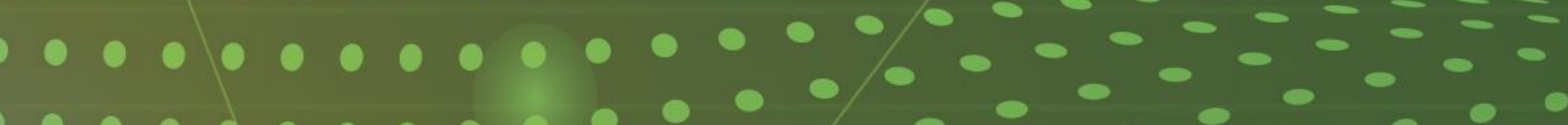

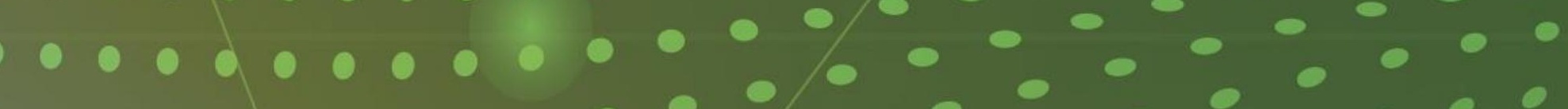

०

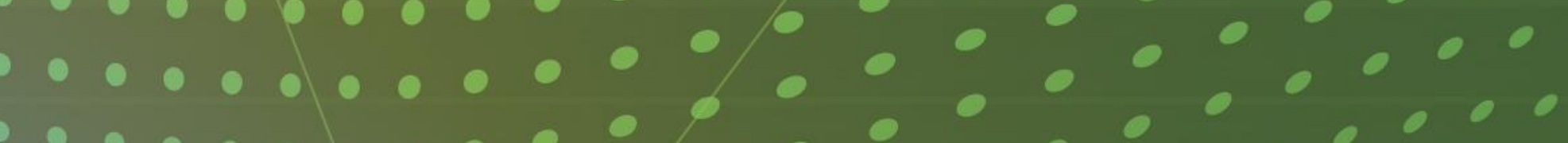

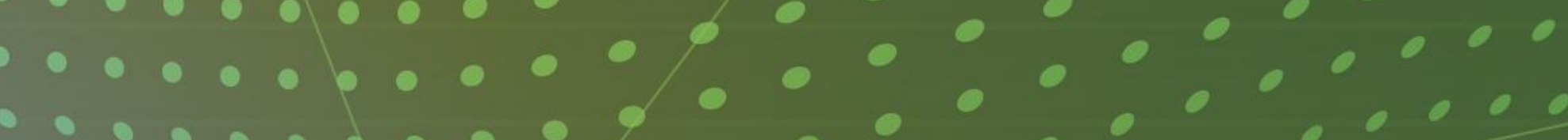

CHAPTER 2:

METHODOLOGY 


\section{CHAPTER 2: METHODOLOGY}

\subsection{Sample}

This survey is conducted in five project-universities in Vietnam, including the National Economics University (NEU), Hanoi University of Industry (HAUI), Hue University (HUE), Ho Chi Minh City University of Technology (HUTECH), and Ho Chi Minh City University of Technology and Education (HCMUTE). The targeted groups in the surveyed sample include students who graduated in 2016. At the time of conducting the survey, these graduates had been already in the job market for a year, and so they are suitable to participate in this tracer-study survey.

The sampling method is multistage-sampling. First, each university member decides on at least three majors included in the survey. After selecting the majors, the universities provide the lists of students who graduated in 2016 in the selected majors. Data on the students on the lists that serve as a survey population include student name, gender, place of birth, major, minor, type of training, email, telephone number,... Second, based on the proportion of graduates in each major, the number of students in the survey sample is determined. The survey sample is randomly selected by applying the Propionate Stratified Random Sampling Method. A statistic software is used for random selection. Data collection must be conducted in the selected sample. Third, replacement for the selected sample is also randomly prepared in advance. About $20 \%$ of the expected sample is reserved for replacement if the randomly selected graduates cannot be reached, or if they refuse to participate the survey.

The final survey sample includes 1710 students covering two science fields: engineering and social sciences. A detailed description of the sample is presented in section 2.3.

\subsection{Data collection}

\subsubsection{Procedures}

An online survey is employed by using the SurveyMonkey, which is an online survey development cloud-based software. Respondents complete the survey questionnaire anonymously online. The survey procedure includes several steps.

Survey upload and pilot: The questionnaire was designed and uploaded online using the SurveyMonkey platform. This online survey was sent to each university to test whether any issues arose. Three graduates from each university participated in the pilot. Some critical issues to check were smoothness, transitional questions, and shifts in the questionnaire. Some minor changes in the questionnaires and shifts were appropriately made after the pilot study to finalize the online questionnaire.

Email confirmation: With the telephone numbers provided on the lists, the selected graduates were called to confirm whether their active email address was the one on the lists. If not, they 
were asked to provide a new email address. The confirmed emails were used to send out the questionnaire to the selected graduates.

Participation invitation: An invitation letter, which was prepared in advance, was sent to the selected graduates at their confirmed email addresses to ask for their participation. The SurveyMonkey generates unique links to the survey questionnaire for each participant, and the links were included in the invitation letter. The recipients just click "start survey", attached in the invitation letter, to directly participate in the survey.

Follow-up: The selected graduates were reminded three times during the duration of the survey from December 2017 to March 2018. The reminder letter was also prepared in advance, and only graduates who had not completed the survey were reminded. After three tries at different times, if graduates did not respond to the survey, a replacement was made by randomly drawing a name from the lists selected in advance.

\subsubsection{Quality assurance}

Quality of the survey is determined by many factors. Based on our research team's experience, many activities/solutions for online surveys help to mitigate the quality gap between expectations and reality:

- $\quad$ Each project-member university was asked to provide necessary information about students who graduated in 2016. The research team applied the same sampling methods and data collection procedures in this project;

Anonymity of the survey was applied to mitigate unbiased opinions and answers;

Although we cannot do a random check for respondents with online surveys, other measures to ensure the quality of the survey were applied. For example, one technique is to put the time to complete the survey on a distribution curve, and surveys that take a significantly short time to complete are viewed with caution. Another technique is to check and deal with surveys containing missing values.

\subsubsection{Sampling bias checks}

Sampling bias occurs when a sample statistic does not accurately reflect the true value of the parameters in the target population. In other words, in the selected sample, it is practically impossible to ensure acceptable randomness and representation in sampling. Sampling bias is problematic because it is possible to make systematically erroneous inferences. Therefore, checking for sample bias is a necessary procedure in this survey.

First, the research team checks sampling bias by using participation shares from each university, in order to check whether shares of survey participation by each university are significantly different from its shares in the total population. The results are presented in Figure 2.1. 
Figure 2.1. Shares of university participation in the population and survey sample

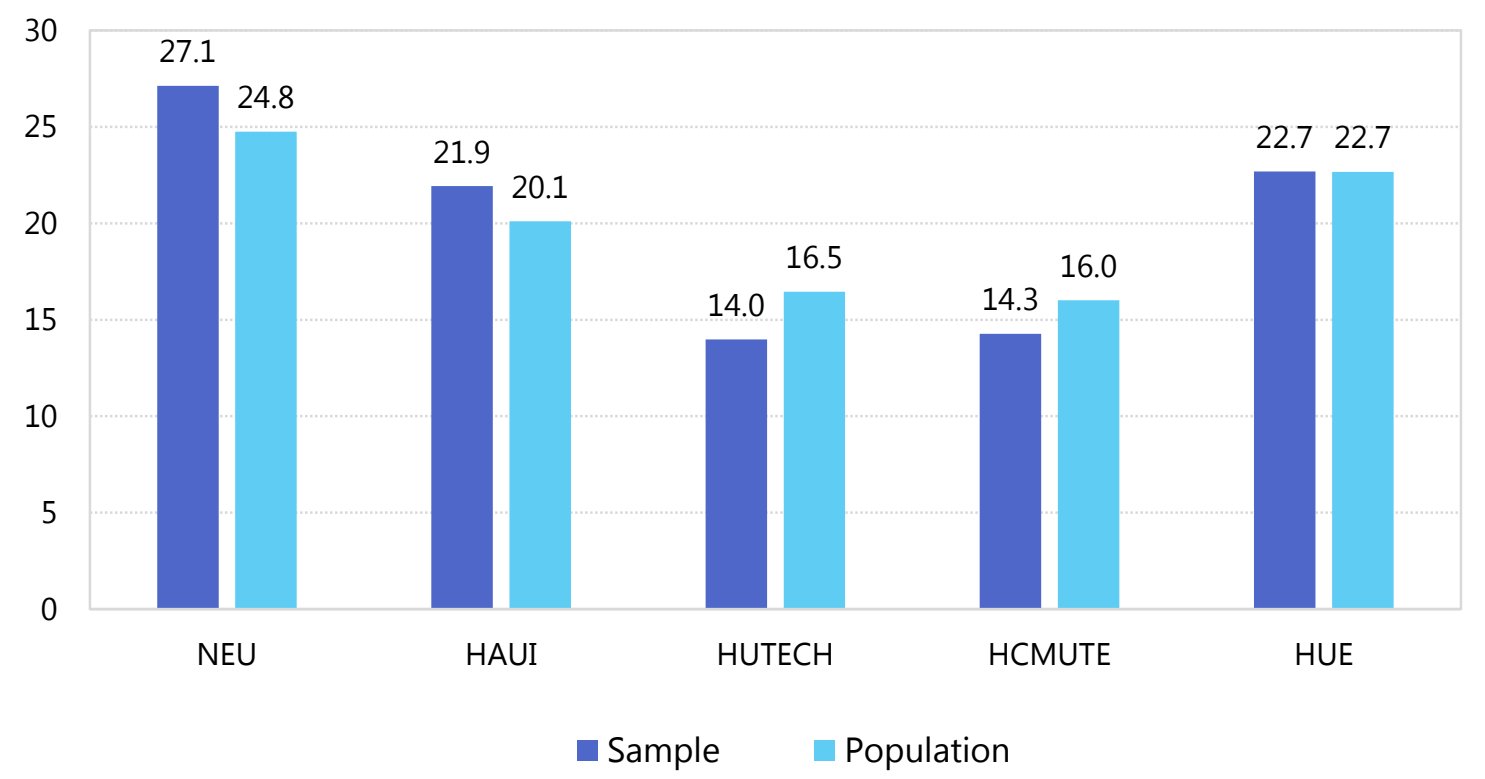

Empirical results indicate that the shares of each university in the sample and total population are similar. Therefore, there is no evidence of sample bias in the participation of university members.

Second, the research team checks sampling bias by using shares of respondents by gender and major, in order to check whether shares of respondents, in terms of gender and major in the sample, are similar to their shares in the population. Empirical results show that there is little evidence of sample bias using the gender and major of graduates (See more in Figure 2.2.).

Figure 2.2. Shares of respondents by gender and major in the population and survey sample

Sampling bias by gender at university level

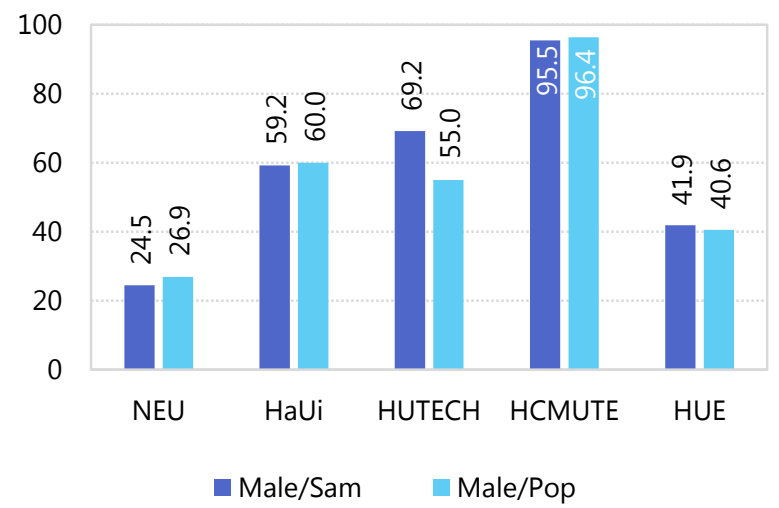

Sampling bias by gender and majors

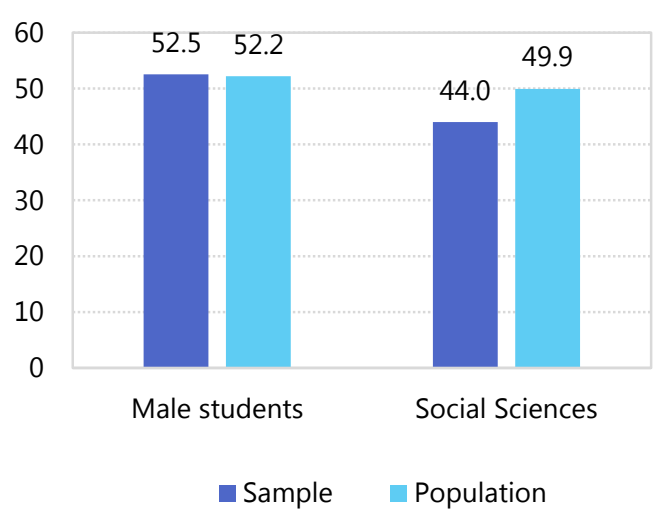




\subsection{Description of the sample}

The survey sample consists of 1710 students who graduated in 2016 from five universities and follow the survey procedures presented above. Response rates of graduates from each university are relatively high, compared to a common online survey, and the average response rate is $54.8 \%$ of the total number of surveys sent out. ${ }^{5}$ Numbers of respondents and response rates of member universities are presented in Figure 2.3.

Figure 2.3. Numbers of respondents and response rates of member universities

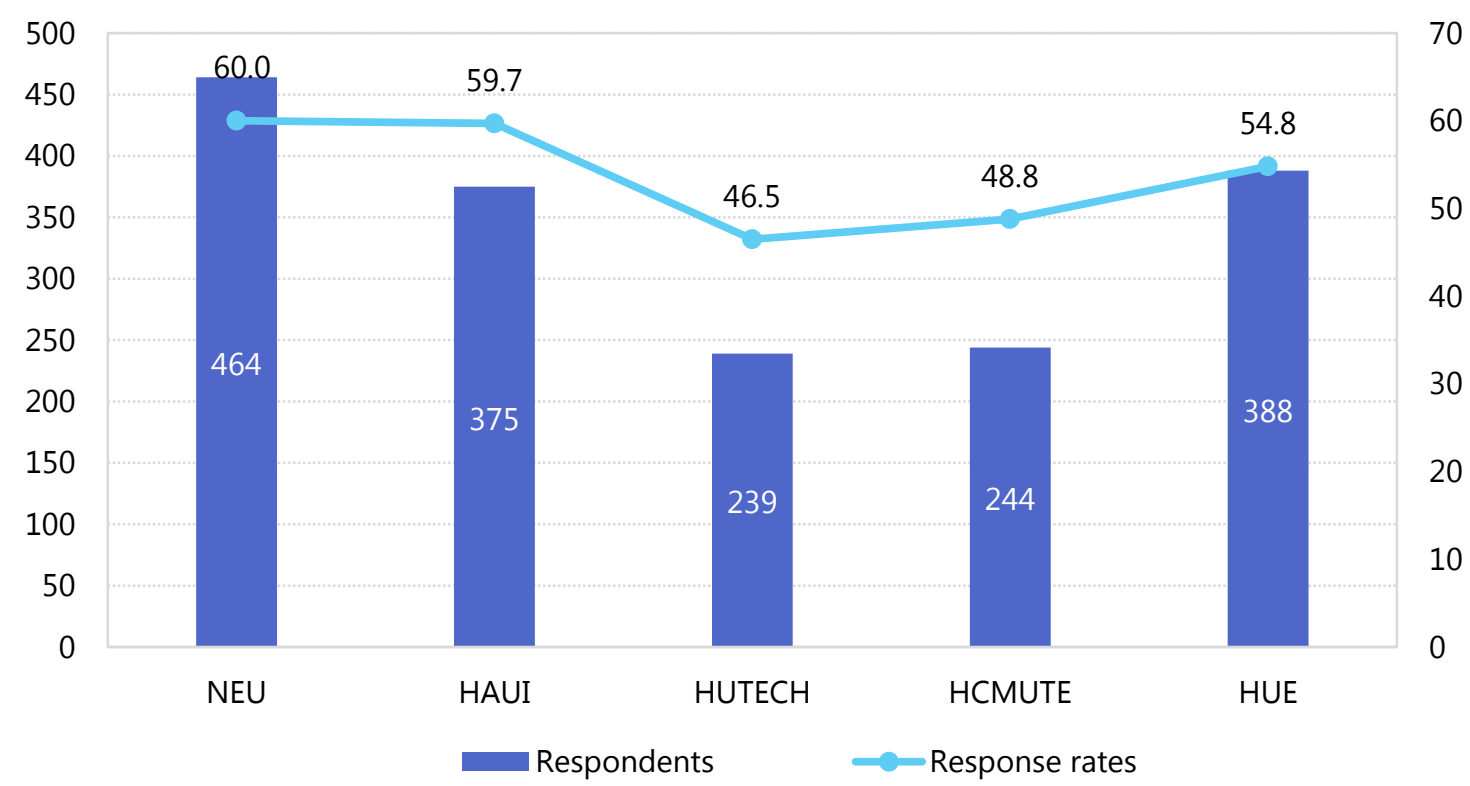

The survey sample covers graduates from 21 majors, of which 5 majors overlap among universities. These majors are finally categorized into two larger science fields: Engineering and Social Sciences. According to the survey sample, $44 \%$ of respondents belong to engineering, $56 \%$ are from the social sciences, $47.7 \%$ are female graduates, and $95 \%$ are from 23 to 26 years old. The following figures show the demographic characteristics, majors, and university composition of the survey respondents.

\footnotetext{
${ }^{5}$ For example, the enterprise survey for the Provincial Competitiveness Index (PCI) conducted by VCCI has a response rate of $9.8 \%$, or the enterprise survey in the "Conflict of Interest survey" conducted by the World Bank Vietnam has a response rate of $10.2 \%$ (WB \& GI, 2016).
} 
Figure 2.4. Composition of the survey sample

\section{Respondents by gender}

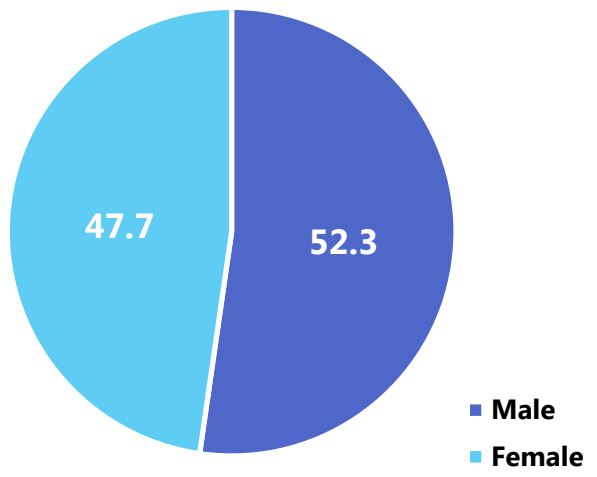

Respondants by field of study

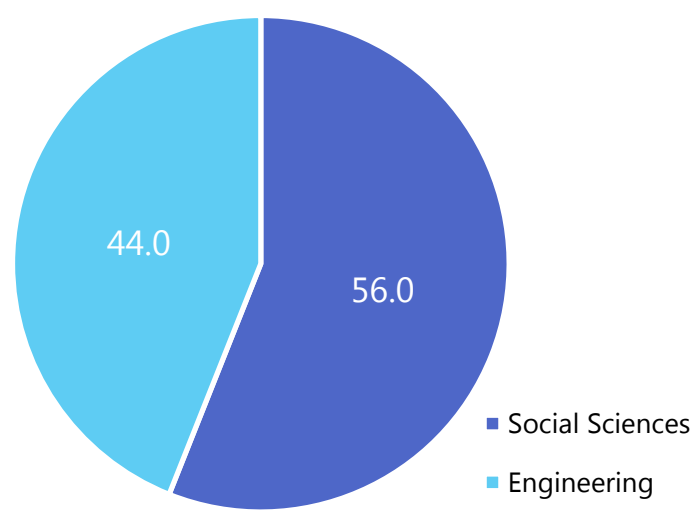

Respondents by university

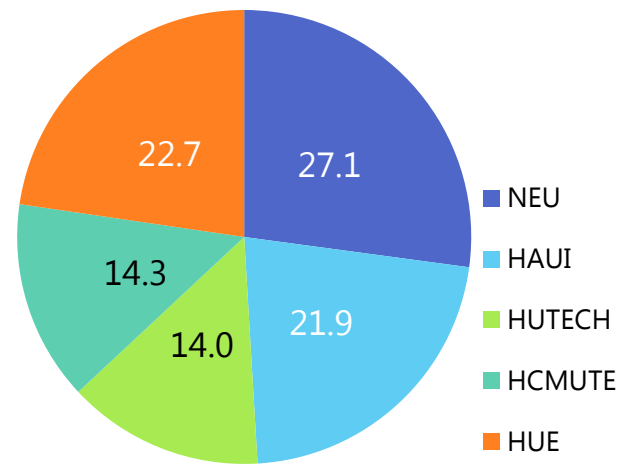

\subsection{Questionnaire}

\subsubsection{Questionnaire Development}

The questionnaire used to collect data was developed in a series of different stages. The most important stages are briefly described next. First, the structure of the questionnaire, its main sections, and the variables to be measured were determined in the meeting that the project members held in Ho Chi Minh City in April 3-7, 2017. In order to make these decisions, the results of the two focus groups held by the project coordinator, in cooperation with the University of Valencia (UV) Team, with groups of Vietnamese graduates and employers were taken into account. Second, the project members from the UV and the National Economic University (NEU) began to write the questionnaire items. Initially, a first draft version of the questionnaire in English was created and later modified after several rounds of reviews between the UV and NEU members. This modified draft version was sent out to other members of the partner universities to gather their comments and suggestions for improvement. Once these comments and suggestions had been incorporated, the resulting version was reviewed by members from all partner universities in the meeting the project members held in Hue in 
October 30 and November 1, 2017. The group review produced a new version of the questionnaire that was translated into Vietnamese in the meeting. Then, the Vietnamese questionnaire was uploaded onto an on-line platform in order to collect a small sample of data that allowed us to conduct a pilot study. The aims of the pilot study were: 1) to check the comprehension of the questionnaire content and the instructions for completing it; 2 ) to check the time required to answer it (considering the different paths of the questionnaire depending on the current employment situation of graduates; i.e., employed, self-employed, unemployed, inactive); 3 ) to check that the filter question (current employment situation) introduced in the questionnaire works well and is properly understood and followed by the respondents; and 4) to check the functioning of the on-line platform. Data from a sample of 27 graduates from the five partner universities were collected. The data provided by this sample were analysed and discussed in a meeting held by the project members involved in the Tracer Study in Hanoi in December 4-5, 2017. The conclusion of the pilot study was that the final version of the questionnaire worked well.

\subsubsection{Structure and content}

The structure of the questionnaire is composed of five main sections:

1. Socio- demographic data

2. Employment situation

3. Employed graduates

4. Unemployed graduates

5. Inactive graduates

The socio-demographic section is composed of five items that ask subjects about:

1. the University where they obtained their (most recent) bachelor's degree,

2. the major of their bachelor's degree,

3. their gender,

4. their age, and

5. the year they initiated their bachelor's degree

The second section is composed of two items that obtain information about:

1. the number of jobs they had after graduation, and

2. their employment situation at the time they answered the questionnaire.

This last question was used as a filter that allowed us to ask different questions to distinct groups of subjects depending on their employment situation (i.e., employed, self-employed, unemployed, inactive).

The third section is focused on employed graduates and is the longest section of the questionnaire. In this section, subjects initially provide information about their first job: 
1. Time needed to find first paid job after graduation

2. Strategies to find first paid job after graduation

Then, they are asked to provide detailed information about their current job:

1. Strategies to find current job after graduation

2. Horizontal match

3. Level of education required for current job

4. Vertical Match

5. Employer organization (type, sector, and size)

6. Location

7. Functional area

8. Hierarchical level

9. Formal written employment contract

10. Duration

11. Part-time vs full-time

12. Monthly income

13. Work satisfaction

14. Importance of a number of competences for good performance

The fourth section is devoted to unemployed graduates. Here, subjects respond to questions about the following aspects:

1. Time they have been looking for a job

2. Job search strategies used

3. Their difficulties in finding a job

4. Their opinion about university career centres' services

Finally, the fifth section is focused on inactive graduates. Here, subjects are asked about their reasons for not looking for a job.

\subsection{Analysis}

The data collected were submitted to descriptive analysis. Depending on the nature of the variable involved, we computed percentages or means to describe the variables measured in the study sample. We also created appropriate graphs to represent the results obtained.

The descriptive analysis was conducted for the total sample of surveyed graduates and for the different groups defined on the basis of the following variables: gender, bachelor major (Social Sciences vs Sciences \& Engineering), and graduate-job matching types (based on the degree to which graduates' jobs are related to the content of their degree and require university education). The results obtained for the different groups were compared using appropriate statistical techniques. 


\subsection{Limitations}

The results reported here come from a large sample of Vietnamese university graduates. However, a number of limitations have to be taken into account when interpreting the study results. The data were collected from subjects who graduated from only five Vietnamese universities. Moreover, although the surveyed graduates had a variety of bachelor majors, not all the majors in the Vietnamese university system were included in the study. These characteristics of the study limit the generalizability of its results to other universities and majors that are not considered. 

$\circ \circ \circ \circ \circ \circ \circ \circ \circ \circ \circ \circ \circ \circ \circ \circ 6 \circ \div:=E=E=$

$\bullet \bullet \bullet \bullet \bullet \bullet \bullet \bullet$

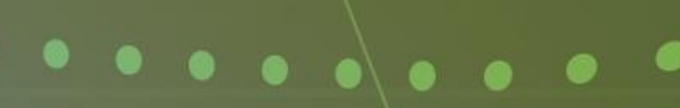

CHAPTER 3:

SURVEY RESULTS FOR THE TOTAL SAMPLE

OF GRADUATES 


\section{CHAPTER 3: SURVEY RESULTS FOR THE TOTAL SAMPLE OF GRADUATES}

In this chapter, we present the results obtained for the total sample of surveyed graduates. In the first section, we focus on the employment situation graduates had at the time they responded to the questionnaire. Because they were asked different questions depending on their employment situation (e. g., employed, unemployed, inactive), after the first section we present the results obtained for employed, unemployed, and inactive graduates.

\subsection{Graduates' employment status}

\subsubsection{Current employment situation}

According to Figure 3.1. 82.6\% of the graduates reported that they were employed at the time they filled in the survey (Table 3.1). In addition, $6.2 \%$ were self-employed, and so at that time, $88.8 \%$ of the graduates were working, $8.8 \%$ were actively searching for a job, and $2.3 \%$ were unemployed and not looking for a job (inactive graduates). Thus, the employment rate amounts to $91.4 \%$ for the subjects in this study.

Figure 3.1. Current employment situation

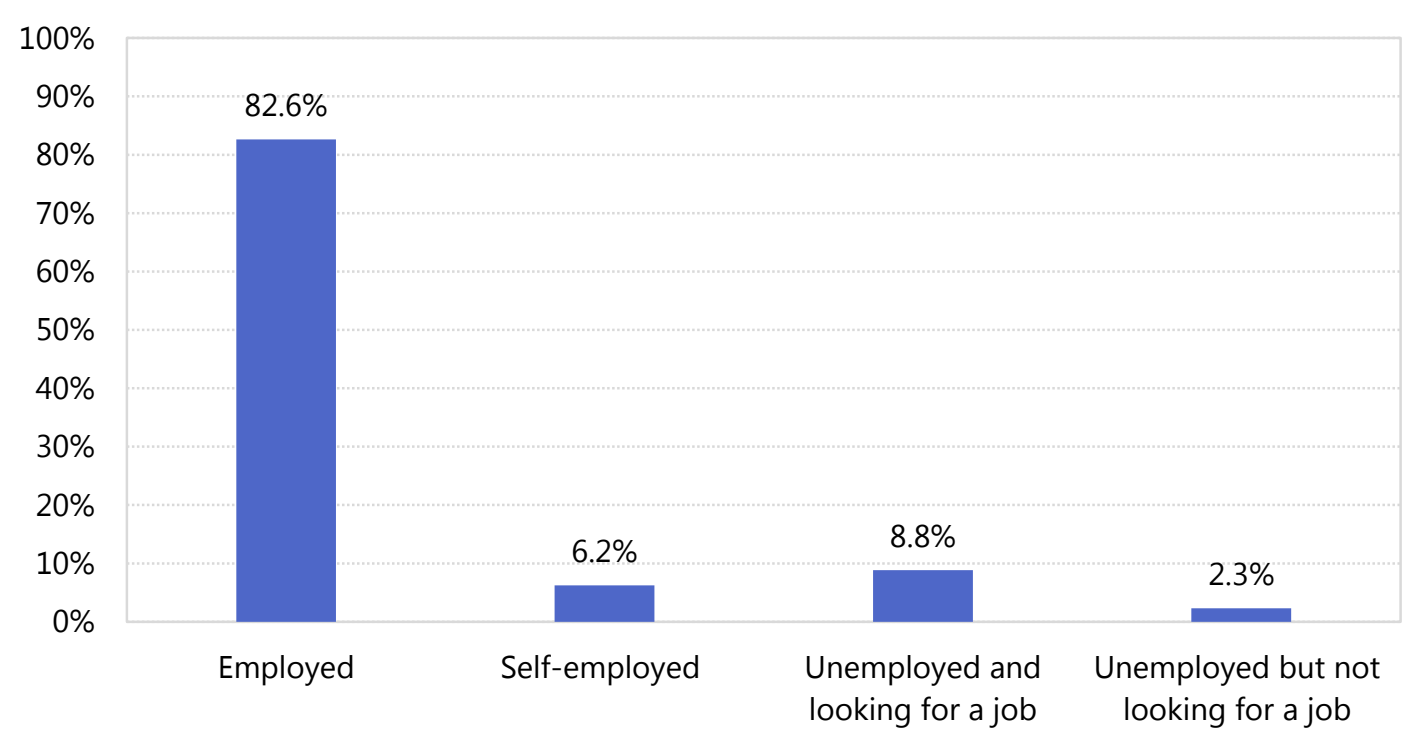




\subsubsection{Number of jobs since graduation}

In all, $42.1 \%$ of the graduates reported that they had had just one job after graduation, whereas another $36.4 \%$ declared that they had worked in two jobs since their graduation. Over $18 \%$ declared more than two jobs during that period, and 3.3\% informed that they had not worked after they graduated (Figure 3.2).

Figure 3.2. Number of jobs since graduation

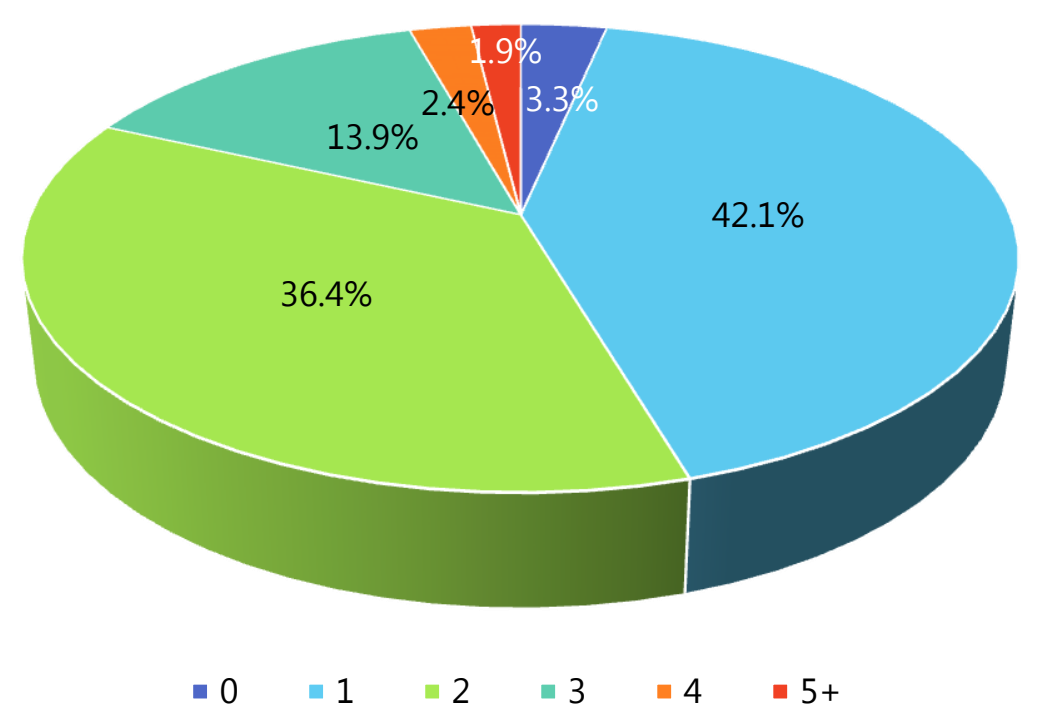

\subsection{Employed graduates ${ }^{6}$}

\subsubsection{Time to find the first paid job after graduation}

In order to find out how long it took the graduates to get a job, we asked them to report, first, if they found their current job before or after they graduated; $53.4 \%$ reported they found the job after graduation, whereas $46.5 \%$ were already employed when they graduated (Figure 3.3).

\footnotetext{
${ }^{6}$ The term 'Employed graduates' includes self-employed graduates and graduates employed by an employer.
} 
Figure 3.3. When did you find your first paid job

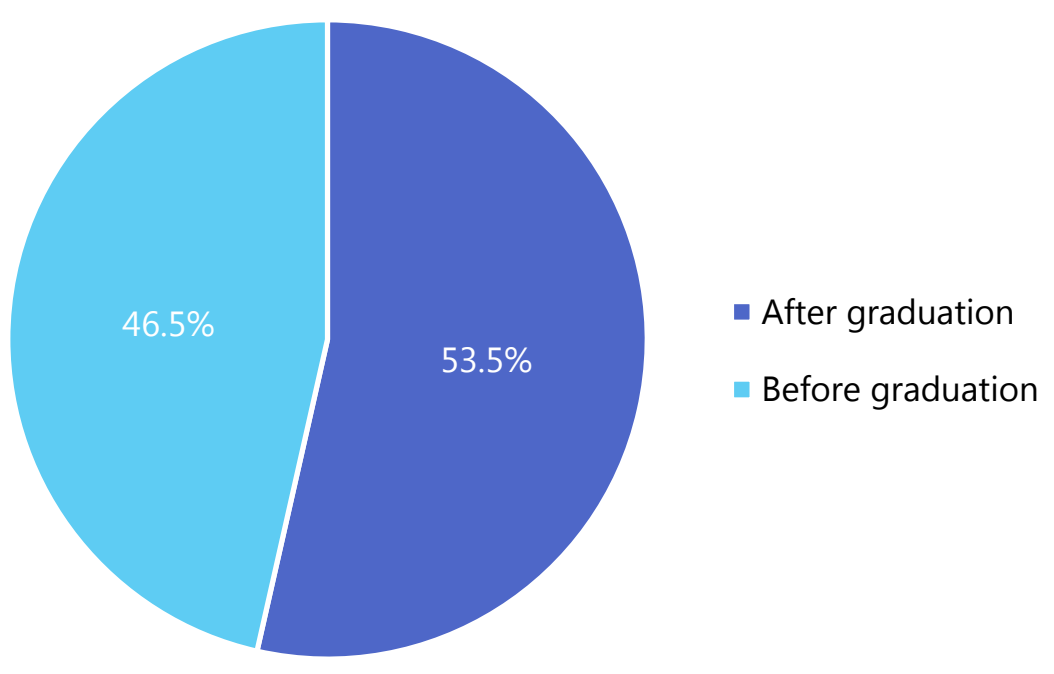

Considering the graduates who found their first paid job after graduation, one third of them found the job in one month, and nearly one fourth of them found it in two months (Figure 3.4). However, $5.6 \%$ of these graduates needed 10 or more months to find their first paid job. In fact, the average time to get their first job after graduation was 3.1 months, and the standard deviation was 3.05 .

Figure 3.4. The average number of months to find their first paid job after graduation

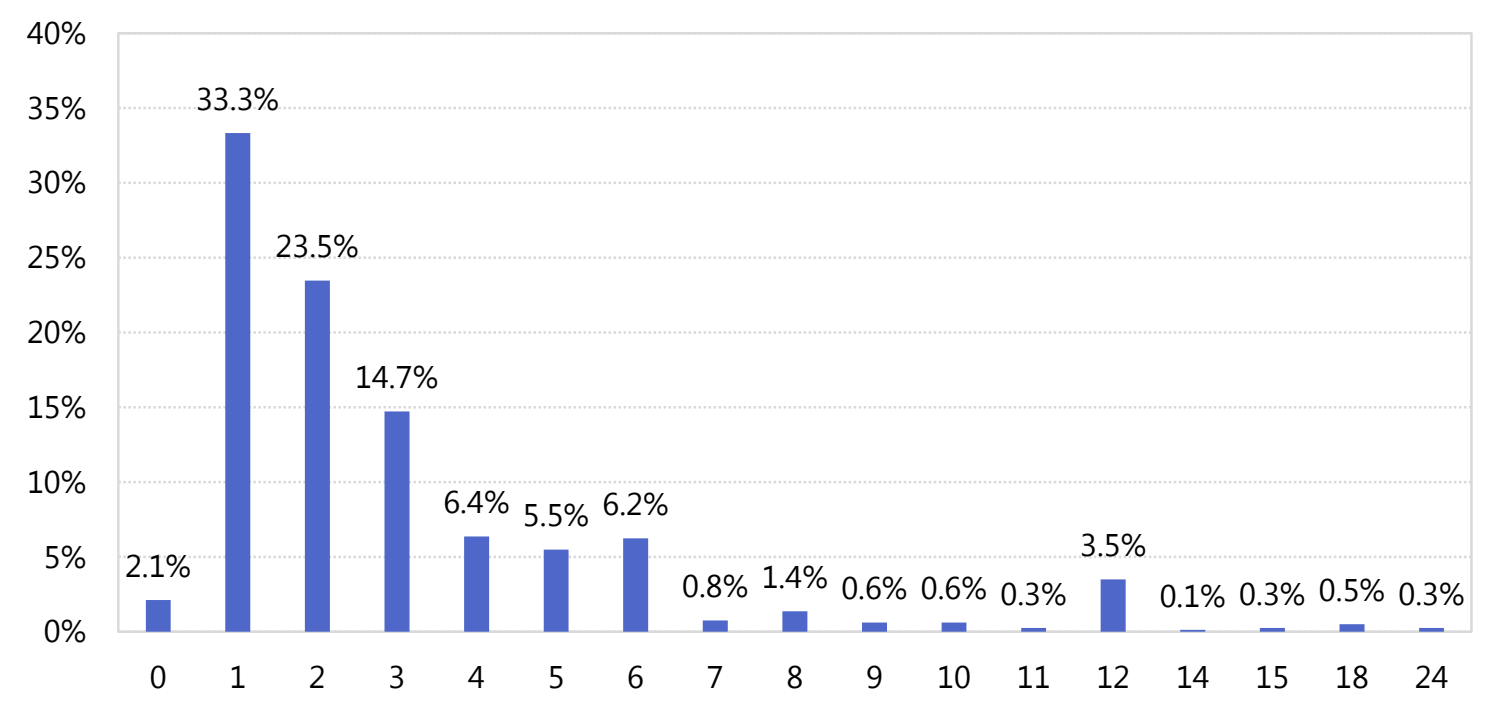




\subsubsection{Strategies to find first paid job after graduation}

The surveyed graduates were asked to report the three most important strategies they used to find their first job (Figure 3.5). The most frequent strategy is social and/or professional internet networks (30.6\% of all the strategies mentioned). The second most important strategy is looking at Internet portals, company websites, and the press $(29,2 \%)$, followed personal contacts $(25.2 \%)$ and contacting the employer on his/her own (24.6\%). Interestingly, formal means, such as contacting employment agencies (1.9\%) and universities' employment services (4.5\%), were among the least frequently used strategies.

Figure 3.5. Strategies to find your first paid job after graduation or the job that you already had when you graduated

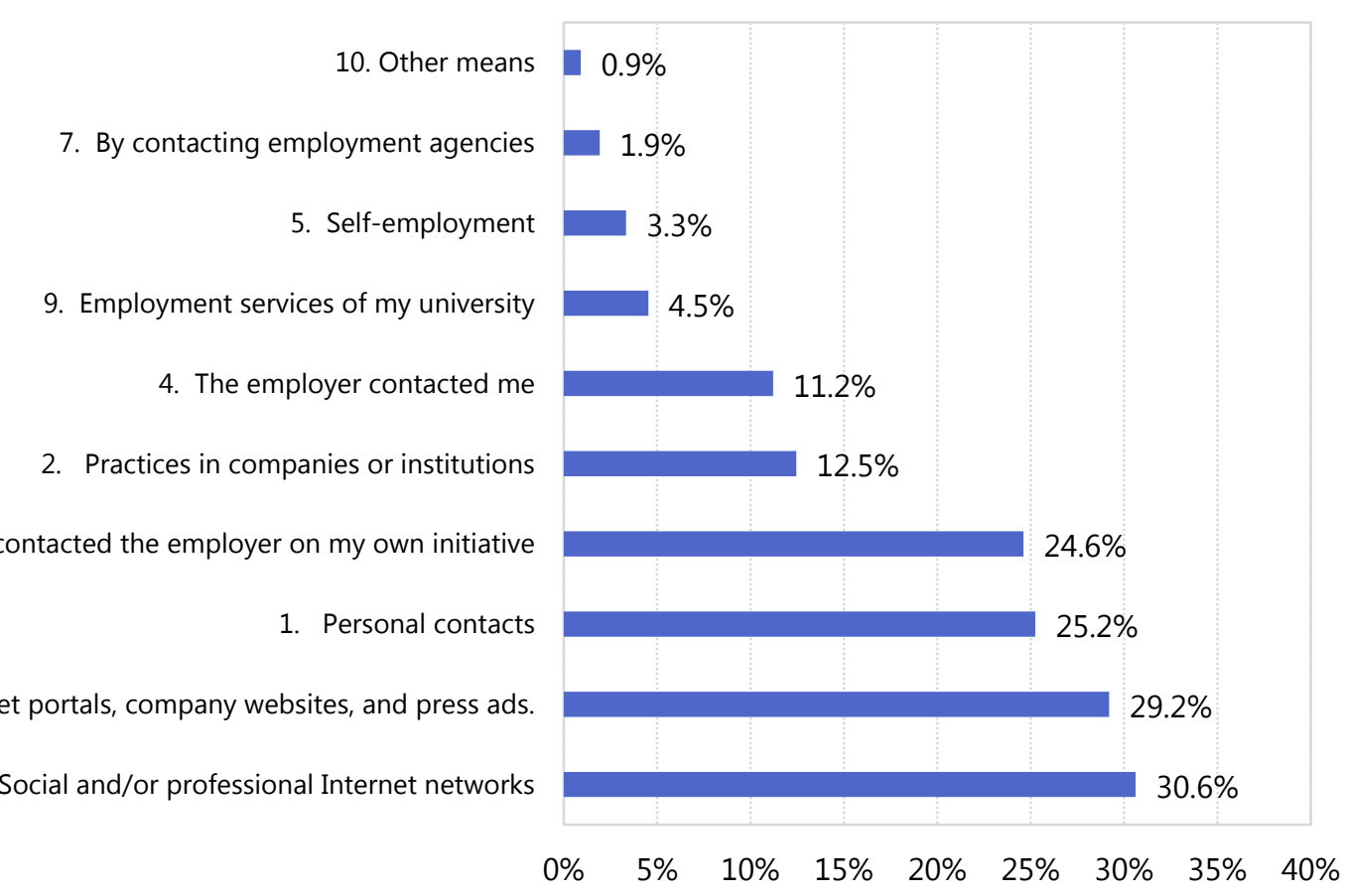

\subsubsection{Strategies to find the current job after graduation}

The Figure 3.6 presents the results corresponding to the strategies participants used to find their "current job" after graduation. A total of 10 alternatives were presented to participants, and they had to choose up to 3 of them. Four strategies were used by participants more frequently than the others: "Social and/or professional Internet networks" (32.2\%); "Internet portals, company websites, and press" (29.9\%); "personal contacts" (27.2\%); and "contacting the employer on their own" (25.5\%). The rest of the strategies were used much less by participants, including the use of university employment services (4\%). 
Figure 3.6. Strategies to find your current job after graduation

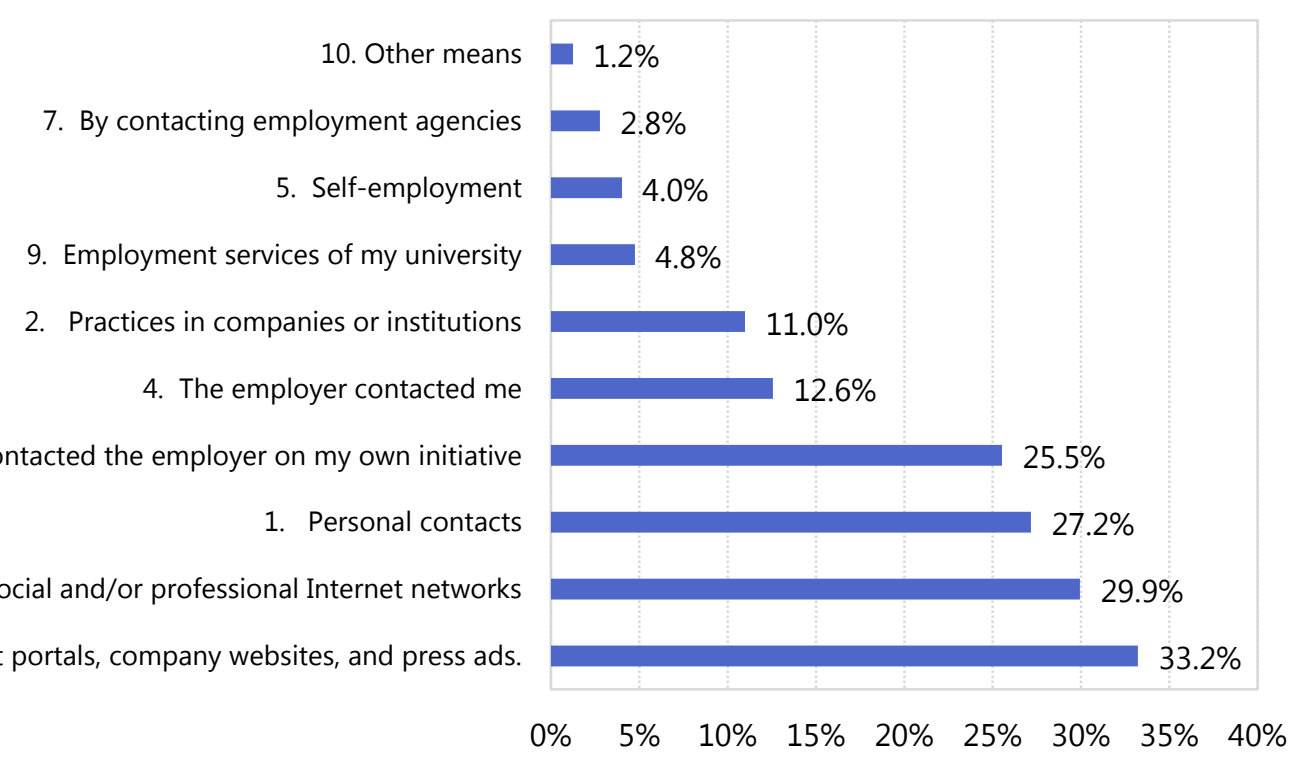

\subsubsection{Horizontal match}

Results about horizontal match (Figure 3.7) indicate the existence of two very balanced groups of participants. Of them, $53 \%$ perceived that their current job is quite (or a lot) related to the content of their degrees, whereas $47 \%$ indicated low (little) or an absence (none) of horizontal match.

Figure 3.7. To what extent is the content of your current job related to the content of your degree

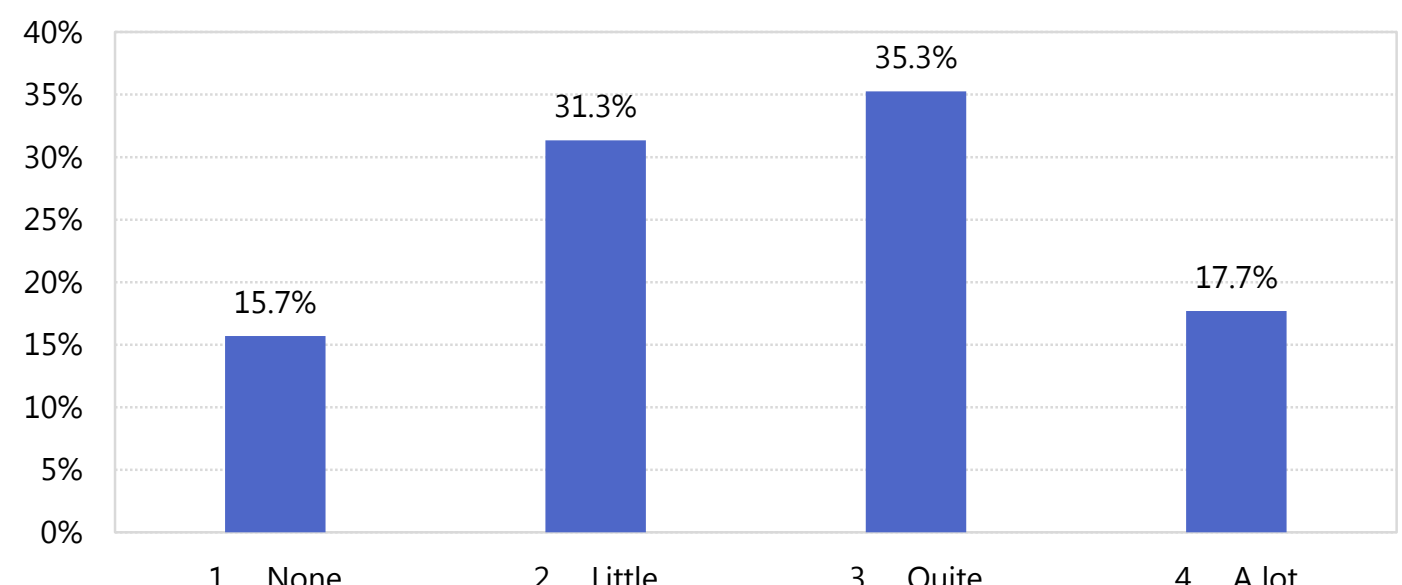

\subsubsection{Level of education required for the current job}

According to the results of the survey study (Figure 3.8), most of the graduates (85.7\%) indicated that the level of education required in their current jobs was a college or university degree. By contrast, only $8.7 \%$ perceived that a Master's degree (or higher) is required. 
Figure 3.8. What is the level of education required for your current job

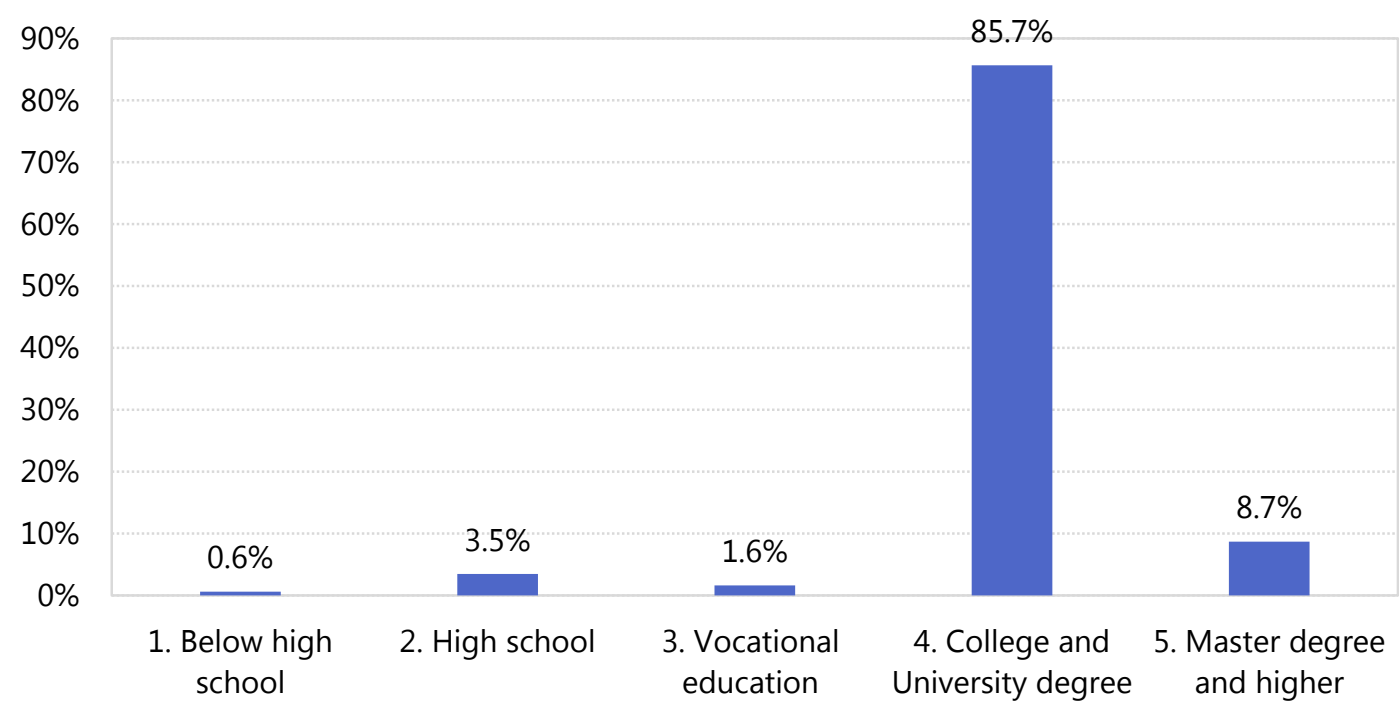

\subsubsection{Competences-job requirement match}

Regarding a vertical match (Figure 3.9), most of the participants (71.2\%) indicated that their competencies match the requirements of their jobs. A group of them (18.1\%) perceive that their competencies are a little bit above (or considerably above) the requirements of the job, whereas only $10.7 \%$ perceive that their competences are quite or a little bit below the requirements of the job.

Figure 3.9. To what extent do your competences match the requirements of your job

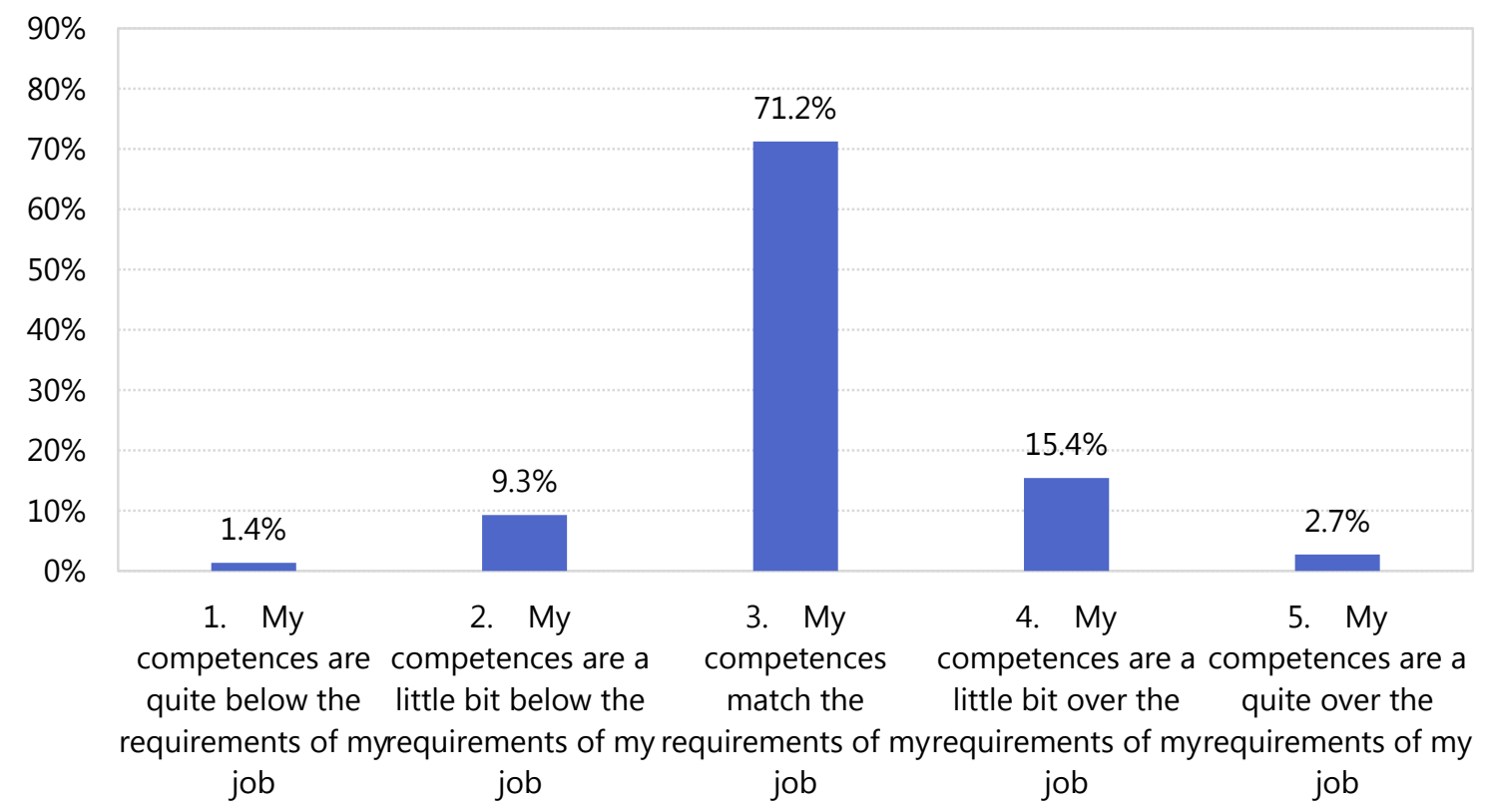




\subsubsection{Employer organization}

Type

As Figure 3.10 shows, most of the surveyed graduates (56.1\%) worked in private companies, whereas only $10.5 \%$ worked in public organizations. Of the remaining graduates, $23.7 \%$ were employed in Foreign Direct Investment (FDI) companies, 3.6\% worked in public-private ventures, $2 \%$ worked in foreign organizations, and only $0.3 \%$ worked in NGOs.

Figure 3.10. The organization you work for

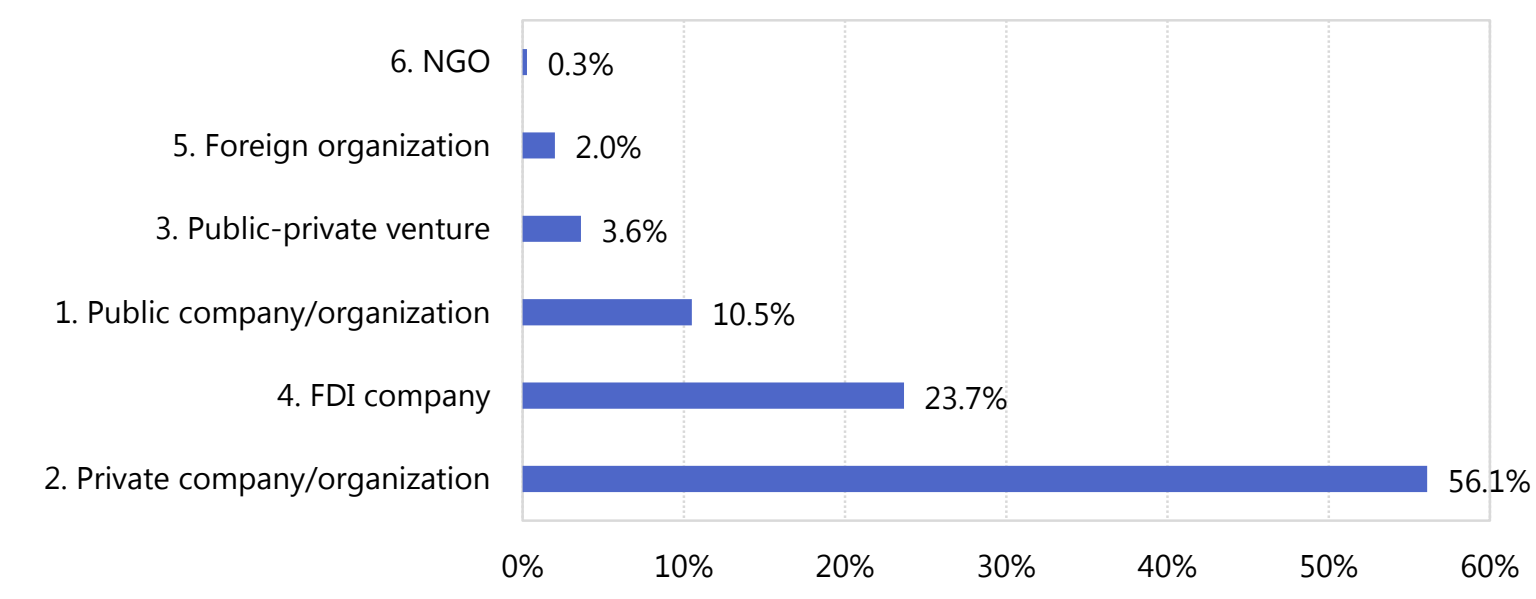

Sector

Regarding the sector of economic activity of the company where the graduates worked, Figure 3.11 shows that the two sectors with the highest percentages were manufacturing (17.2\%) and "banking, finance and insurance" (10.7\%). The remaining sectors showed percentages equal to or less than $6 \%$.

Figure 3.11. What is the sector of economic activity of your organization

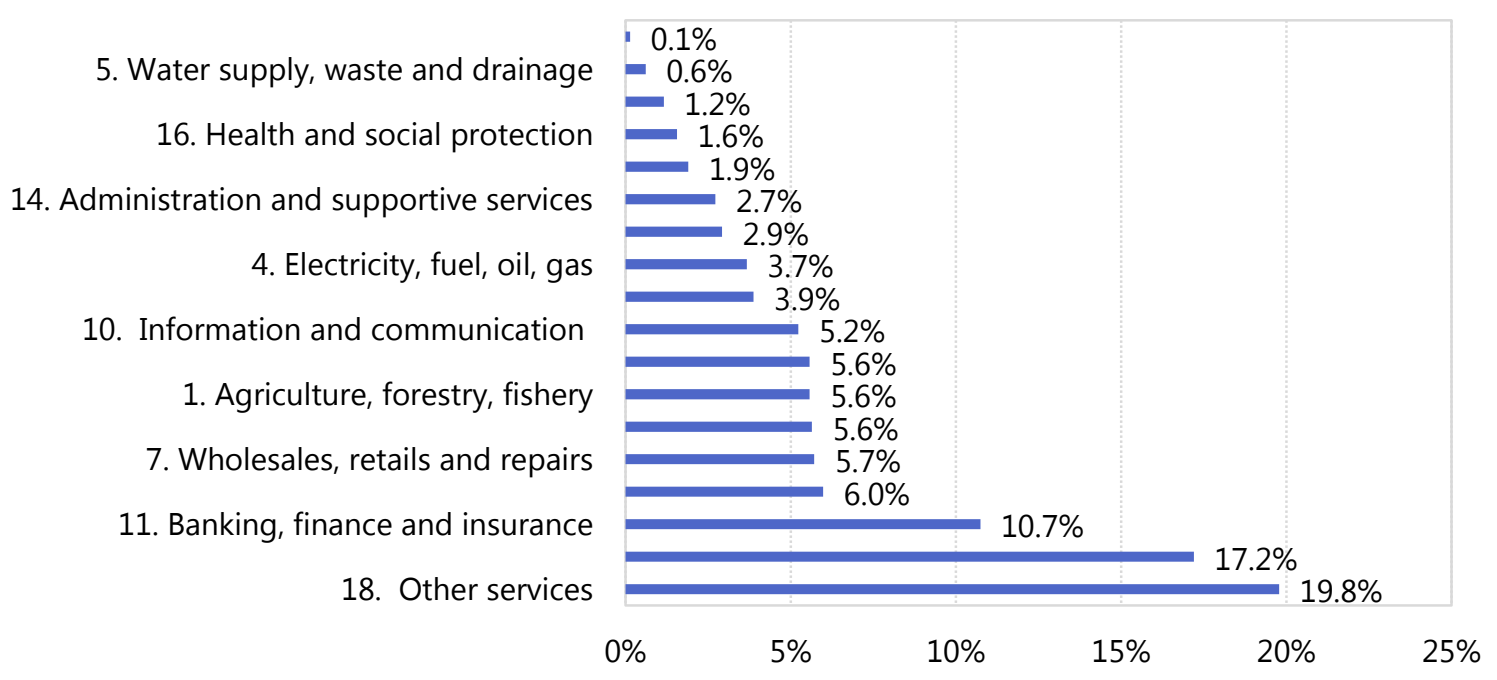


As to the size of the companies where graduates worked (see Figure 3.12), most graduates worked either in large companies (43.8\%) or small ones (39.5\%). Only $10.2 \%$ worked in micro companies, and $6.5 \%$ worked in medium-sized companies.

Figure 3.12. How many employees does your company have

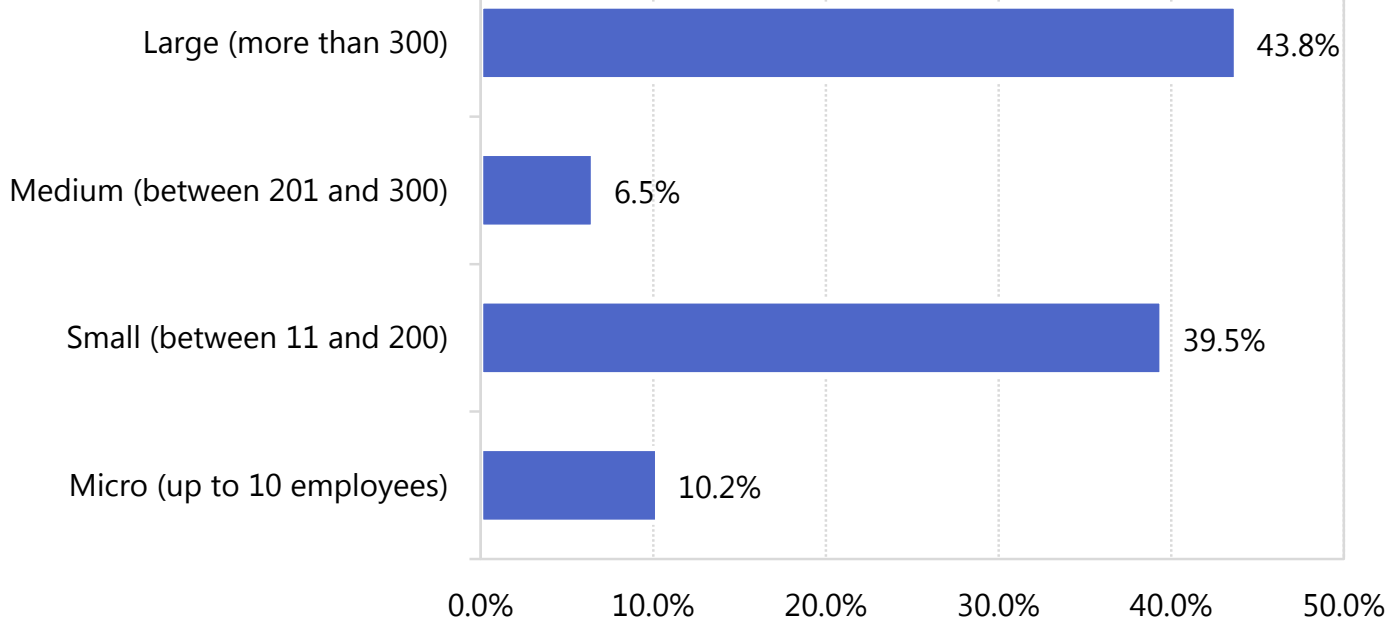

\subsubsection{Location}

Regarding the location of the graduates' jobs, Figure 3.13 shows that for more than half of the sample (56.3\%), the job was located in another region apart from where the graduate's family lived. For $18 \%$ of the graduates, the job was located in the province where their families lived. For the remaining cases, $13.4 \%$ of the graduates had a job in the town where their family lived, and $9.1 \%$ in the same region where the family lives. Only 3.3\% of the graduates worked abroad in another country.

Figure 3.13. Where is your current job located

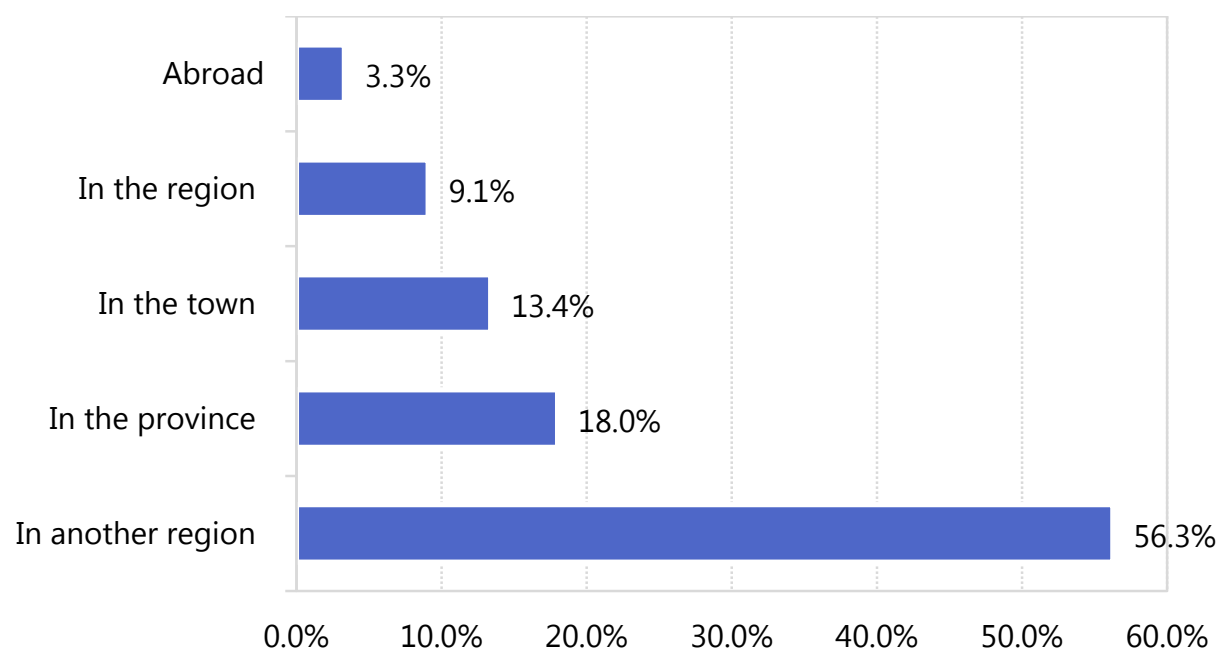




\subsubsection{Functional area}

About $40 \%$ of the participants had their current job in one of the two most frequently mentioned functional areas: production and/or provision of services $(20.9 \%)$ or sales and marketing (10.8\%) (Figure 3.14). A total of 7 functional areas were mentioned by a percentage of participants ranging between $5 \%$ and $10 \%$ : quality control, customer service, administrative and finance, research/research \& development $\&$ innovation, general management, computing, and education. The rest of the functional areas were mentioned by less than $5 \%$ of participants.

Figure 3.14. In what functional area of the company is your current job included

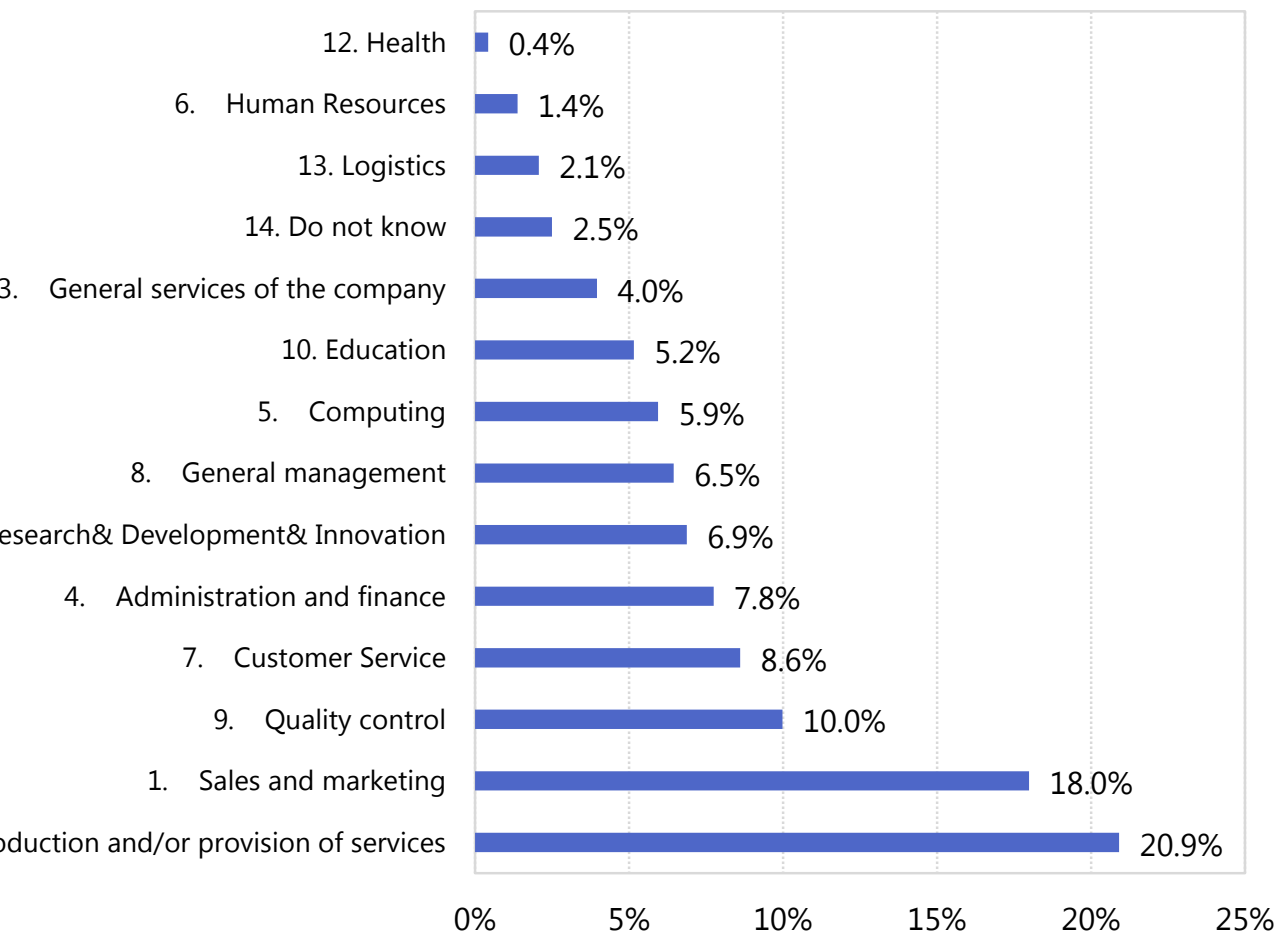

\subsubsection{Hierarchical level}

Regarding the hierarchical level, the majority of the graduates were entry-level employees (83.3\%; see Figure 3.15). Only $15 \%$ of the surveyed graduates had a higher hierarchical level (supervisor: $1.4 \%$; middle manager: $5.4 \%$; manager: $7.9 \%$; top manager: $0.7 \%$ ). Finally, $1.3 \%$ were apprentices. 
Figure 3.15. What is the hierarchical level of your current job

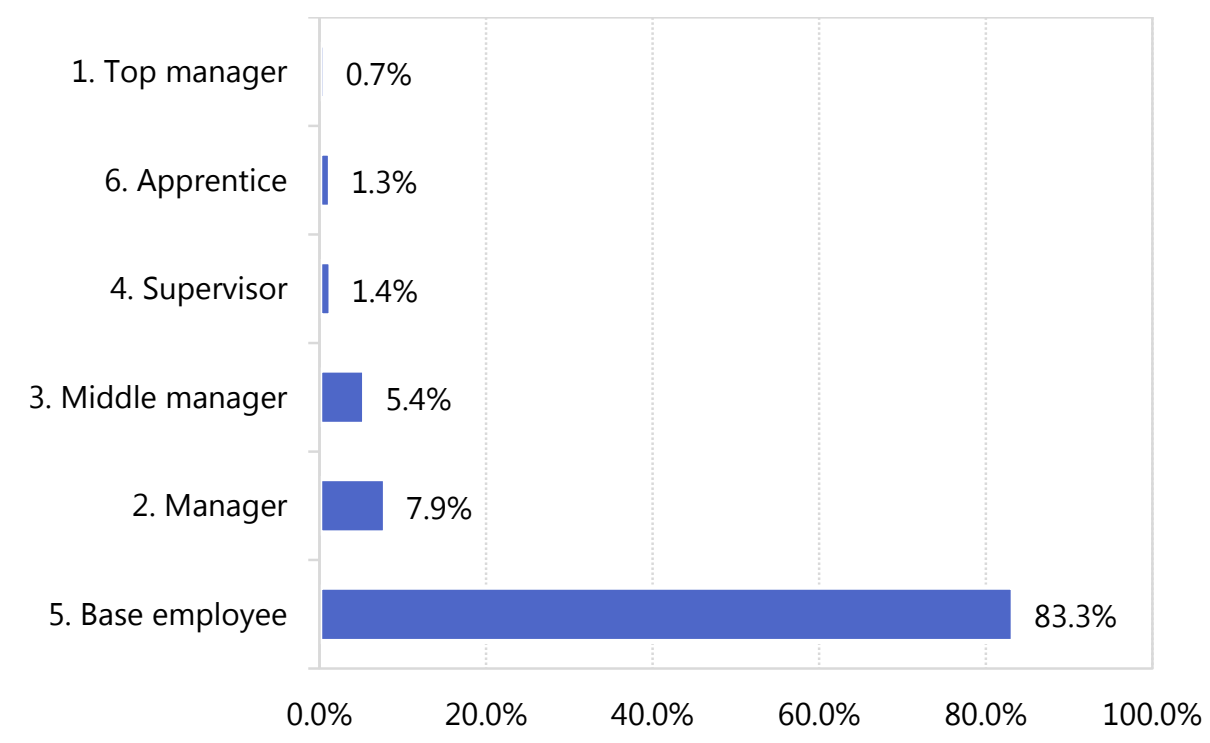

\subsubsection{Formal written employment contract}

As Figure 3.16 shows, the majority of graduates (86.7\%) signed a formal written employment contract. However, the remaining $13.3 \%$ of the graduates performed their job without a formal written employment contract.

Figure 3.16. Did you sign a formal written employment contract for your current job

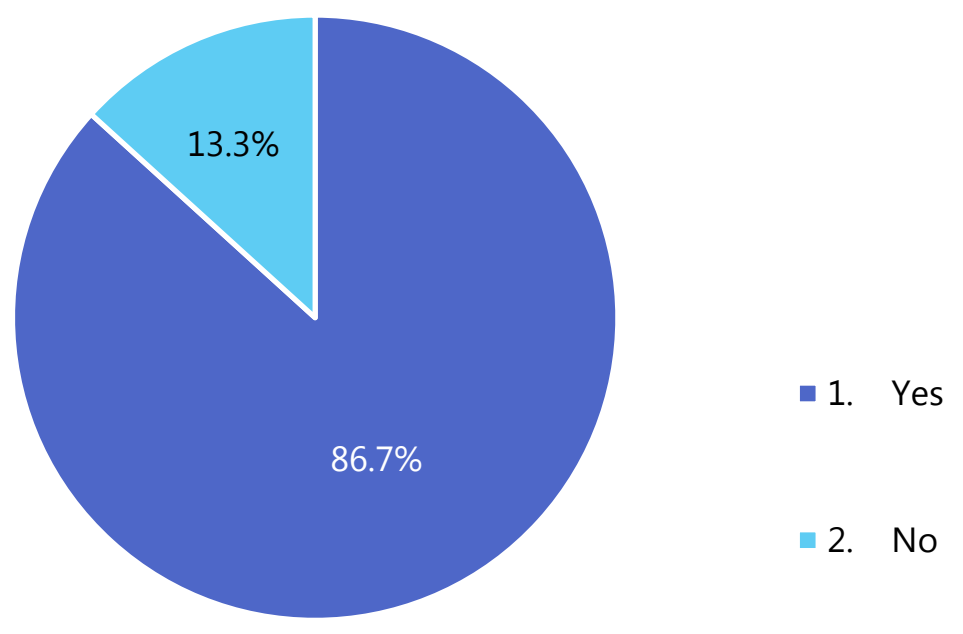

\subsubsection{Duration of the contract}

More than two-thirds of the graduates (69.9\%) had long-term jobs, whereas only $11.4 \%$ had short-term jobs (Figure 3.17). In addition, $16.6 \%$ of the graduates responded by saying they had an unidentified-term job, whereas $2.1 \%$ did not know the duration of their job. 
Figure 3.17. Is your current job...

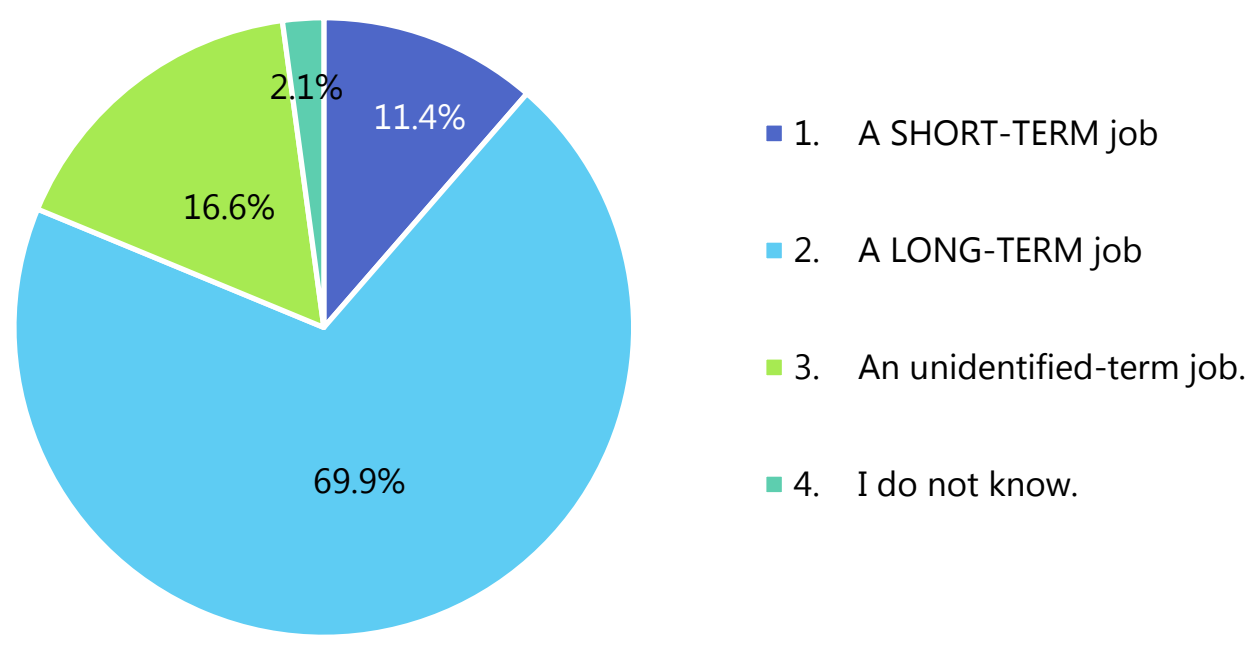

\subsubsection{Part-time vs. full-time}

Almost all of the surveyed graduates (96.8\%) had a full-time job. Only 3.2\% of them performed a part-time job (Figure 3.18).

Figure 3.18. Is your current job...

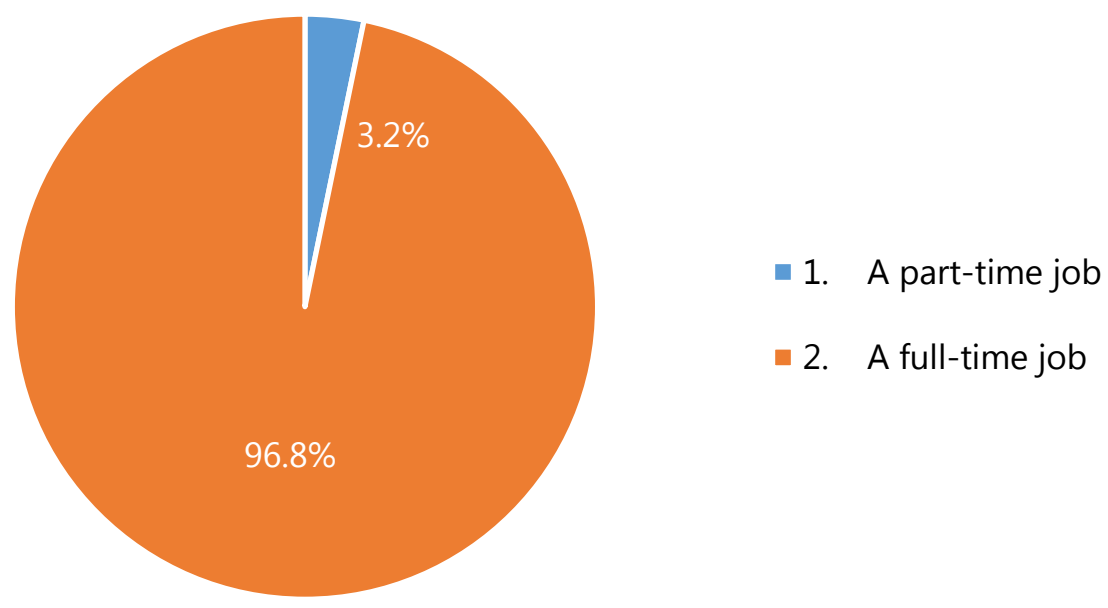

\subsubsection{Monthly income}

Regarding the monthly income of the surveyed graduates, the results obtained show that almost two-thirds of the sample (63.9\%) had monthly incomes between 5 and 10 million Vietnamese dongs (Figure 3.19). Moreover, $11 \%$ had a lower monthly income, and $25 \%$ had monthly incomes of more than 10 million Vietnamese dongs. 
Figure 3.19. An estimation of your monthly income in your current job

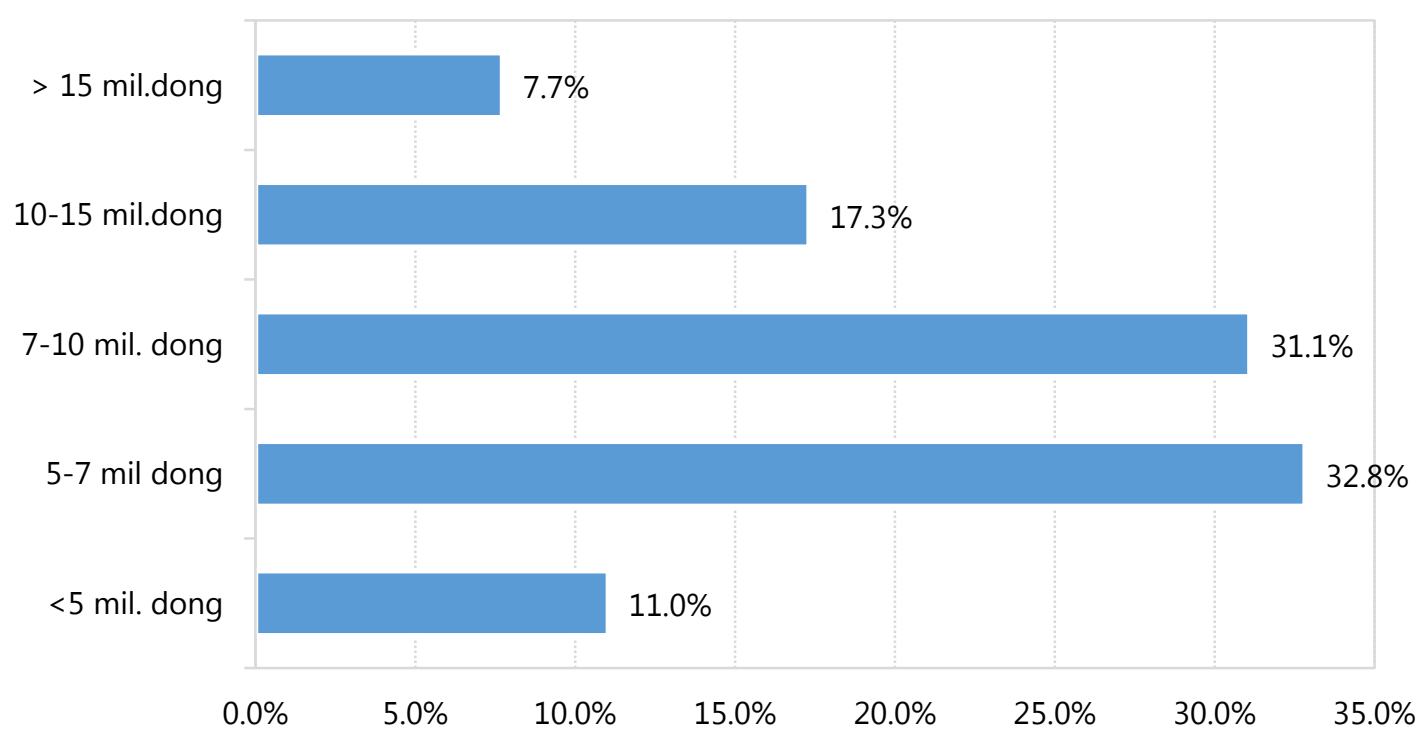

\subsubsection{Work satisfaction}

Figure 3.20 shows the averages obtained for the surveyed graduates' satisfaction with several aspects of their job. The response scale used was the following: 1. Very dissatisfied, 2. Dissatisfied, 3. Satisfied, 4. Very satisfied. Therefore, the scale's intermediate point is 2.5. The results showed that graduates were moderately satisfied with their jobs (overall job satisfaction average: 2.83 ). The aspect that showed the highest satisfaction average was the working conditions (2.94), and the aspect that showed the lowest satisfaction average was income (2.65). The standard deviations for all the satisfaction scores were between 0.53 and 0.67.

Figure 3.20. What is the degree of satisfaction or dissatisfaction produced by each of the following aspects of your job

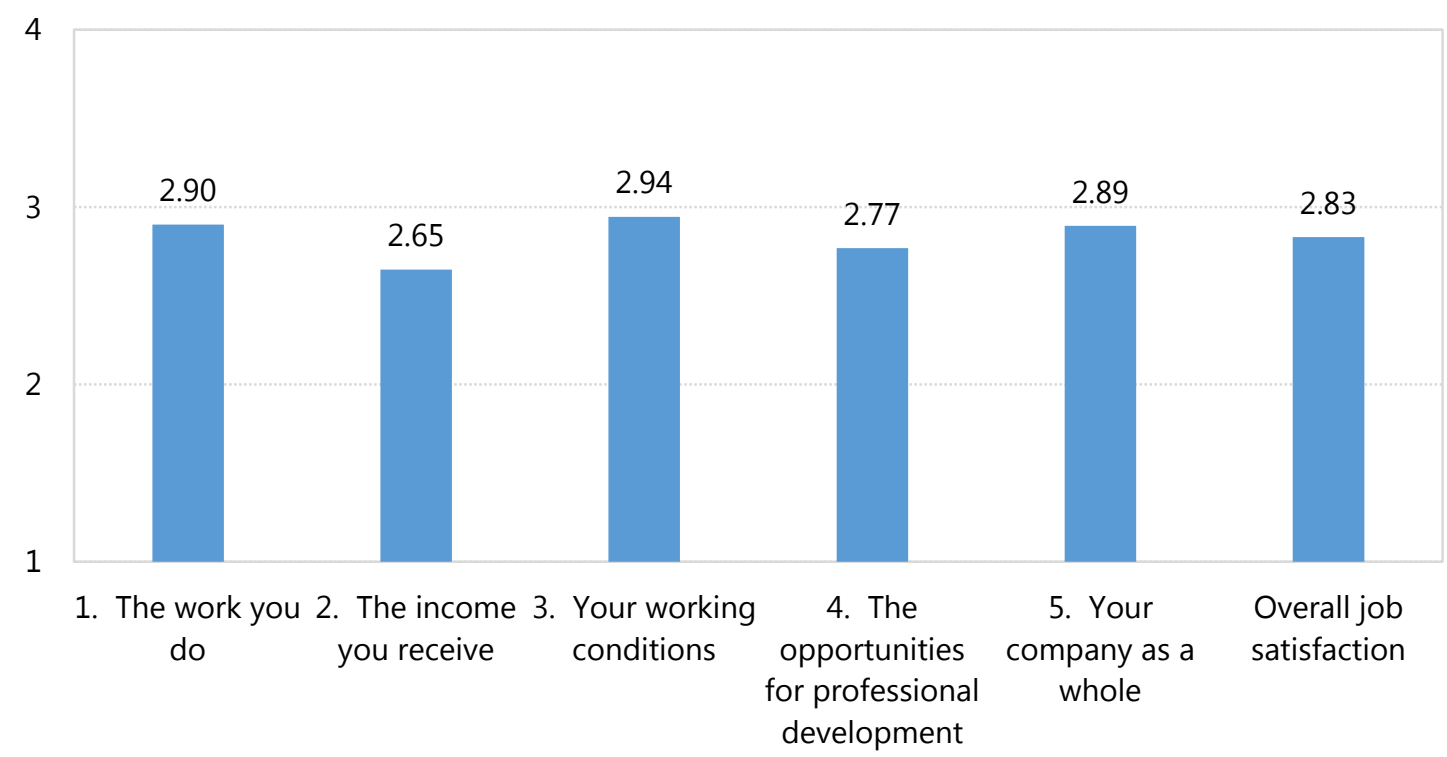




\subsubsection{Importance of competences for good performance}

We asked the surveyed graduates to rate the importance of a number of different competences in attaining good performance in their job. The response scale used was the following: 1 . None, 2. Some, 3. Intermediate, 4. Quite, 5. A lot.

The rated competences can be classified into the following groups: cognitive, management, interpersonal, instrumental, and attitudinal.

Regarding the importance of cognitive competences, the averages obtained (Figure 3.21) showed that two competences stood out over the rest: problem solving (4.26) and continuous learning (4.20). The remaining competences were rated as moderately important (systematic thinking: 3.89; creativity: 3.76; critical thinking: 3.74; report writing: 3.66; transferring theory to practice: 3.59 ). These results suggest that the ability to solve problems by keeping up to date is an important factor in good job performance.

Figure 3.21. Rate the importance of each of the following factors and competences for good performance in your current job: cognitive competences

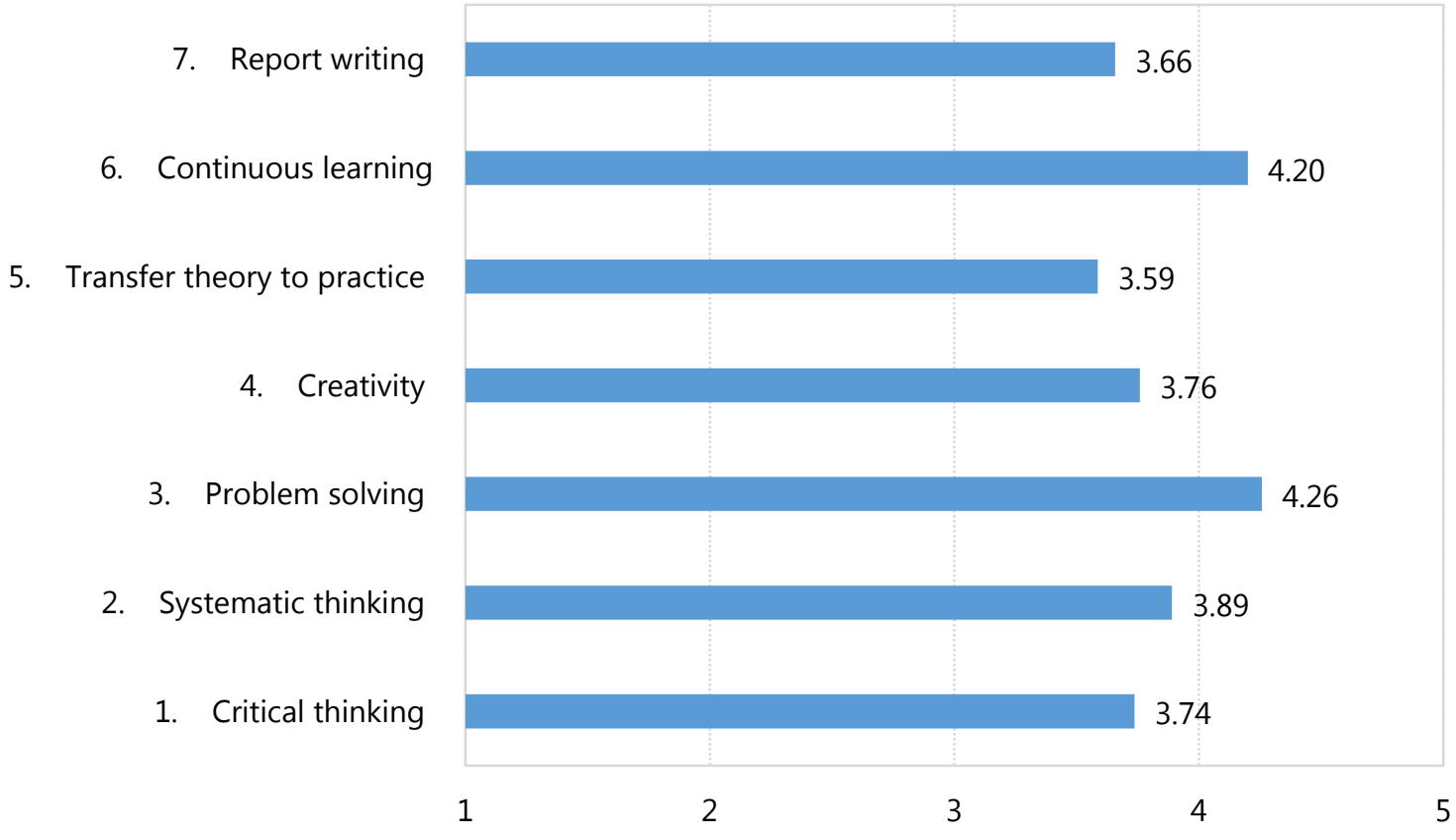

Figure 3.22 shows the results obtained for the importance of several management competences. In this case, the three competences that were rated as more important were planning (4.03), time management (4.01), and decision making (4.01). The other two management competences considered were rated as moderately important (motivate others: 3.74; leadership: 3.69). These results suggest that management competences related to others (motivate others and leadership) are considered less important for good performance than management competences focused on personal skills (planning, time management, and decision making). 
Figure 3.22. Rate the importance of each of the following factors and competences for good performance in your current job: management competences

5. Decision making

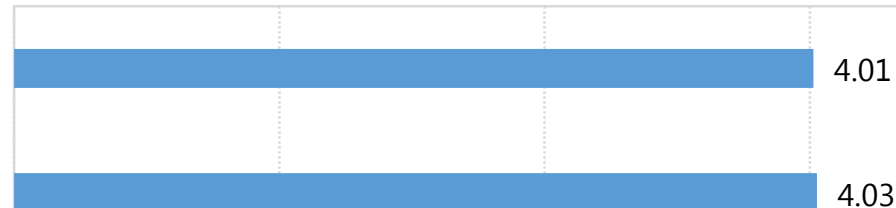

4. Planning

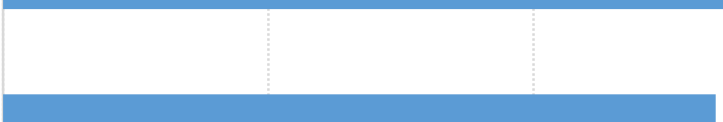

3. Leadership

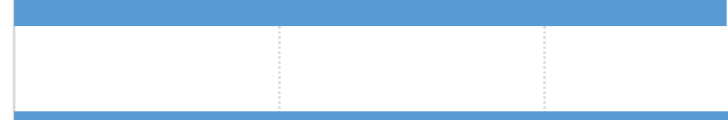

3.69

2. Motivate others

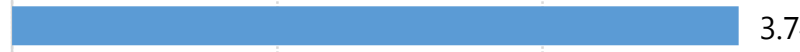

3.74

1. Time management

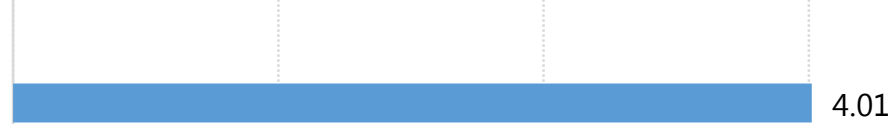

1

2

3

4

As to interpersonal competences, the results obtained showed that, generally, all of them were considered quite important, with averages around 4 (Figure 3.23). However, one competence stood out above the rest: communication skills (4.29). A number of interpersonal competences showed averages very close to 4: team work (4.01), customer relationship skills (3.97), conflict solving (3.94), and inter-cultural skills (3.89). The competence with the lowest average was presentation skills (3.75). Interestingly, the competence with the highest average (communication skills) is one that underlies the other competences considered in this group.

Figure 3.23. Rate the importance of each of the following factors and competences for good performance in your current job: interpersonal competences

7. Customer relationship skills

6. Inter-cultural skills

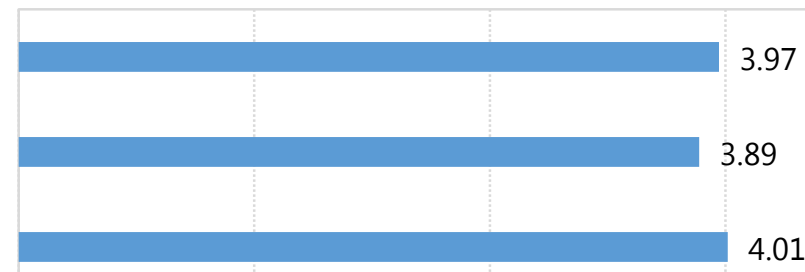

5. Negotiation skills

4. Presentation skills

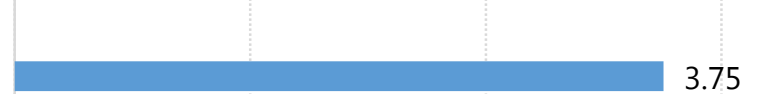

3. Communication skills

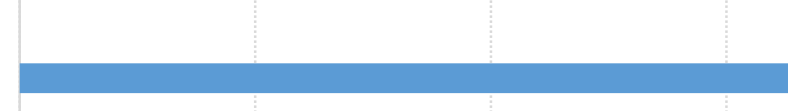

2. Team work
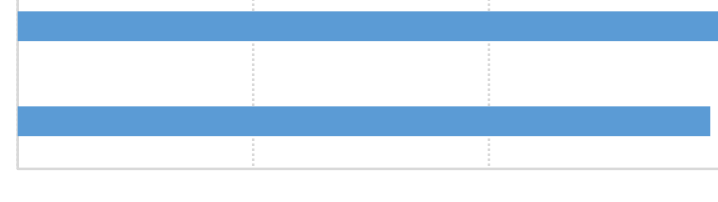

1. Conflict solving 
With regard to the importance graduates give to instrumental competences (Figure 3.24) such as office skills, computer skills, and foreign language skills to perform their current jobs, on average, the students rate all of them as "quite" important. Computer skills are rated (4.05), followed by office skills (3.89) and foreign language skills (3.84).

Figure 3.24. Rate the importance of each of the following factors and competences for good performance in your current job: instrumental competences

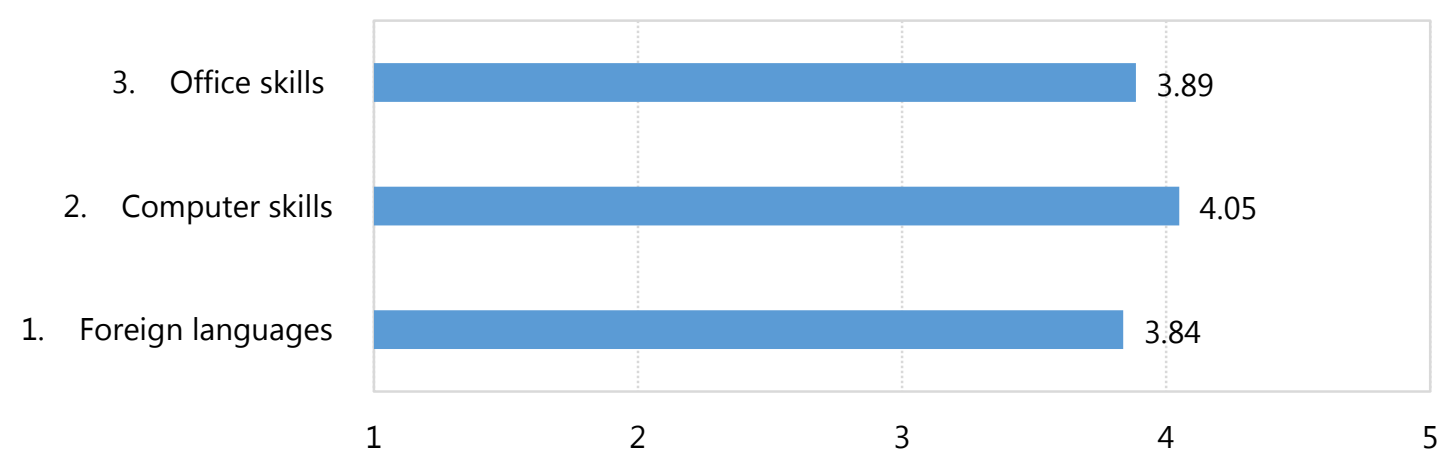

Finally, the importance attributed by the graduates to attitudinal competencies in their current job tends to be high (Figure 3.25). In fact, "Task responsibility" is scored the highest (average 4.24), followed by "punctuality" (4.15) and "adaptability" (4.14). The "Rule compliance" average is slightly above 4, and "commitment" lies slightly below (3.91). Interestingly enough, "entrepreneurship" presents the lowest value (3.54). Considered as a whole, the graduates' jobs involves competences such as responsibility for tasks, punctuality, and compliance with the rules. They also require flexibility, but commitment and entrepreneurship are less frequently required in the job.

Figure 3.25. Rate the importance of each of the following factors and competences for good performance in your current job: attitudinal competences

6. Take responsibility

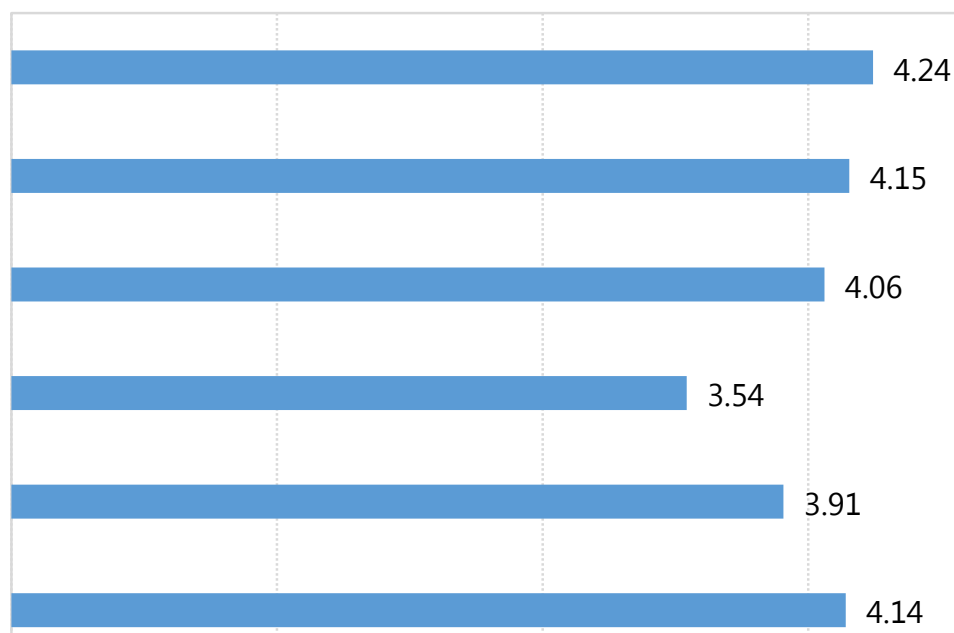

1. Adaptability 


\subsection{Unemployed graduates}

\subsubsection{Time looking for $a$ job}

Unemployed graduates who were looking for a job, on average, had already spent 6.4 months looking for a job when they answered the survey (Figure 3.26). However, when we look the distribution, it is interesting to point out that nearly $30 \%$ had only been looking for a job for one month or less, whereas a similar number of graduates (12.01\%) had been looking for a job for 7 12 months, and $16.01 \%$ for more than one year.

Figure 3.26. How many months have you been looking for a job

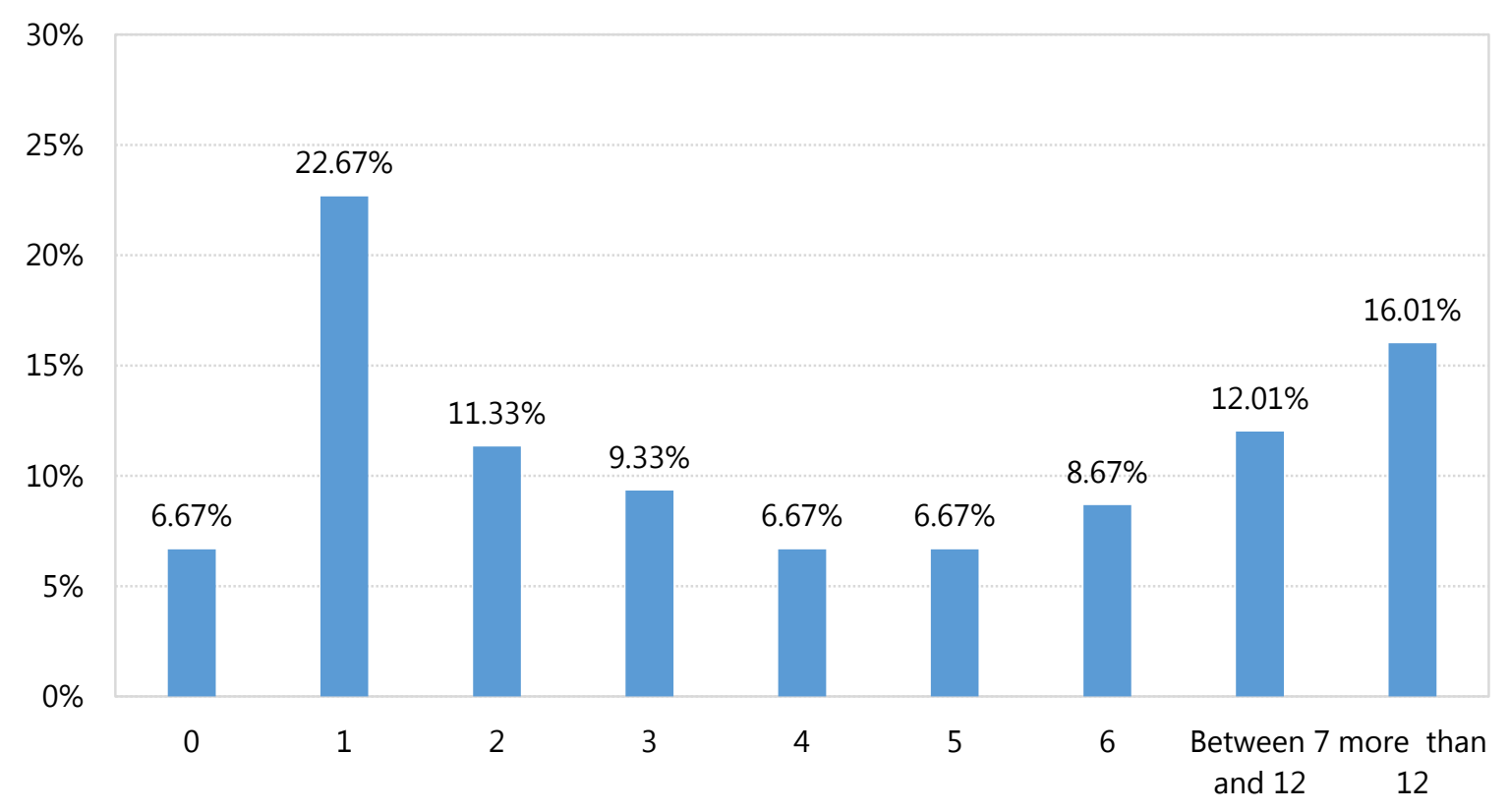

\subsubsection{Job search strategies used}

The strategy most frequently used to search for a job was to use Internet portals, company websites, and press ads (78\% of graduates used this type of strategy) (Figure 3.27). The second most frequently used strategy was the use of social and professional Internet networks $(65.3 \%$ of the graduates). Personal contacts were used by $45.3 \%$ of the graduates searching for a job. More formal strategies such as contacting employment agencies (10.0\%) and using the employment services of their own University $(3,3 \%)$ were used by a minority of the graduates searching for a job. 
Figure 3.27. What are the 3 job search strategies you have been using more frequently

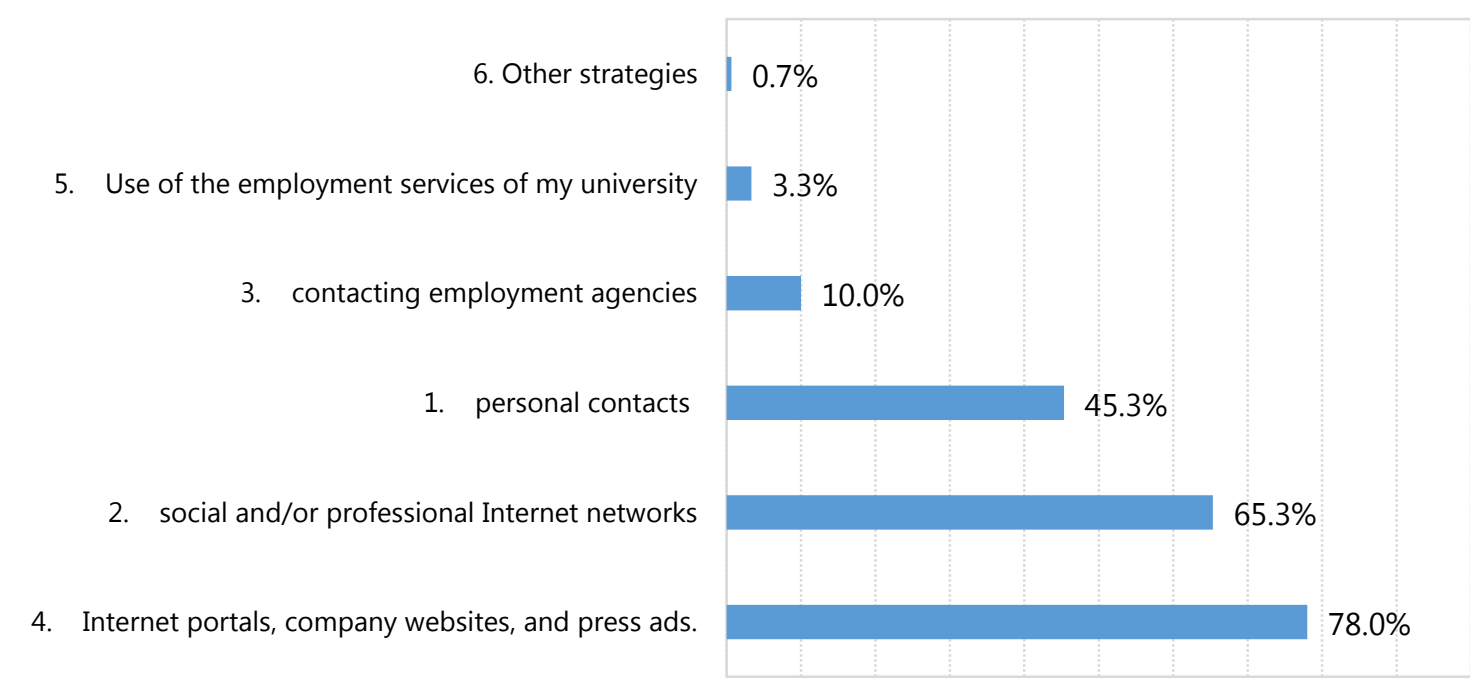

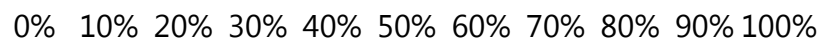

\subsubsection{Difficulties in finding $a$ job}

Graduates who were unemployed and searching for a job provided information about the main factors that contribute to their difficulties in finding a job (Figure 3.28). The most important reason mentioned is the lack of, or insufficient, professional practice and experience (the average reached is 3.6, which means the impact of this factor is between "3.intermediate" and "4.quite"). The second factor mentioned is "Lack of language skills" (3.3). This factor is clearly scored higher than "lack of computer skills" (2.6) and "Deficiencies in the university education I received". One area that is quite important in hampering the graduates' opportunities of finding a job is their "lack of knowledge about the labour market" (3.1) and their "lack of job search skills" (2.9). Moreover, it is also relevant that the graduates find the labour market saturated (3.0). The graduates also decide not to accept a job for several reasons that kept them from taking a job offer. They gave these factors intermediate or lower relevance. "The jobs you have been offered do not have an adequate wage" (3) is a reason of intermediate importance. It is followed by "the jobs you have been offered are not related to your degree" (2.7), and a reason with a lower average score is "you do not like the jobs you have been offered" (2.5). Finally, the two least important factors hampering the opportunities to get a job are the existence of personal circumstances that keep the graduate from working (2.1) and "my demographic characteristics (gender, age, etc.)" (2.1). 
Figure 3.28. Rate the degree of responsibility of each of the following factors in your difficulties in finding a job

12. My demographic characteristics (gender, age, etc.)

9. There are personal circumstances that prevent you from working

6. You do not like the jobs you have been offered

5. Lack of computer skills

8. The jobs you have been offered are not related to your degree

1. Deficiencies in the university education I received

10. Lack of job search skills

7. The jobs you have been offered do not have an adequate wage

11. Saturation of the labor marke

3. Lack of knowledge about the labor market

4. Lack of language skills
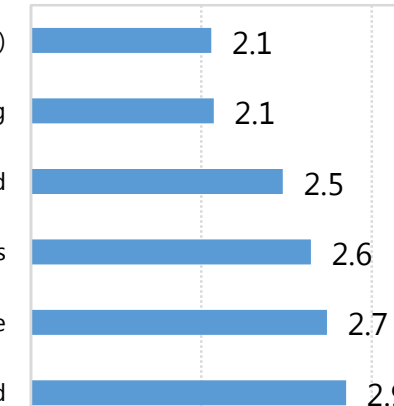

s.
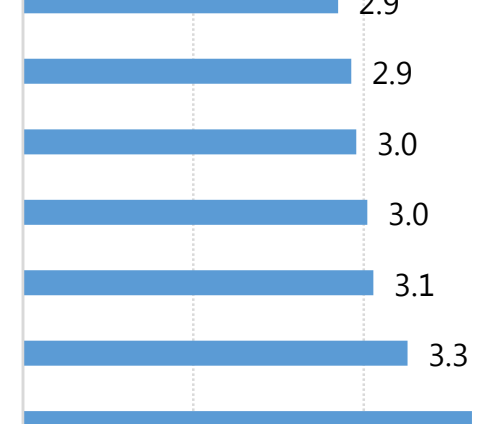

2. Lack of, or insufficient, professional practice and experience

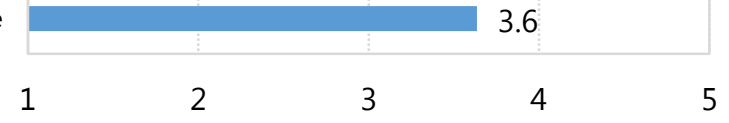

\subsubsection{University career centre: demand and services}

Nearly three out of four graduates report that they want their University to support them in searching for a job (Figure 3.29).

Figure 3.29. Do you want the career centre of your university to support you in searching for a job?

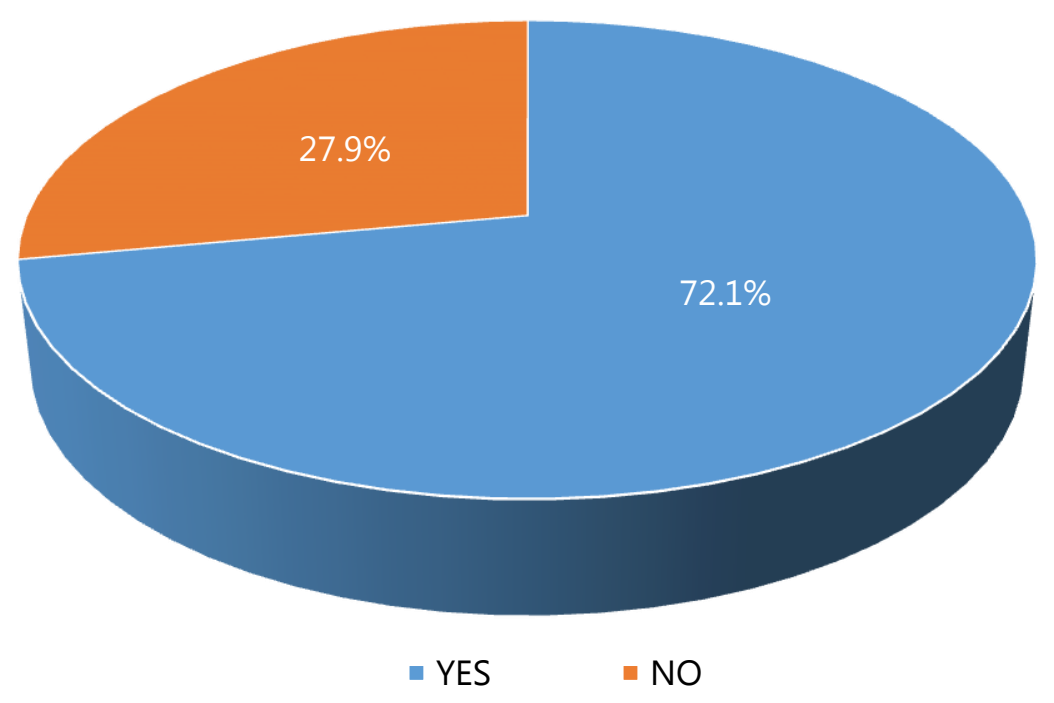


This demand is further specified in Figure 3.30, where we find that "providing job opportunities for each major" is requested by $68.4 \%$ of graduates who requested support from their Universities in searching for a job. Next, the graduates ask the Universities to provide "general information on the labour market and job opportunities" (55.1\%), "hosting job fairs and other events with employers" (43.9\%), and "job search consulting services" (40.8\%). Training services are requested, on average, by approximately 4 out of 10 graduates. Thus, both the "information on training opportunities" and the "soft skill training services (communication, team working,..." are requested by $38.8 \%$ of the graduates who request support from their universities in finding a job. Finally, "the training in job-hunting skills" reaches the lowest percentage (27.6\%).

Figure 3.30. If so, what do you want the Career Centre to offer (multiple responses)

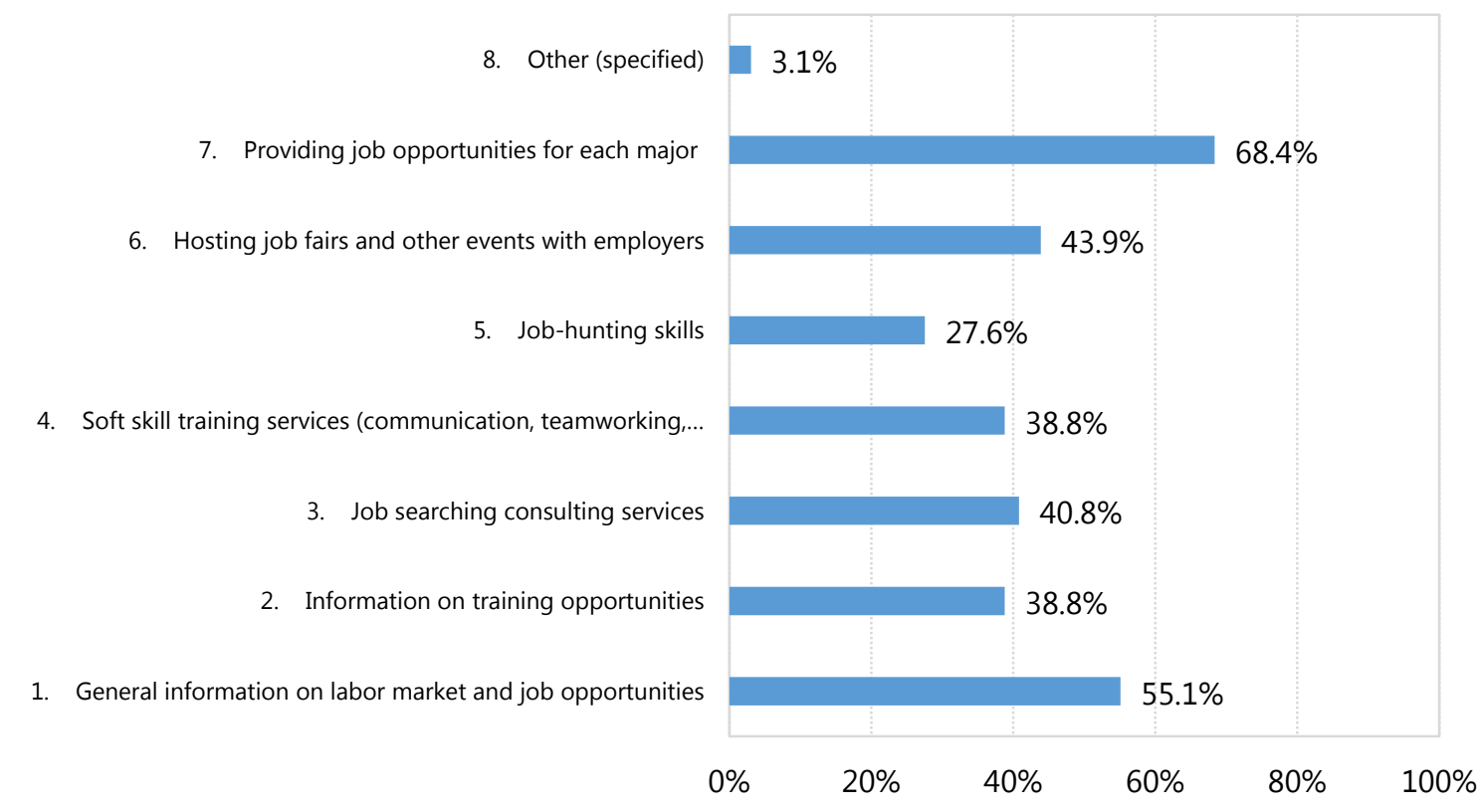

\subsection{Economic inactive graduates}

\subsubsection{Reason not to look for $a$ job}

Inactive graduates are those who are not employed or searching for a job. They just represent $2.3 \%$ of all the graduates who answered the survey. Still we wanted to know the reasons for not looking for a job at the time the survey was answered. Two-thirds of the inactive graduates indicate that they continue to study (Figure 3.31). All the other reasons are provided by approximately 1 out of 10 graduates: e.g.: "Because I have to take care of my family and/or housework" (11.1\%), or "because I have lost hope in finding work" (8.3\%), which may be complemented by the following reason "because there are no jobs for people with my degree" (5.6\%). Finally, $8.3 \%$ reported that they do not want to work. 
Figure 3.31. Why are you not looking for a job right now? (choose the most important reason)

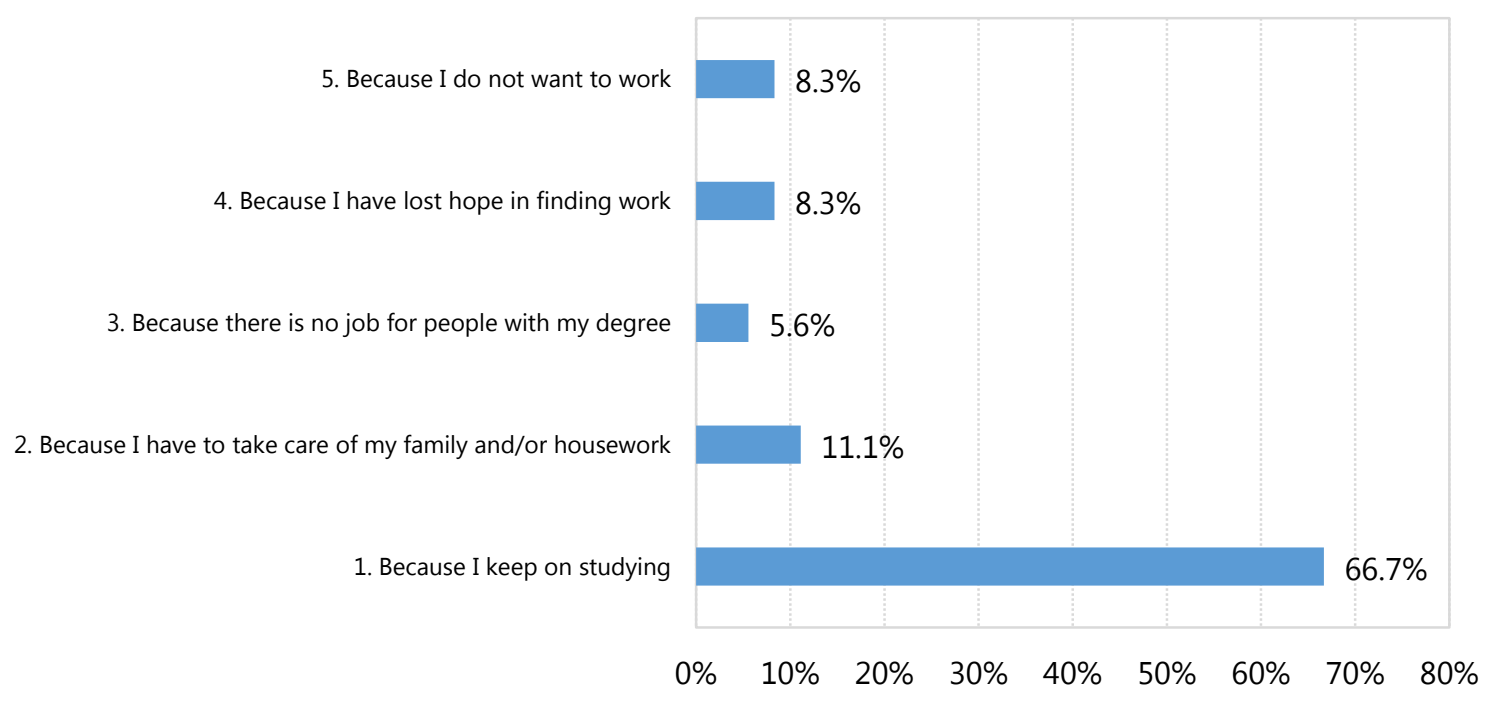

\subsection{Summary and conclusions}

The results presented in this chapter show that $82.6 \%$ of the graduates were employed by an employer, and only $6.2 \%$ were self-employed. The percentages of unemployed graduates (8.8\%) and inactive graduates (2.3\%) were low. Overall, the employment rate was $91.4 \%$.

$46.5 \%$ of the graduates were already employed when they graduated. For those who were not, it took them 3.1 months, on average, to find their first paid job.

The strategies most frequently used to find the first and current jobs were "social and/or professional Internet networks", "Internet portals, company websites, and press", and "personal contacts".

Regarding the characteristics of the job, 53\% of the graduates reported that their current job was quite or very related to the content of their degrees (horizontal match), and $85.7 \%$ said the level of education required by their current jobs was a college or university degree (vertical match). The hierarchical level of the graduates' current job was generally entry-level employee (83.3\%). Almost two-thirds of the sample (63.9\%) had monthly incomes between 5 and 10 million Vietnamese dongs. Most graduates' jobs (56.3\%) were located in another region where the graduate's family lives.

As to the organization where they worked, most graduates $(56.1 \%)$ worked in private companies and either large (more than 300 employees; 43.8\%) or small (between 11 and 200 employees; 39.5\%) companies.

Regarding the employment contract, $13.3 \%$ of the graduates performed their jobs without a formal written employment contract. However, $70 \%$ of the graduates had long-term jobs, and 98.8\% had a full-time job. 
With regard to work satisfaction, the surveyed graduates were moderately satisfied (overall work satisfaction average: 2.83 , scale range; 1 -4).

Regarding the importance of a number of different competences for attaining good performance in their job, the most important competences within the corresponding category were the following: problem solving (cognitive competences), planning (management competences), communication skills (interpersonal competences), computer skills (instrumental competences), and task responsibility (attitudinal competencies).

Finally, for unemployed graduates, the factor that mostly contributes to their difficulties in finding a job is the lack of, or insufficient, professional practice and experience. 


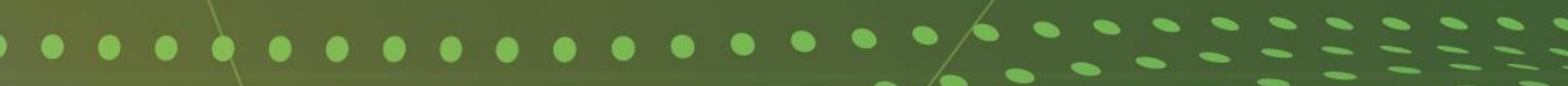

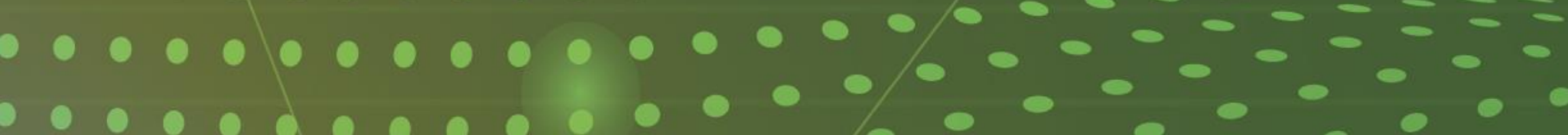

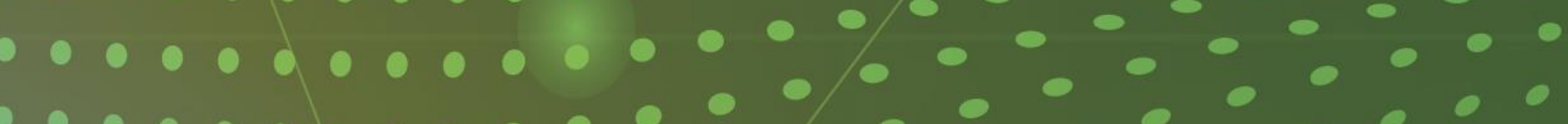

$\cdots \cdots$

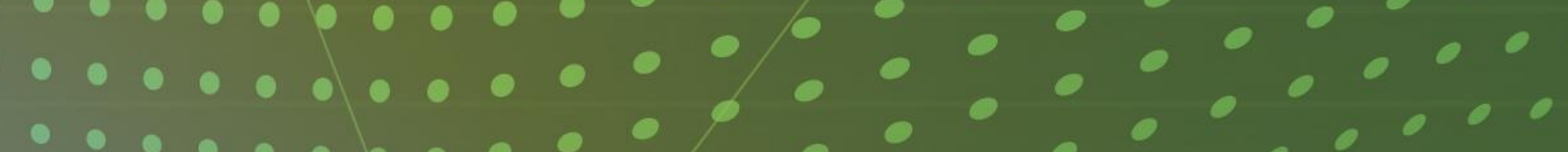

$\cdots \cdots$

CHAPTER 4.

GENDER DIFFERENCES 


\section{CHAPTER 4. GENDER DIFFERENCES}

In this chapter, we present the results obtained for the sample of surveyed graduates, differentiating by gender (women vs. men). In the first section, we focus on the employment situation the men and women had at the time they responded to the questionnaire. We also present the results obtained by gender for employed, unemployed, and inactive graduates.

\subsection{Graduates' employment status}

\subsubsection{Current employment situation}

The relationship between gender and the current employment situation was not statistically significant. Most of the men (82.2\%) and women (83.1\%) were working (Figure 4.1). By contrast, percentages of men and women corresponding to other possible situations (self-employed, looking for a job, unemployed but not looking for a job) were always below $10 \%$.

Figure 4.1. Current employment situation by gender

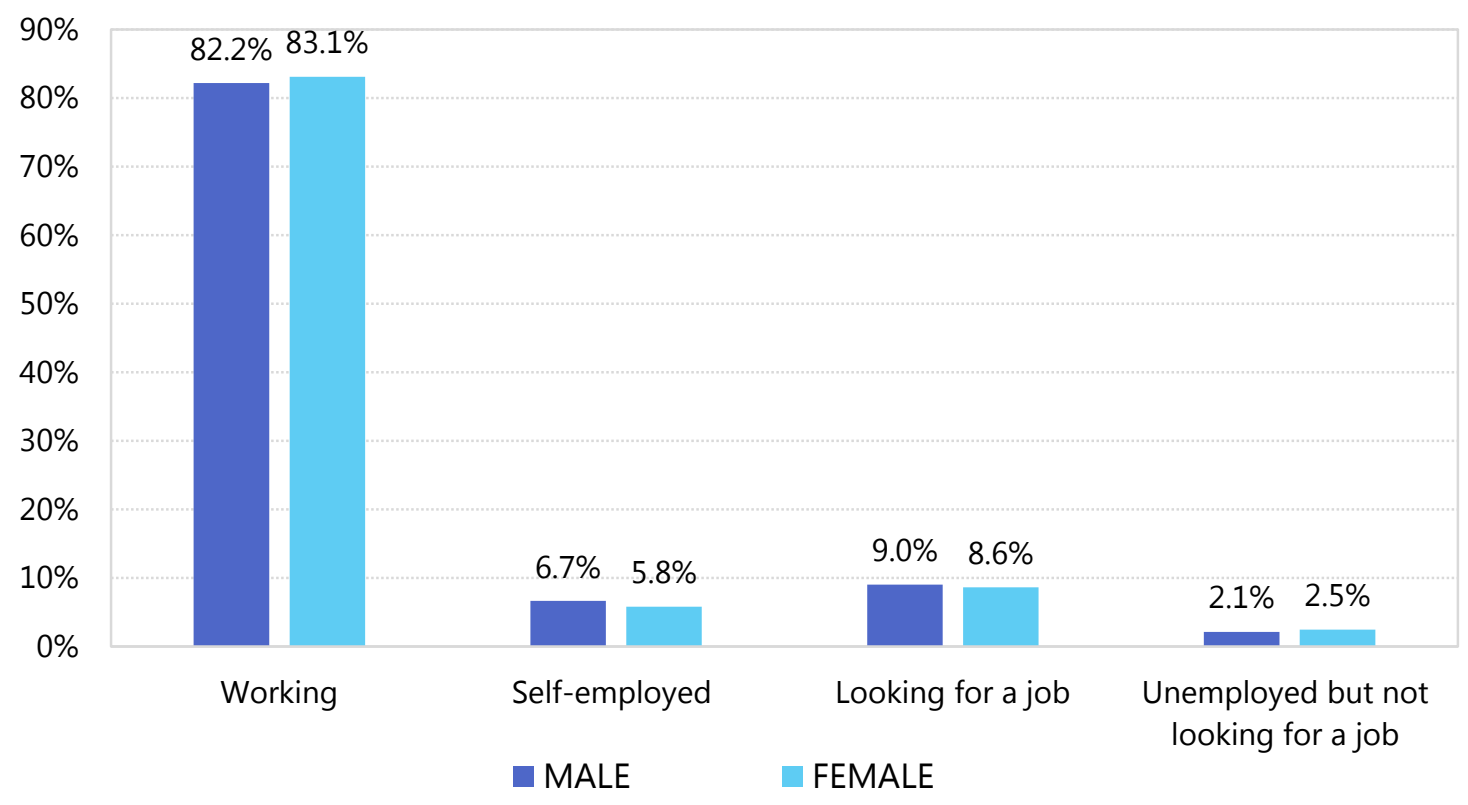

\subsubsection{Number of jobs since graduation}

The relationship between gender and the number of jobs since graduation was not statistically significant. Most of the men (79.2\%) and women (77.8\%) had had one or two jobs since graduation (Figure 4.2). The percentages of men (3.5\%) and women (3.1\%) without any job since graduation were very small. 
Figure 4.2. Number of jobs since graduation by gender

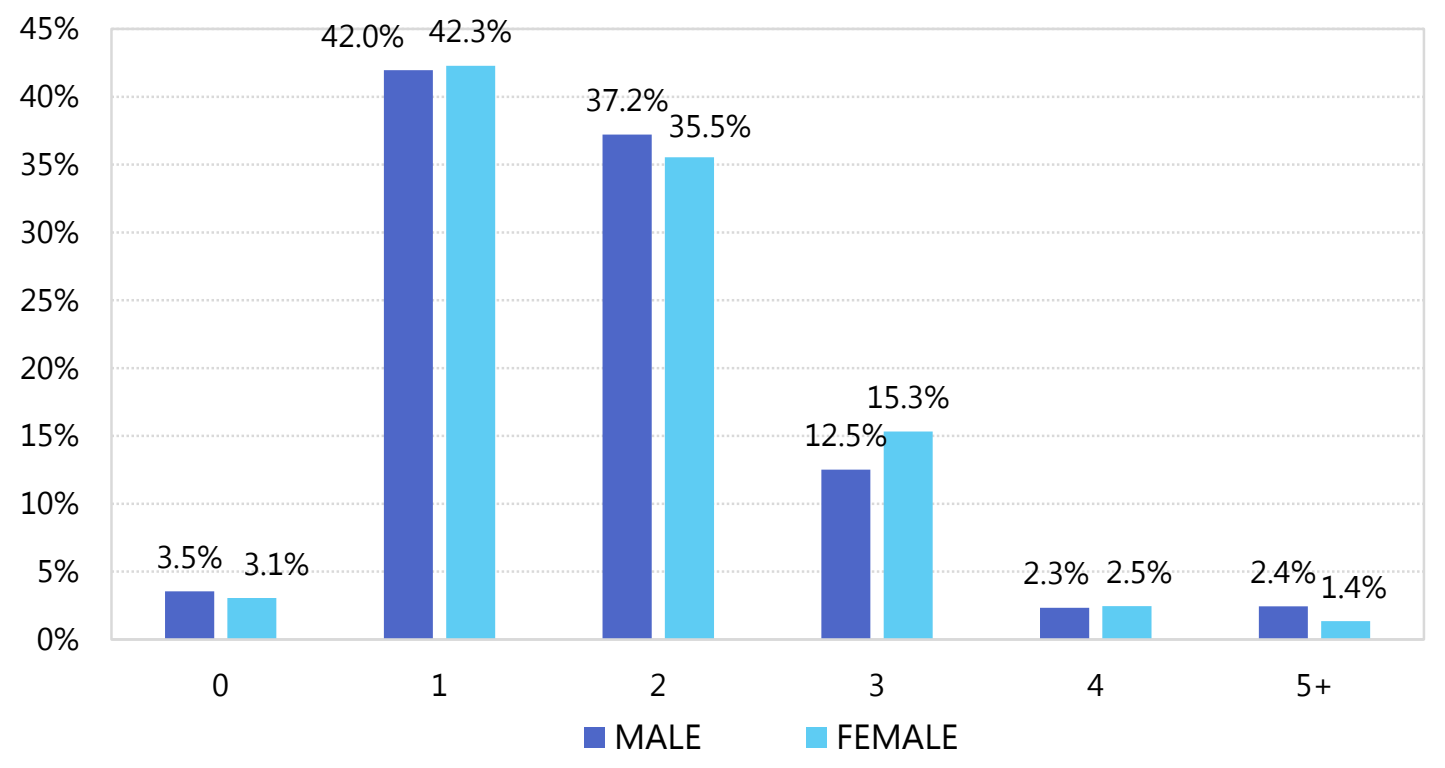

\subsection{Employed graduates ${ }^{7}$}

\subsubsection{Time needed to find their first paid job after graduation}

The relationship between gender and the time needed to find their first job after graduation was statistically significant. The percentage of men who found a job "before graduation" was greater than the percentage of women, whereas the percentage of women who found a job "after graduation" was greater than the percentage of men (Figure 4.3.).

Figure 4.3. When did you find your first paid job? by gender

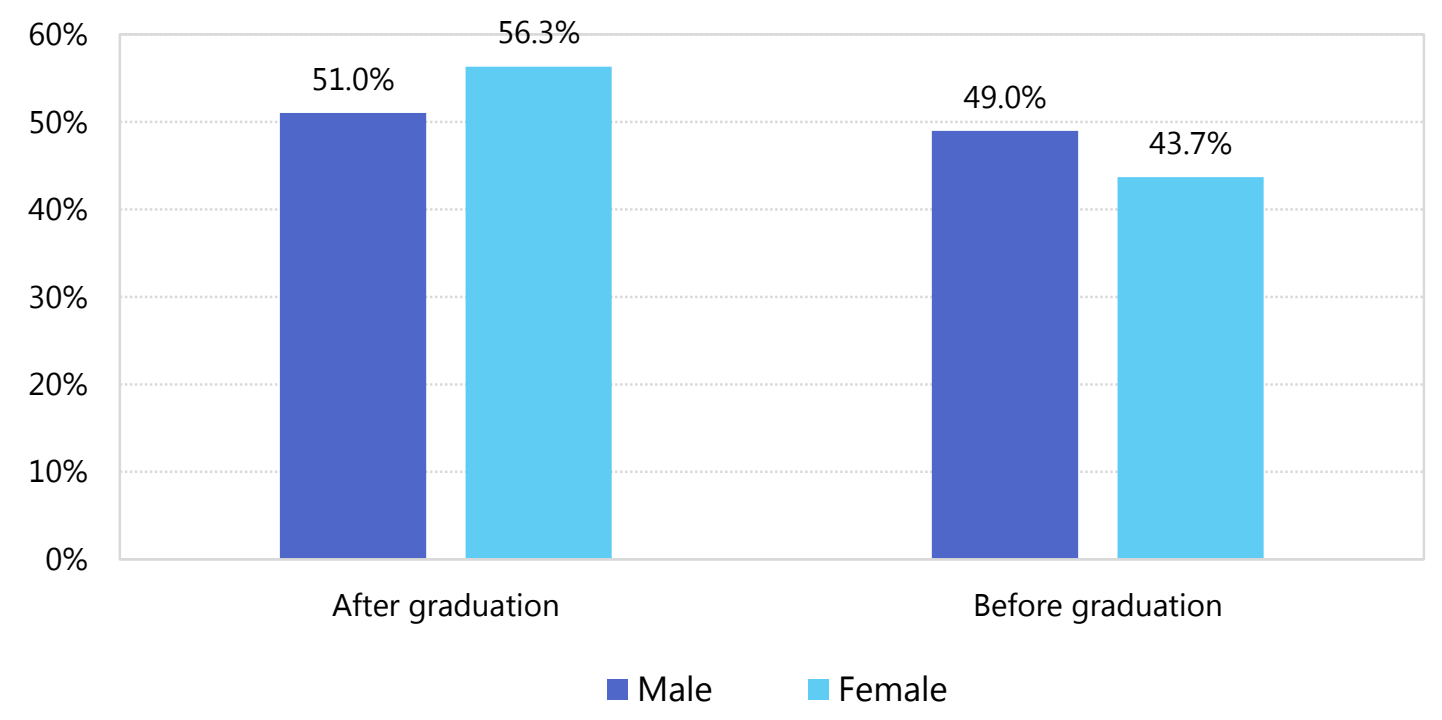

\footnotetext{
${ }^{7}$ The term 'Employed graduates' includes self-employed graduates and graduates employed by an employer.
} 
There were no significant differences between men and women in terms of the number of months it took to find their first paid job (Figure 4.4). Both men and women took about 3 months, on average, to find their first paid job.

Figure 4.4. The average number of months to find the first paid job after graduation, by gender

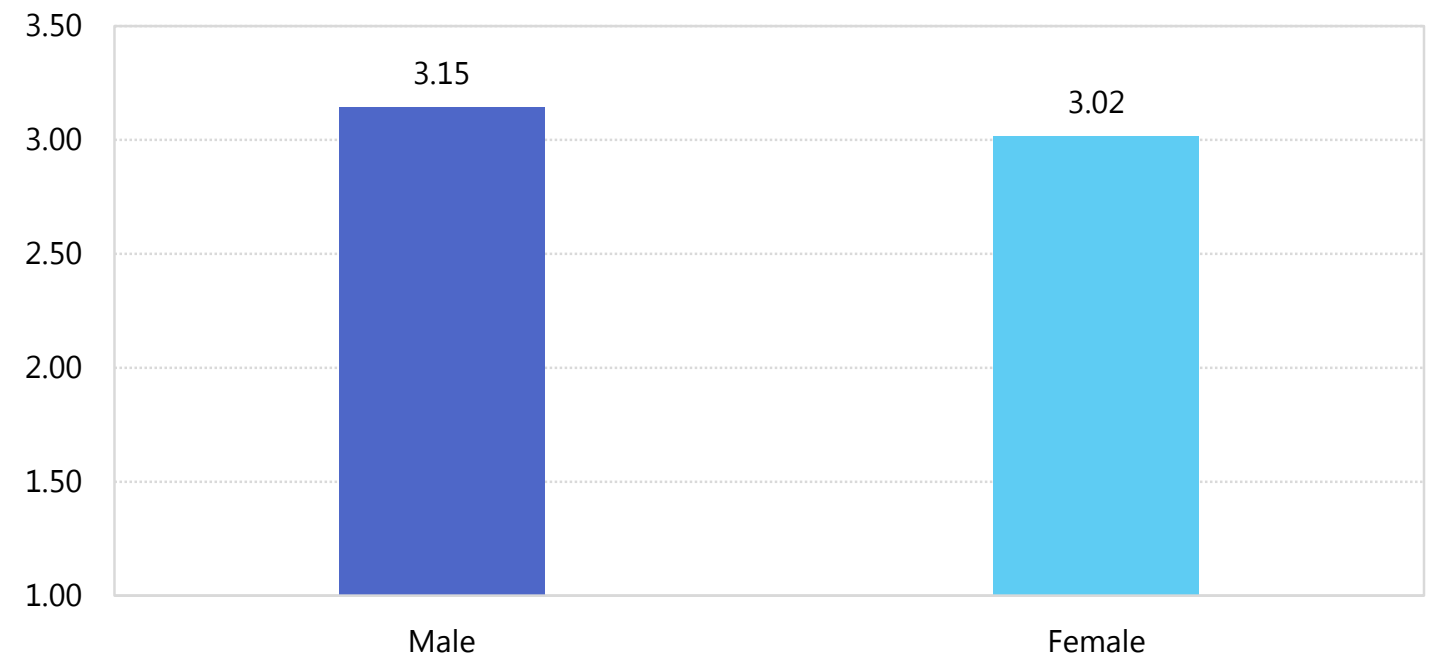

\subsubsection{Strategies to find their first paid job after graduation}

There was a significant relationship between gender and strategies to find their first job after graduation (Figure 4.5). Women tended to use social and professional Internet networks more than men.

Figure 4.5. Strategies to find your first paid job after graduation or the job that you already had when you graduated by gender

9. Through the employment services of my university

$$
\text { 10. Other means } 1.9 \%
$$

8. Through Internet portals, company websites, and press ads.

7. By contacting employment agencies

6. I contacted the employer on my own initiative

5. By creating my own job, company or business (Selfemployment)

4. The employer contacted me

3. Through social and/or professional Internet networks

2. Through the practices that I performed in companies or institutions

1. Through personal contacts (relatives, friends, ...)
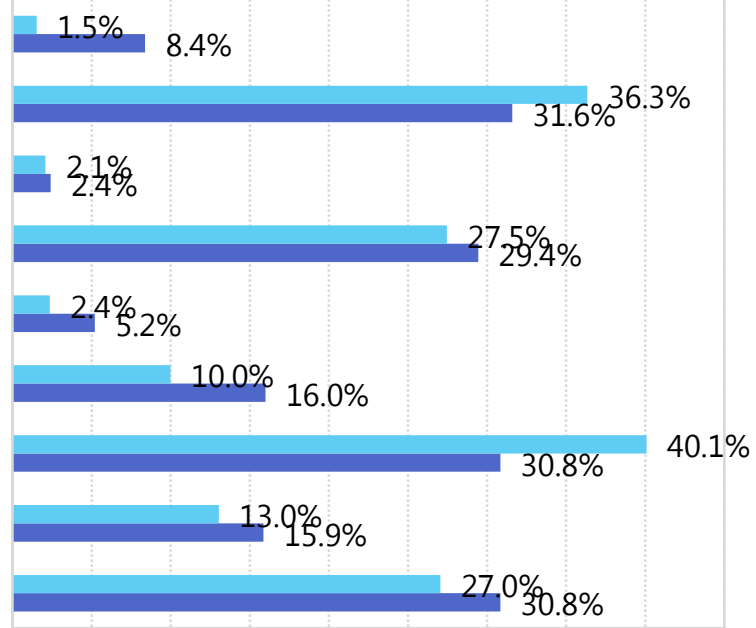

$\begin{array}{lllllllllll}0 \% & 5 \% & 10 \% & 15 \% & 20 \% & 25 \% & 30 \% & 35 \% & 40 \% & 45 \%\end{array}$

$$
\text { Female } \quad \text { Male }
$$




\subsubsection{Strategies to find their current job after graduation}

There was a significant relationship between gender and strategies to find their current job after graduation (Figure 4.6). Women tended to use social and professional Internet networks more frequently than men. Men were contacted by the employer more frequently than women.

Figure 4.6. Strategies to find your current job after graduation by gender

the employment services of my university

8. Through Internet portals, company websites, and press advertisement.

7. By contacting employment agencies

6. I contacted the employer on my own initiative

5. By creating my own company or business (Selfemployment)

4. The employer contacted me

3. Through social and/or professional Internet networks

2. Through the internship that I performed in companies or institutions

1. Through personal contacts (relatives, friends, ...)
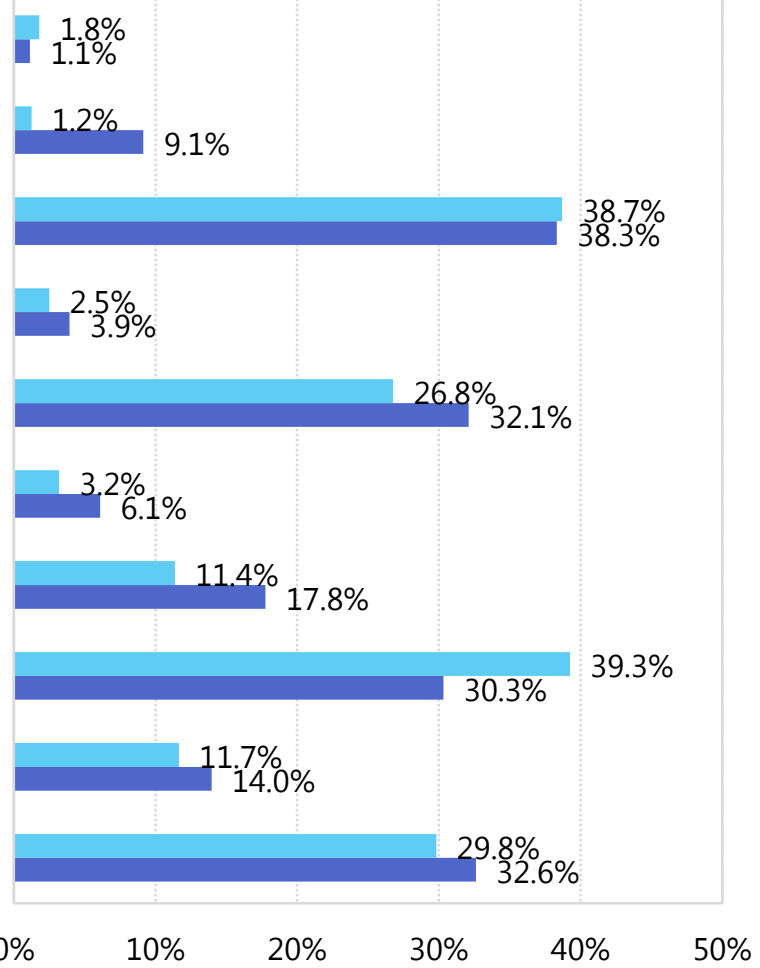

Female

Male

\subsubsection{Horizontal match}

Horizontal match refers to the degree to which the current job is related to the content of the degree. There was a significant association between gender and horizontal match. The job was more related to the content of the degree for men than for women (Figure 4.7). Most of the men (58.9\%) perceived a high horizontal match ("quite" or "a lot"). By contrast, most of the women (53.5\%) perceived a low horizontal match ("little" or "none"). 
Figure 4.7. To what extent is the content of your current job related to the content of your degree? by gender

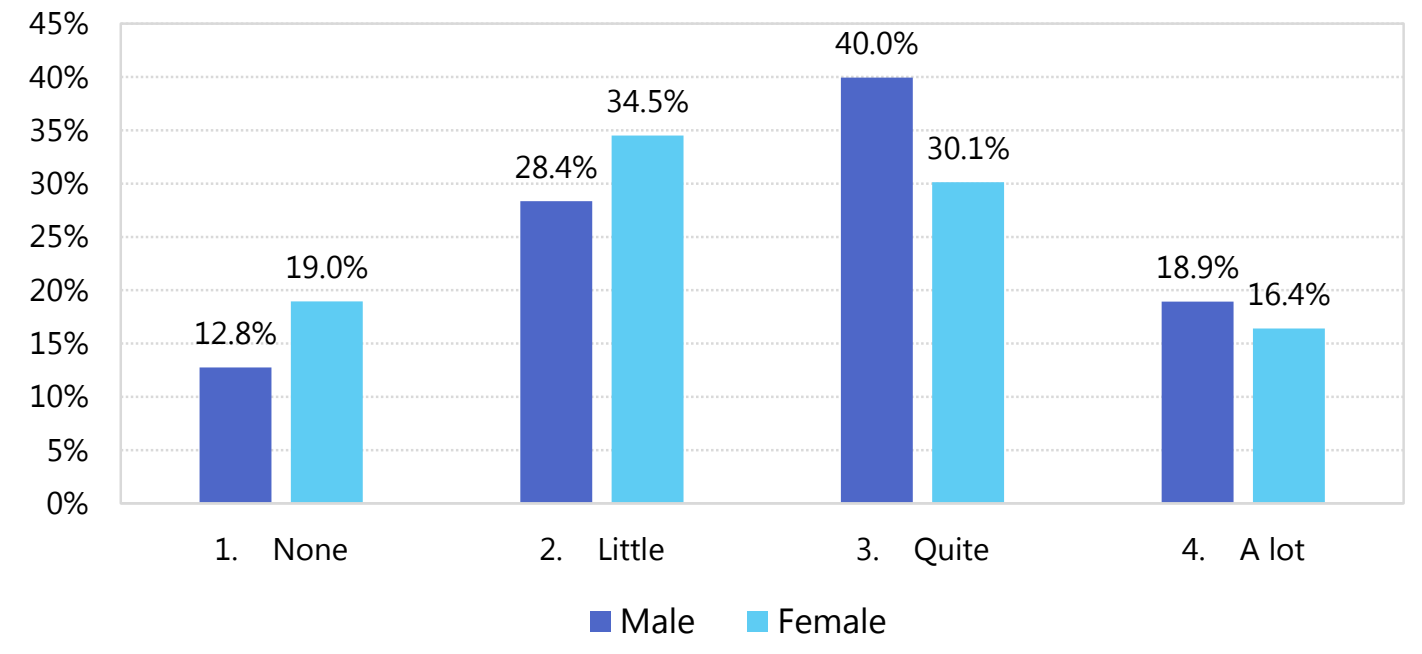

\subsubsection{Level of education required for the current job}

There was no significant association between the level of education required for the current job and gender (see Figure 4.8). The vast majority of men and women perceived that their current job requires a university degree.

Figure 4.8. What is the level of education required for your current job? by gender

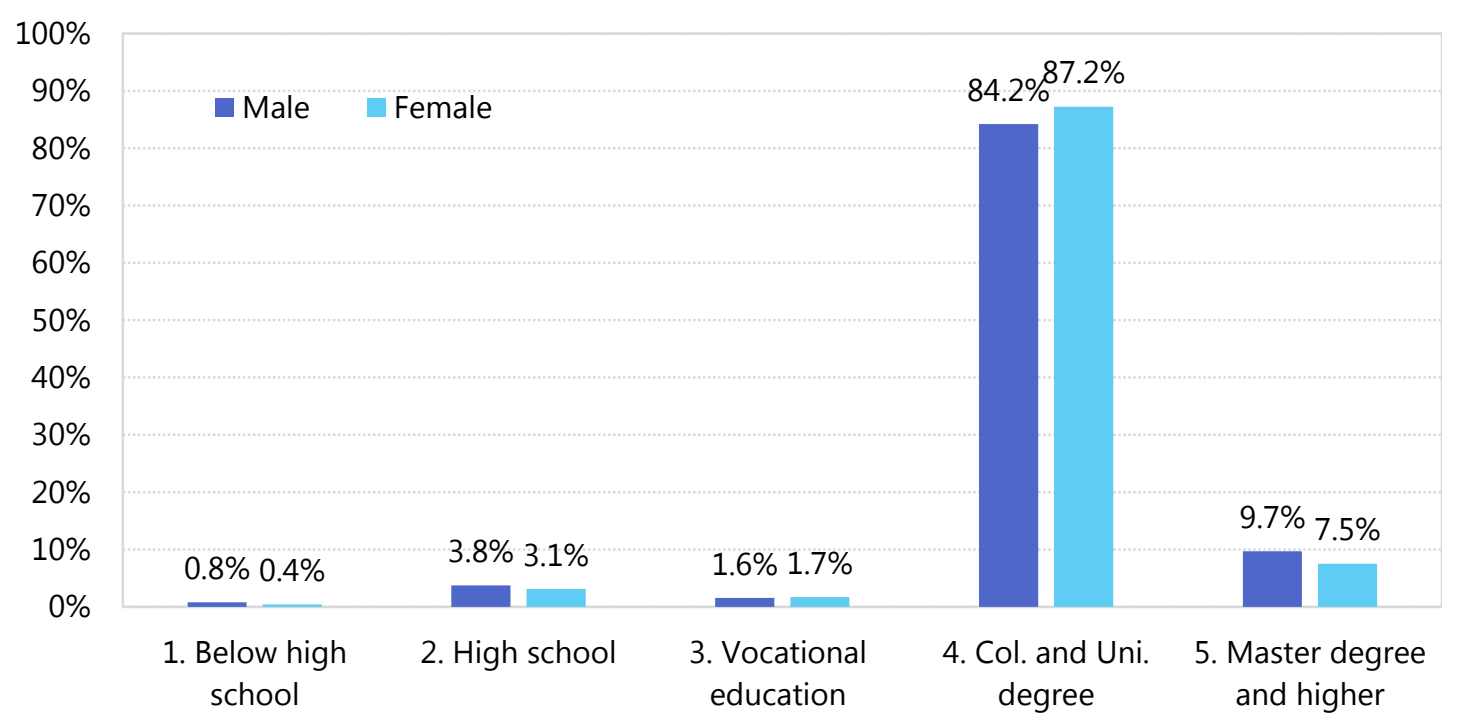

\subsubsection{Competences-job requirement match}

There was a significant relationship between gender and the degree to which the competences matched the requirements of their jobs (Figure 4.9). Men felt a little more underqualified than women. More specifically, more men indicated that their competences are a little below the requirements of the job than women. In general, most men and women perceived a match between their competences and the job requirements. 
Figure 4.9. To what extent do your competences match the requirements of your job? by gender

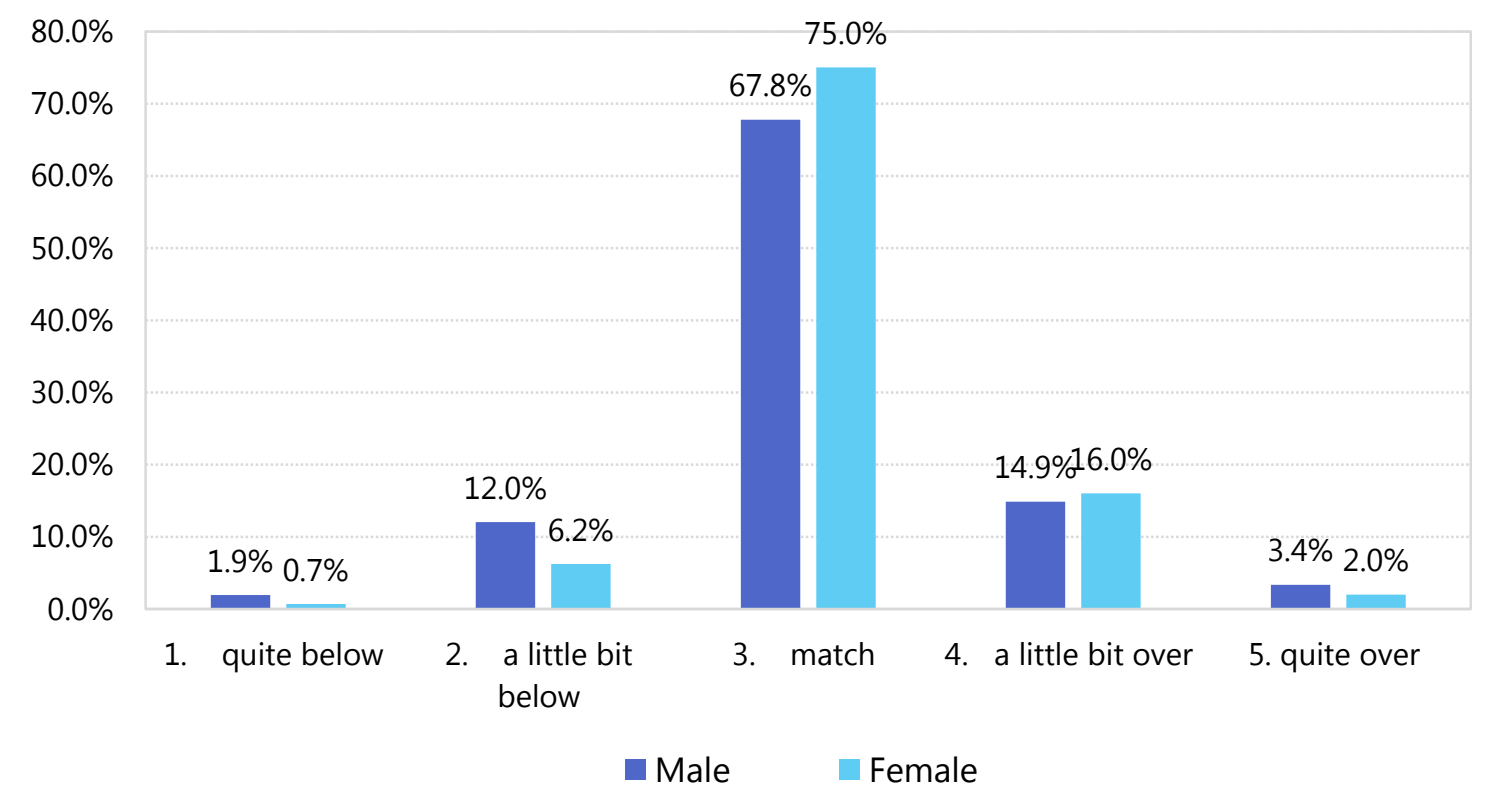

\subsubsection{Employer organization}

Type

There was a significant association between gender and the type of company where respondents worked (Figure 4.10). Men worked in foreign organizations and Foreign Direct Investment (FDI) companies more often than women. By contrast, women worked in private companies more often than men.

Figure 4.10. The organization you work for, by gender

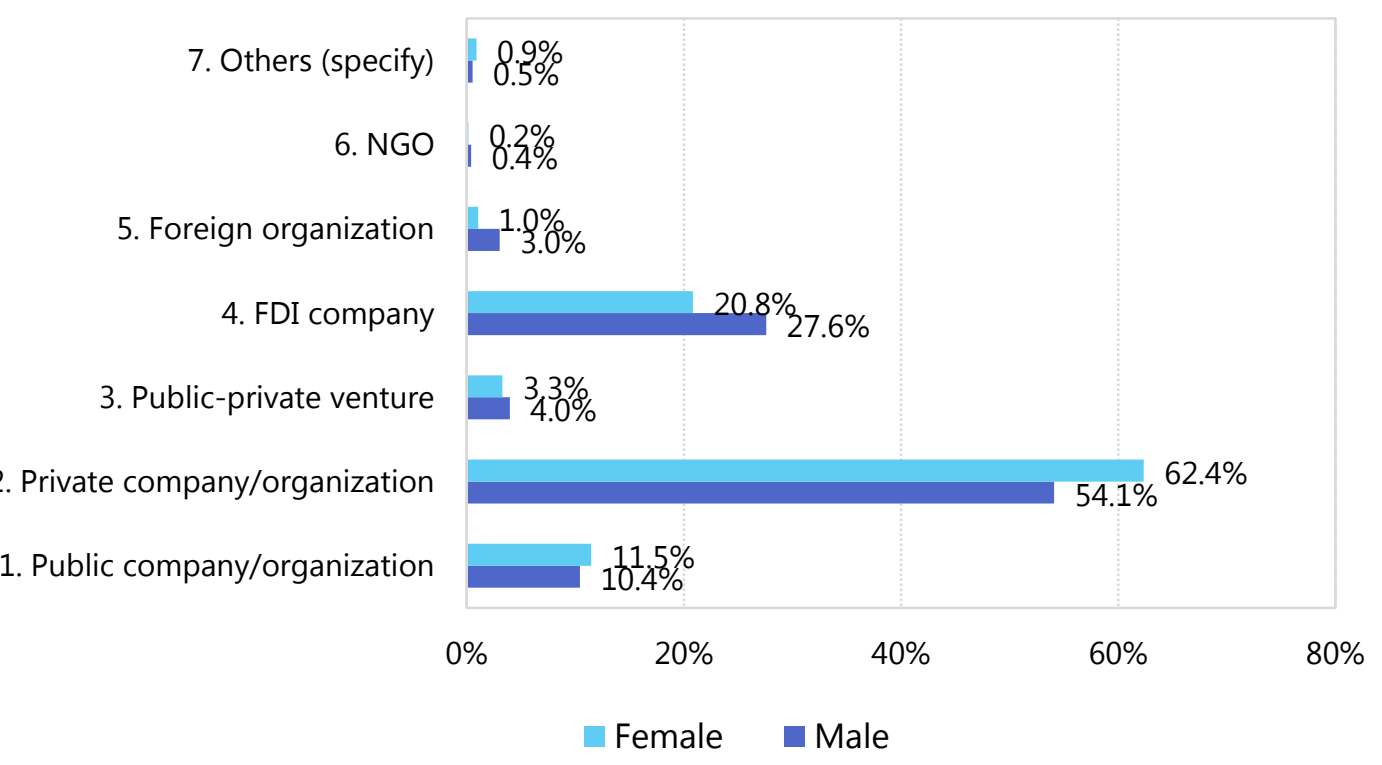


There was a significant association between gender and the sector where respondents worked (Figure 4.11). Women and men differed in their profiles. Women were present more than men in: transportation and logistics, food-accommodation services, banking-finance-insurance, administrative-supportive services, and education and training. Men were more present in: manufacturing, electricity-fuel-gas (energy), construction, and professional-science-technology.

Figure 4.11. Sector of economic activity of your organization by gender

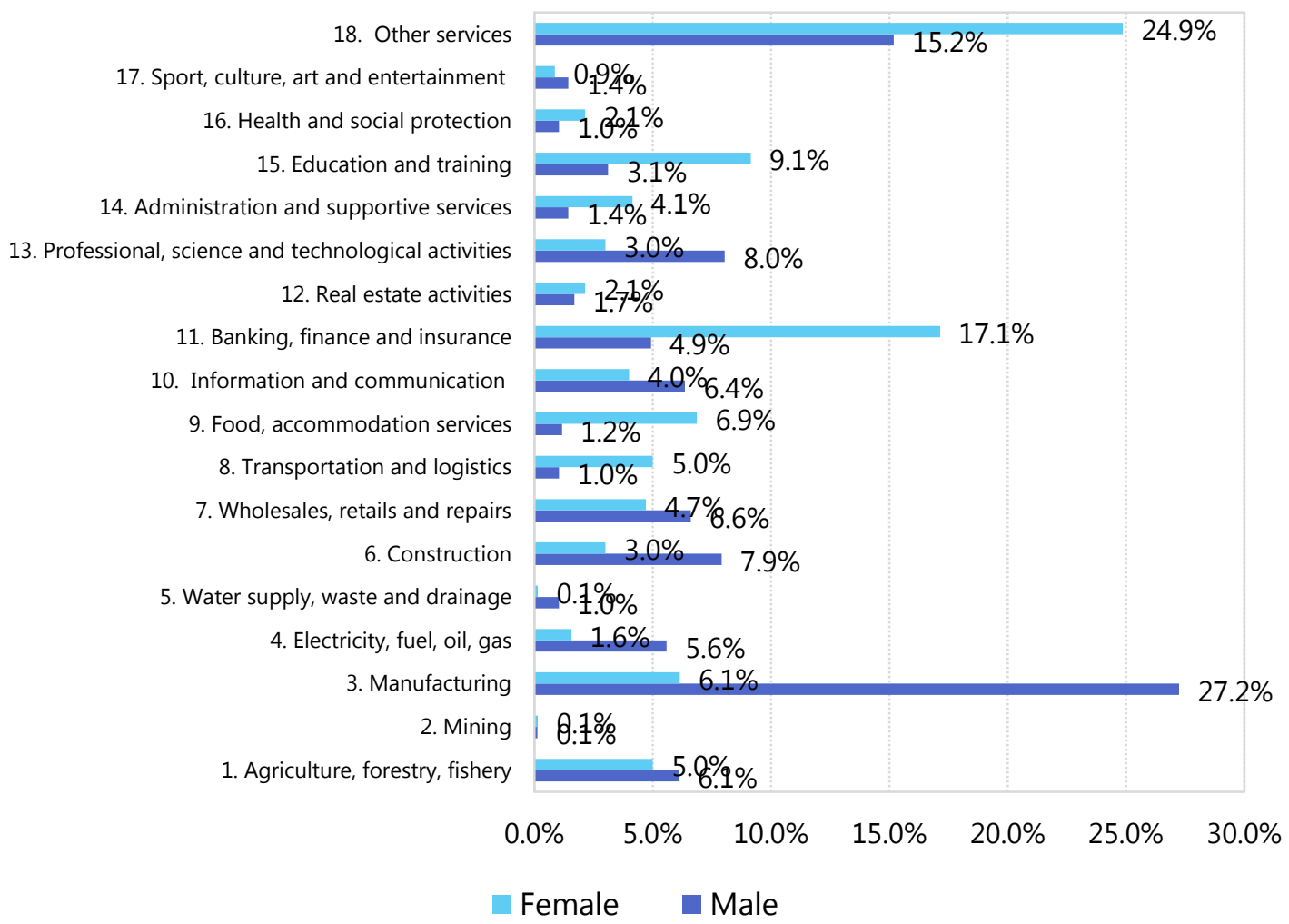

Size

There was a significant association between gender and the size of the company where respondents worked (Figure 4.12). Women tended to work more in small companies (up to 10 employees) and companies with between 11 and 200 employees, whereas men tended to work in large companies more (more than 200 employees). 
Figure 4.12. How many employees does your company have? by gender

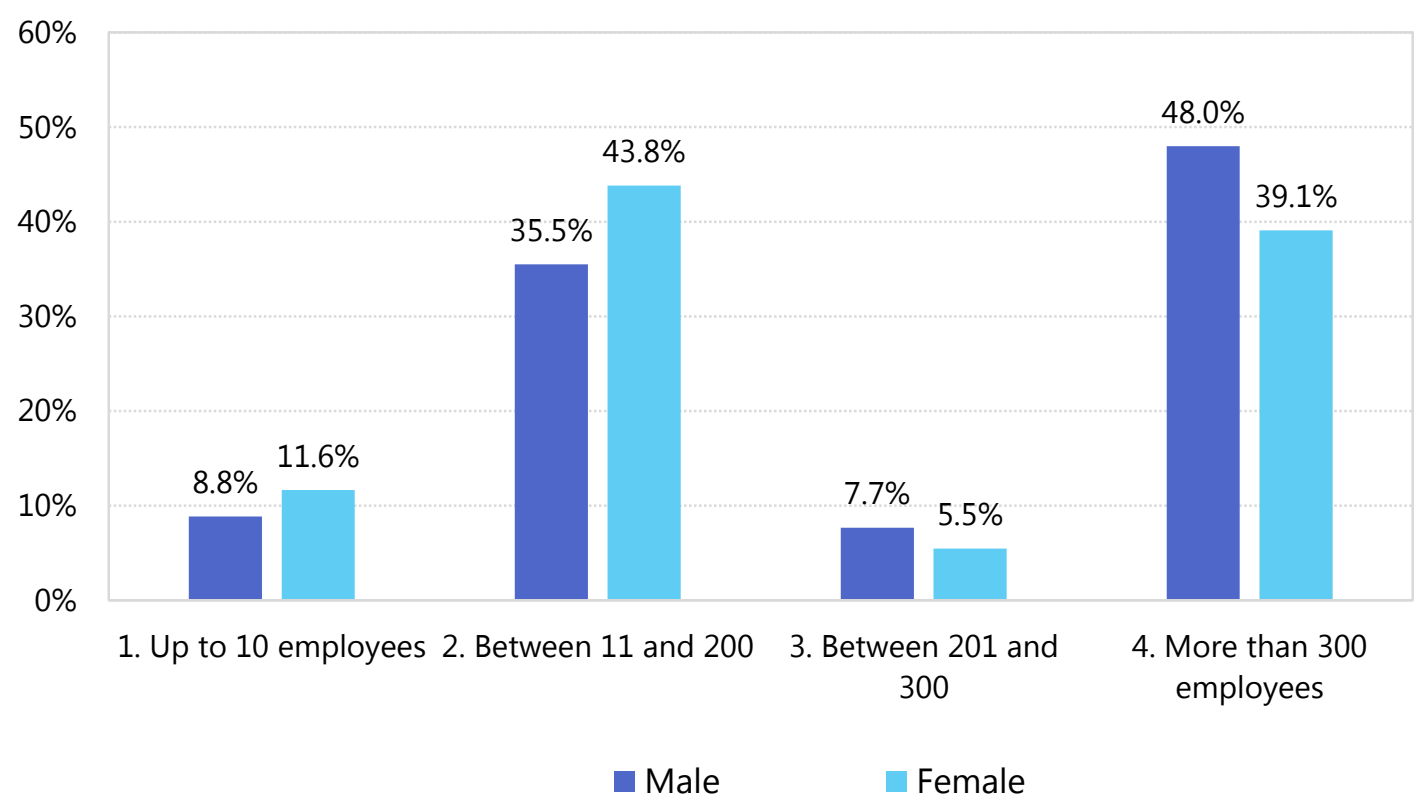

\subsubsection{Location}

There was a significant association between gender and the location of the job (Figure 4.13). Women tended to work in workplaces that are closer to places where their families live than men.

Figure 4.13. Where is your current job located? by gender

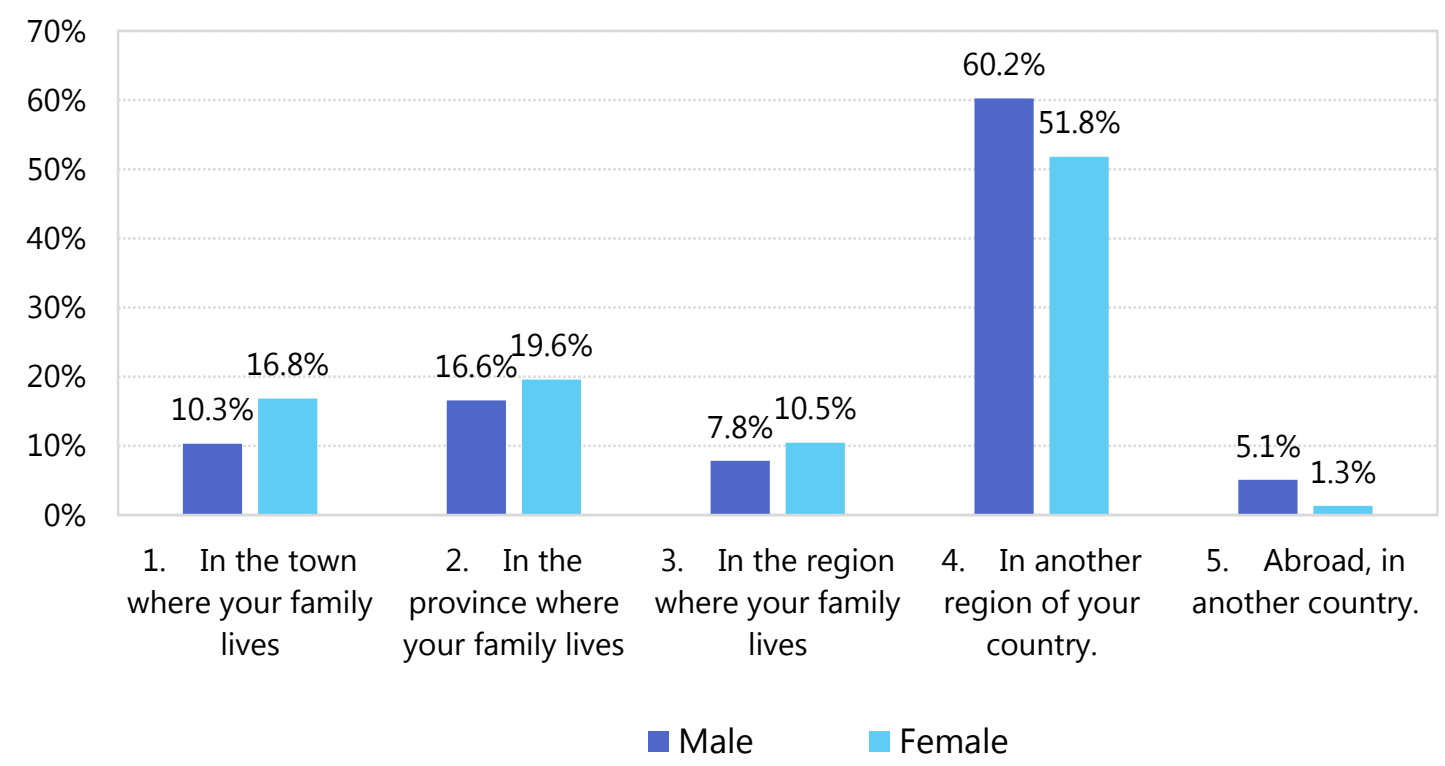

\subsubsection{Functional area}

There was a significant association between gender and the functional area where respondents work (Figure 4.14). Women and men differed in their profiles. Women worked more often in 
Administration and finance, computing, customer services, education, and logistics. By contrast, men worked more often in Production and/or provision of services, quality control, and Research \& Development \& Innovation.

Figure 4.14. In what functional area of the company is your current job included? by gender

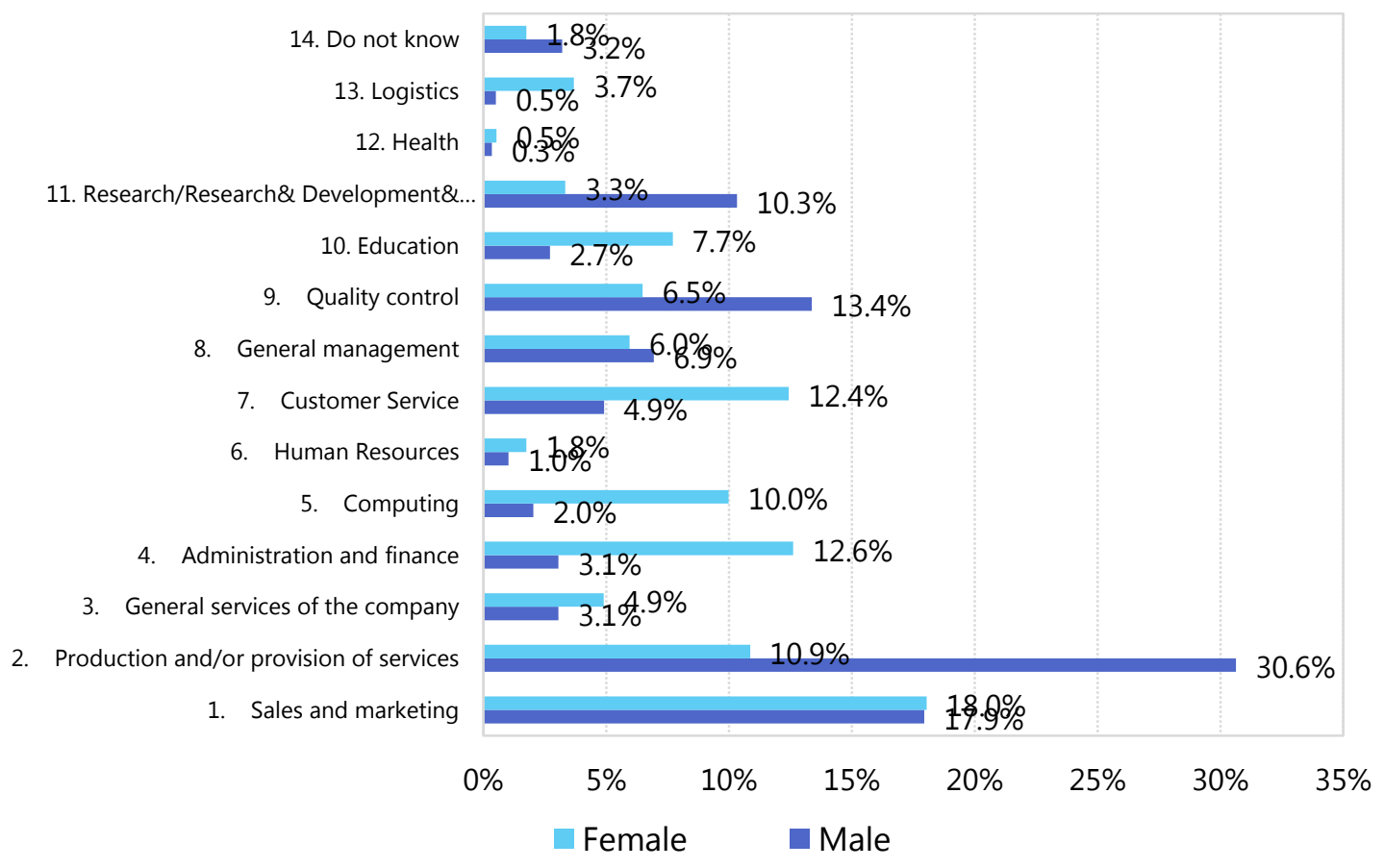

\subsubsection{Hierarchical level}

There was a significant association between gender and the hierarchical position of jobs (Figure 4.15). Men tended to occupy manager and middle manager positions more often than women. By contrast, women were more often in "entry-level employee" positions than men.

Figure 4.15. What is the hierarchical level of your current job? by gender

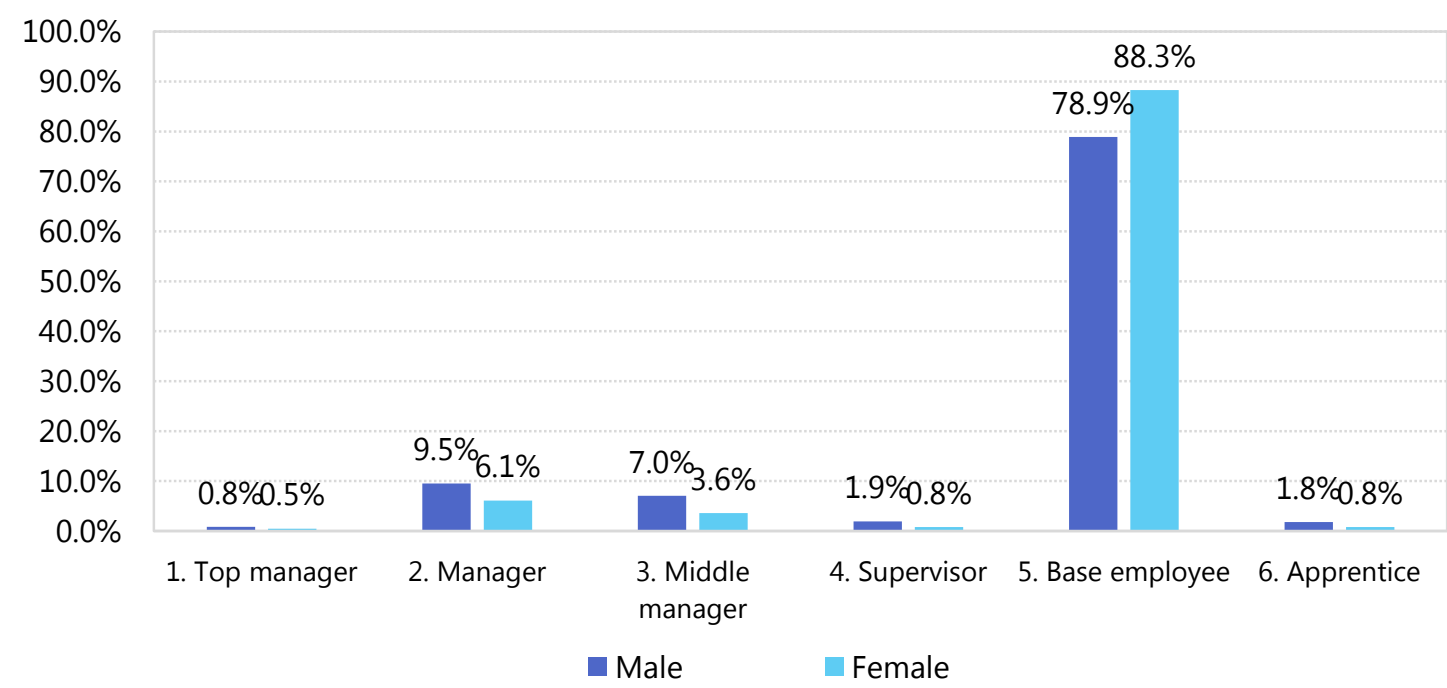




\subsubsection{Formal written employment contract}

There was a significant association between gender and signing a formal written employment contract, although the differences were not strong (Figure 4.16). Men tended to have formal contracts more frequently than women.

Figure 4.16. Did you sign a formal written employment contract for your current job? by gender

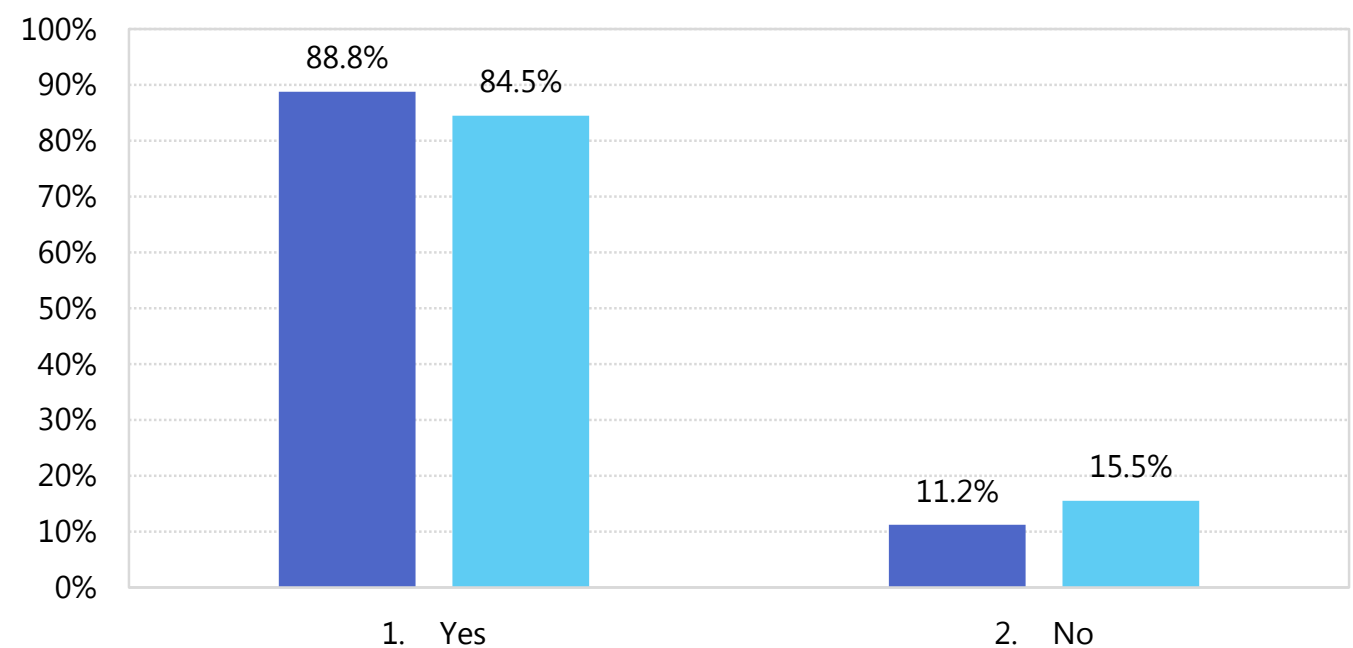

\subsubsection{Duration of the contract}

There was no significant association between gender and the duration of the job (Figure 4.17). Most of the men and women had a long-term job.

Figure 4.17. Is your current job... by gender

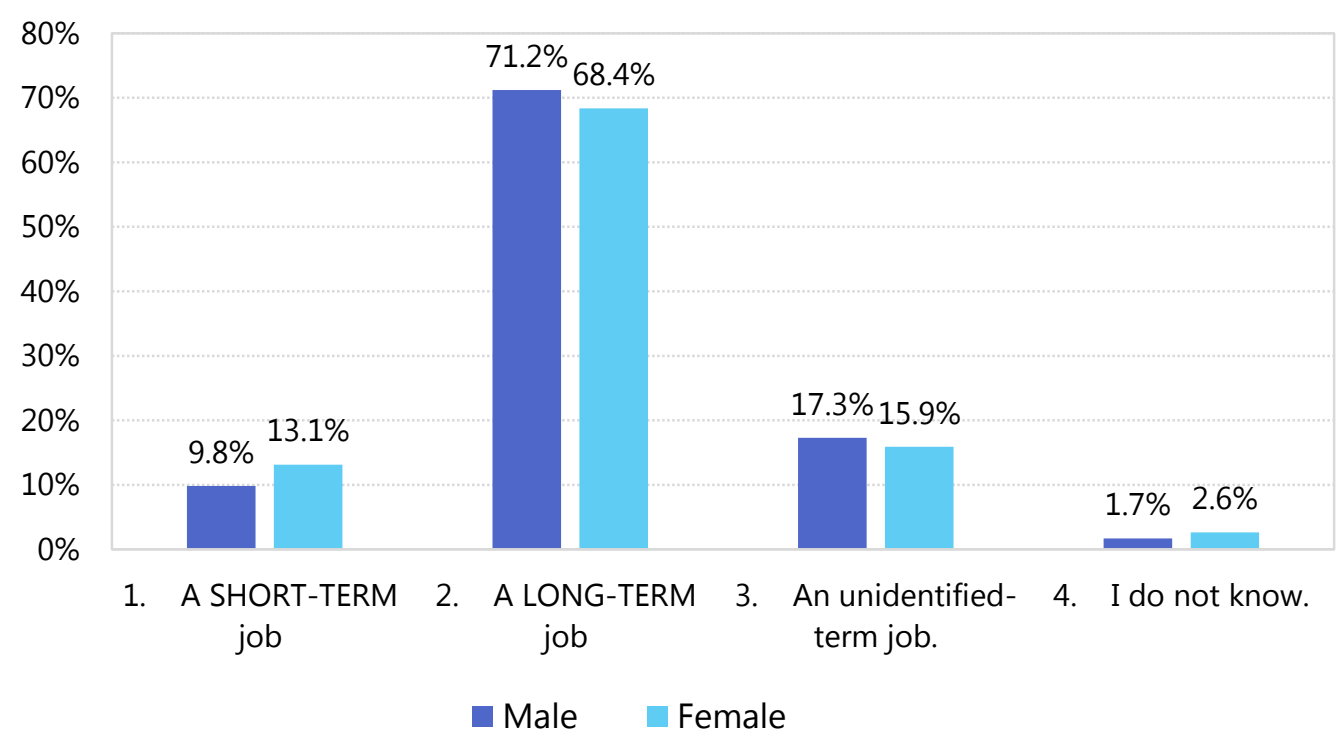




\subsubsection{Part-time vs. full-time}

There was no significant association between gender and time dedicated to the job (Figure 4.18). The vast majority of both men and women had a full-time job.

Figure 4.18. Is your current job...? by gender

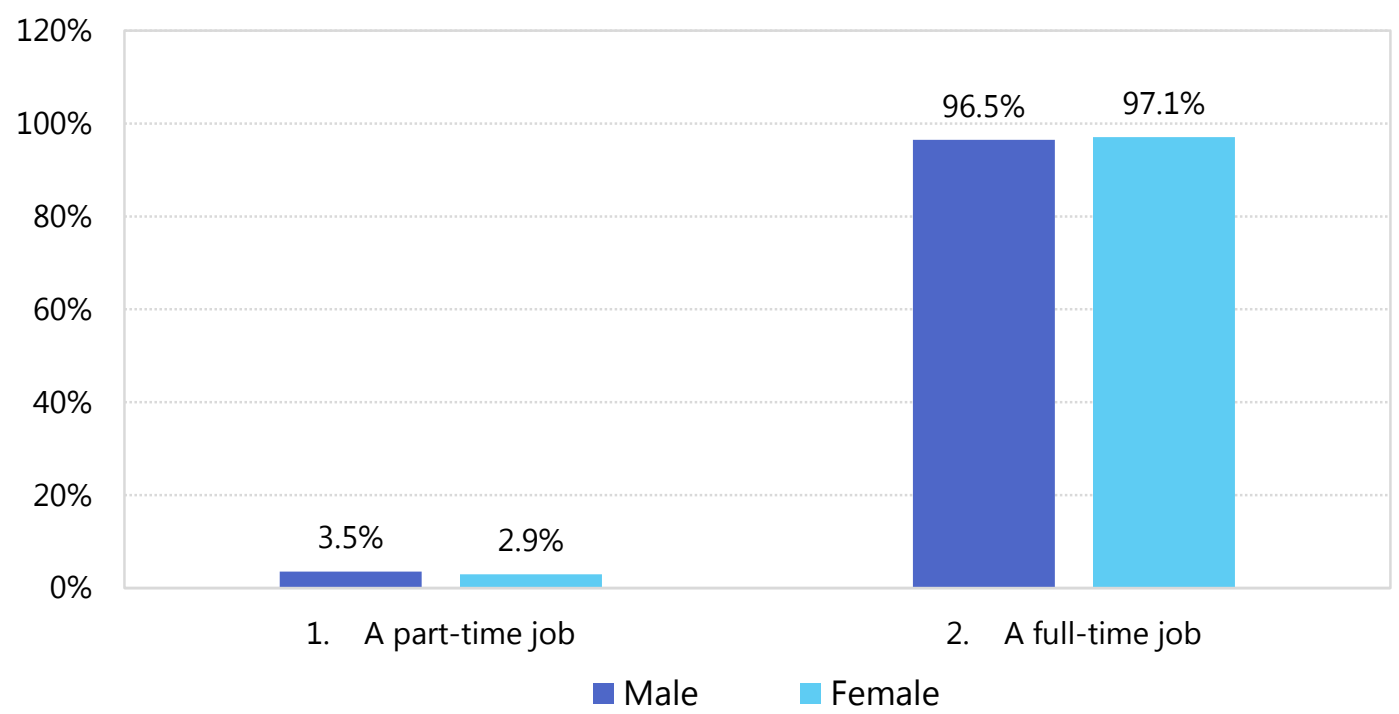

\subsubsection{Monthly income}

There was a strong and significant association between monthly income and gender (Figure 4.19). Men had a larger monthly income than women.

Figure 4.19. An estimation of your monthly income in your current job, by gender

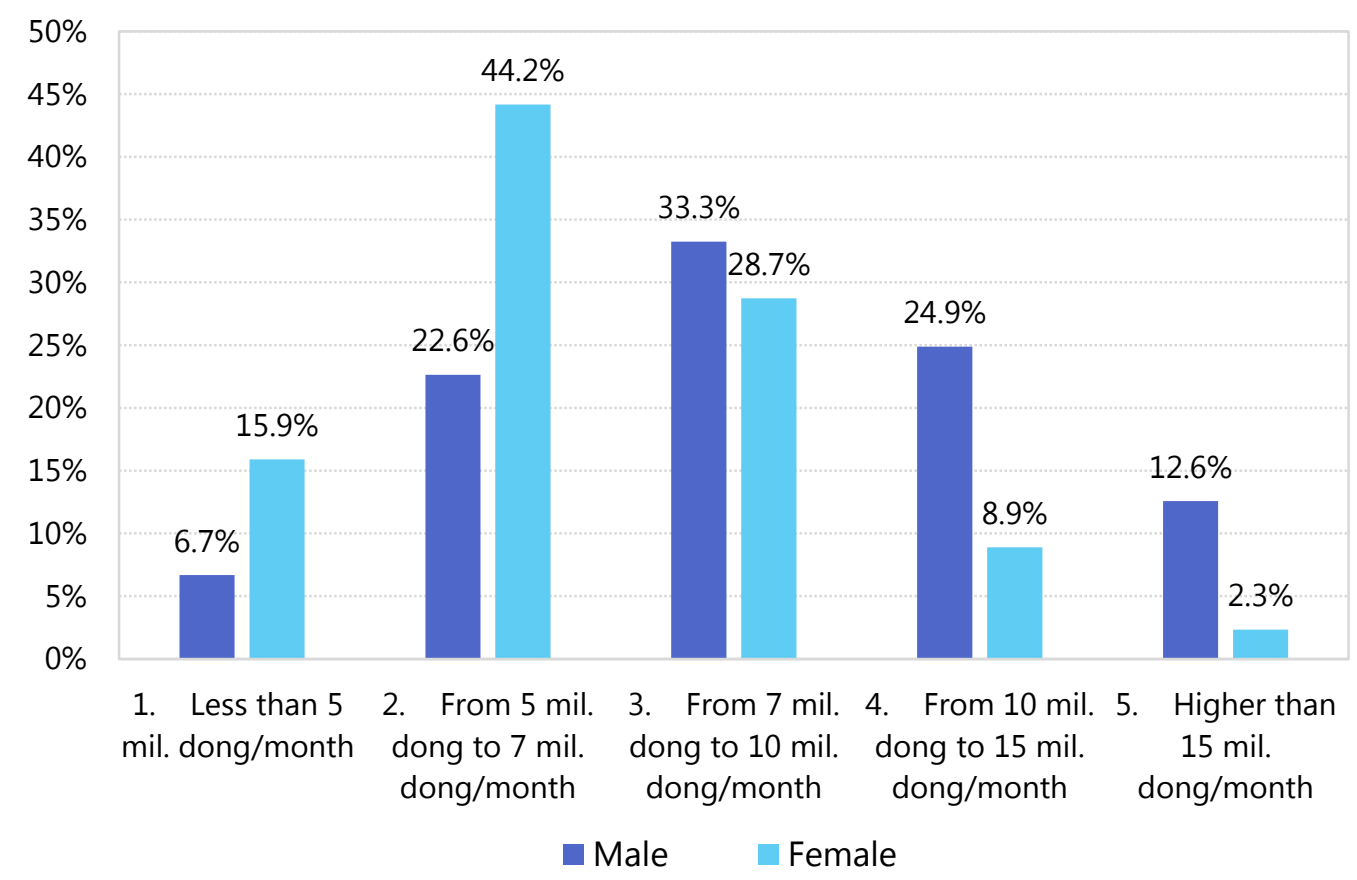




\subsubsection{Work satisfaction}

There were significant differences between men vs. women in their work satisfaction, although the differences were not strong (Figure 4.20). Men were more satisfied than women on overall job satisfaction (the composite scale of satisfaction). Men were also more satisfied than women on items 2 (income) and 4 (opportunities for professional development).

Figure 4.20. What is the degree of satisfaction or dissatisfaction produced by each of the following aspects of your job? by gender

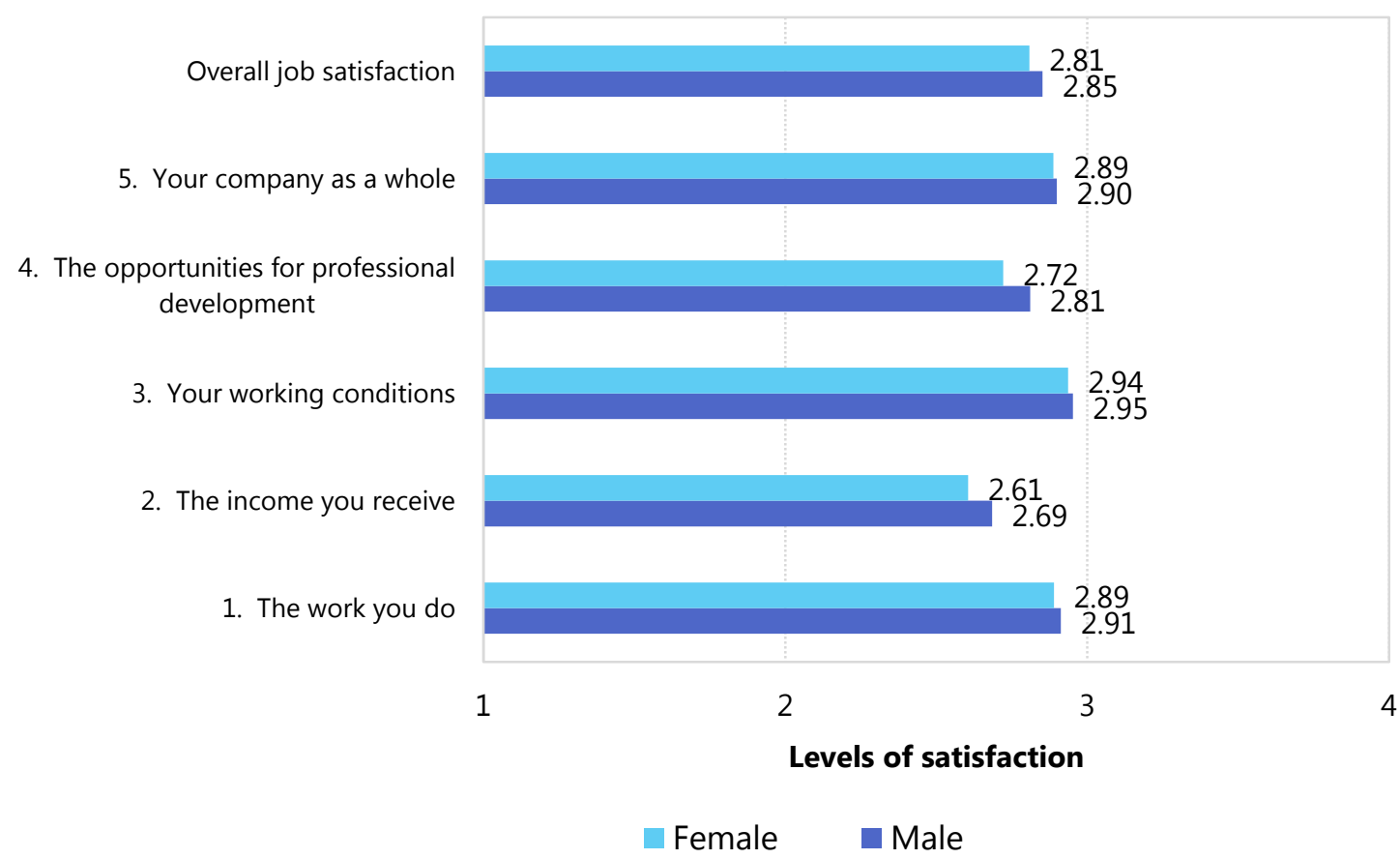

\subsubsection{Importance of competences for good performance}

There were significant differences between women vs. men in the importance attributed to three cognitive competences (Figure 4.21) in good performance: report writing, creativity, and systematic thinking. Men attributed more importance to all three competences than women.

There were significant differences between women and men in the importance attributed to four management competences (Figure 4.22) in good performance: decision making, planning, leadership, and motivating others. Men attributed more importance to all four competences than women. 
Figure 4.21. Rate the importance of each of the following factors and competences for good performance in your current job by gender: cognitive competences

7. Report writing

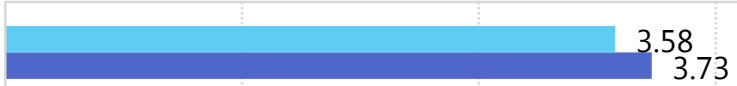

6. Continuous learning

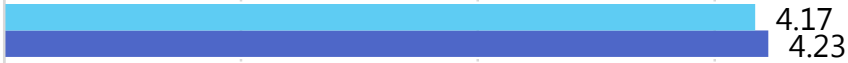

5. Transfer theory to practice

4. Creativity
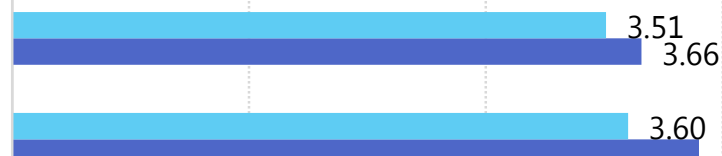

3. Problem solving

2. Systematic thinking
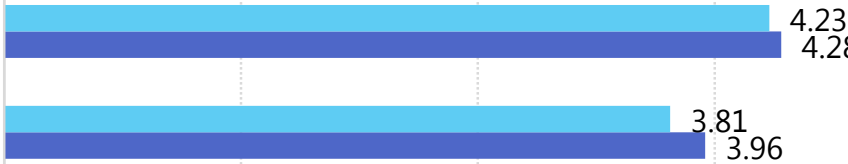

1. Critical thinking

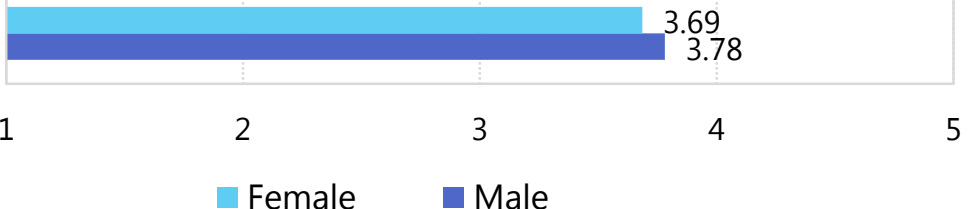

Figure 4.22. Rate the importance of each of the following factors and competences for good performance in your current job by gender: management competences

5. Decision making

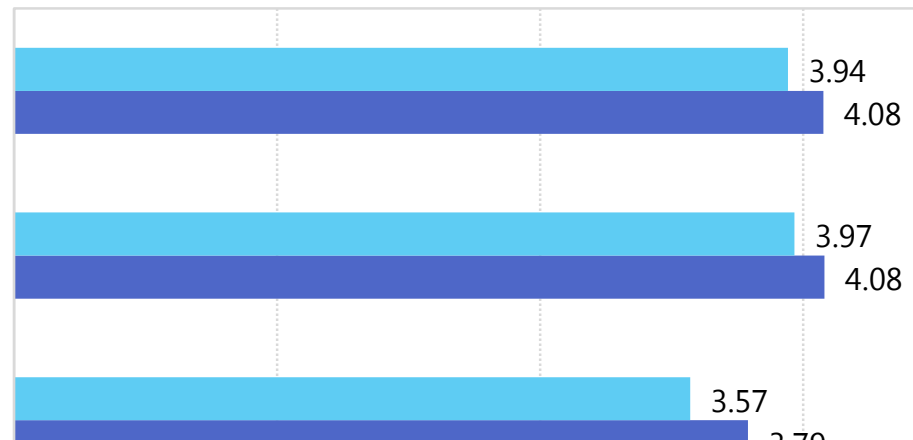

3. Leadership

2. Motivate others

1. Time management

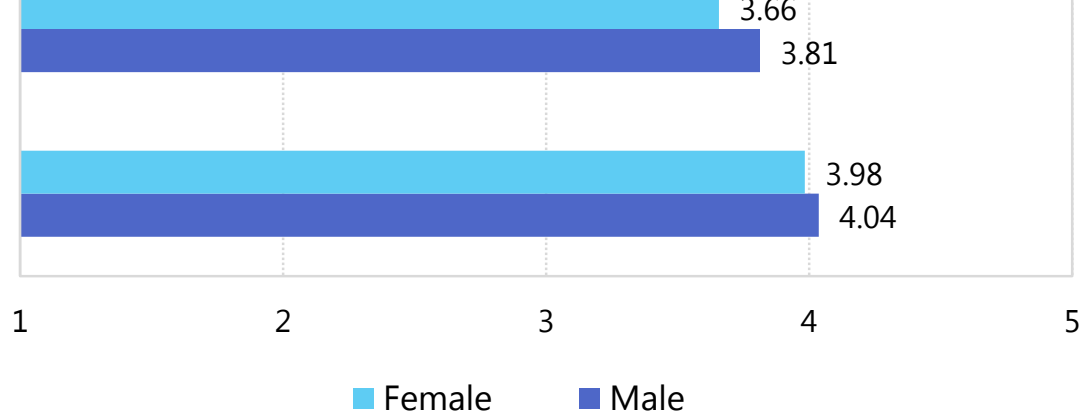


There were significant differences between women and men in the importance attributed to three interpersonal competences (Figure 4.23) in good performance: customer relationship skills, presentation skills, and team work. Women attributed more importance to customer relationship skills than men. By contrast, men attributed more importance to presentation skills and team work than women.

Figure 4.23. Rate the importance of each of the following factors and competences for good performance in your current job by gender: interpersonal competences

7. Customer relationship skills

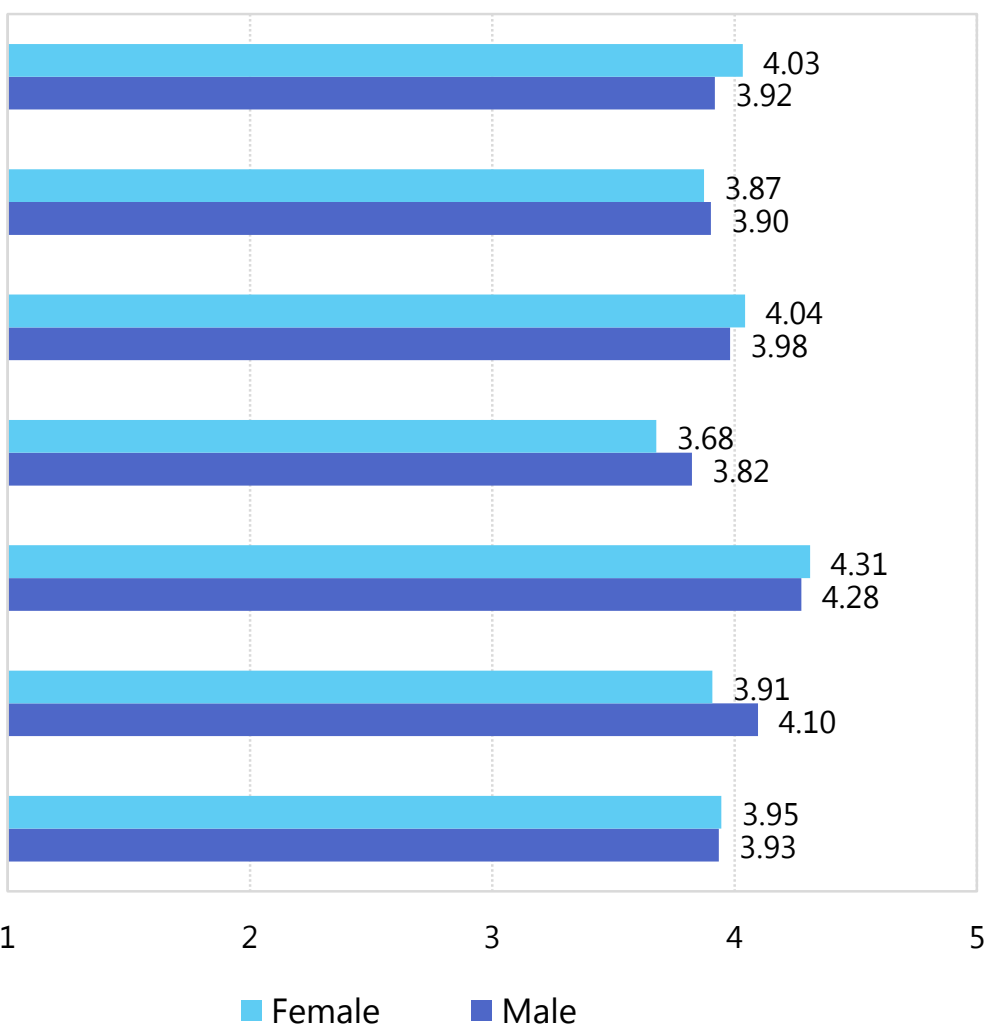

3. Communication skills

2. Team work

1. Conflict solving

6. Inter-cultural skills

5. Negotiation skills

4. Presentation skills

Male

There was a significant difference between men and women in one of the instrumental competences (Figure 4.24): office skills. Women attributed more importance to office skills in good performance than men. 
Figure 4.24. Rate the importance of each of the following factors and competences for good performance in your current job by gender: instrumental competences

3. Office skills

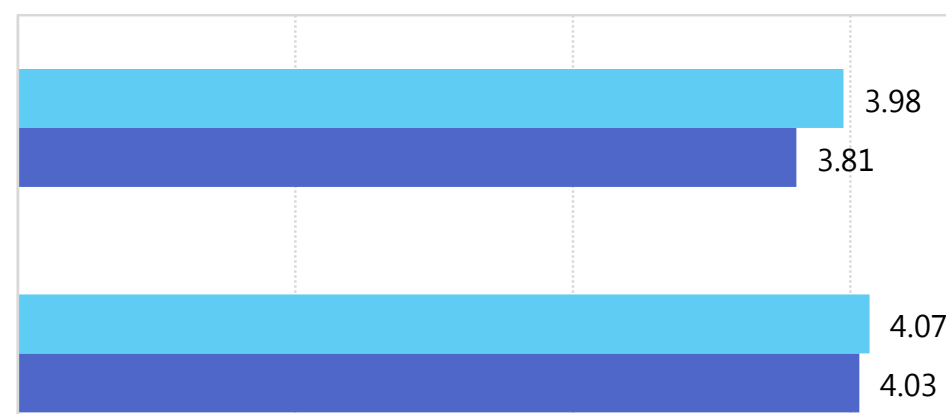

1. Foreign languages

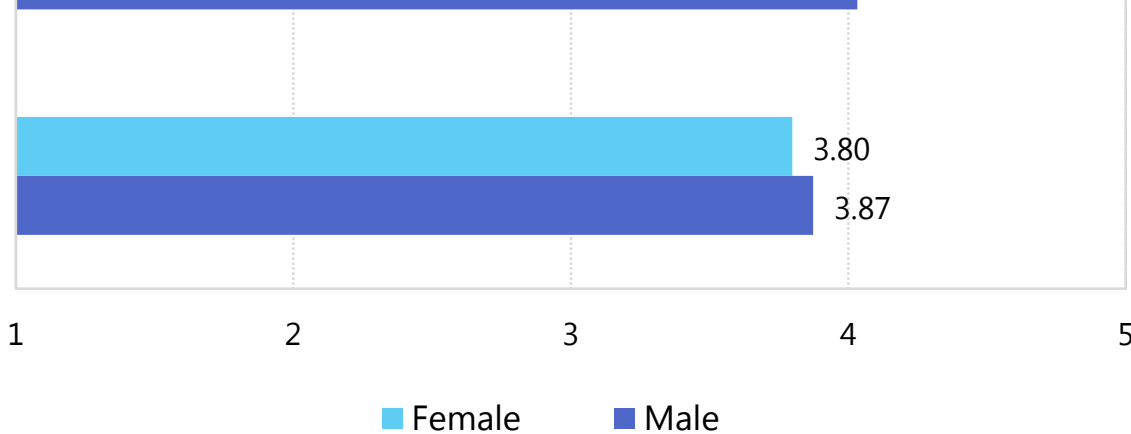

There were significant differences between women and men in the importance attributed to three attitudinal competences (Figure 4.25) in good performance: rule compliance, entrepreneurship, and commitment. Men attributed more importance to all these three competences than women.

Figure 4.25. Rate the importance of each of the following factors and competences for good performance in your current job by gender: attitudinal competences

6. Take responsibility

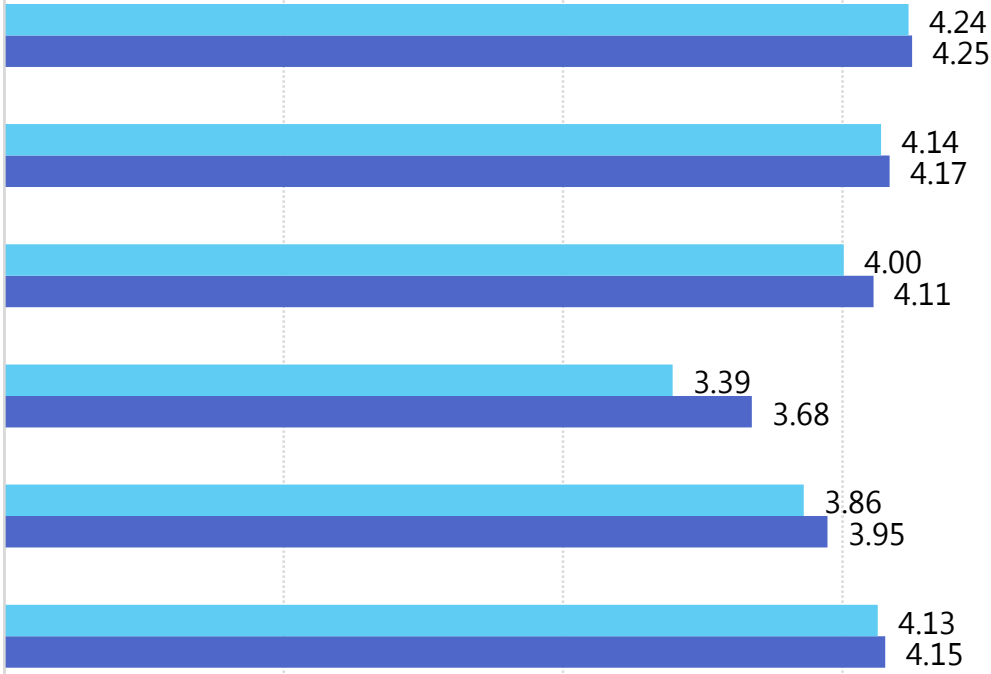

1. Adaptability

$$
\text { Female } \quad \text { Male }
$$




\subsection{Unemployed graduates}

\subsubsection{Time looking for a job}

There was no significant association between gender and the time spent looking for a job (Figure 4.26). On average, men and women spent between 6 and 7 months looking for a job.

Figure 4.26. Average number of months you have been looking for a job, by gender

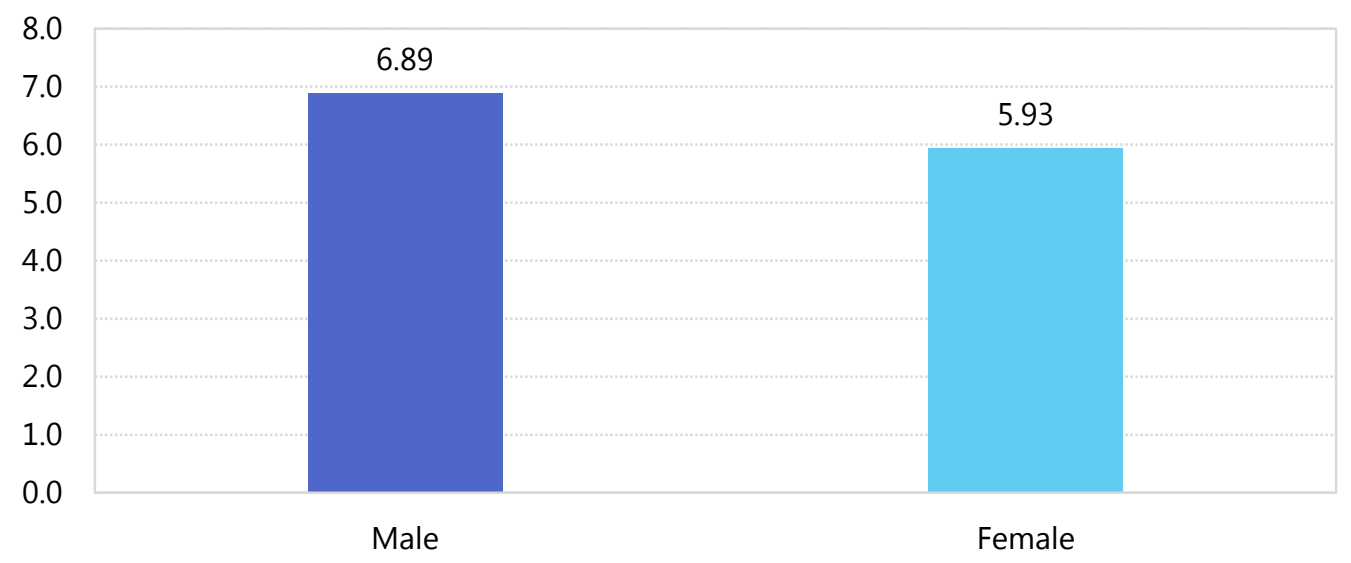

\subsubsection{Job search strategies used}

There was a significant association between gender and strategies used to find a job (Figure 4.27). The strategy related to using "social and/or professional Internet networks" was used more frequently by women than by men. The rest of the strategies ("personal contacts", "employment agencies", "Internet portals, company websites, ...", and "university employment services") were used more frequently by men than by women.

Figure 4.27. What are the 3 job search strategies you have used more frequently? by gender

5. Use of the employment services of my university

4. Internet portals, company websites, and press ads.

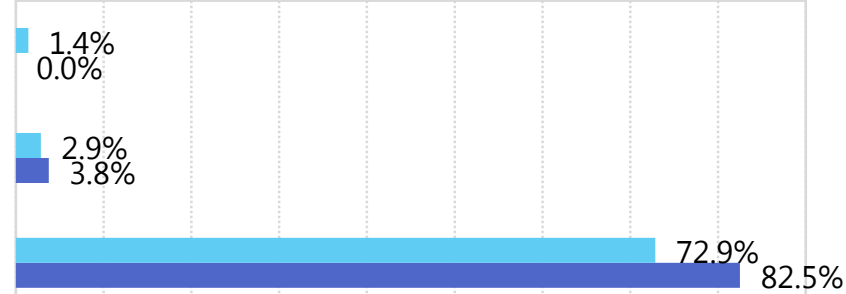

3. contacting employment agencies

2. social and/or professional Internet networks

1. personal contacts (relatives, friends, ...)

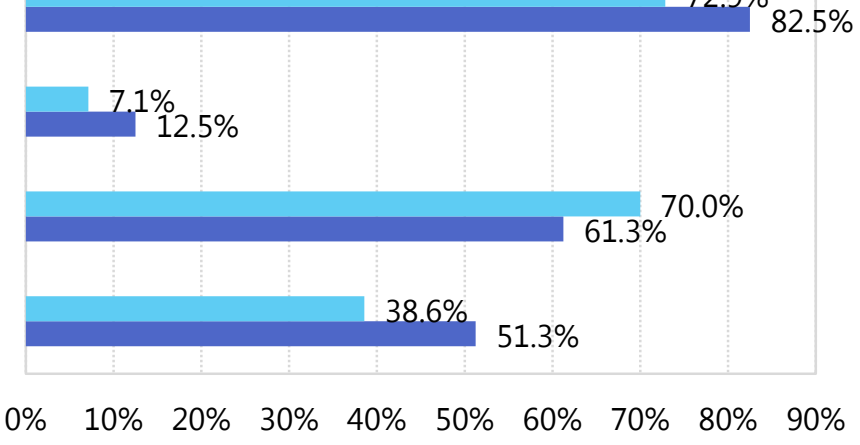

Female Male 


\subsubsection{Difficulties in finding $a$ job}

There were no significant differences between women and men in the difficulties they perceive in finding a job (Figure 4.28). The main difficulty for both women and men was "lack of, or insufficient, professional practice and experience".

Figure 4.28. Rate the degree of responsibility of each of the following factors in your difficulties in finding a job, by gender

12. My demographic characteristics (gender, age, etc.)

11. Saturation of the labor market

10. Lack of job search skills

9. There are personal circumstances that prevent you from working

8. The jobs you have been offered are not related to your degree

7. The jobs you have been offered do not have an adequate wage

6. You do not like the jobs you have been offered

5. Lack of computer skills

4. Lack of language skills

3. Lack of knowledge about the labor market

2. Lack of, or insufficient, professional practice and experience

1. Deficiencies in the university education I received

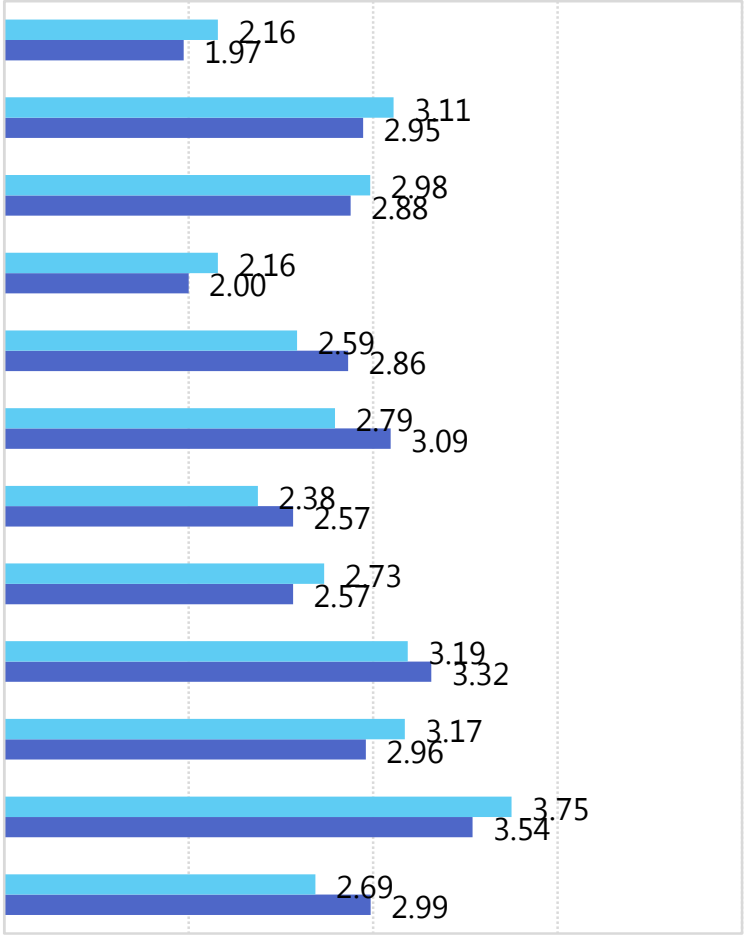

1

2

3

4

Female

Male

\subsubsection{University career centre: demand and services}

Although more women than men wanted the university career service to help them, there was no significant association with gender (Figure 4.29). 
Figure 4.29. Do you want the career centre of your university to support you in searching for a job? by gender

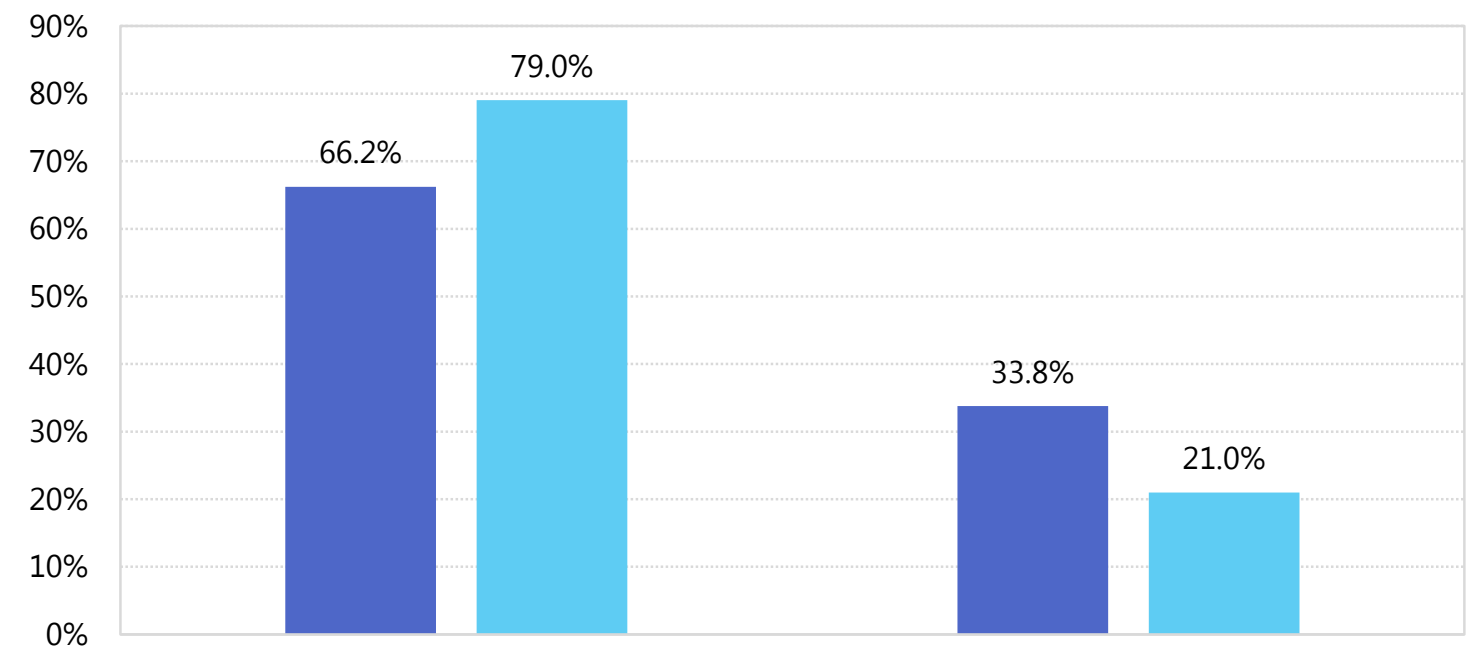

1. Yes

Male Female

2. No

Among those respondents who wanted the university career service to help them to find a job, two specific actions of this type of services ("Hosting job fairs and other events with employers" and "Soft skill training services (communication, teamworking, ...)" were preferred more by men than by women (Figure 4.30).

Figure 4.30. If so, what do you want the Career Centre to offer? by gender (multiple responses)

8. Other (specified)

7. Providing job opportunities for each major

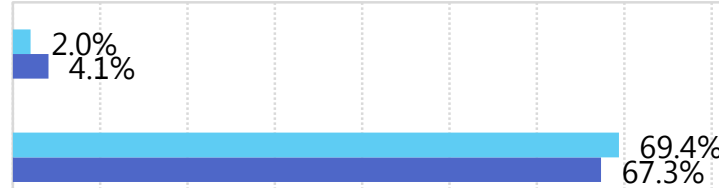

6. Hosting job fairs and other events with employers

5. Job-hunting skills

4. Soft skill training services (communication, teamworking,...

3. Job searching consulting services

2. Information on training opportunities

1. General information on labor market and job opportunities

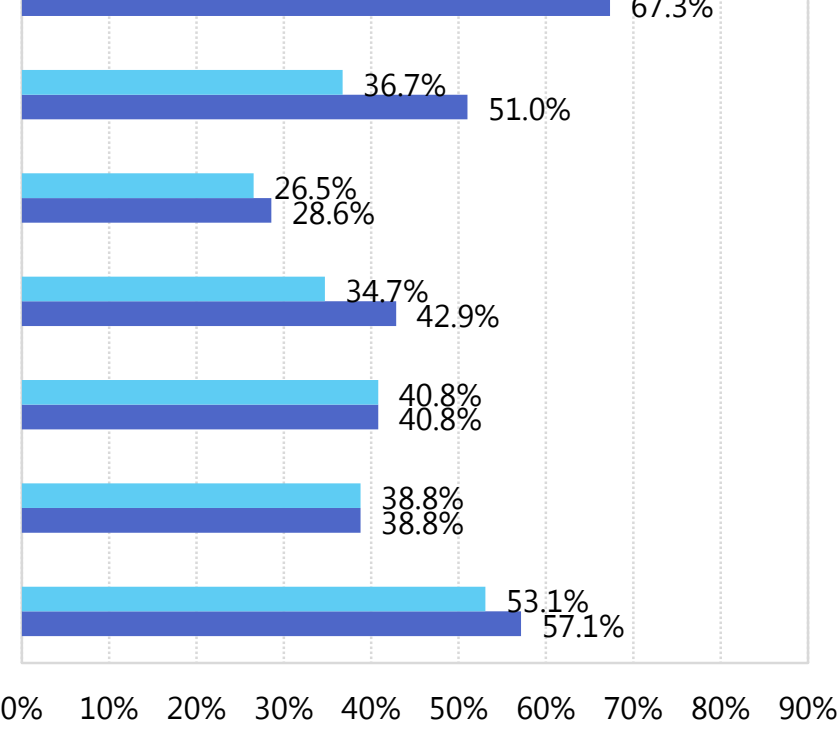

Female Male 


\subsection{Economic inactive graduates}

\subsubsection{Reason for not looking for $a$ job}

Among the respondents who did not look for a job, there was no association between gender and their reasons for not looking for a job. Most of the women and men indicated that the most important reason was "to continue to study" (Figure 4.31).

Figure 4.31. Why are you not looking for a job right now? by gender (choose the most important reason)

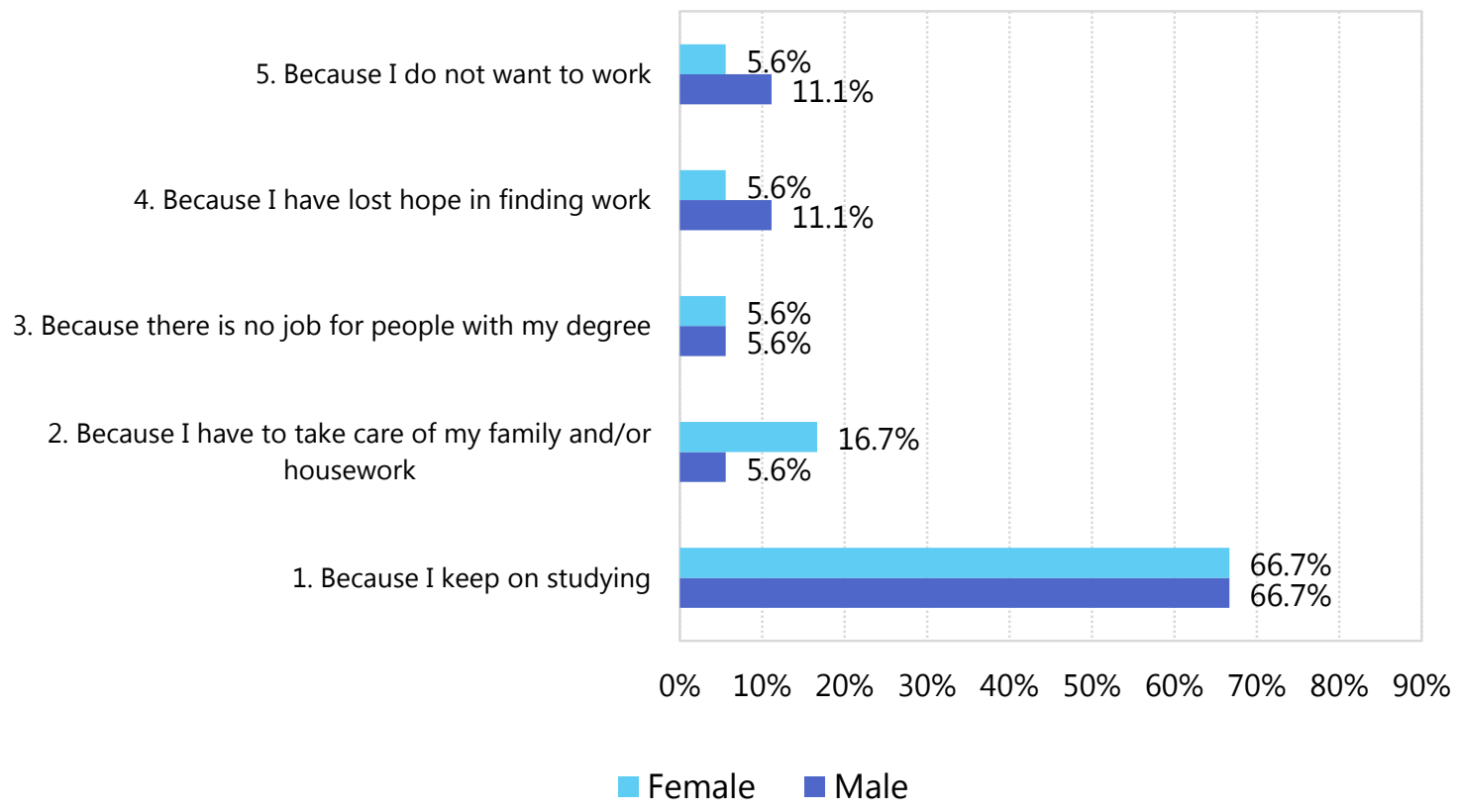

\subsection{Summary and conclusions}

Graduates' gender was not related to their current employment situation, the number of months spent looking for their first paid job, or the number of jobs they had after graduation. However, the percentage of men who found a job "before graduation" (49\%) was slightly higher than the percentage of women (43.7\%).

Regarding strategies to find a job, women tended to use social and professional Internet networks more frequently than men.

As to job characteristics, horizontal match was higher for men than for women, but there were no significant differences in vertical match. Men tended to occupy manager and middle manager positions more often than women, and they had a larger monthly income than women.

Considering the organization where the graduates performed their jobs, women worked in private companies (62.4\%) more frequently than men (54.1\%). Women also tended to work in 
smaller companies more frequently than men, and in jobs located closer to places where their families live.

Regarding the employment contract, men tended to have formal contracts slightly more frequently than women. However, there were no relevant differences in the contract duration or the type of time arrangement (part-time vs. full-time).

In the case of work satisfaction, men showed higher levels of overall work satisfaction, satisfaction with income, and satisfaction with opportunities for professional development than women.

As to the importance of a number of different competences in attaining good performance in their job, men tended to attribute more importance to cognitive, management, and attitudinal competences than women. However, women tended to assign more importance to interpersonal and instrumental competences.

Focusing on unemployed graduates, there were differences between men and women in the strategies used to find a job. Women tended to use "social and/or professional Internet networks" more frequently than men, and the latter tended to use the other strategies considered more frequently. 



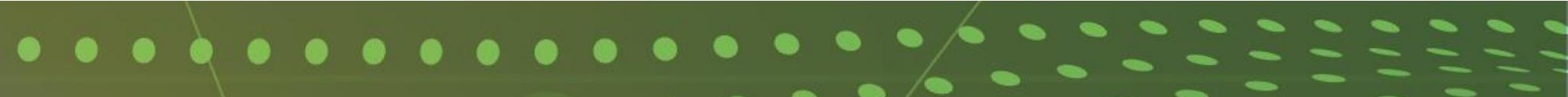

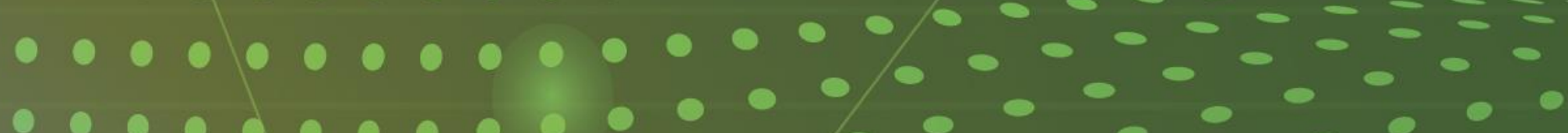

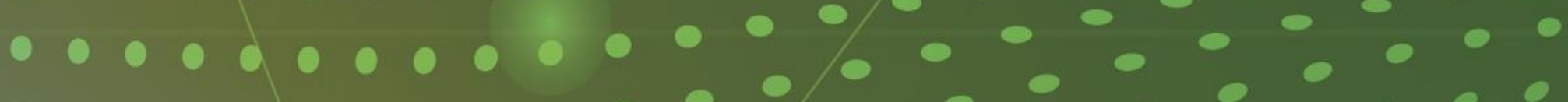

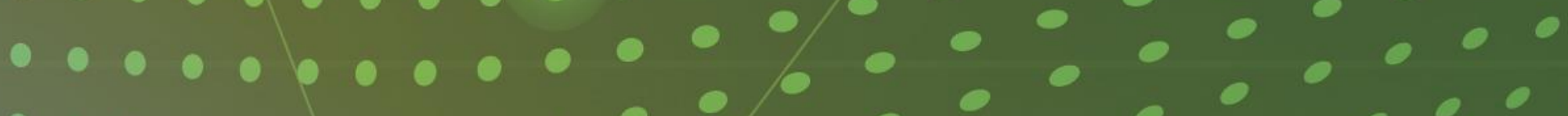

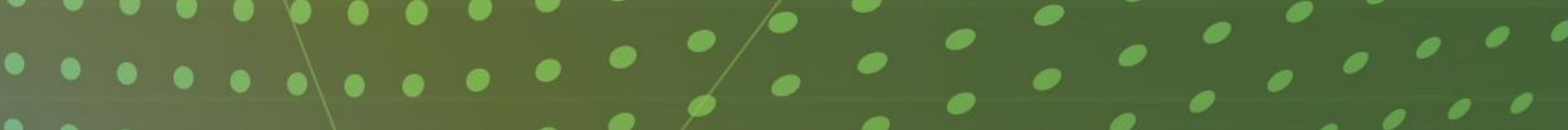

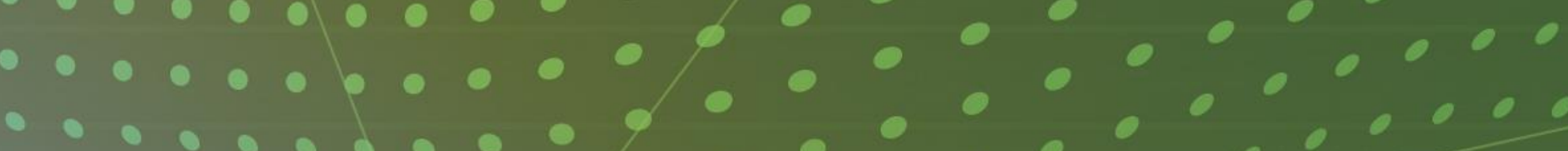

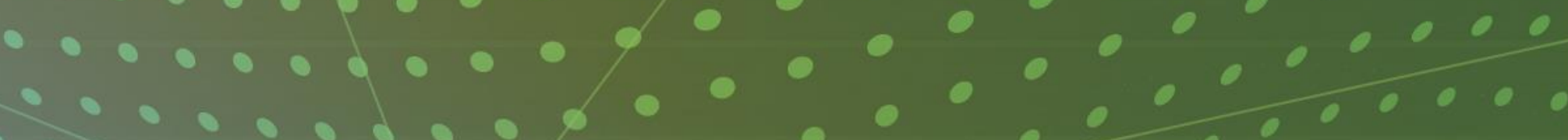

\section{CHAPTER 5:}

\section{DIFFERENCES BY MAJORS}




\section{CHAPTER 5: DIFFERENCES BY MAJORS}

In this chapter, we analyse the results obtained according to the surveyed graduates' majors. We distinguish between two major categories: 1. Engineering and Science (ES) and 2. Social Sciences (SS). The first category (ES) includes different majors in engineering (e.g., electronic, electrical, mechatronic, and automotive engineering) and life sciences (e.g., veterinary, aquaculture, and livestock science). The second category (SS) includes different majors in the area of business (e.g., economics, business, accounting, and banking and finances) and specific majors in social sciences, law, tourism, and English.

\subsection{Graduates' employment status}

\subsubsection{Current employment situation}

The relationship between the graduates' major and their current employment situation was not statistically significant. Most graduates with majors in SS (81.2\%) and ES (84.5\%) were working when they were surveyed (Figure 5.1). By contrast, percentages of graduates with SS and ES majors corresponding to other possible situations (self-employed, looking for a job, unemployed but not looking for a job) were not higher than $10 \%$.

Figure 5.1. Current employment situation by major

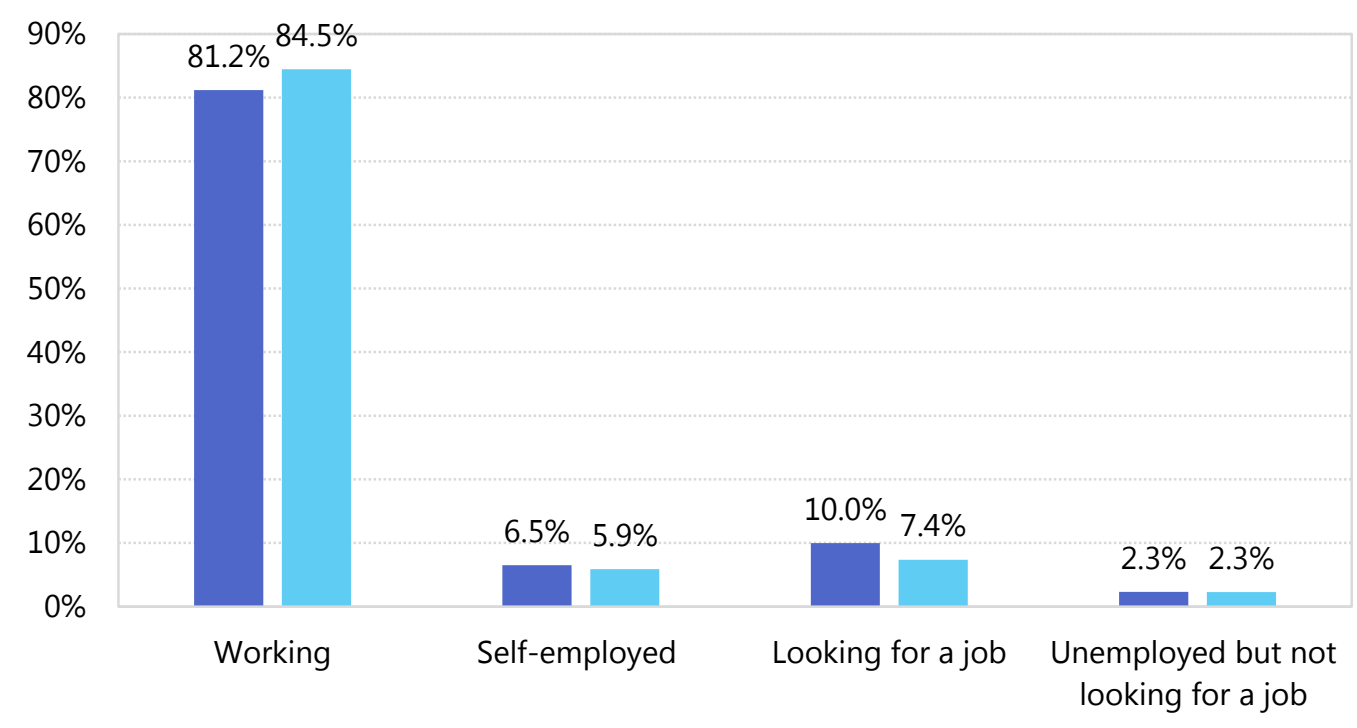

- Social Sciences Engineering \& Sciences 


\subsubsection{Number of jobs since graduation}

The relationship between the major and the number of jobs subjects had since graduation was not statistically significant. Most of the SS (79.0\%) and ES (78.1\%) graduates had one or two jobs since graduation (Figure 5.2). The percentages of SS (2.8\%) and ES graduates (3.9\%) without any job since graduation were very small. Finally, the average number of jobs since graduation for the two major categories considered was 2.8.

Figure 5.2. Number of jobs since graduation by major

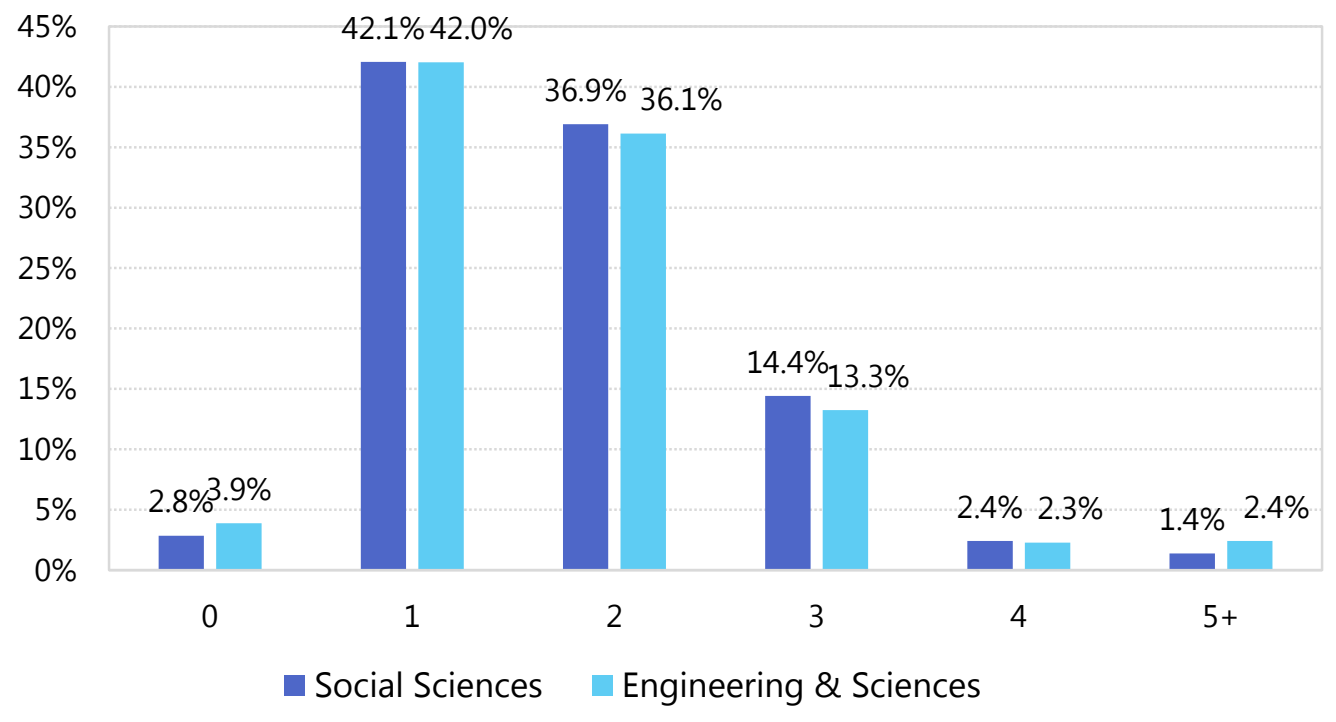

\subsection{Employed graduates ${ }^{8}$}

\subsubsection{Time needed to find the first paid job after graduation}

The relationship between the major and the time needed to find the first job after graduation was statistically significant. The percentage of ES graduates who found a job "before graduation" (51.9\%) was greater than the percentage of SS graduates $(42 \%)$, whereas the percentage of SS graduates who found a job "after graduation" (58\%) was greater than the percentage of ES graduates (48.1\%) (Figure 5.3.).

\footnotetext{
${ }^{8}$ The term 'Employed graduates' includes self-employed graduates and graduates employed by an employer.
} 
Figure 5.3. When did you find your first paid job? by major

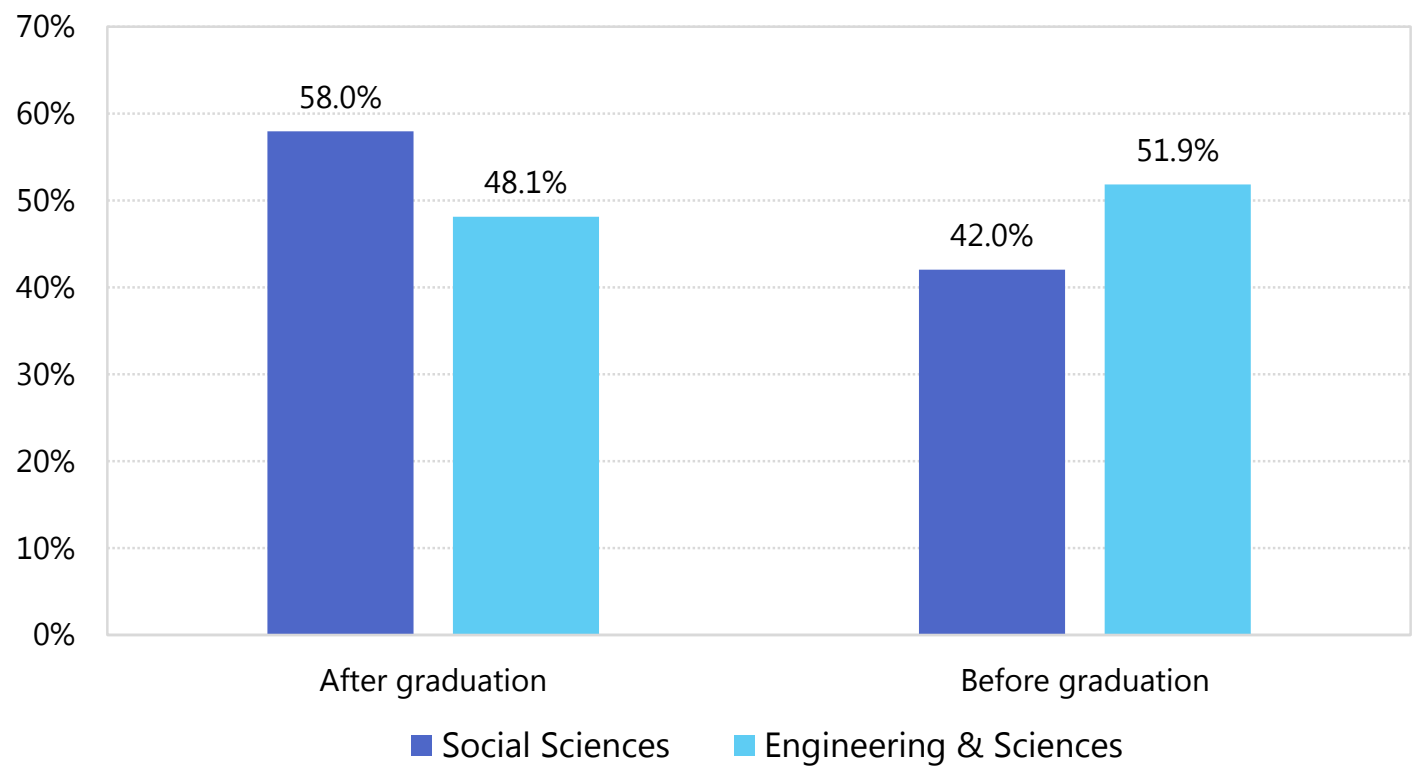

In addition, the average number of months it took to find the first paid job was slightly higher for SS graduates (3.28 months) than for ES graduates (2.79) (Figure 5.4).

Figure 5.4. The average number of months to find the first paid job after graduation, by major

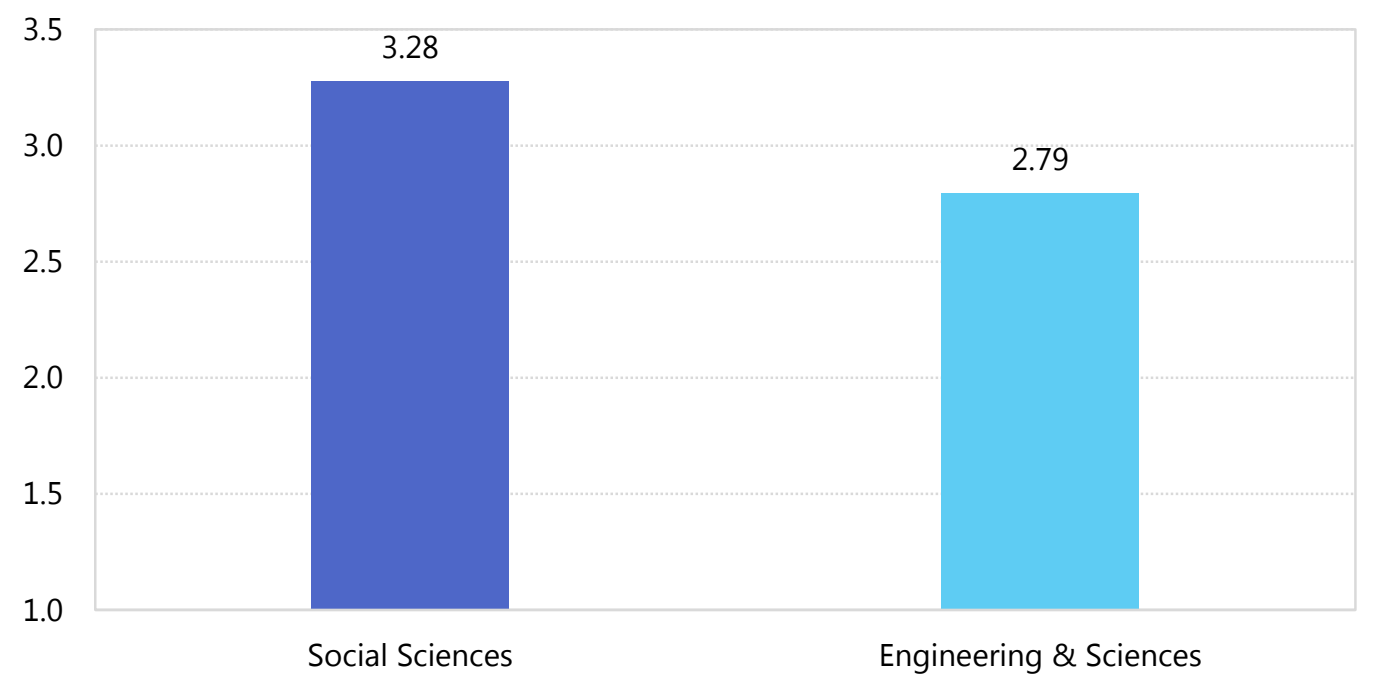




\subsubsection{Strategies to find the first paid job after graduation}

Regarding the strategies used to find the first paid job after graduation, ES graduates tended to use the following strategies more often (Figure 5.5): personal contacts; contacts initiated by the employer; contacts with the employer initiated by the graduate; employment agencies; Internet portals, company websites, and press ads; and university employment services. SS graduates tended to use the following strategies more often (Figure 5.5): practices in companies or institutions; social and/or professional Internet networks; and self-employment (creating their own job, company, or business).

Figure 5.5. Strategies to find your first paid job after graduation or the job that you already had when you graduated, by major

9. Through the employment services of my university

8. Through Internet portals, company websites, and press ads.

7. By contacting employment agencies

6. I contacted the employer on my own initiative

5. By creating my own job, company or business (Self-employment)

4. The employer contacted me

3. Through social and/or professional Internet networks

2. Through the practices that I performed in companies or institutions

1. Through personal contacts (relatives, friends, ...)

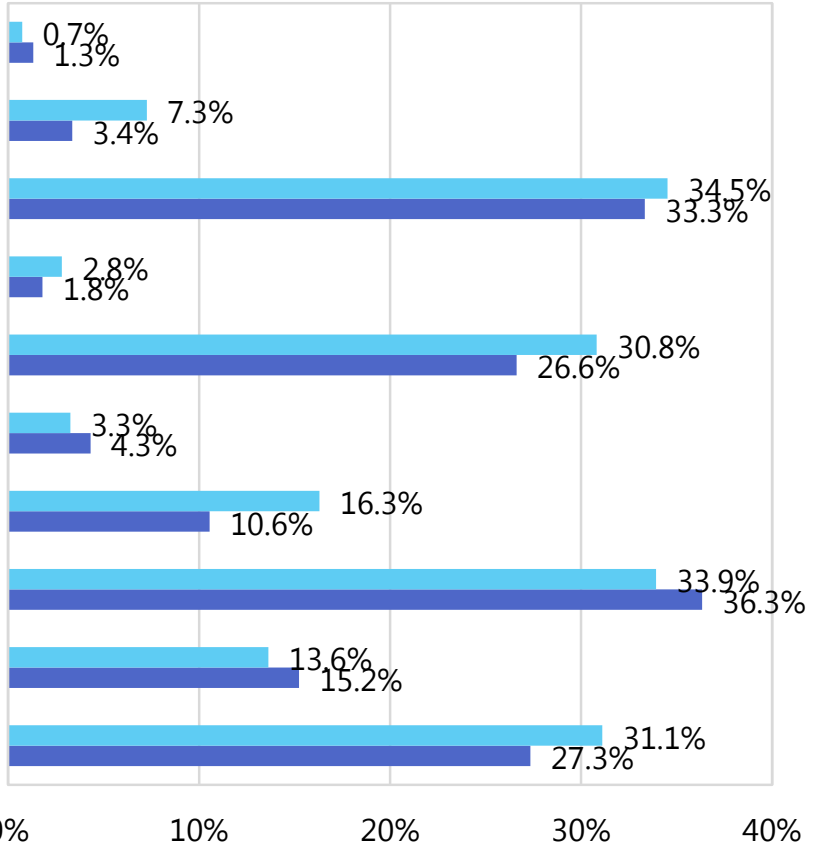

Engineering \& Sciences

n Social Sciences

\subsubsection{Strategies to find the current job after graduation}

Regarding the strategies used to find the job graduates had when they were surveyed, the results were very similar to the ones obtained for the first paid job. ES graduates tended to use the following strategies more (Figure 5.6): personal contacts; contacts initiated by the employer; contacts with the employer initiated by the graduate; employment agencies; and university employment services. SS graduates tended to use the following strategies more (Figure 5.6): internships in companies or institutions; social and/or professional Internet networks; and selfemployment (creating their own job, company or business). The two groups of graduates showed similar percentages of the tendency to use Internet portals, company websites, and press advertisements. 
Figure 5.6. Strategies to find your current job after graduation by major

8. Through Internet portals, company websites, and press advertisement.

7. By contacting employment agencies

6. I contacted the employer on my own initiative

5. By creating my own company or business (Selfemployment)

4. The employer contacted me

3. Through social and/or professional Internet networks

2. Through the internship that I performed in companies or institutions

1. Through personal contacts (relatives, friends, ...)

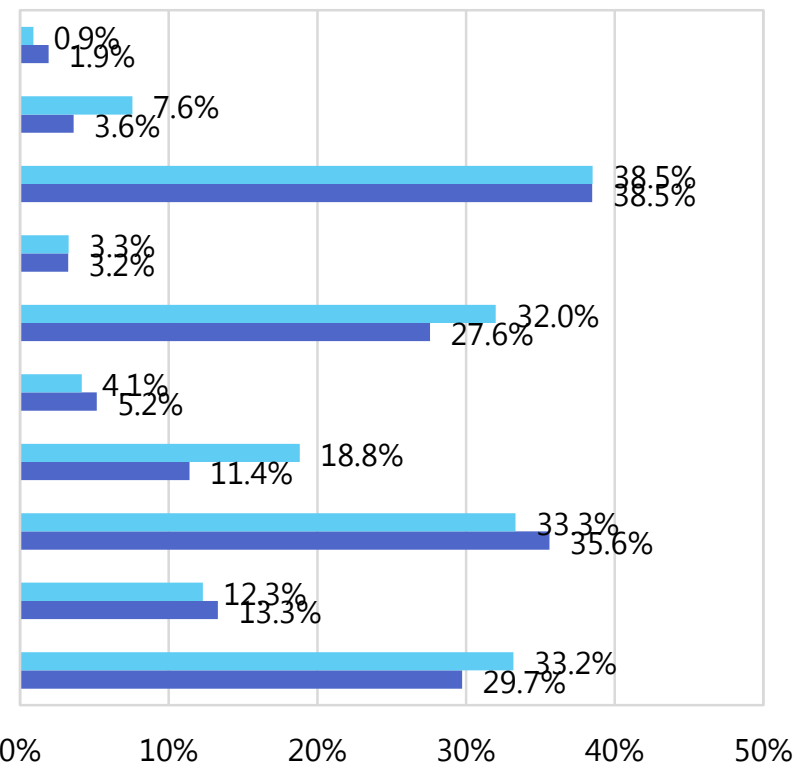

Engineering \& Sciences $\square$ Social Sciences

\subsubsection{Horizontal match}

The results obtained for the horizontal match of the current job (i.e., the relationship between the content of the current job and the content of the graduate's university degree) showed that ES graduates had a higher horizontal match than SS graduates. The percentages of ES graduates with "quite" and "a lot" of horizontal match ( $40.5 \%$ and $18.8 \%$, respectively) were higher than the corresponding percentages for SS graduates (31\% and 16.9\%, respectively) (Figure 5.7). Conversely, the percentages of SS graduates with "none" and "little" horizontal match (17.5\% and $34.6 \%$, respectively) were higher than the corresponding percentages of SS graduates (13.4\% and $27.3 \%$, respectively).

Figure 5.7. To what extent is the content of your current job related to the content of your degree? by major

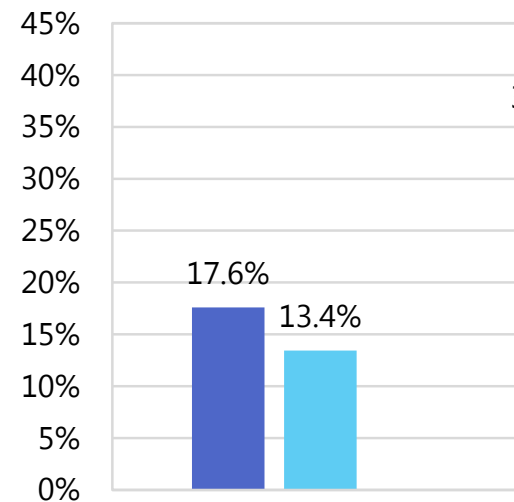

1. None
$40.5 \%$

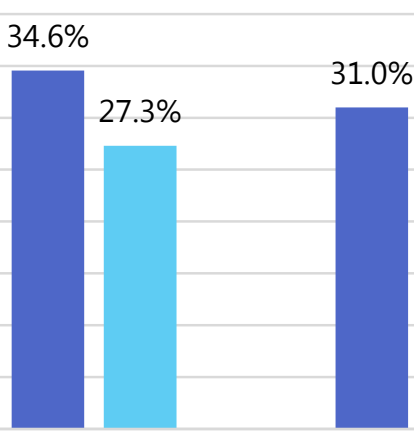

3. Quite

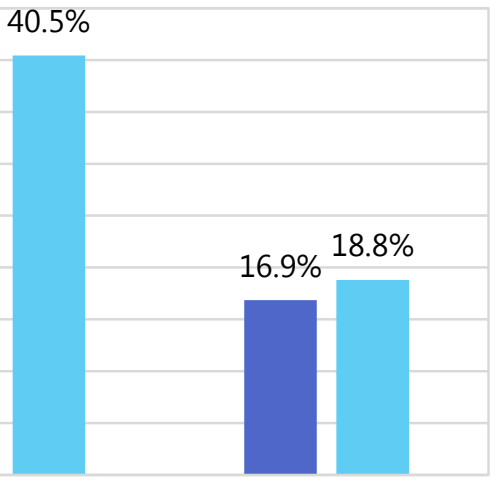

4. A lot

- Social Sciences Engineering \& Sciences 


\subsubsection{Level of education required for the current job}

Regarding the level of education required by the current job, there were no significant differences between the two major categories (Figure 5.8). In the two categories, most of the graduates' current jobs required a university degree (SS: $85 \%$, ES: $86.4 \%$ ).

Figure 5.8. What is the level of education required for your current job? by major

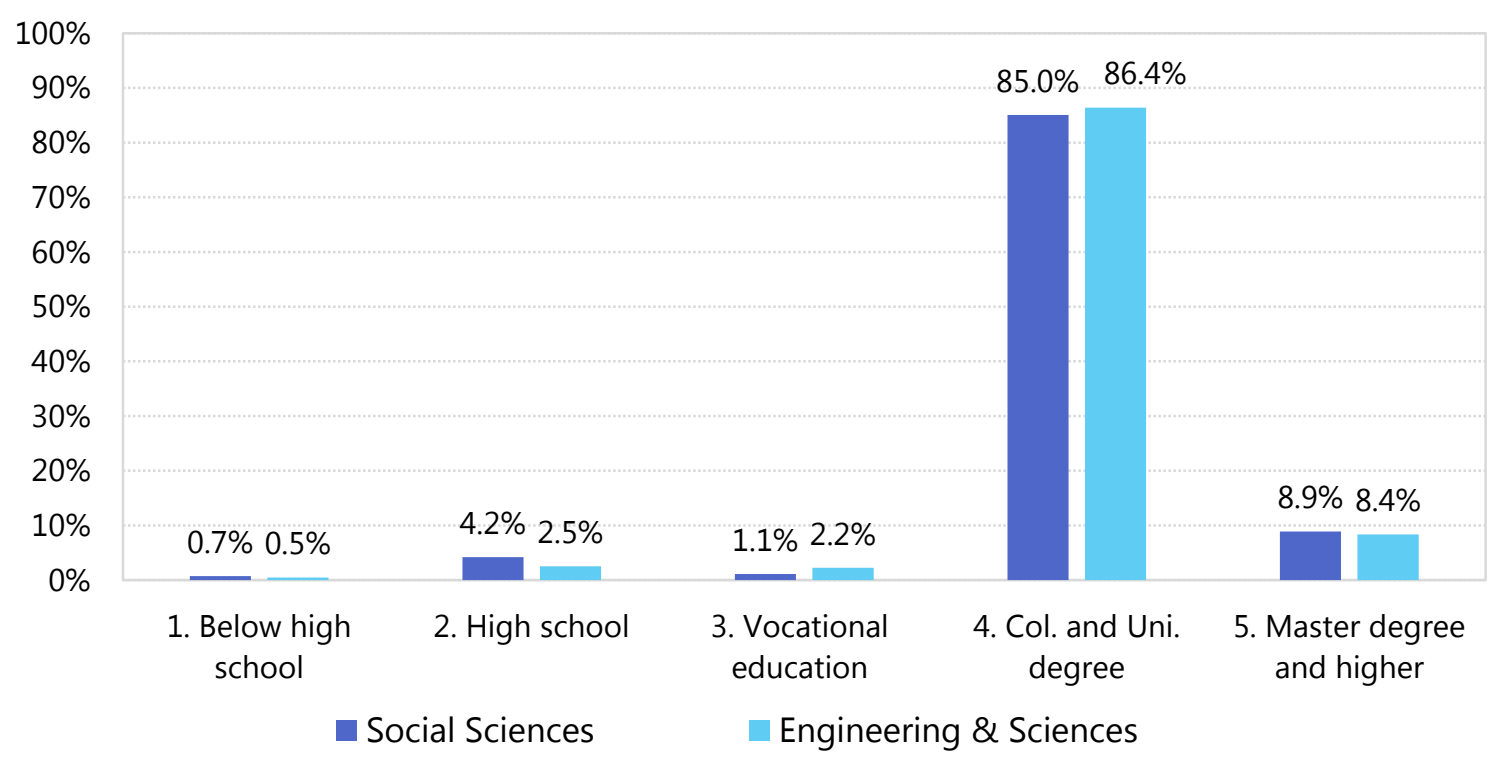

\subsubsection{Competences-job requirement match}

When we asked the surveyed graduates about the extent to which their competences matched the requirements of their job, the results obtained were similar for ES and SS graduates (Figure 5.9). In both categories, most graduates reported that their competences closely matched the requirements of their jobs (SS: 71.9\%; ES: 70.4\%).

Figure 5.9. To what extent do your skills match the requirements of your job? by major

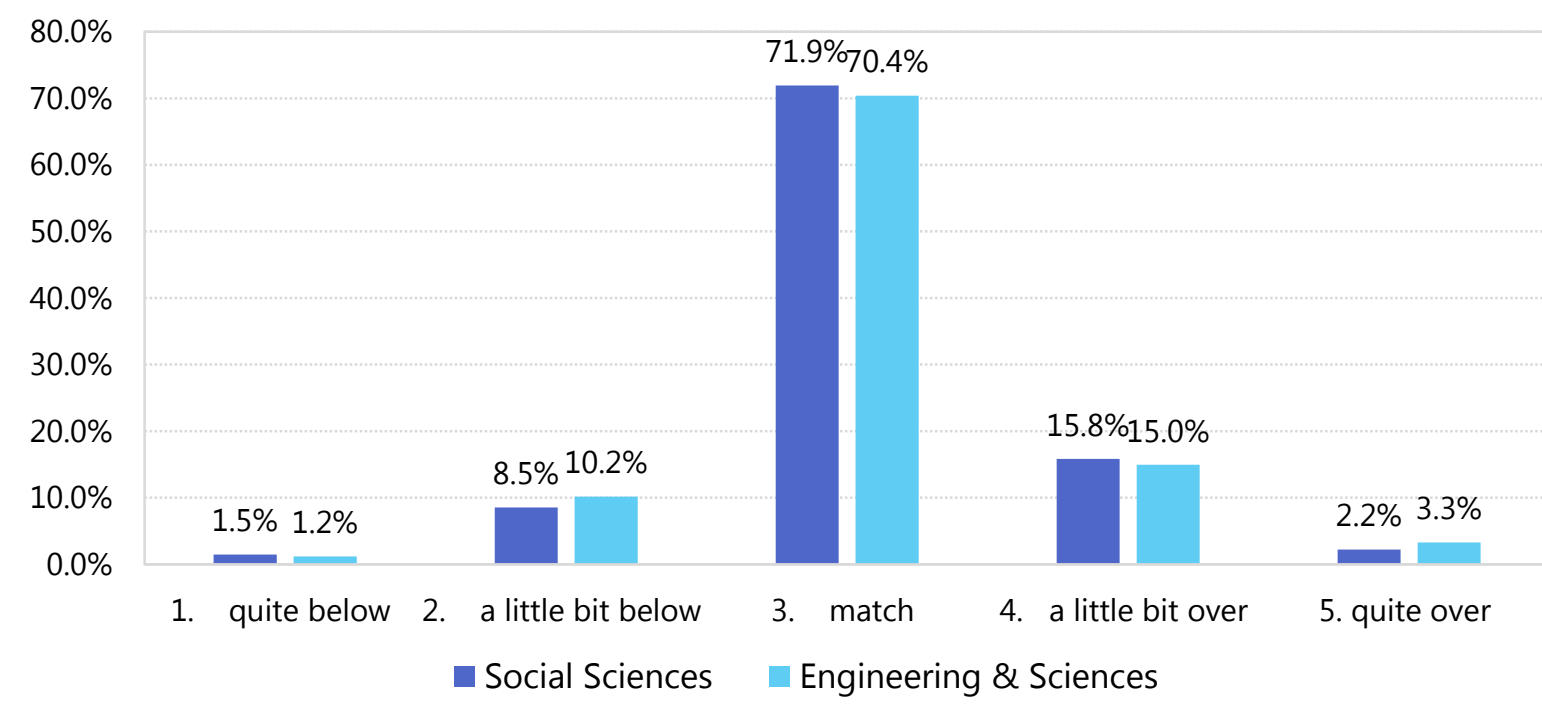




\subsubsection{Employer organization}

Type

The results obtained for the type of organization the surveyed graduates worked for (Figure $5.10)$ revealed that the percentages of SS graduates working for private companies (61.8\%) and public organizations (12.4\%) were higher than the corresponding percentages of ES graduates (53.5\% and 9.2\%, respectively). However, the percentages of ES graduates working for FDI (Foreign Direct Investment) companies (30\%) were higher than the corresponding percentages of SS graduates (19.6\%).

Figure 5.10. The organization you work for, by major

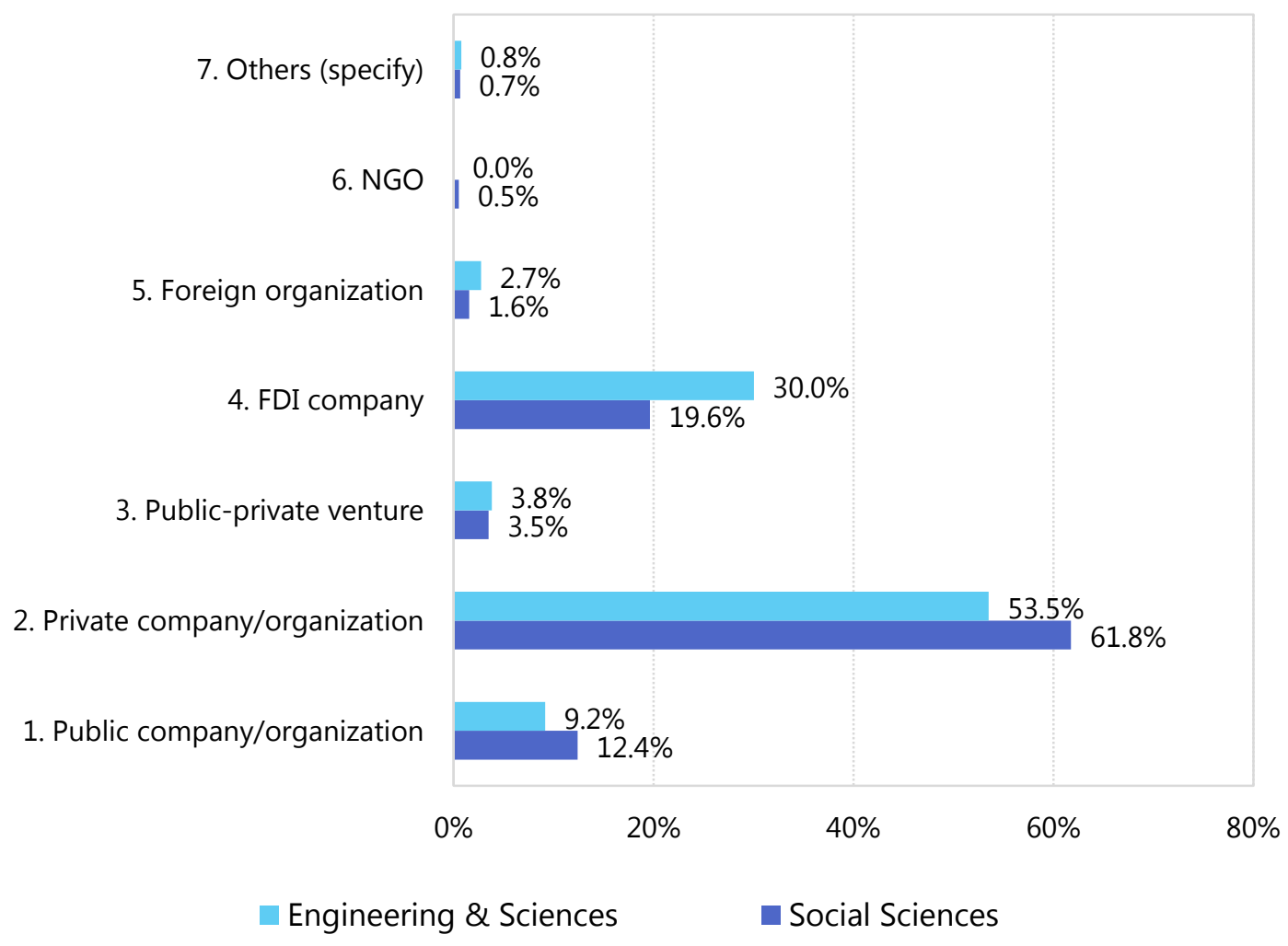

Sector

In the case of the sector of economic activity where the graduates' organization operated, the results obtained showed that the percentages of SS graduates were clearly higher in the following sectors (Figure 5.11): banking, finance and insurance; food, accommodation services; transportation and logistics; and administration and supportive services. On the other hand, the percentages of ES graduates were clearly higher in the following sectors (Figure 5.11): professional, science and technological activities; electricity, fuel, oil, and gas; construction; agriculture, forestry, and fishery; information and communication; and education and training. 
Figure 5.11. What is the sector of economic activity of your organization? by major

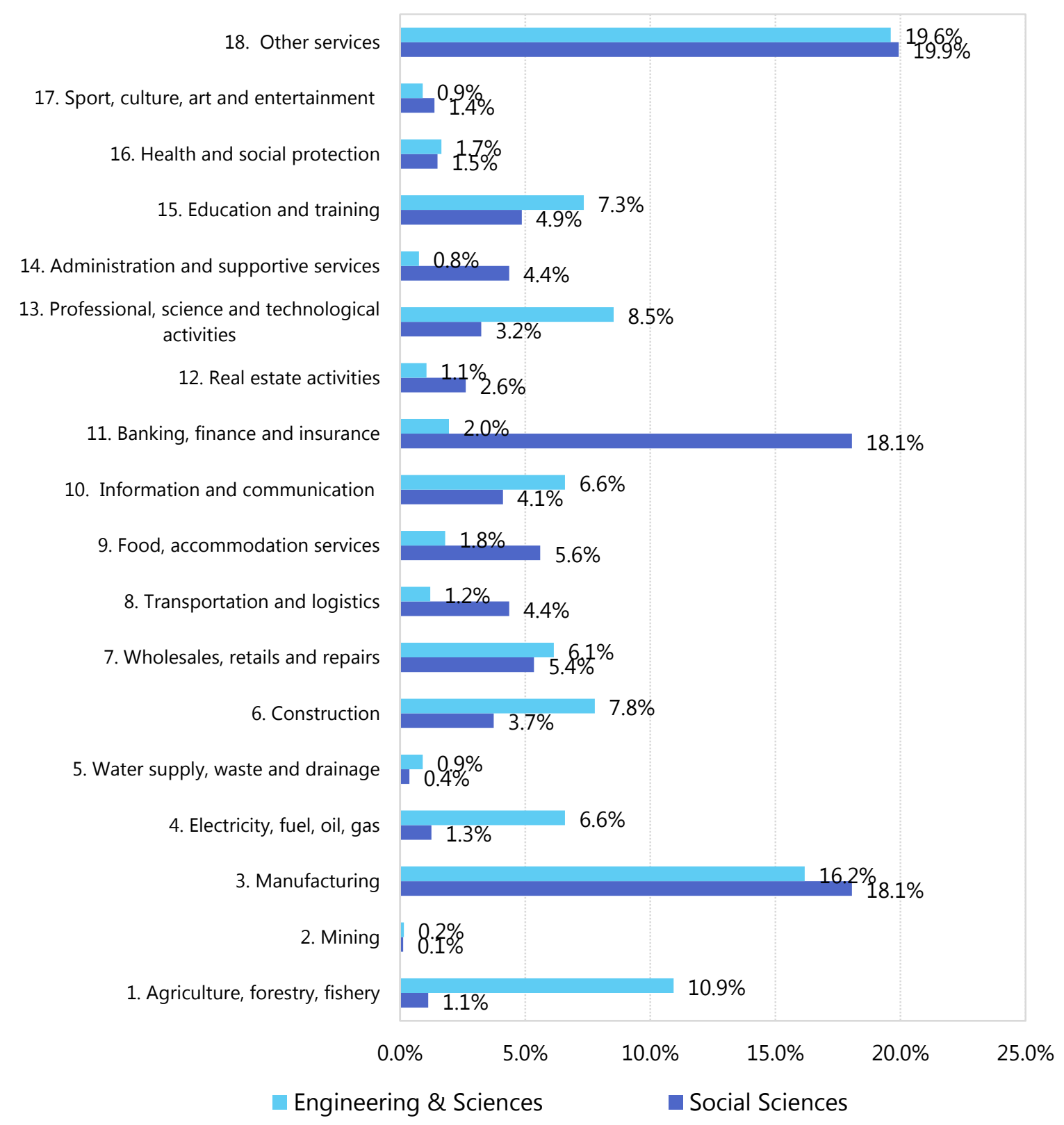

Size

The results obtained showed a significant relationship between graduates' major and the size of the companies in which they performed their current job. ES graduates tended to work in larger companies than SS graduates (Figure 5.12). Thus, 57.5\% of ES graduates worked in companies with more than 200 employees, whereas this percentage was $44.5 \%$ for SS graduates. Conversely, 55.5\% of SS graduates worked for companies with fewer than 201 employees, whereas this percentage was $42.6 \%$ for SS graduates. 
Figure 5.12. How many employees does your company have? by major

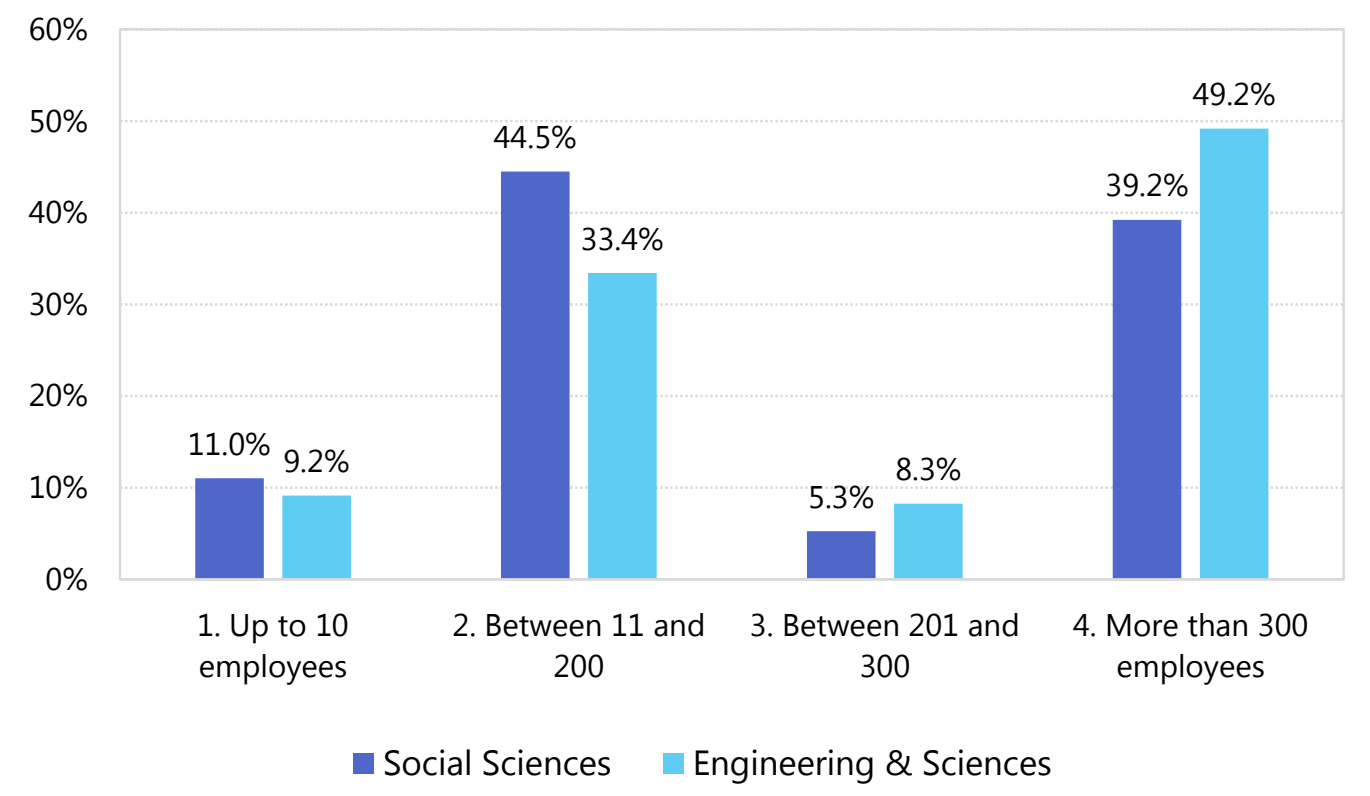

\subsubsection{Location}

Regarding the location of the current job, the results obtained showed that SS graduates tended to work close to their families more than ES graduates. For instance, 59.9\% of ES graduates worked in a region that was different from the region where their families lived (Figure 5.13). This percentage was $53.2 \%$ for SS graduates. Finally, $43.8 \%$ of SS graduates lived in the same town, province, or region where their families lived, whereas this percentage was $36.6 \%$ for ES graduates.

Figure 5.13. Where is your current job located? by major

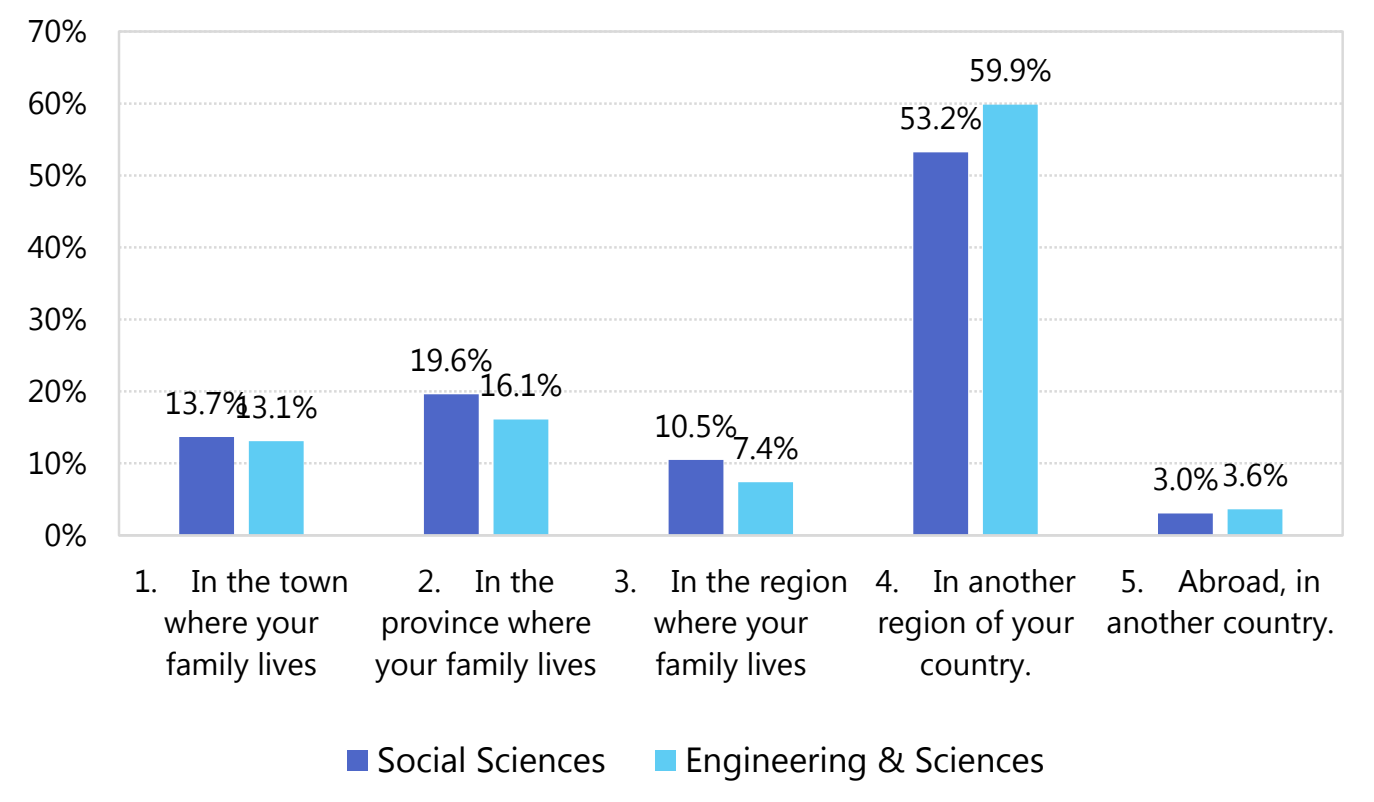




\subsubsection{Functional area}

Regarding the functional area of the company where the surveyed graduates performed their current job, the results obtained showed that, on the one hand, a higher percentage of SS graduates than ES graduates tended to have jobs in the following areas: sales and marketing, administration and finance, customer services, computing, and logistics. On the other hand, a higher percentage of ES graduates than SS graduates tended to have jobs in the following areas: production and/or provision of services; quality control; and education, research, development and innovation (see Figure 5.14).

Figure 5.14. In what functional area of the company is your current job included? by major

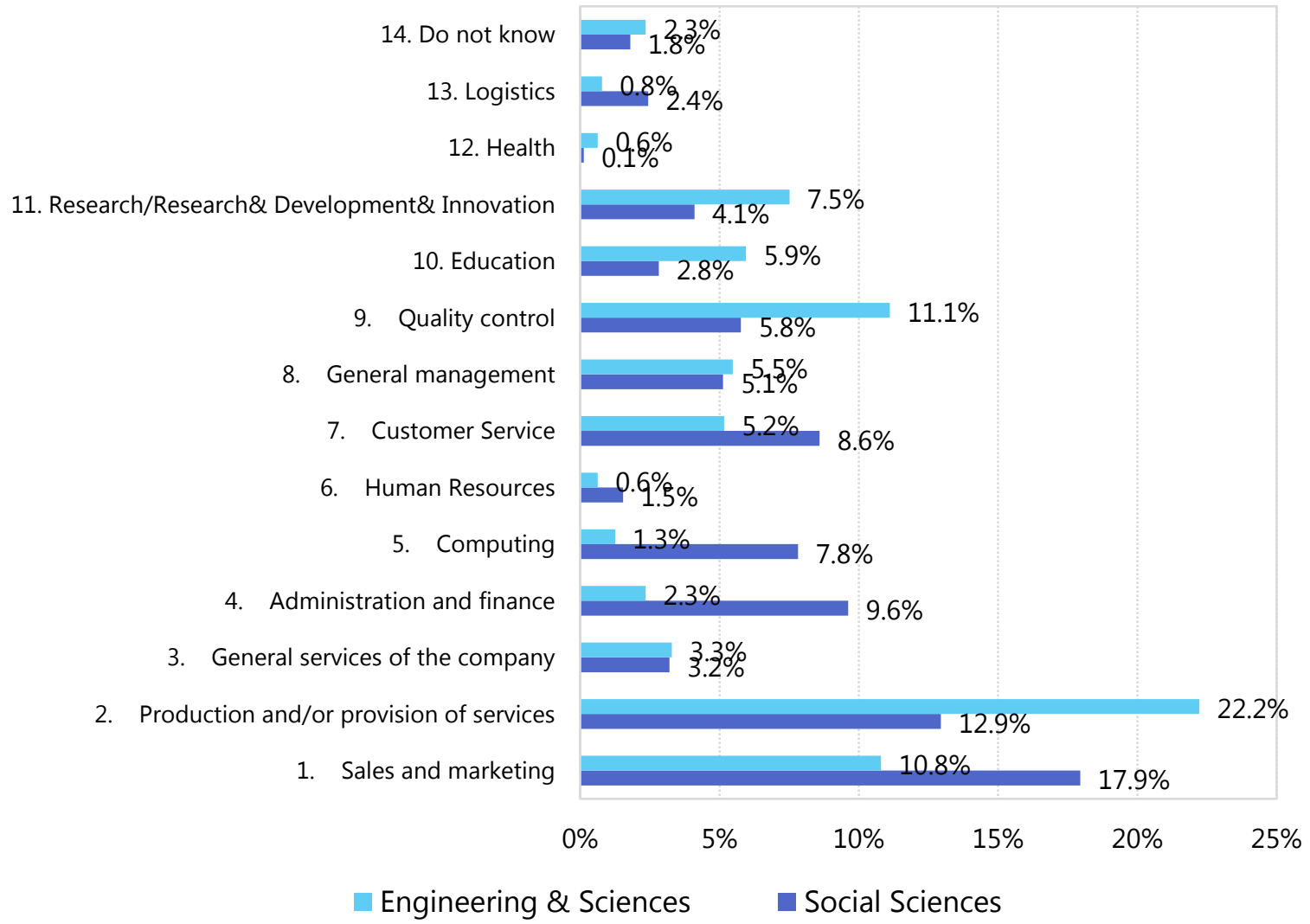

\subsubsection{Hierarchical level}

Regarding the hierarchical level of the surveyed graduates' current job, the results obtained showed a slight tendency: ES graduates tend to occupy managerial positions more frequently than SS graduates. For instance, $15.9 \%$ of ES graduates had a manager or middle manager position, whereas this percentage was $11.1 \%$ for SS graduates (Figure 5.15 ). Conversely, $86 \%$ of SS graduates worked as entry-level employees, whereas this percentage was smaller (80.1\%) for ES graduates. 
Figure 5.15. What is the hierarchical level of your current job? by major

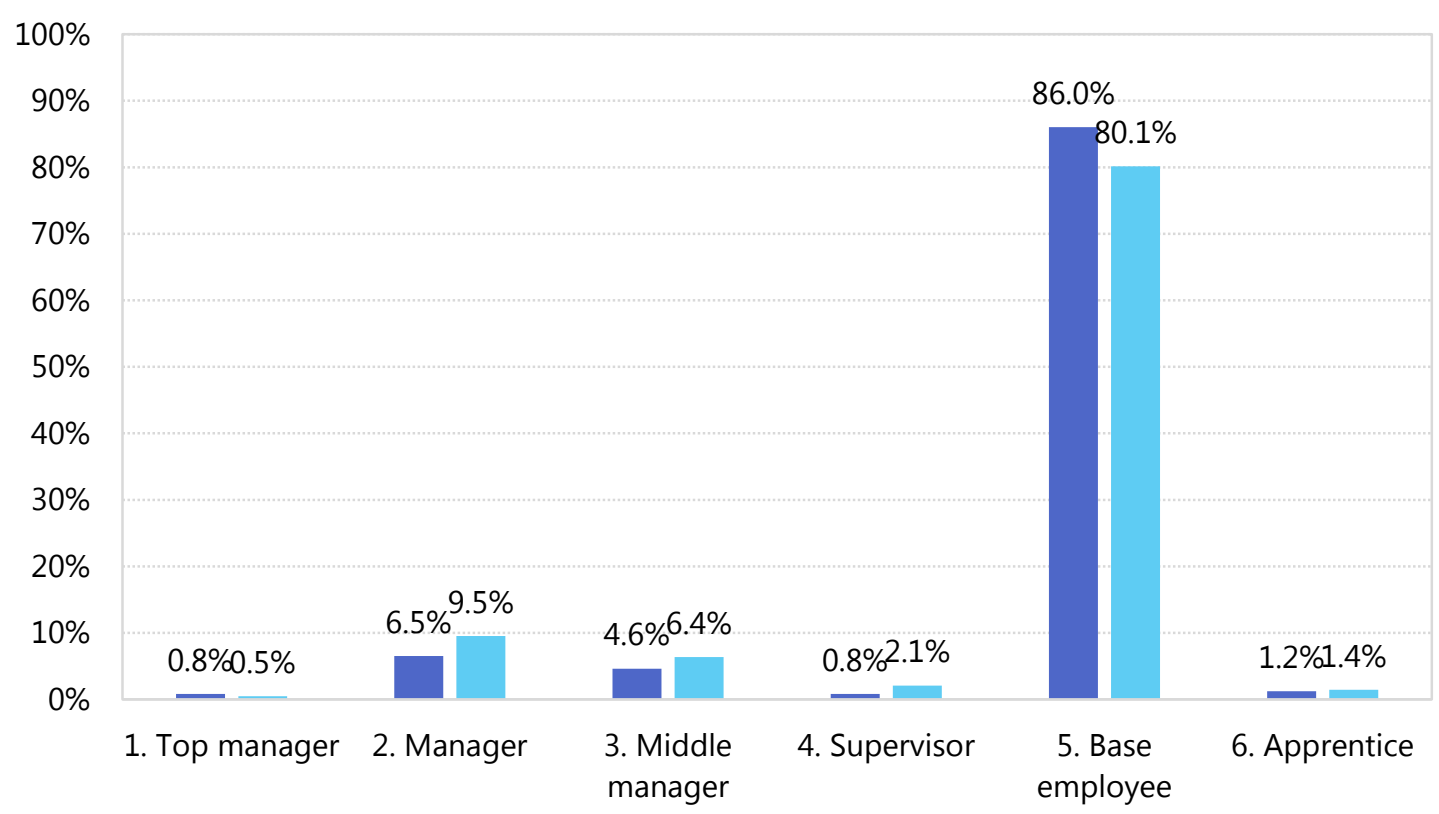

- Social Sciences Engineering \& Sciences

\subsubsection{Formal written employment contract}

There was a significant relationship between the major and the existence of a formal written employment contract (Figure 5.16). The percentage of graduates with a formal written employment contract was slightly higher for ES graduates (88.7\%) than for SS graduates (85.1\%).

Figure 5.16.. Did you sign a formal written employment contract for your current job? by major

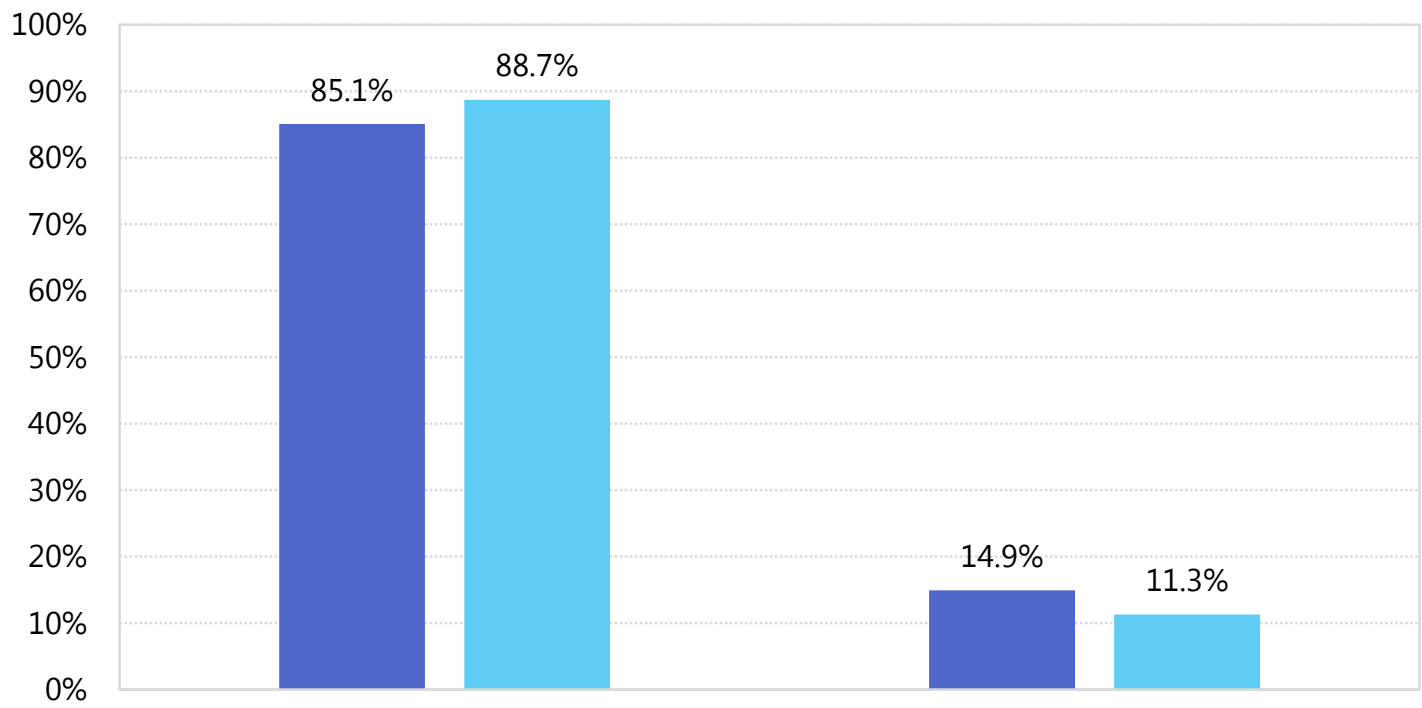

1. Yes

2. No

Social Sciences Engineering \& Sciences 


\subsubsection{Duration of the contract}

There was also a significant relationship between major and the current job duration (Figure 5.17). The percentage of graduates with a long-term job was higher for ES graduates (73\%) than for SS graduates (67.2\%).

Figure 5.17. Is your current job...? by major

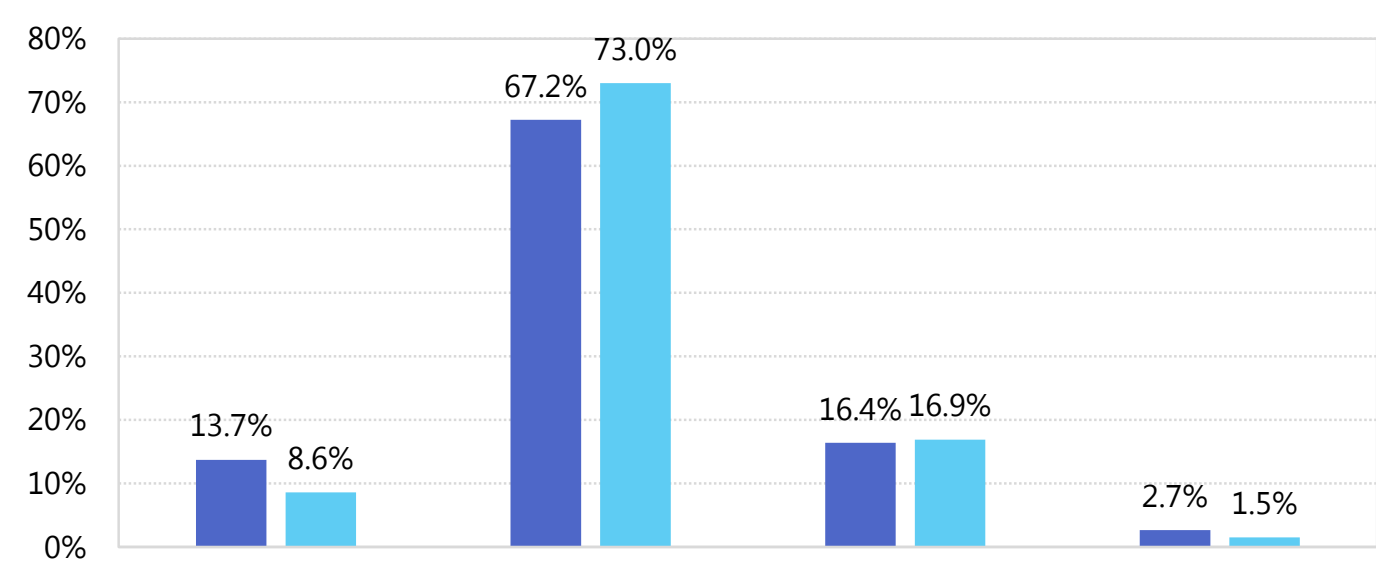

1. A SHORT-TERM 2. A LONG-TERM job 3. An unidentified- 4. I do not know. job term job.

Social Sciences $\quad$ Engineering \& Sciences

\subsubsection{Part-time vs. full-time}

However, there was no association between the major and the type of job (part-time vs fulltime). Most of the SE and SS graduates ( $97 \%$ and $96.5 \%$, respectively) have a full-time job (Figure 5.18).

Figure 5.18. Is your current job...? by major

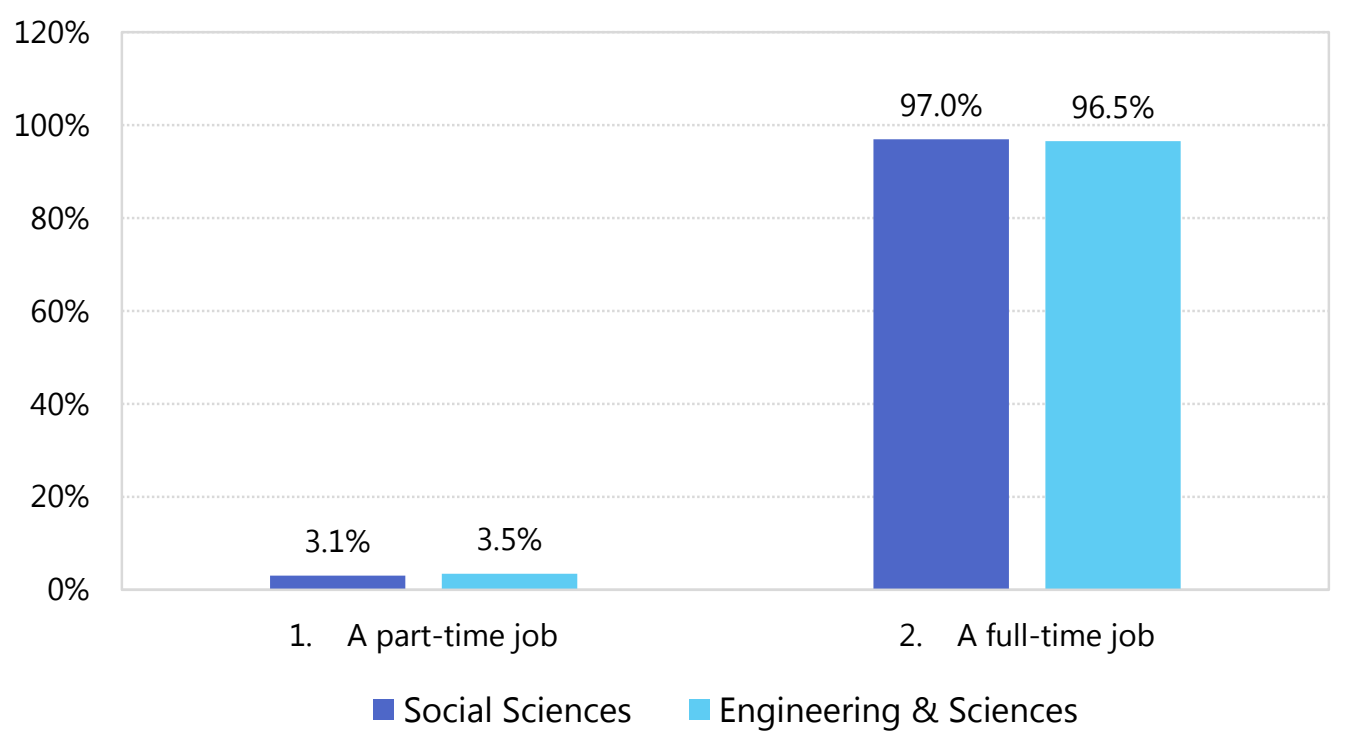




\subsubsection{Monthly income}

The results obtained showed a significant relationship between graduates' major and their monthly income (Figure 5.19). The percentage of graduates earning more than 7 million dong per month was higher in ES graduates (67.1\%) than in SS graduates (46.9\%).

Figure 5.19. An estimation of your monthly income in your current job, by major

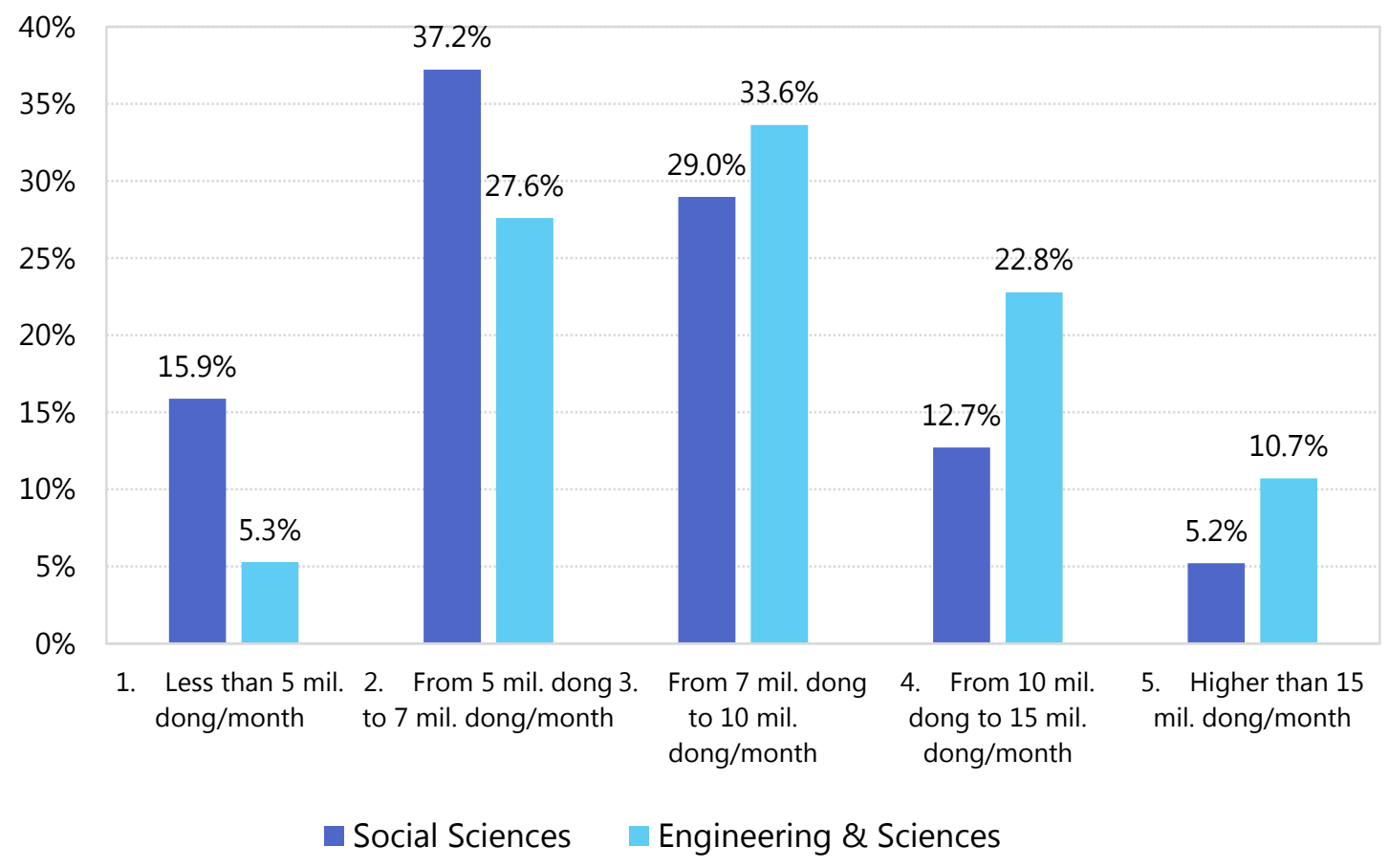

\subsubsection{Work satisfaction}

There was a significant relationship between the major and the graduate's work satisfaction. On four of the six indicators obtained (the work itself, income, professional development, and the composite indicator of overall work satisfaction that combined the five items considered), the average score for ES graduates was higher than the average score for SS graduates (see Figure 5.20). However, on all the indicators, the averages for both groups were above the intermediate point on the response scale (2.5). For instance, on overall work satisfaction, the means for ES and SS were 2.87 and 2.80 , respectively. 
Figure 5.20. What degree of satisfaction or dissatisfaction does each of the following aspects of your job produce? by major

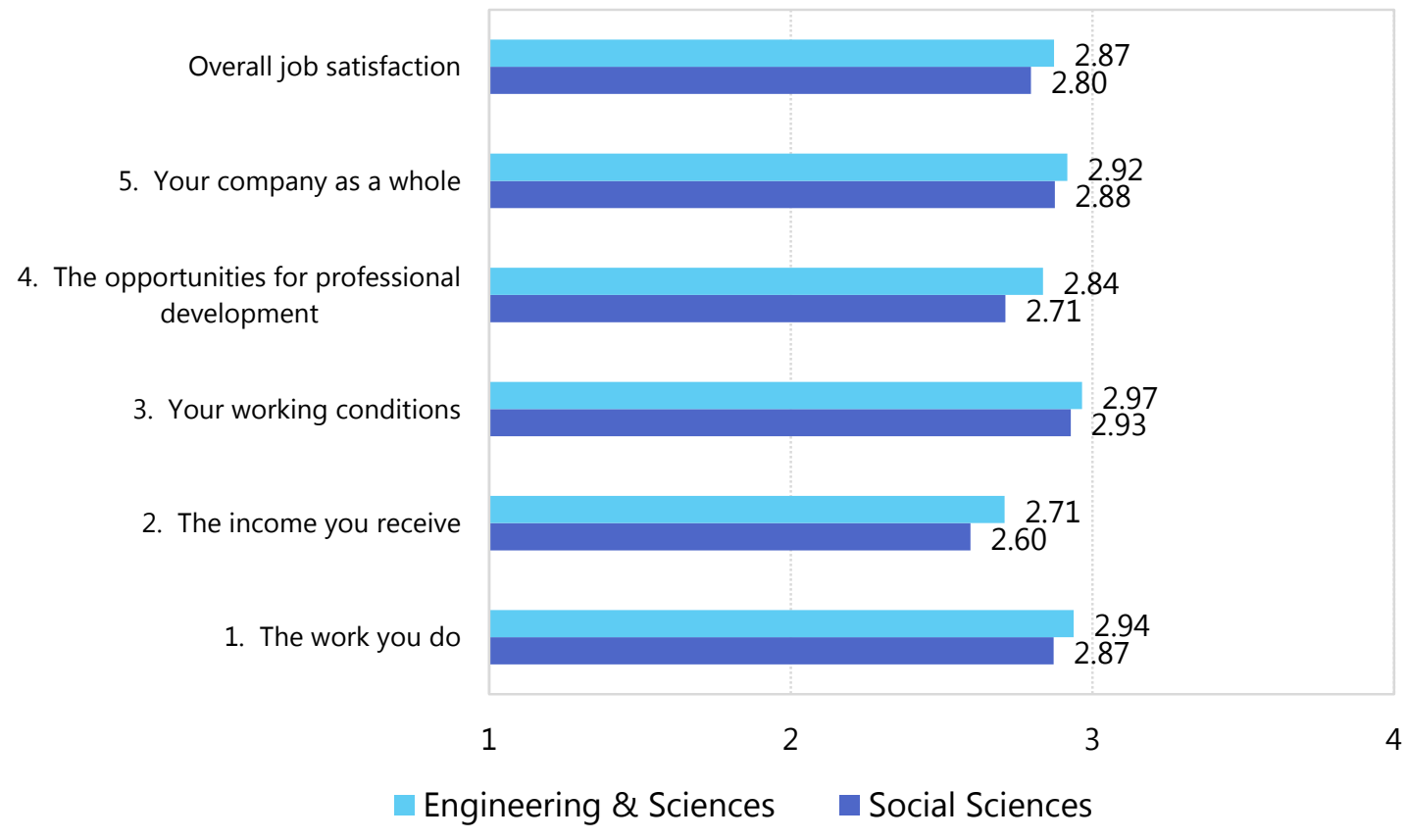

\subsubsection{Importance of competences for good performance}

There was a significant relationship between the major and the importance graduates assigned to some cognitive competences for good performance in their current job. Critical thinking was more important for SS graduates (3.78) than for ES graduates (3.69). However, creativity was more important for ES graduates (3.87) than for SS graduates (3.66). There were no significant differences in the other cognitive competences considered (see Figure 5.21)

Figure 5.21. Rate the importance of each of the following factors and competences for good performance in your current job, by major: cognitive competences

7. Report writing

6. Continuous learning

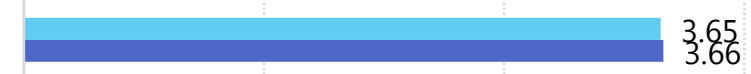

$$
\text { - }
$$

5. Transfer theory to practice

4. Creativity

3. Problem solving

2. Systematic thinking

1. Critical thinking

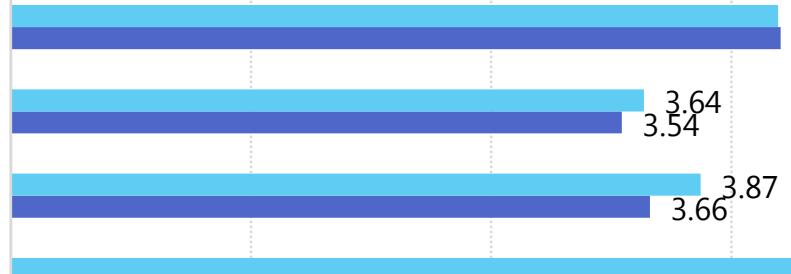
4.21
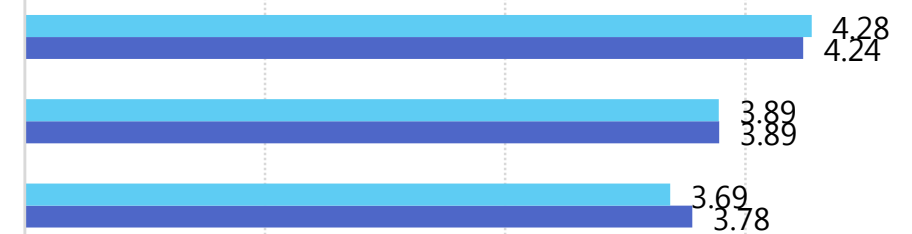

1 2 3 4 
There was a significant relationship between the major and three of the five management competences considered. In all of them, SS graduates assigned greater importance to these competences for good performance than ES graduates. These competences were the following: motivating others (SS: 3.82; SE: 3.67), leadership (SS: 3.77; SE: 3.61), and decision making (SS: 4.09; SE: 3.95) (Figure 5.22).

Figure 5.22. Rate the importance of each of the following factors and competences for good performance in your current job, by major: management competences

5. Decision making

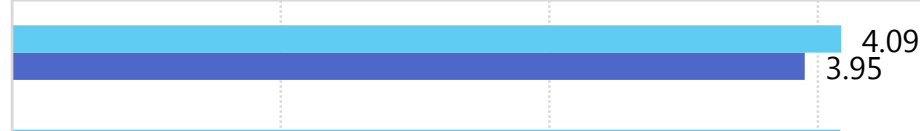

4. Planning

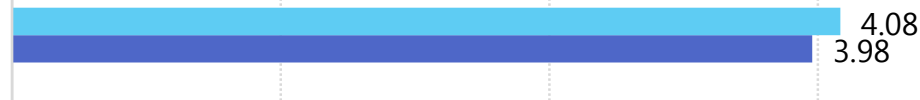

3. Leadership

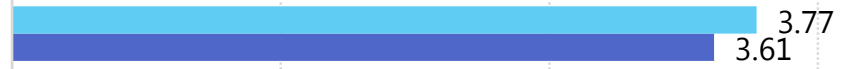

2. Motivate others

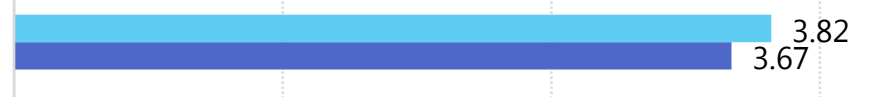

1. Time management

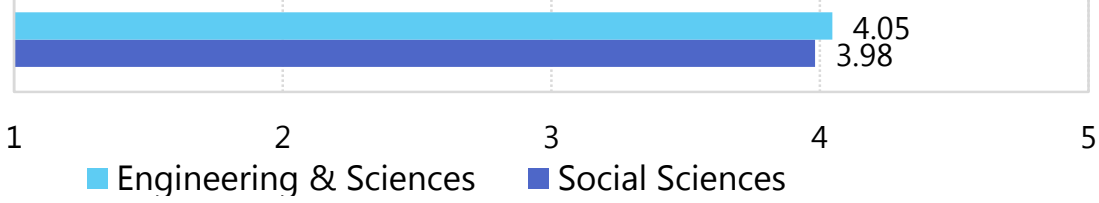

There was a significant relationship between the major and the importance graduates assigned to some interpersonal competences for good performance in their current job. Communication skills and negotiation skills were more important for SS graduates (4.32 and 4.05, respectively) than for ES graduates (4.26 and 3.96, respectively). However, teamwork was more important for ES graduates (4.10) than for SS graduates (3.93). There were no significant differences in the other interpersonal competences considered (see Figure 5.23).

Figure 5.23. Rate the importance of each of the following factors and competences for good performance in your current job, by major: interpersonal competences

7. Customer relationship skills

6. Inter-cultural skills

5. Negotiation skills

4. Presentation skills

3. Communication skills

2. Team work

1. Conflict solving

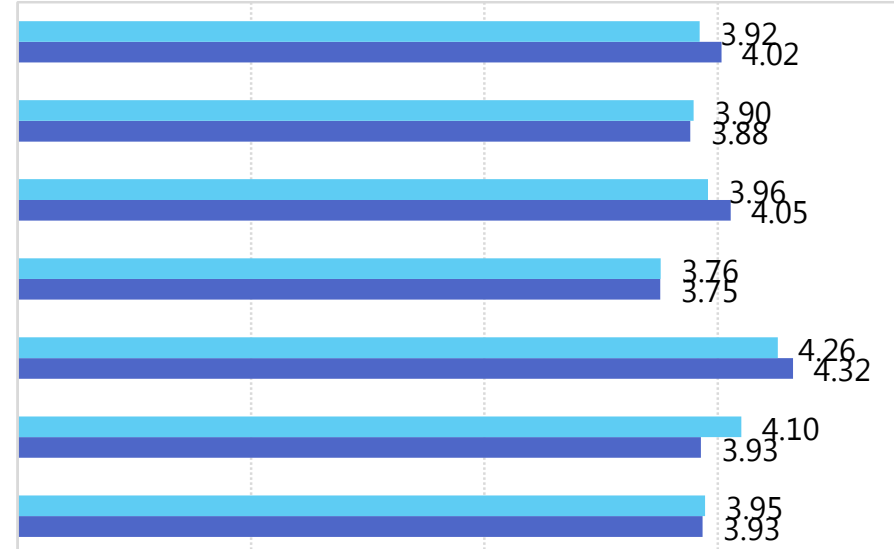

1 2 3 4 5 Engineering \& Sciences $\square$ Social Sciences 
Regarding instrumental competencies, SS graduates assigned more importance to foreign languages (3.95) than ES graduates (3.74). However, office skills were more important for SE graduates (3.95) than for SS graduates (3.81). There were no differences in the importance assigned to computer skills (see Figure 5.24 ).

Figure 5.24. Rate the importance of each of the following factors and competences for good performance in your current job, by major: instrumental competences

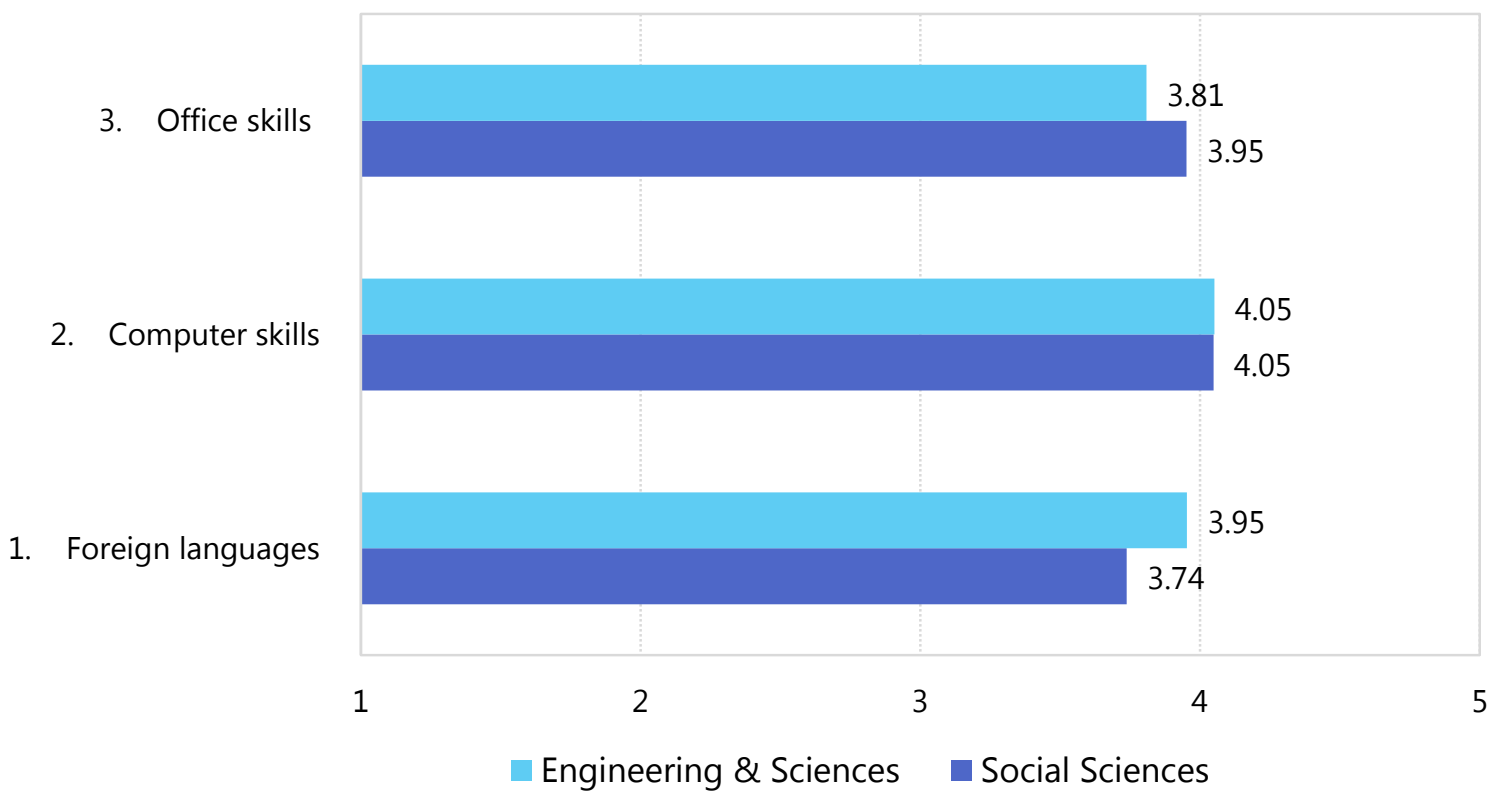

Finally, in the case of attitudinal competences, there were significant differences between the two major groups on two of the six competences considered. ES graduates assigned more importance to commitment (3.96) and entrepreneurship (3.68) than SS graduates (3.86 and 3.43, respectively) (see Figure 5.25).

Figure 5.25. Rate the importance of each of the following factors and competences for good performance in your current job, by major: attitudinal competences

6. Take responsibility

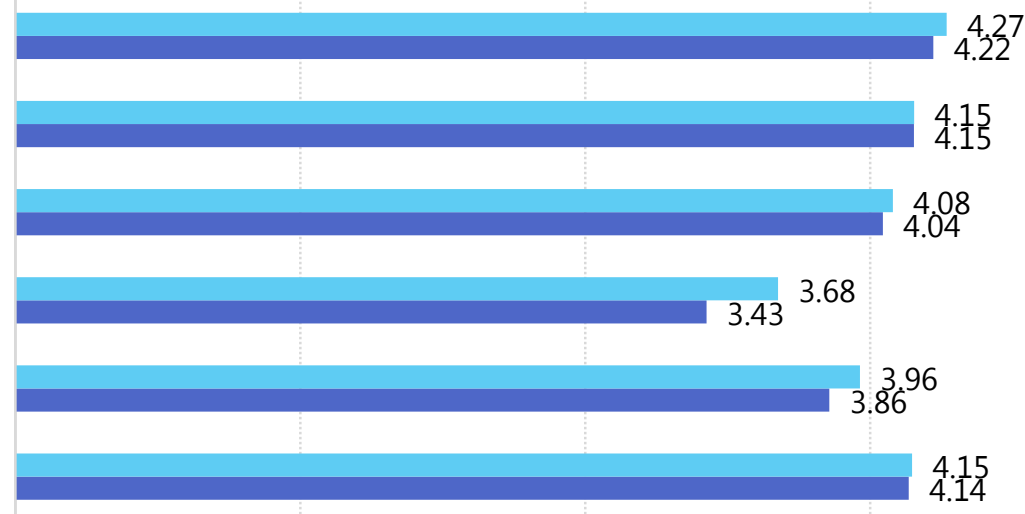

5. Punctuality

4. Rule compliance

3. Entrepreneurship

2. Commitment

1. Adaptability 


\subsection{Unemployed graduates}

\subsubsection{Time}

\section{looking for a job}

When focusing on unemployed graduates and the time they had been looking for a job, the results obtained showed very similar results for the two groups of majors. The average time spent looking for a job was 6.39 months for SS graduates and 6.53 for SE graduates (Figure 5.26).

Figure 5.26. Average number of months you have been looking for a job, by major

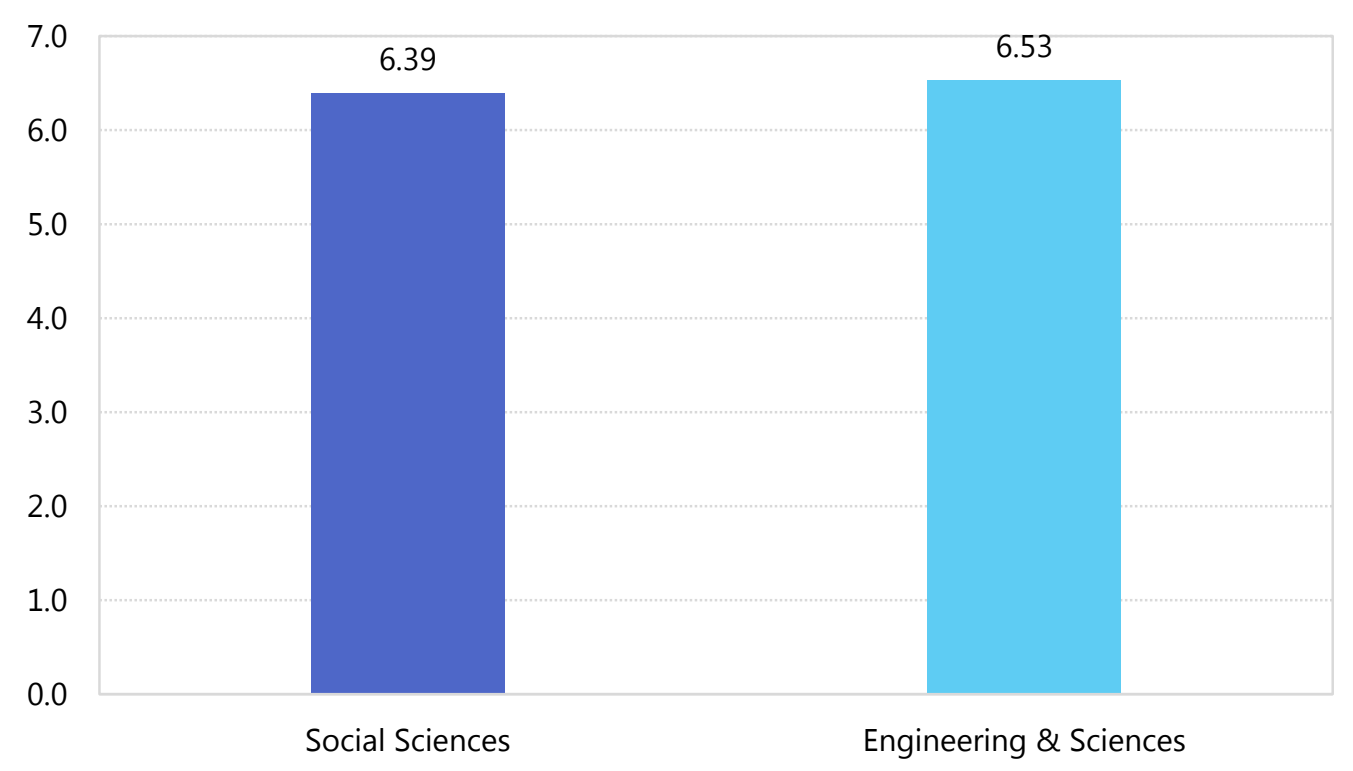

\subsubsection{Job search strategies used}

Regarding the strategies used by unemployed graduates to search for a job, the results obtained are very similar for SE and SS graduates. The most frequently used strategies are (Figure 5.27): Internet portals, company websites, and press ads (SS: 76.8\%; SE: $80 \%$ ); social and/or professional Internet networks (SS: 65.3\%; SE: 65.5\%); and personal contacts (relatives, friends, ...) (SS: 43.2\%; SE: 49.1\%). 
Figure 5.27. What are the 3 job search strategies you have used more frequently, by major university

6. Other strategies

$0.0 \%$

$1.1 \%$

5. Use of the employment services of my

4. Internet portals, company websites, and press ads.

3. contacting employment agencies

2. social and/or professional Internet networks

1. personal contacts (relatives, friends, ...)
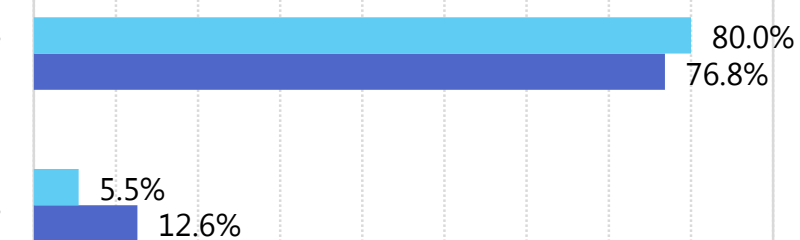

$5.5 \%$

$12.6 \%$

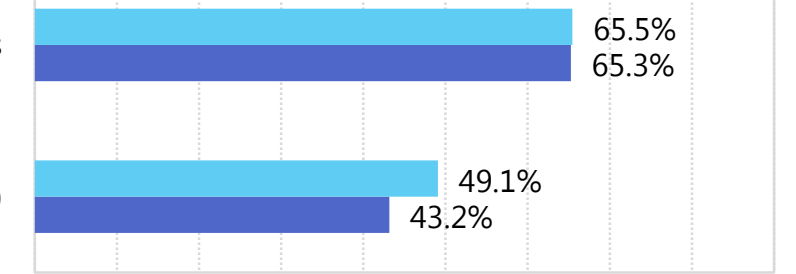

$\begin{array}{llllllllllll}0 \% & 10 \% & 20 \% & 30 \% & 40 \% & 50 \% & 60 \% & 70 \% & 80 \% & 90 \%\end{array}$

Engineering \& Sciences $\quad$ Social Sciences

\subsubsection{Difficulties in finding $a$ job}

When unemployed graduates were asked about the degree of responsibility that different factors had in their difficulties in finding a job, the results obtained showed some differences and similarities in the most important factors, depending on the graduate's major. For SS unemployed graduates, the most important factors were (Figure 5.28): lack of, or insufficient, professional practice and experience (3.67); lack of language skills (3.38); and lack of knowledge about the labour market (3.13). For ES unemployed graduates, the most important factors were: lack of, or insufficient, professional practice and experience (3.58); the jobs offered did not have an adequate wage (3.17); and saturation of the labour market (3.13). Thus, the most important factor was the same in the two groups, but the second and third most important factors were different. 
Figure 5.28. Rate the degree of responsibility of each of the following factors in your difficulties in finding a job, by major

12. My demographic characteristics (gender, age, etc.) 11. Saturation of the labor market 10. Lack of job search skills

9. There are personal circumstances that prevent you...

8. The jobs you have been offered are not related to...

7. The jobs you have been offered do not have an...

6. You do not like the jobs you have been offered

5. Lack of computer skills

4. Lack of language skills

3. Lack of knowledge about the labor market

2. Lack of, or insufficient, professional practice and...

1. Deficiencies in the university education I received

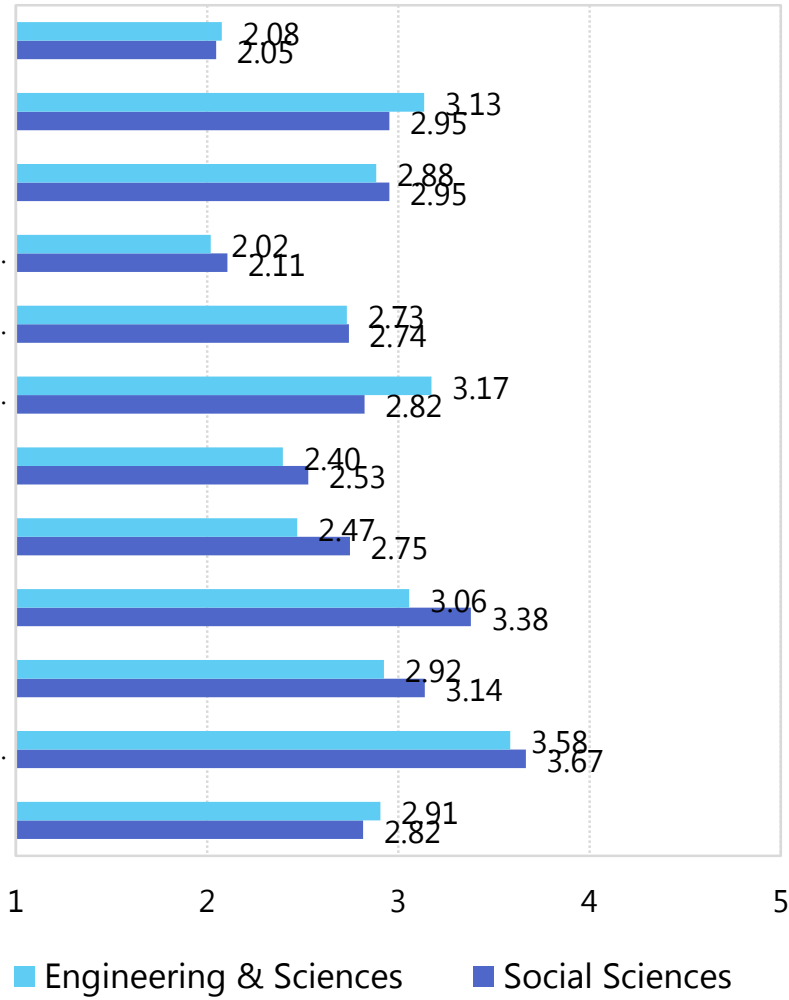

\subsubsection{University career centre: demand and services}

Regarding the unemployed graduates' demands for support from the university career centres in their search for a job, there were no differences by major. Most SS and SE graduates (72.6\% and $71.2 \%$, respectively) expected this support (Figure 5.29 ).

Figure 5.29. Do you want the career centre of your university to support you in searching for a job? by major

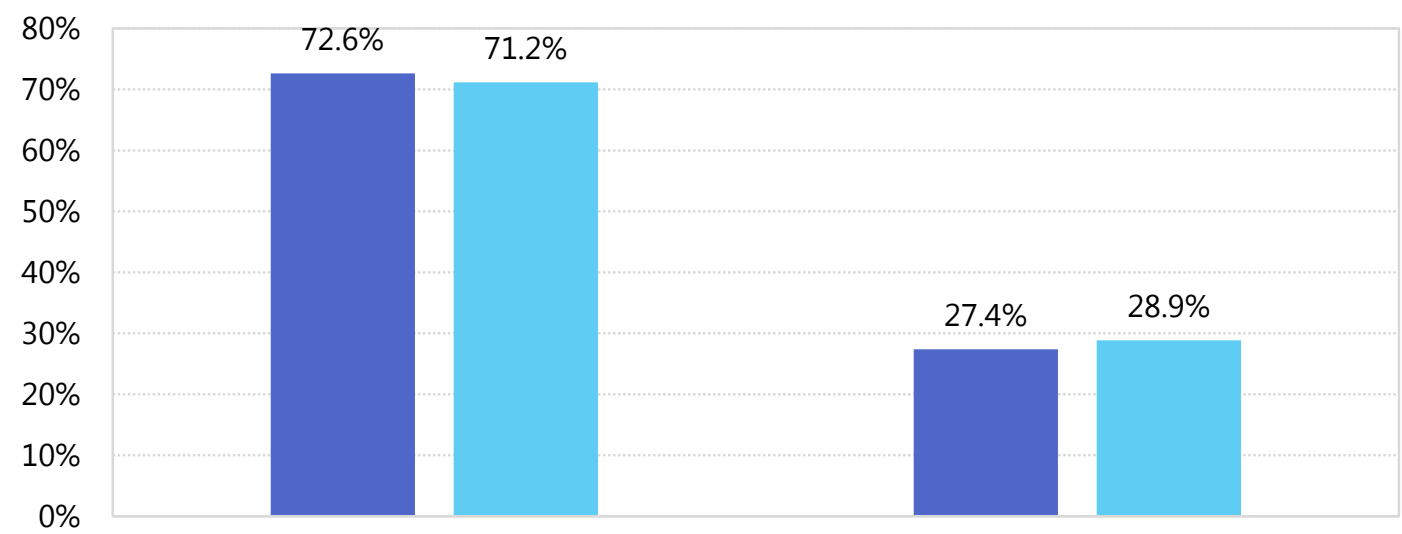

1. Yes

2. No

Social Sciences Engineering \& Sciences 
For the unemployed graduates who expected the university career centre's support, there were differences in the type of activities provided by the career centres based on graduates' major. SS graduates wanted more information on training opportunities, whereas SE graduates expected the career centre to provide more job opportunities for each major and more job-hunting skills (Figure 5.30).

Figure 5.30. If your answer is yes, what do you want the Career Centre to offer? by major (multiple responses)

6. Hosting job fairs and other events with employers

5. Job-hunting skills

4. Soft skill training services (communication, teamworking,,..

3. Job searching consulting services

2. Information on training opportunities

1. General information on labor market and job opportunities

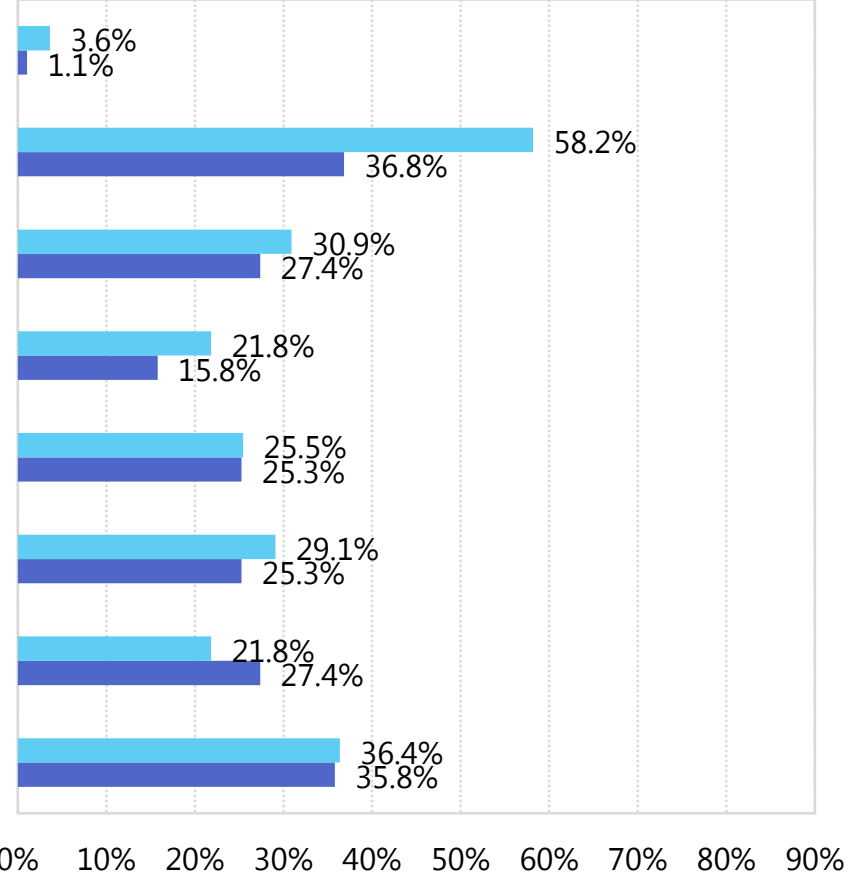

Engineering \& Sciences

- Social Sciences

\subsection{Economic inactive graduates}

\subsubsection{Reason for not looking for a job}

Focusing on economically inactive graduates (that is, those who are not employed or searching for a job), there were no significant associations between the major and the reason they were not looking for a job. However, SS graduates more frequently reported having lost any hope in finding a job, whereas SE graduates more frequently reported having to take care of their family and/or housework, and "there are no jobs for people with my degree". 
Figure 5.31. Why are you not looking for a job right now? by major (choose the most important reason)

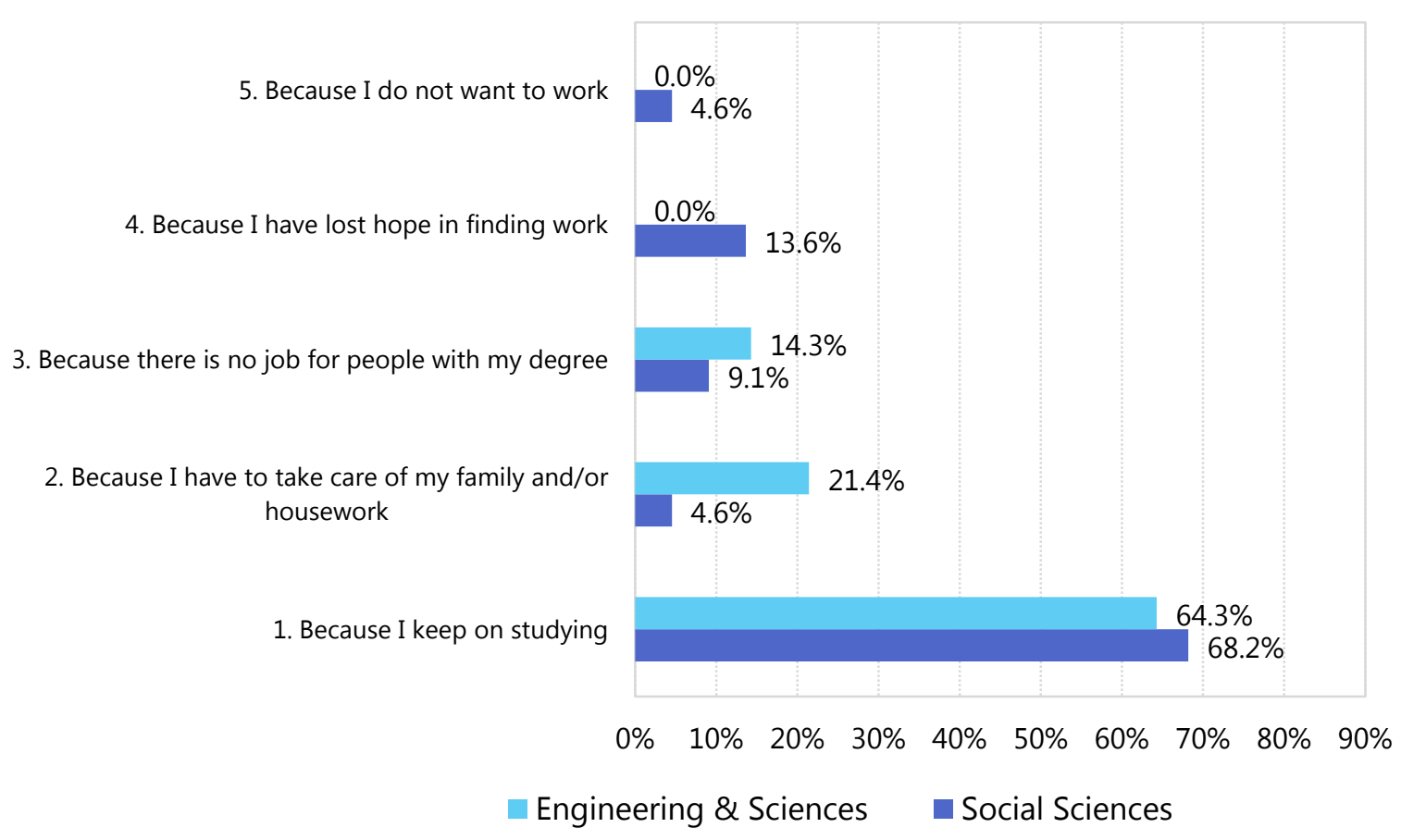

\subsection{Summary and conclusions}

Graduates' major (ES vs SS) was not related to their current employment situation or the number of jobs they had after graduation. However, the percentage of ES graduates who found a job "before graduation" (51.9\%) was higher than the percentage of SS graduates who did so (42\%). Moreover, the average number of months spent to find the first paid job was slightly higher for SS graduates (3.28 months) than for ES graduates (2.79).

There were differences in the strategies used to find a job; ES graduates tended to use personal contacts more, whereas SS graduates tended to use social and/or professional Internet networks more.

With regard to graduates' job characteristics, ES graduates had a higher horizontal match than SS graduates. However, there were no differences in the vertical match. SS graduates tended to work closer to their families than ES graduates. The latter tended to occupy managerial positions more frequently than the former, and they had higher monthly incomes.

Regarding the organization where graduates performed their job, SS graduates tended to work more in private and public companies than ES graduates. However, ES graduates tended to work in larger companies more than SS graduates.

As to the employment contract, ES graduates tended to have formal contracts slightly more frequently than SS graduates. Moreover, the percentage of graduates with a long-term job was 
higher for ES graduates (73\%) than for SS graduates. However, there were no relevant differences in the type of time arrangement (part-time vs. full-time).

With regard to work satisfaction, ES graduates tended to show higher levels of satisfaction than SS graduates.

In the case of the importance of a number of different competences for attaining good performance in their jobs, SS graduates tended to assign higher importance to management competences than ES graduates, whereas the latter attributed more importance to attitudinal competences than SS graduates.

Focusing on unemployed graduates, the results obtained by the two major groups were quite similar. 



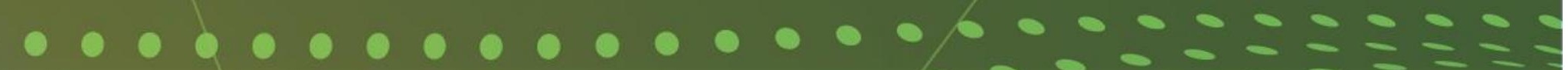

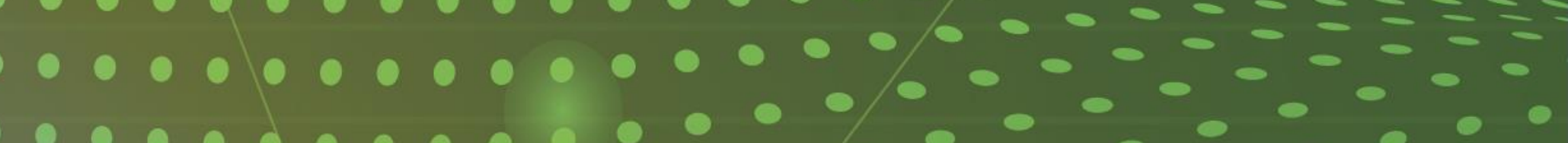

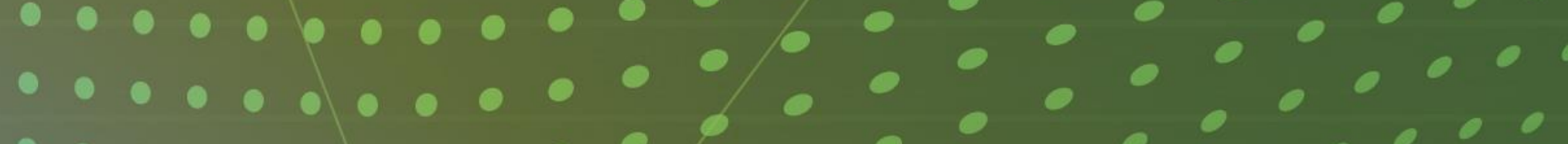

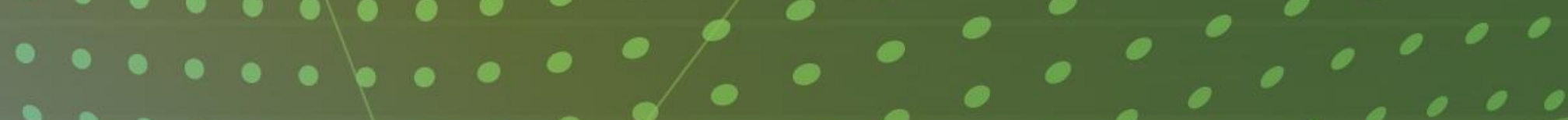

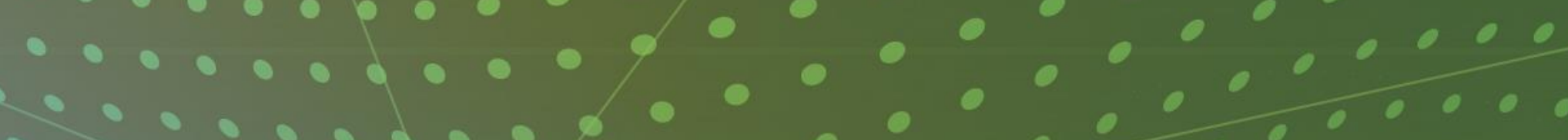

CHAPTER 6: GRADUATE-JOB MATCHING TYPES 


\section{CHAPTER 6: GRADUATE-JOB MATCHING TYPES}

\subsection{Introduction}

As presented in previous chapters, an important issue when studying the graduates' labourmarket entry is to analyse both the vertical and the horizontal match between the qualification of the graduates and the jobs for which they are hired. Vertical match was assessed on the questionnaire with two questions. One asked about the level of education required for your current job?: 1. Below high school; 2. High school; 3. Vocational education; 4. College and University degree; 5 Master degree and higher. Taking into account that the survey respondents are University graduates, the operationalization of vertical match is scored as a match when the respondents chose options 4 or 5 , whereas answers 1 to 3 were considered a mismatch.

Horizontal match refers to the congruence between the content of the degree studied and the contents of the current job. For instance, if a graduate has studied medicine and he or she works as government civil servant on topics not related to medicine, the horizontal match will be none. The question posed to the graduates participating in the survey to operationalize the horizontal match was as follows: To what extent is the content of your current job related to the content of your degree? The answer scale was: 1 . None; 2. Little; 3. Quite; and 4. A lot. Thus, we considered answers 1 and 2 to be a mismatch and answers 3 and 4 to be a match.

We have combined the two types of (mis)matches in a variable that we have labelled 'doublematch'. It differentiates four groups: G1 Horizontal Low (HL) Vertical Low (VL) matching; G2: Horizontal High (HH) Vertical Low (VL); G3: Horizontal Low (HL) Vertical High (VH); and G4: Horizontal High $(\mathrm{HH})$ Vertical High $(\mathrm{VH})$. This categorical variable provides clear information about the quality of the jobs held by graduates in terms of their fit to their qualifications. Then, it indicates whether they are overqualified or not for the job, and if they have the opportunity to work in a sector or type of job clearly related to the discipline and profession of their choice.

The general assumption in this chapter is that the graduates' jobs that show a double match will present better quality on the indicators studied than the jobs that do not show either of the two matches considered. 


\subsection{Distribution of graduates by groups according to the double match}

Figure 6.1 presents the general distribution of the graduates in the four groups resulting from the double match. More than half of the sample holds a job with high horizontal and high vertical matches. Interestingly, an important percentage of the rest of the students hold jobs with a high vertical fit and a low horizontal fit. This indicates that a significant number of students work in university-level jobs that are hardly related to the major they studied. A more detailed analysis of the majors in which this happens would be helpful, so that the academic authorities can consider possible changes in the contents of the education, given the distribution of graduates in these matching groups. Finally, it is interesting to note that the pattern 'High Horizontal and low vertical' (G2) is only represented by $1 \%$ of the sample, and the low horizontal-low vertical match group (G1) only contains $6 \%$ of the sample.

Figure 6.1. Double match: general results

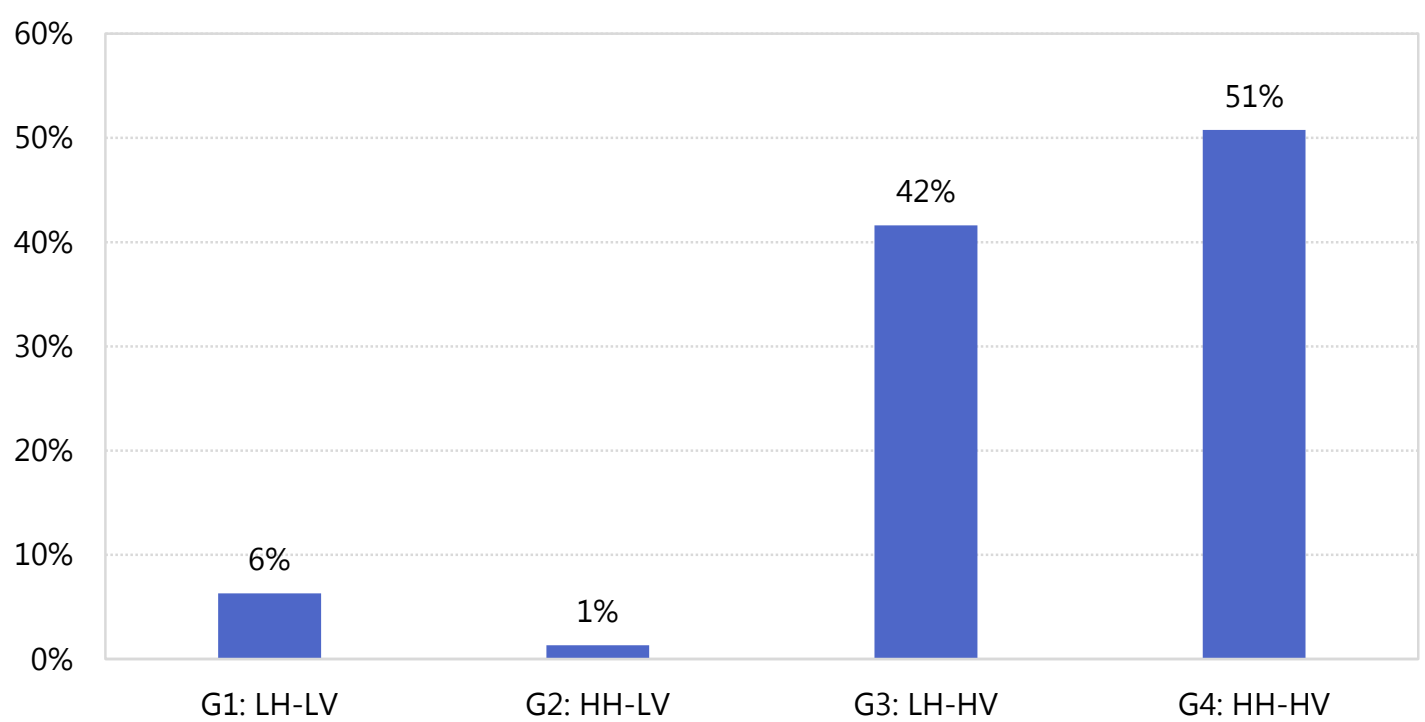

Given these results, in the following, we will often only pay attention to the results of groups G3 and G4 because they include $93 \%$ of the total employed sample. When the data for group G1 or G2 show something special, we will also refer to these groups. 


\subsection{Matching types and gender}

The differential analysis by gender shows that males hold double-matched jobs $16 \%$ more than females (G4). Conversely, in the group with High Vertical fit but low horizontal fit, females exceed males by $10 \%$. Finally, among the graduates working in jobs with clear horizontal and vertical mismatches (G1), females exceed males by $4 \%$. In sum, males more frequently held higher quality jobs in terms of matching, whereas females are more frequently employed in jobs with vertical matches (jobs that require University qualifications), but in different types of professions from the ones related to their major. In $\mathrm{G} 2$, the males largely exceed the females in percentage, but this group only includes $1 \%$ of the total sample. In general, the jobs held by males present higher quality on this indicator of double matching than those held by females. The women occupy more generalist jobs that are less focused on the contents of their studies.

Figure 6.2. Matching types and gender

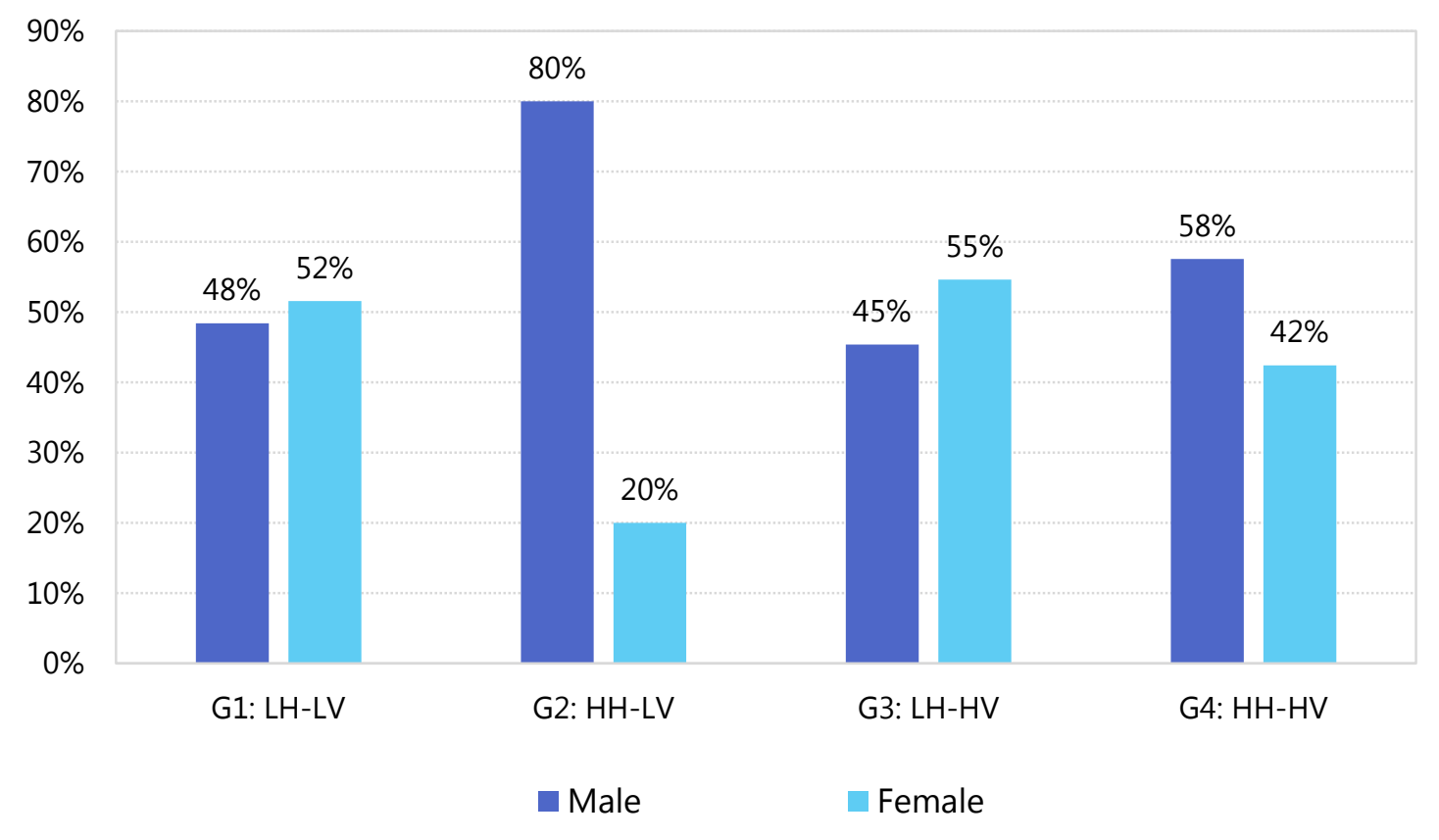

\subsection{Matching types and major}

The data on the double match of the jobs, split by the study major, show that in G4 (High Horizontal, High vertical), the distribution is quite similar (51\% Engineering and Sciences and 49\% Social Sciences). However, Social Science graduates exceeded Engineering and Sciences graduates by $22 \%$ in holding Jobs with a high vertical match and low horizontal match. In fact, this may indicate that Social Science graduates may adapt better to University level jobs that do not require specific training in a specific profession. Finally, it is interesting to note that the jobs with low horizontal-low vertical match are held mostly by graduates in Social Sciences (twothirds), and only one-third are held by engineers and scientists. We can conclude that the preparation in Social Sciences helps the graduates with these degrees to adapt better to jobs 
requiring university preparation, even when it is not specific to the degree studied or when they do not find or prefer the jobs offered within their specialty.

Figure 6.3. Matching types and major

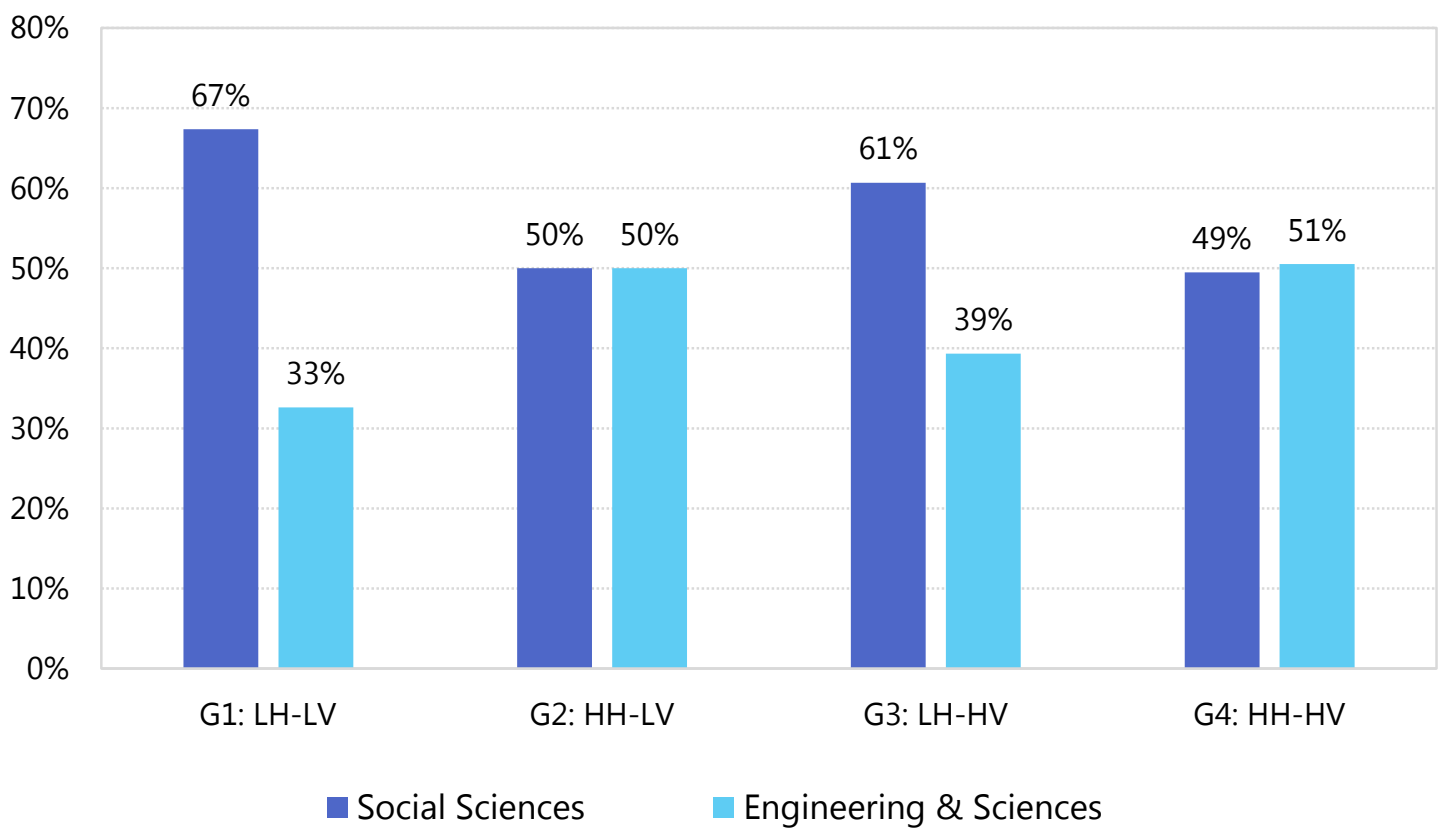

\subsection{Matching types and job search strategies.}

It is interesting to find out whether graduates in different groups based on the vertical and horizontal match/mismatch differ in the job search strategies they perform. In order to shed light on this issue, we asked the graduates in the sample the following question: CJ1. How did you find your current job? (Choose the 3 most important strategies). The potential responses were:

1. Through personal contacts (relatives, friends, ...)

2. Through the internship I had in companies or institutions

3. Through social and/or professional Internet networks

4. The employer contacted me

5. By creating my own company or business (self-employment)

6. I contacted the employer on my own initiative

7. By contacting employment agencies

8. Through Internet portals, company websites, and press advertisements.

9. Through the employment services of my university

10. Other means 
It is important to note that every candidate has the possibility of choosing up to three options. Then the percentage for each strategy is computed based on the total number of choices made by the people surveyed.

Figure 6.4a. Matching type (G1) and job search strategies

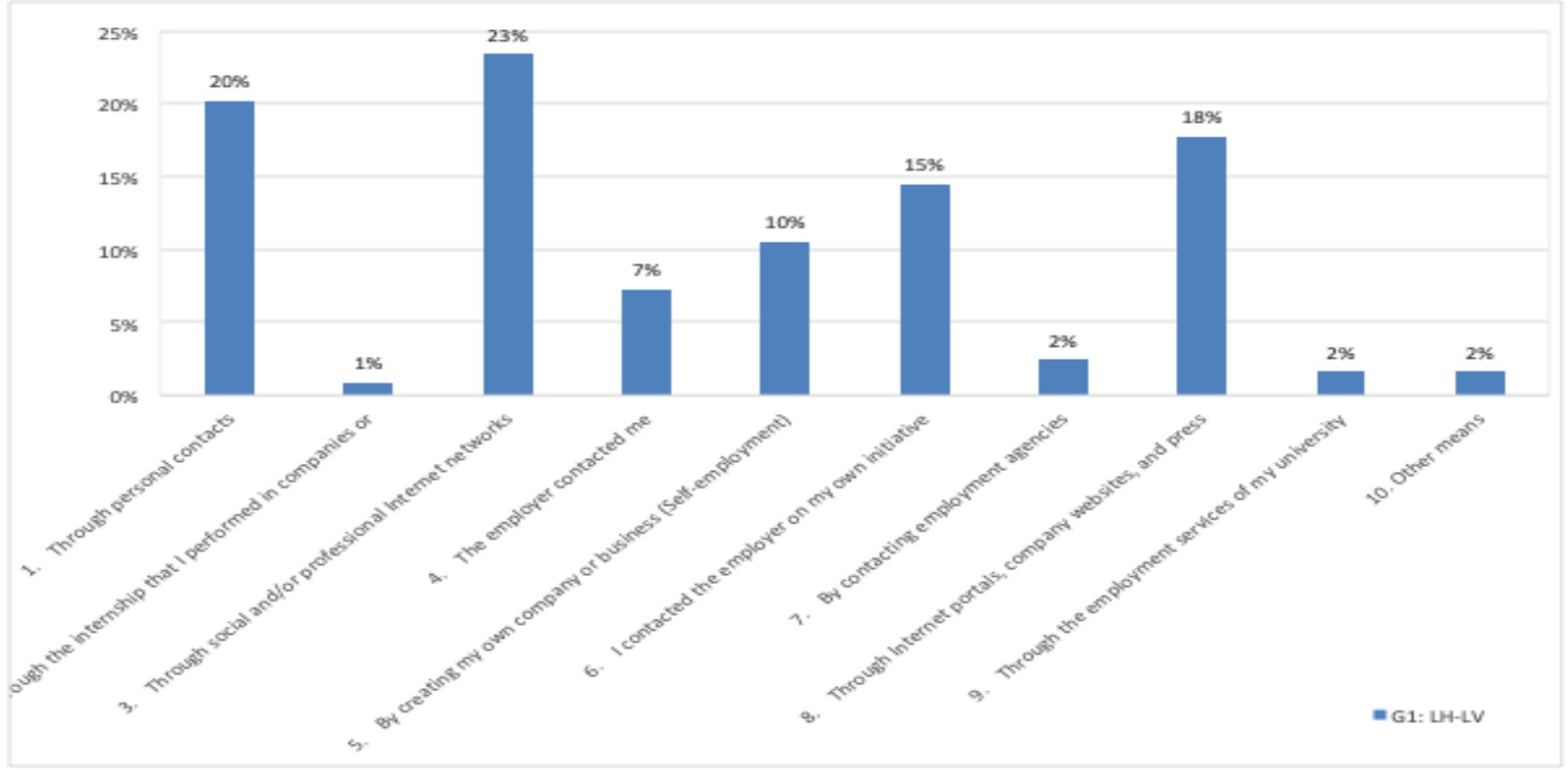

Figure 6.4b. Matching type (G2) and job search strategies

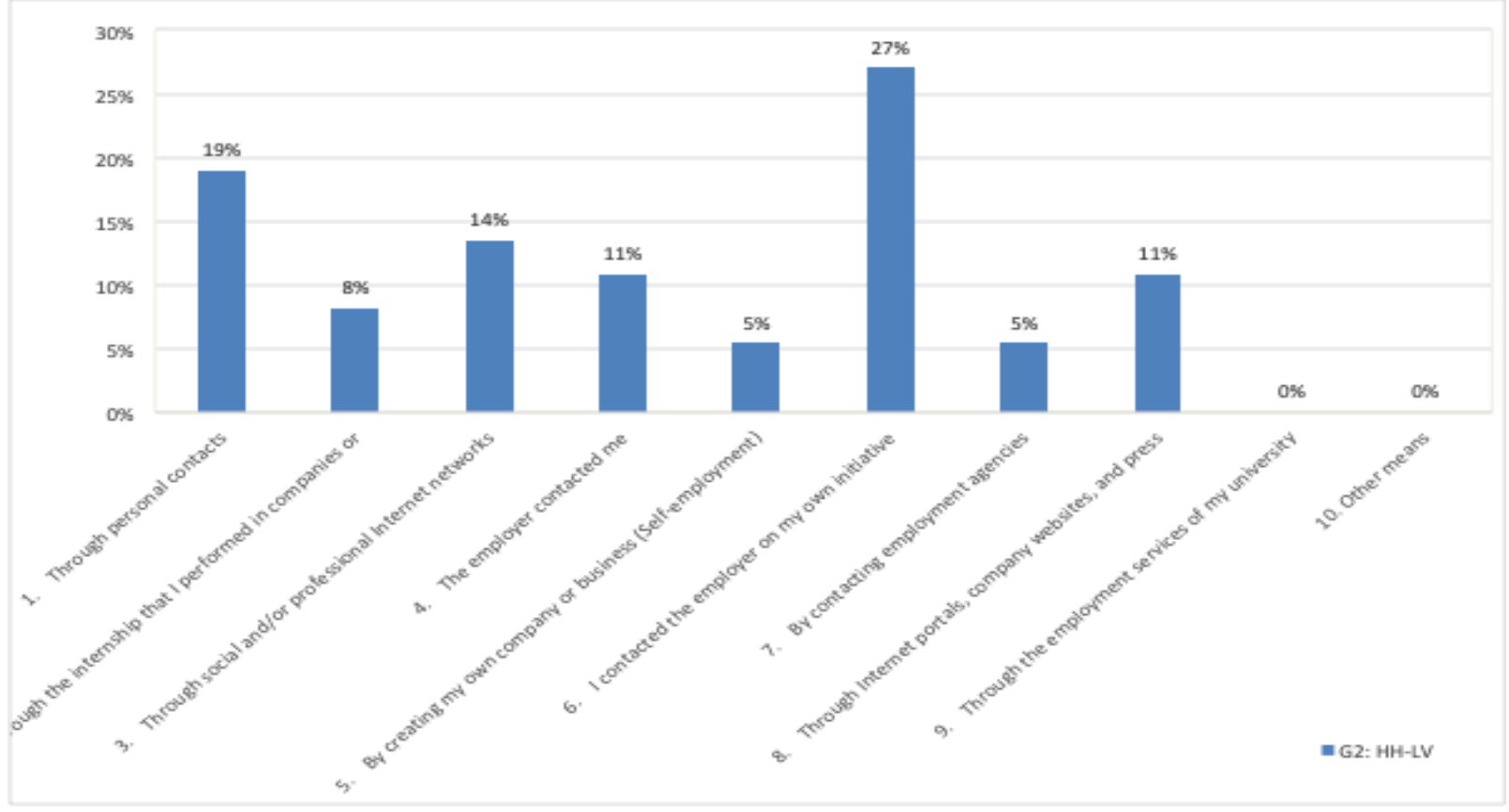


Figure 6.4c. Matching type (G3) and job search strategies

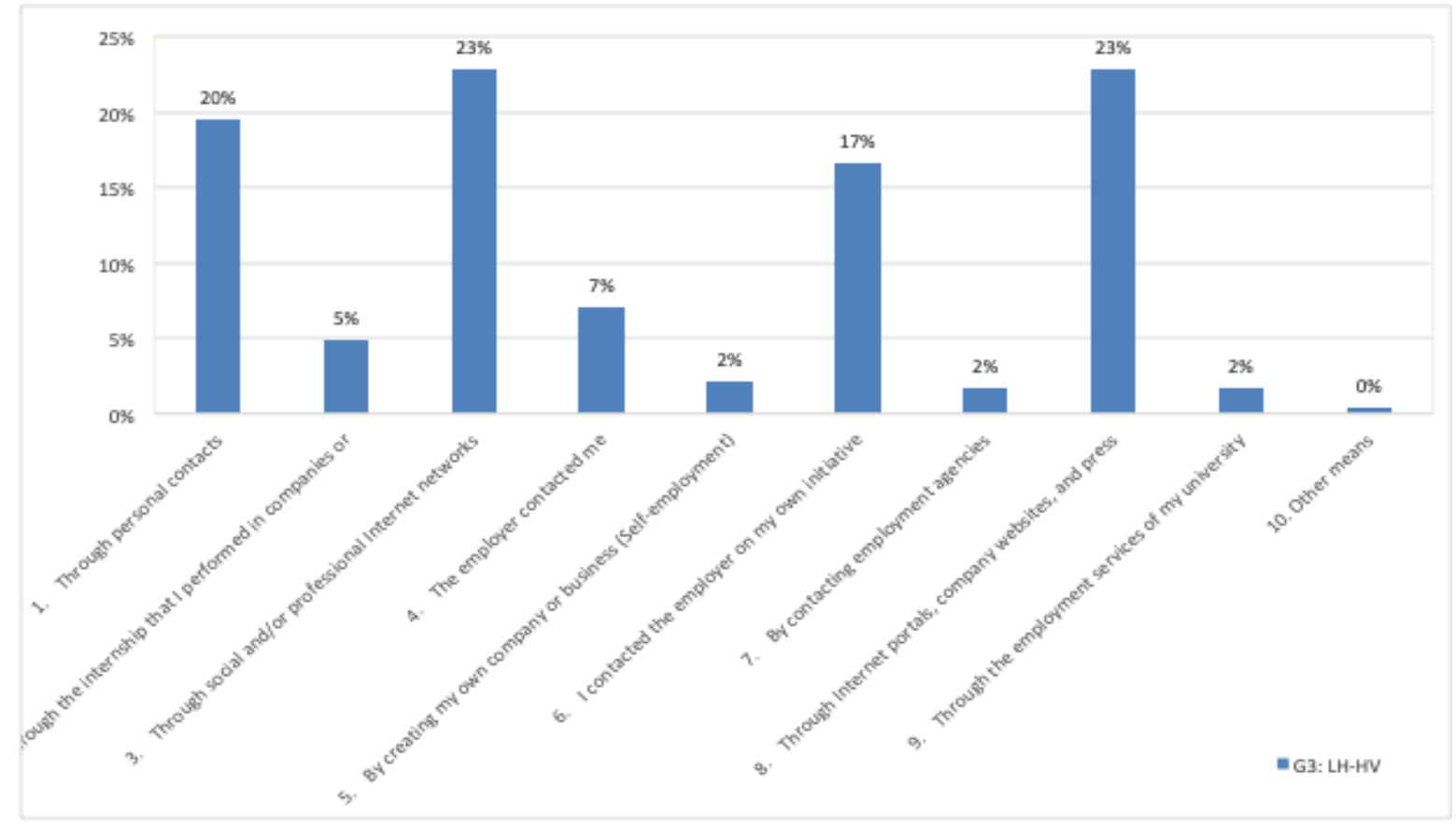

Figure 6.4d. Matching type (G4) and job search strategies

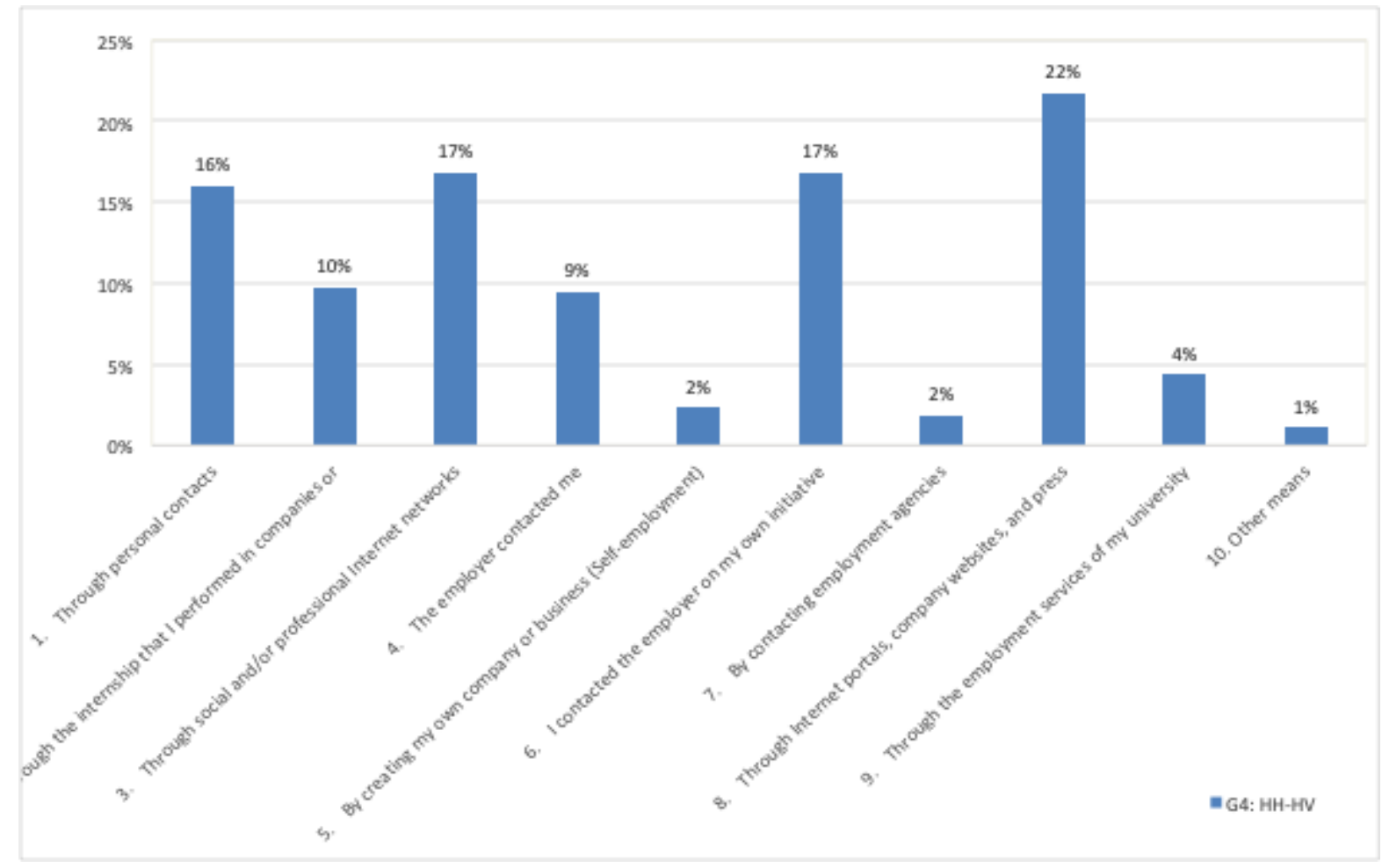


The results obtained for the different groups show a similar trend. In fact, in all cases, the four most frequently chosen job search methods are: through personal contacts (relatives, friends, ...); through social and/or professional Internet networks; by contacting the employer on one's own initiative; and through Internet portals, company websites, and press advertisements. Of course, the Internet and other electronic means are prevalent among the young graduates, but personal contacts also play an important role. However, the employment services and career services are much less frequently used strategies. Even though the most frequently used strategies are the same for the four groups considered, we still find a clear difference in the groups with higher quality employment (they hold a job that requires University studies, whether it fits their major or not). These two groups tend to more frequently use Internet portals, company websites, and press, in addition to contacting employers on their own. In fact, in G4 (double matched jobs), $39 \%$ of the choices referred to these two strategies, and in G3 this figure reached $40 \%$. For G1, the two categories add up to $33 \%$. On the other hand, this group uses Personal contacts and Internet professional networks (43\%) more often than G4 (33\%). The G4 group also presents the highest percentage of the strategy "Through the internship I had in companies or institutions" (10\%, whereas in $\mathrm{G} 1$, it was only $1 \%)$.

\subsection{Matching types and employed vs self-employed}

One important piece of information the graduates can provide is whether they are employed or self-employed. The latter type of work is often an indicator of entrepreneurship. In order to obtain this information, we have included the following question in the survey: SA2. What is your current employment situation?

1. I have a job now and work for an employer.

2. I am self-employed now

3. I am unemployed and looking for a job

4. I am unemployed but not looking for a job

In this chapter, we focus on the match between qualifications and job demands of those who are employed; thus, we have only considered the two first categories. The results obtained when cross tabulating the type of employment and the matching groups are clear. The percentage of self-employed graduates decreases in the groups that work in a job that requires a university degree (the G3 and G4), whereas it is higher in those whose jobs do not require a degree, especially in G1 (20\% of graduates in this group are self-employed. It is interesting to note that often when graduates opt for self-employment, they develop a work activity that is rather low in terms of the qualifications required. 
Figure 6.5. Matching types and employed vs. self-employed

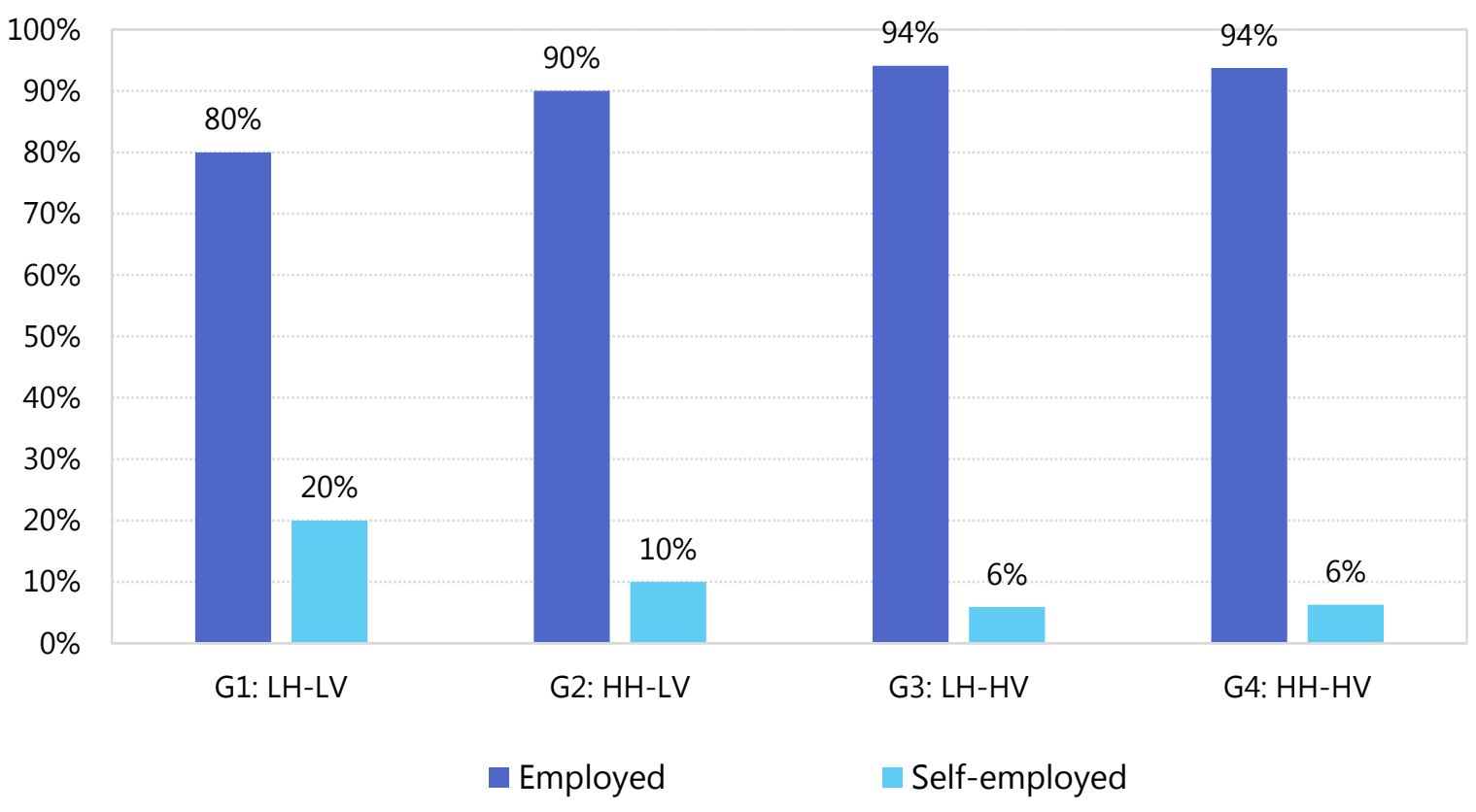

\subsection{Matching types and sectors.}

In the present section, we focus on the differences in the sectors of the jobs based on the double matched groups. As Figure 6.4.a shows, the jobs with a low horizontal match and a low vertical match are mostly in "other services" (21\%), "wholesale, retail, and repairs" (18\%), and "manufacturing" (11\%).

Figure 6.6.a. Matching G1: LH-LV and sectors

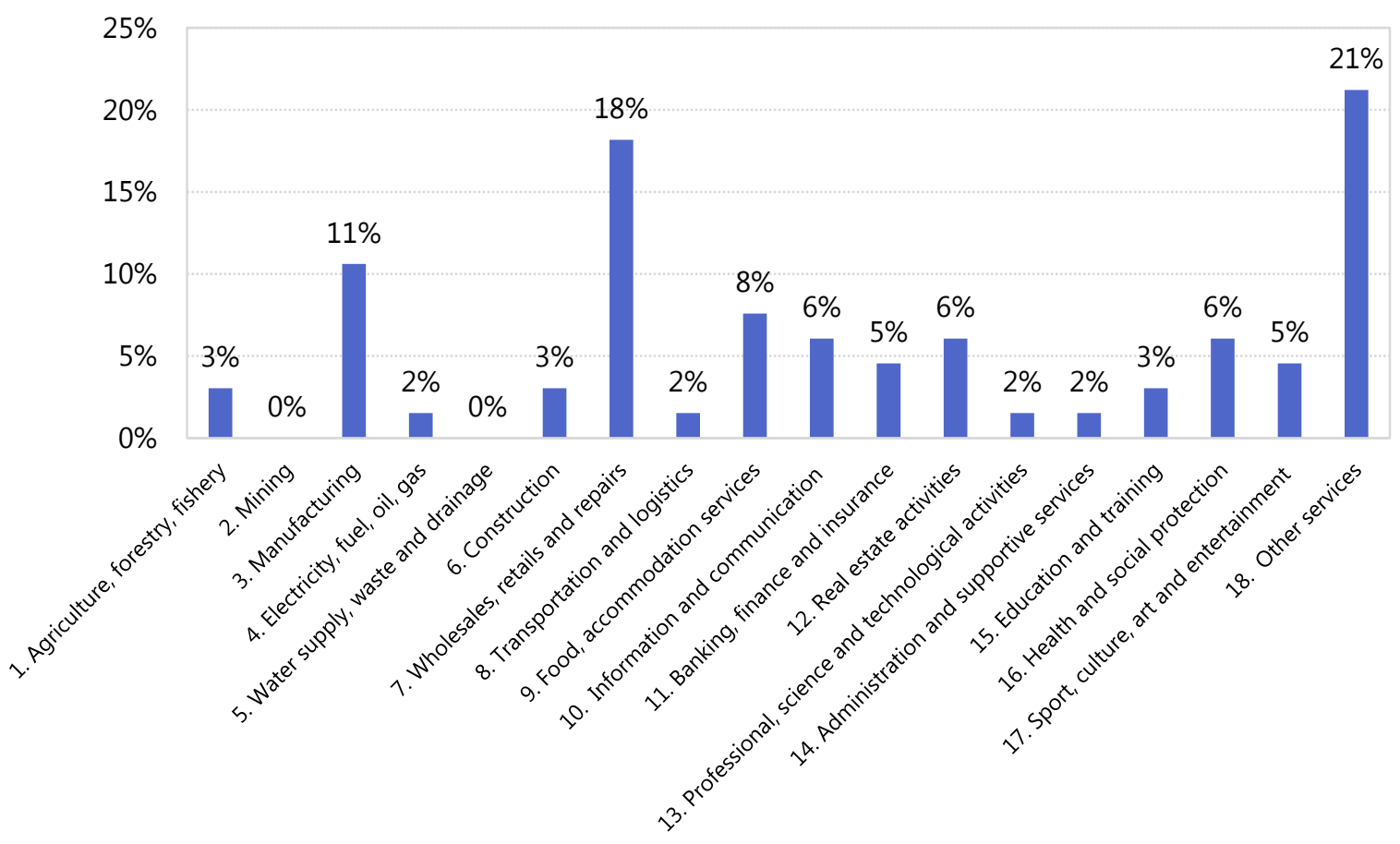


The jobs that present a high horizontal match but a low vertical match (only $1 \%$ of the total jobs considered) are mostly concentrated in "manufacturing" (39\%).

Figure 6.6.b. Matching G2: HH-LV and sectors

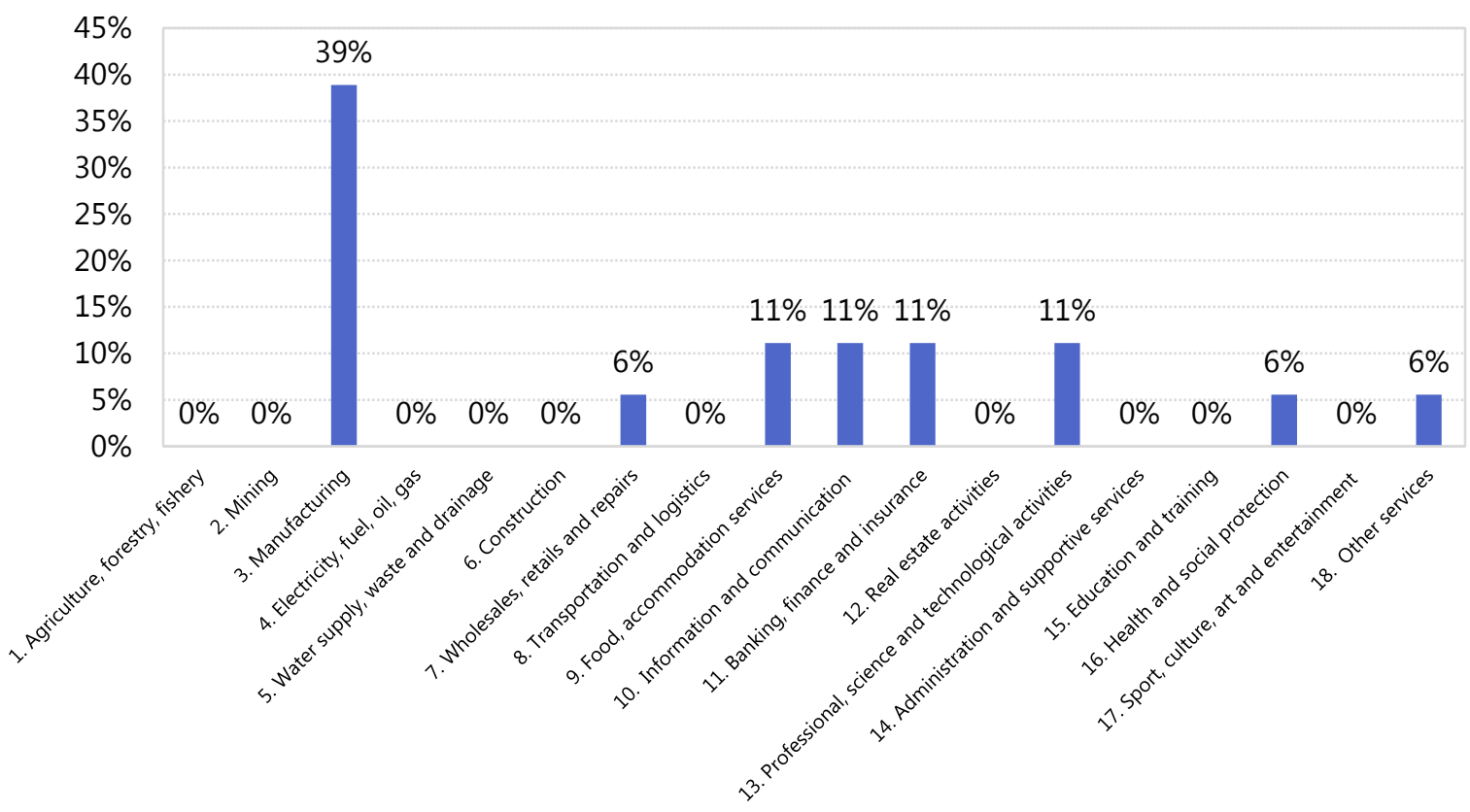

Interestingly, the jobs that present a low horizontal match and a high vertical match are mostly included in the following sectors: "Other Services" (21\%), "Manufacturing" (16\%), and "Banking, finances, and insurance" (10\%).

Figure 6.6.c. Matching G3: LH-HV and sectors

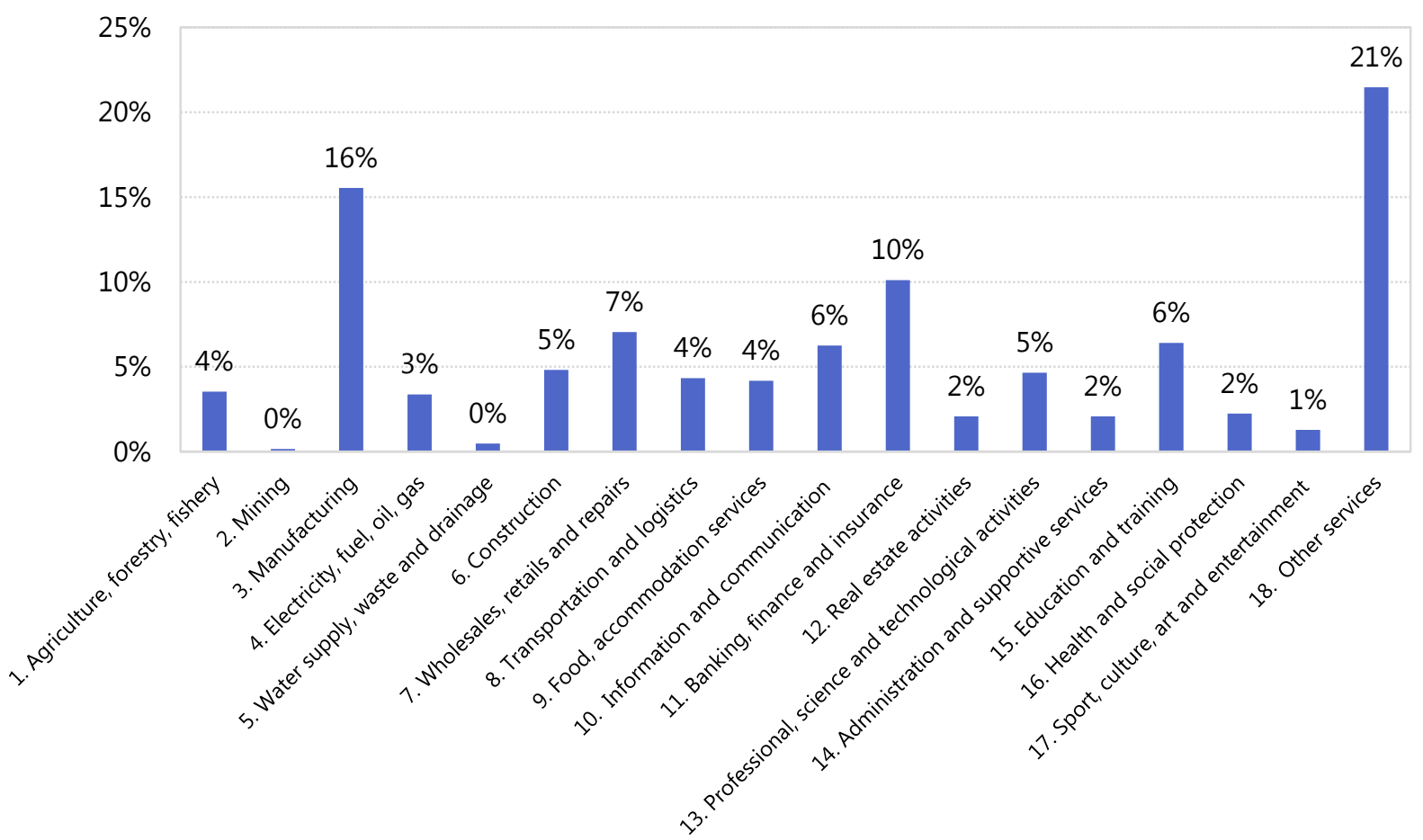


Finally, the jobs with both a high horizontal match and a high vertical match are also concentrated mostly in "Other Services" (19\%), "Manufacturing" (19\%), and "Banking, finances, and insurance" (12\%).

Figure 6.6.d. Matching G4: HH-HV and sectors

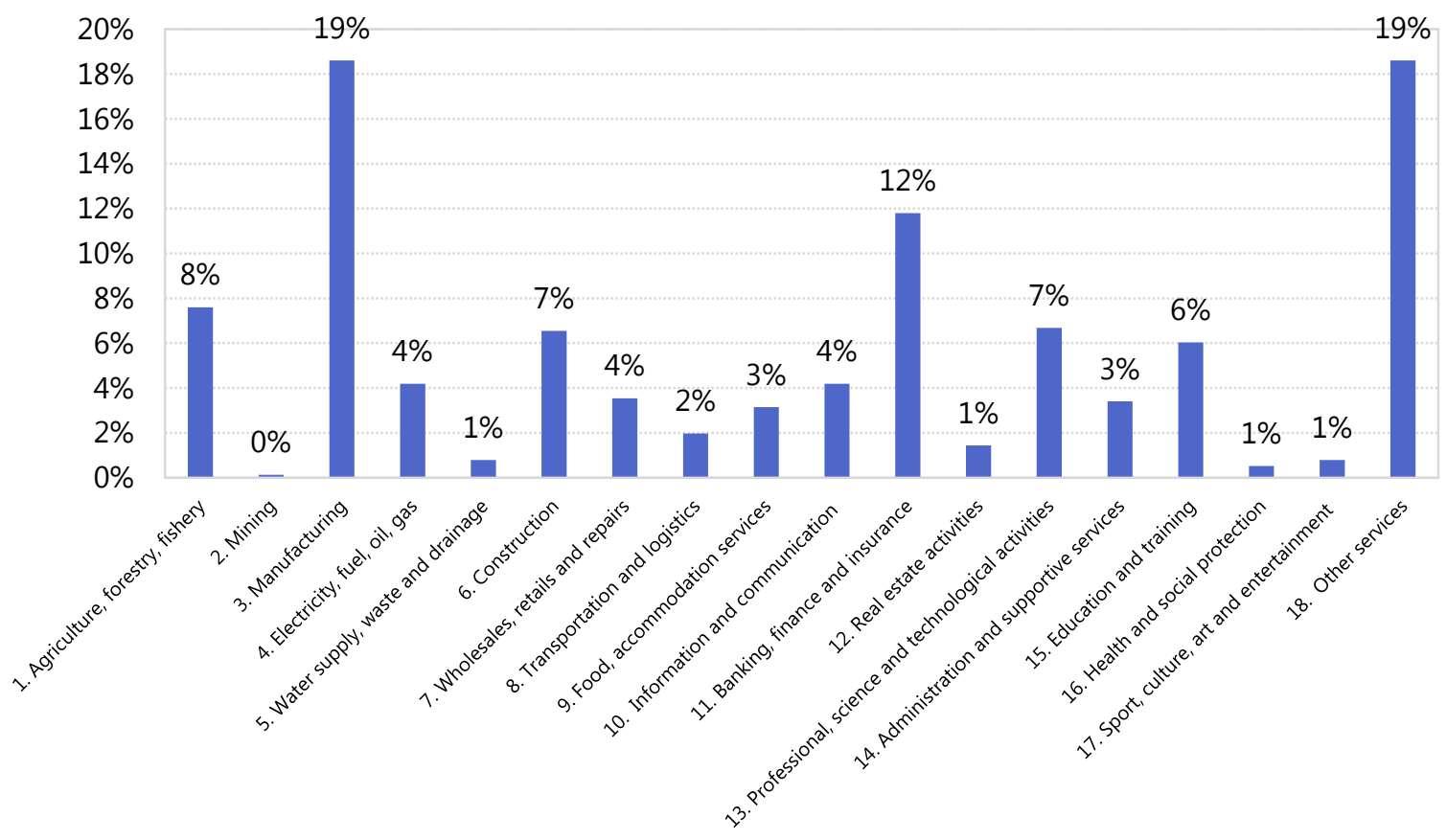

\subsection{Matching types and Job location}

One interesting issue to better understand the differences in the jobs held by the graduates in different matching groups is the location of these jobs compared to the location where their families live. In order to obtain this information, we asked the following question CJ9.Where is your current job located? (choose the most accurate option). The response options were:

1. In the town where your family lives

2. In the province where your family lives

3. In the region where your family lives

4. In another region of your country.

5. Abroad, in another country.

Interestingly enough, about six out of ten graduates in G2, G3, and G4 (the groups that show at least one type of match) work in a different region of the country from the one their family lives in. However, for $\mathrm{G} 1$ this percentage is about $20 \%$ lower. Thus, mobility across country regions is an important factor in getting higher quality employment. Another interesting feature of the data (Figure 6.6) is the fact that in each of the two larger groups, only $3 \%$ of the graduates are 
working in another country. This figure is rather low for graduates, although it is possible that those working abroad are underrepresented in the sample gathered.

Figure 6.7. Matching types and job location

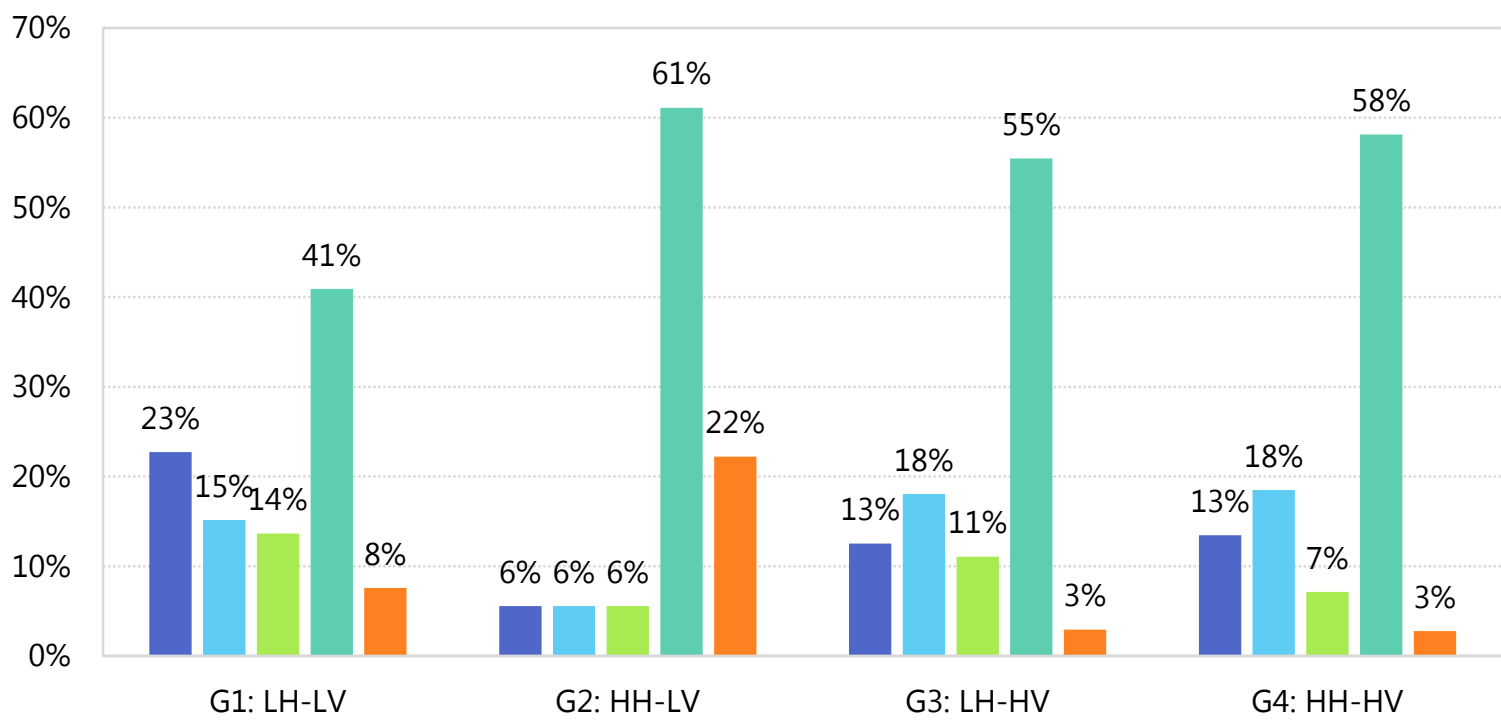

1. In the town where your family lives

2. In the province where your family lives

3. In the region where your family lives

4. In another region of your country.

5. Abroad, in another country.

\subsection{Matching types and organization type}

It is interesting to identify the types of jobs that different types of employers offer to the graduates. In order to do so, we asked the graduates the following question: CJ5. Is the organization you work for $a$...?

1. Public company/organization

2. Private company/organization

3. Public-private venture

4. FDI company (Foreign Direct Investment)

5. Foreign organization

6. NGO

7. Others (specify) 
Figure 6.8. Matching types and organization type

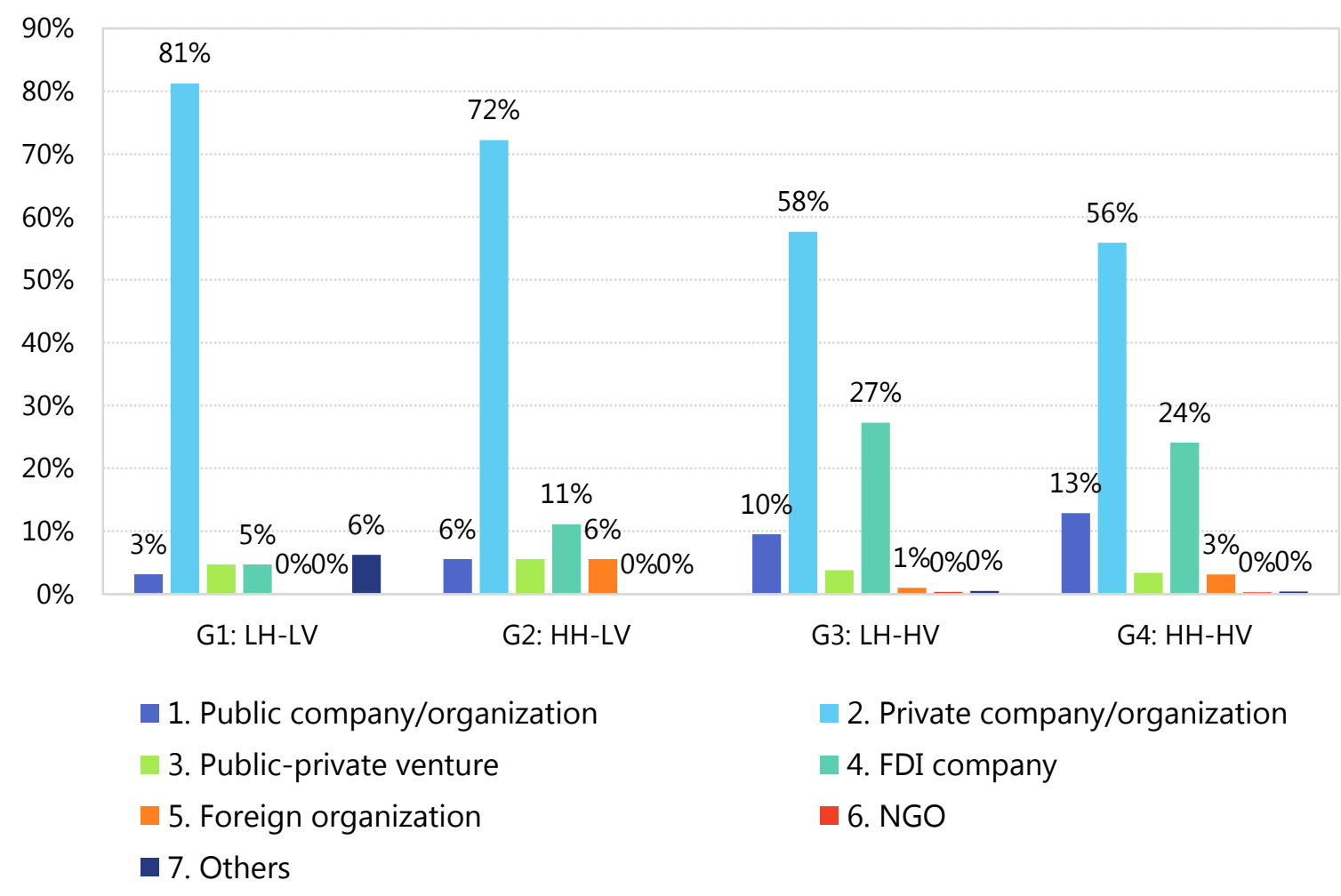

As Figure 6.8 shows, as the match increases, employment in the private companies/organizations decreases: in $\mathrm{G} 1,81 \%$ of the graduates are employed in these types of companies, whereas in $\mathrm{G} 4$, only $56 \%$ of the graduates work in these companies. By contrast, the graduates with jobs in group G3 and group G4 are hired significantly more in the FDI companies (G3: $27 \%$ and G4: $24 \%$ ). It is also interesting to note that the public companies/organizations more often hire people with high matches. In fact, only $3 \%$ of the G1: LH-LV are hired by these companies, whereas in the $\mathrm{G} 4: \mathrm{HH}-\mathrm{HV}$, the percentage of graduates hired in the public sector reaches $13 \%$.

\subsection{Matching types and organization size}

In order to identify the types of companies, in terms of their size, that offer jobs to the graduates and the quality of jobs offered in terms of the match between the graduate's qualifications and those required by the job, we asked the participants to answer the following question: CJ8. How many employees does your company have?

1. Up to 10 employees

2. Between 11 and 200

3. Between 201 and 300

4. $\quad$ More than 300 employees 
Figure 6.9. Matching types and organization size

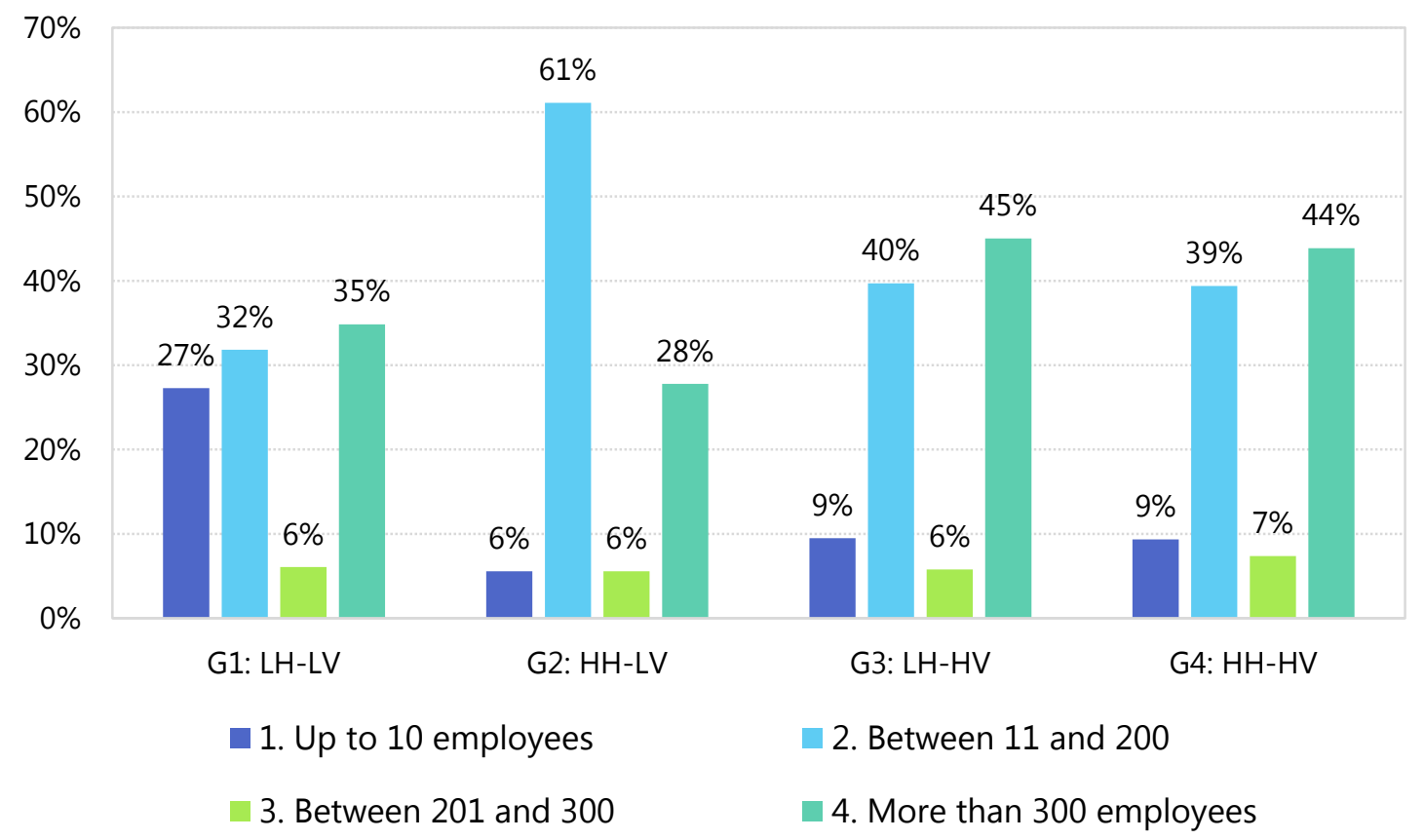

The quality of the jobs tends to be higher in larger companies than in smaller ones. In fact, in G4, 51\% of the graduates work in organizations with more than 200 employees. The graduates in G3 show the same percentage of graduates in these types of companies. However, this percentage declines to $34 \%$ for graduates in G2, and to $41 \%$ in G1. Conversely, the graduates with a low match in both the vertical and horizontal dimensions, as well as those with a low match in the horizontal dimension, tend to work more often in smaller companies.

\subsection{Matching types and type of contract.}

The formalization of the employment relations between the employer and the employee is an important feature and a source of guarantees for both parties involved. Thus, we included the following question in the survey: CJ11. Did you sign a formal written employment contract for your current job? The response alternatives were:
1. Yes
2. No

The results clearly show that when a double match occurs, more that 9 out of ten contracts are formal and written (G4: 91\%), whereas only $58 \%$ of the jobs were supported by a written formal contract when the graduates and jobs had low horizontal and low vertical matches (G1). The two groups in between show that when there is a vertical match, the percentage of formal contracts is higher (85\%) than when there is only a horizontal match $(78 \%)$. 
Figure 6.10. Matching types and formal contracts

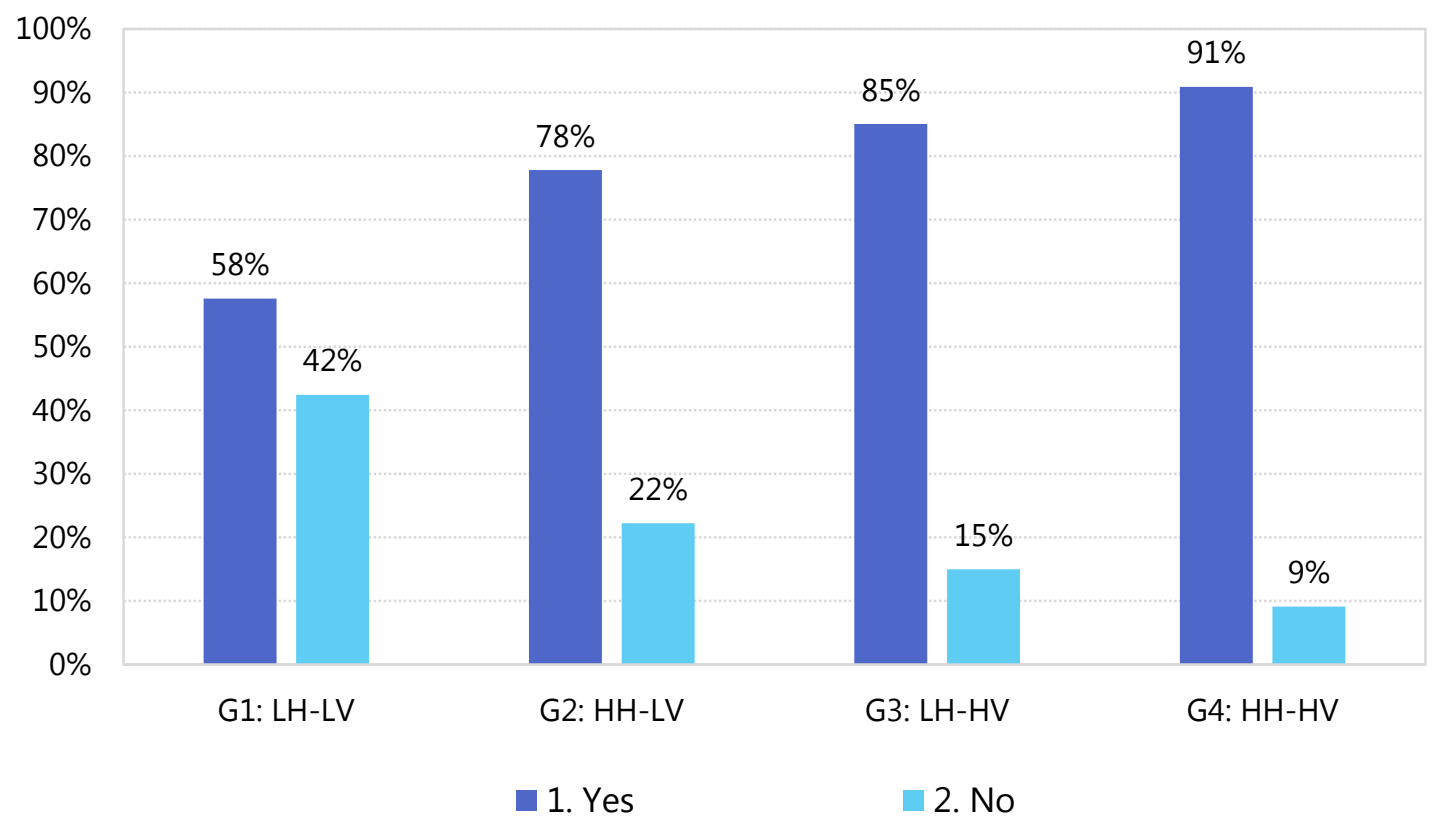

\subsection{Matching types and job duration}

Usually work stability is a job characteristic valued by employees. Thus, it is usually considered a feature of good quality jobs. However, job flexibility in the labour market is increasing because of the growing trend toward short-term and fixed-term jobs. In order to find out the types of jobs the graduates hold, we included the following question: CJ12. Is your current job ...?

1. A short-term job

2. A long-term job

3. An unidentified-term job.

4. I do not know.

The results clearly show that double matching is a significant antecedent of the permanent job rate. Thus, in G4 (horizontal and vertical matches) the rate of long-term jobs is $77 \%$ of the total, whereas in $\mathrm{G} 1$, where there is no match, the rate is $39 \%$. In the two middle categories with only one match, the rates of long-term jobs are in between (G2: 67\% and G3: 64\%). 
Figure 6.11. Matching types and job duration

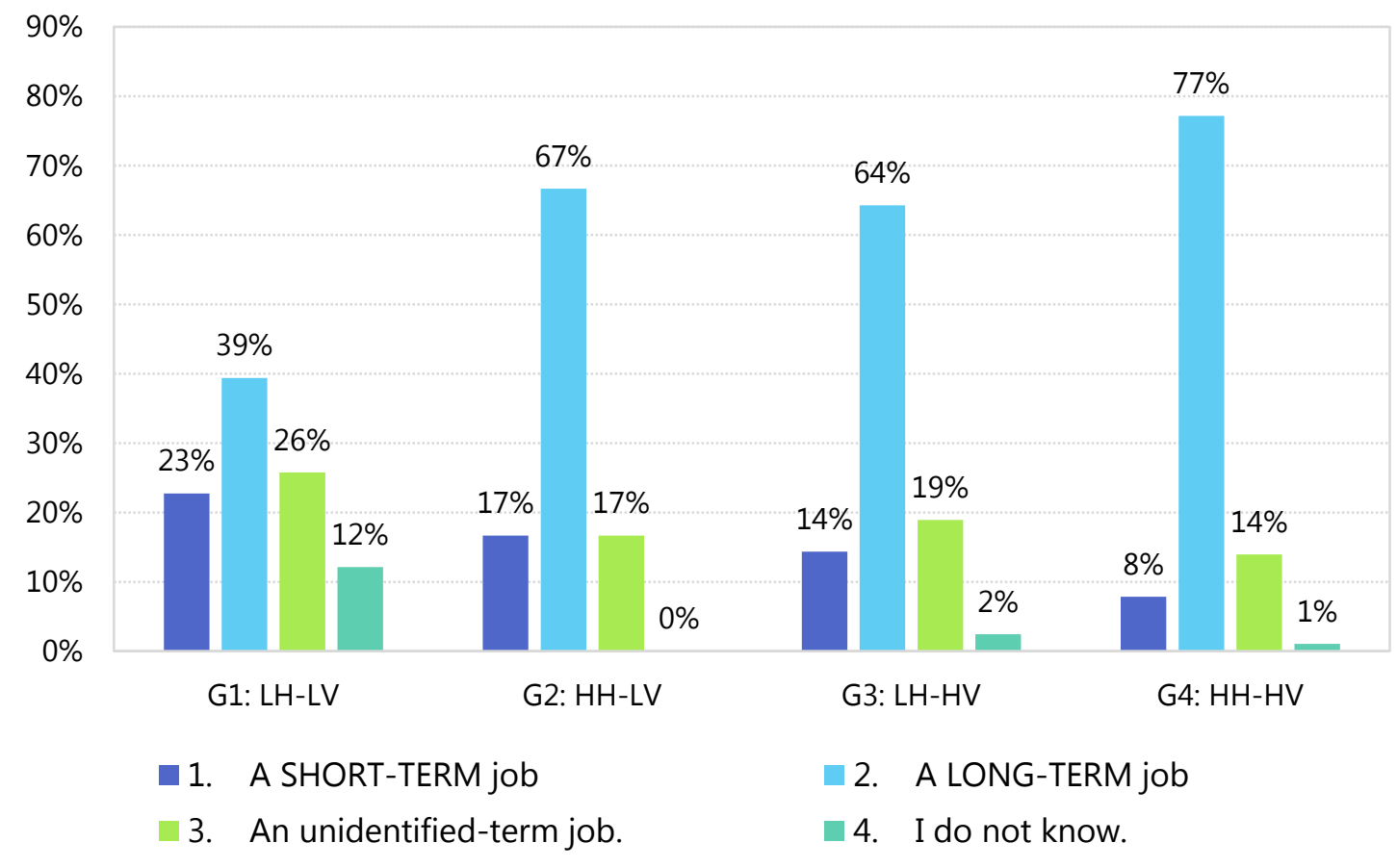

\subsection{Matching types and full-time vs part-time job.}

Another feature of the jobs is time dedication. Often, there is a distinction between full-time jobs and part-time jobs. In order to clarify the distribution of this feature, we included the following question in the survey: $\mathbf{C J 1 3}$. Is your current job ...?. The response alternatives were:

1. A part-time job

2. A full-time job

In most cases, the young graduates in normal conditions prefer full-time jobs. Our results show that nearly all the jobs (97\%) held by the graduates in G3-G4 are full time. However, in the G1 (low match in vertical and horizontal dimensions), the percentage is $88 \%$. 
Figure 6.12. Matching types and full-time vs part-time job

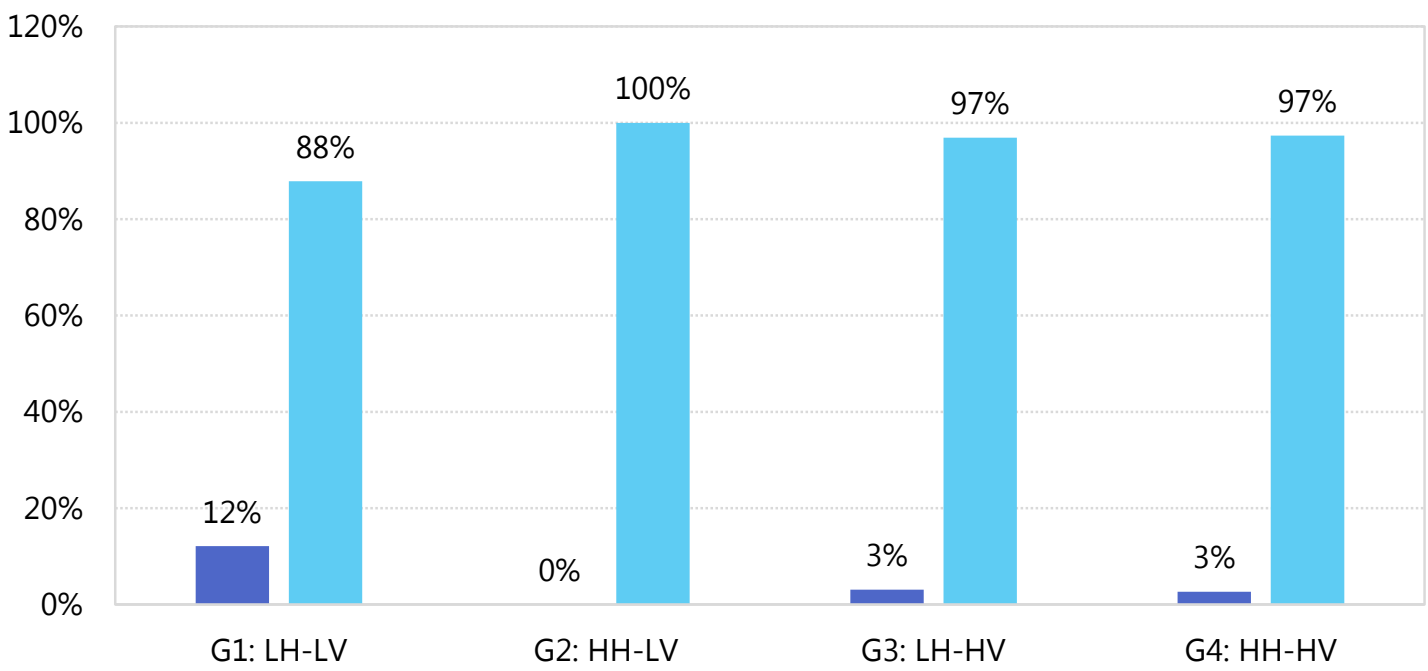

1. A part-time job $\quad$ 2. A full-time job

\subsection{Matching types and hierarchical level}

It is also interesting to clarify whether the different groups of jobs on the basis of double matching differ in their hierarchical level. In order to clarify this issue, we asked the graduate the following question: CJ10. What is the hierarchical level of your current job?

5. Top manager

6. Manager

7. Middle manager

8. Supervisor

9. Entry-level employee

10. Apprentice

The results show that most of the graduates (between $78 \%$ and $84 \%$ ) work as entry-level employees. However, between $6 \%$ and $11 \%$ work as managers, although the statistical analysis shows non-significant differences between the groups based on the group to which the graduates belong. Therefore, there is no significant relationship between the double matching and the hierarchical level of the current job. 
Figure 6.13. Matching types and hierarchical level

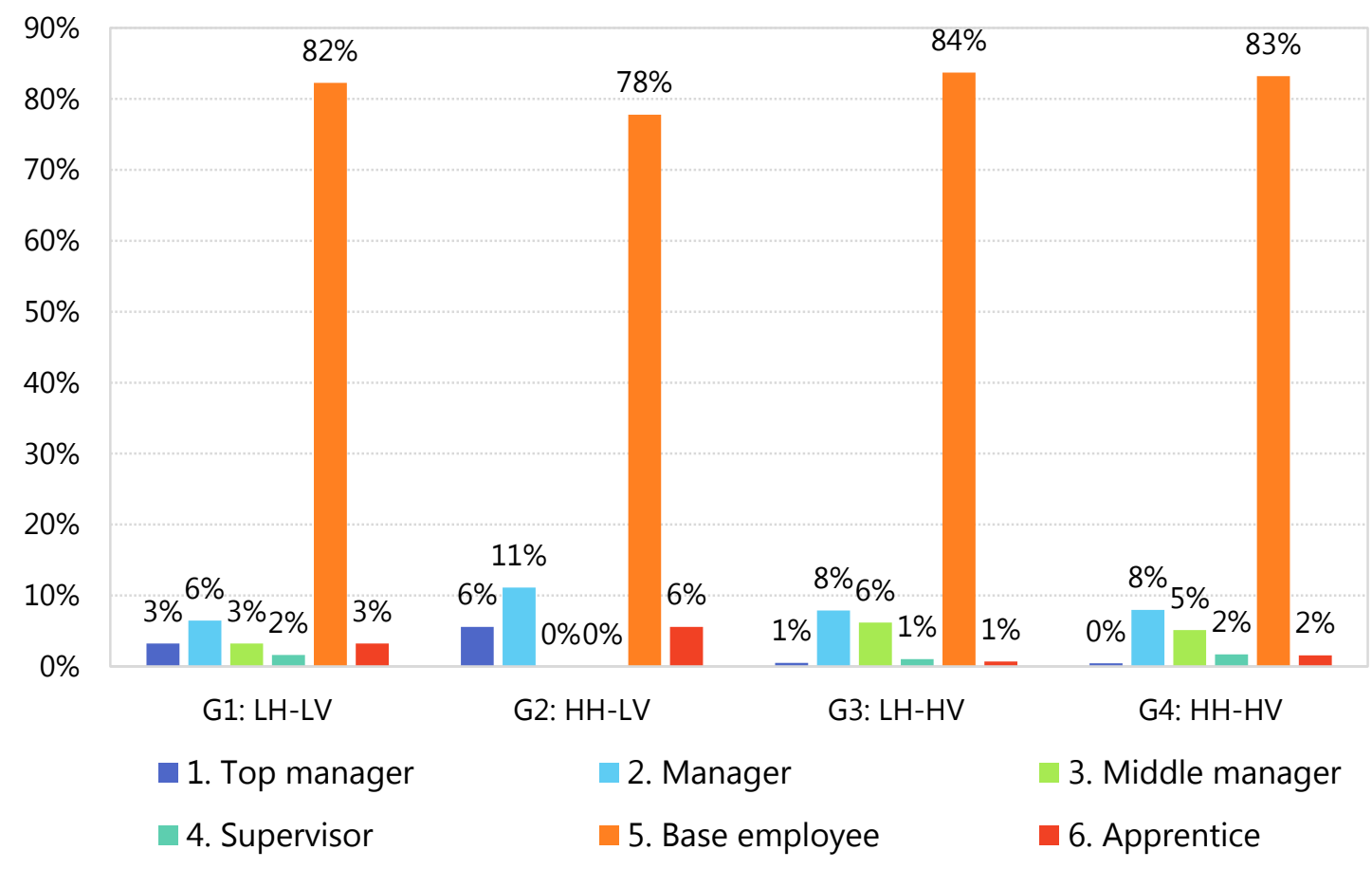

\subsection{Matching types and monthly income}

One indicator of the quality of the job that the graduates hold is the monthly income they receive. In order to obtain information about it, the following question was posed to them:

\section{CJ14. Please, give an estimation of your monthly income in your current job:}

1. Less than 5 million dong/month

2. From 5 million dong to 7 mil. dong/month

3. From 7 million dong to $10 \mathrm{mil}$. dong/month

4. From 10 million dong to 15 mil. dong/month

5. Higher than 15 million dong/month

Looking at the distribution of the salaries among the groups, it is interesting to note that the lowest percentage of graduates that earn over 7000 dong is in G1: LH-LV (with low vertical and horizontal match. Only 37\% of the graduates in this group earn more than 7000 dongs. Group 2 (high horizontal match but low vertical match) presents the highest percentage of graduates (67\%) who get paid more than 7000 dongs. Nevertheless, it is important to highlight that this group only includes one percent of the total sample. It is more interesting to compare the two most populated groups. Whereas $51 \%$ of the graduates included in $\mathrm{G} 3(\mathrm{LH}-\mathrm{HV})$ receive a monthly income above 7000 dongs, in the G4 (the one with high vertical and horizontal matches), $61 \%$ receive more than 7000 dongs. 
Thus, based on this indicator, we can conclude that working in a job with a high horizontal and high vertical match is important in terms of salary because they are more often better paid than those in a job with a vertical match and a poor horizontal match.

Figure 6.14. Matching types and monthly income

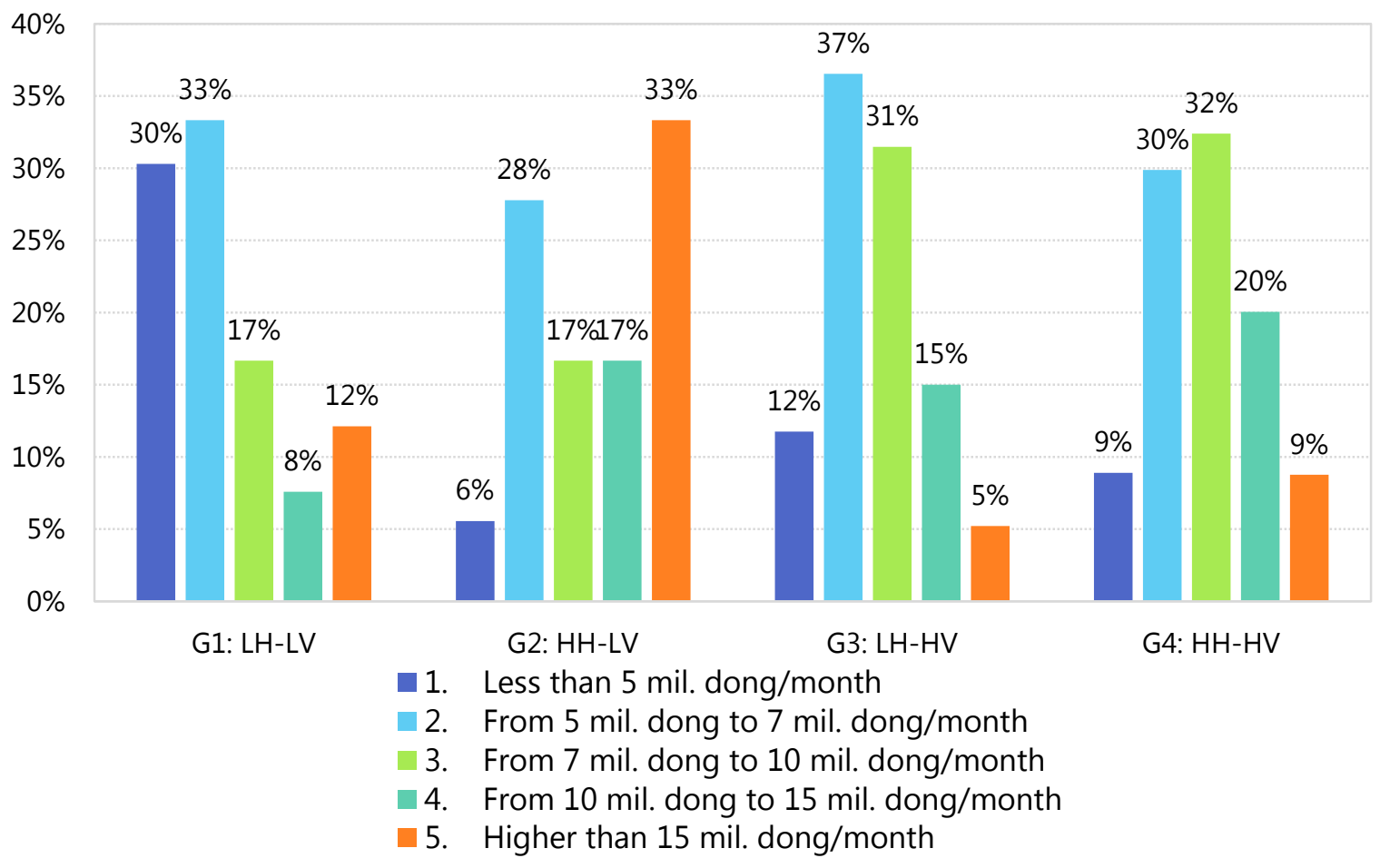

\subsection{Matching types and work satisfaction}

Another quality indicator of the jobs held by the university graduates is operationalized as work satisfaction. Work satisfaction is a positive cognitive and affective response of employees to different facets of the work they perform. In this survey, we have measured work satisfaction with the following questions: CJ15. What is the degree of satisfaction or dissatisfaction produced by each of the following aspects of your job? To respond to these items, choose one of the options from the following response scale: 1 (strong dissatisfaction), 2 (a lot of dissatisfaction), 3 (some dissatisfaction), 4 (some satisfaction), 5 (a lot of dissatisfaction) and 6 (strong satisfaction). The facets we asked about are: 1) The work you do, 2) the income you receive, 3) your working conditions, 4) the opportunities for professional development, and 5) your company as a whole.

The results disaggregated by the four groups established according to the double match criterion show very clearly that in every facet considered, those graduates who work in jobs that fulfil the horizontal and vertical match (G4) present a significantly higher work satisfaction average score than those who work in jobs with a vertical match but without a horizontal match (G3). As Figure 6.10 shows, in every facet of job satisfaction, group 4 presents a significantly higher average score on job satisfaction than group 3. There are also some significant 
differences between the G4 scores and scores obtained in $\mathrm{G} 1$ and/or G2, but they are less relevant given that the number of graduates in each of these groups is rather low.

In sum, double matching is a clear indicator of the quality of the graduates' jobs when considering employees' work satisfaction with job facets as an indicator of job quality. The employees with high vertical and horizontal matches are more satisfied with the activities they perform, the income they receive, the working conditions they have, their opportunities for professional development, and the company where they work as a whole.

Figure 6.15. Matching types and work satisfaction

5. Your company as a whole

4. The opportunities for professional development

3. Your working conditions

2. The income you receive

1. The work you do

$$
1
$$

G4: HH-HV
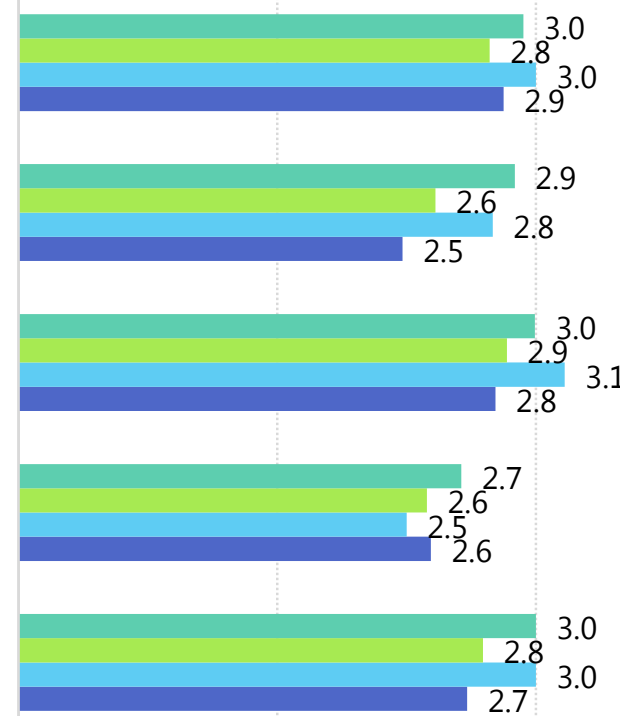

2.7

3

$\mathrm{G} 4>\mathrm{G} 3$

$\mathrm{G} 4>\mathrm{G} 3, \mathrm{G} 1 ; \mathrm{G} 2>\mathrm{G} 1$

$\mathrm{G} 4>\mathrm{G} 3, \mathrm{G} 1$

$\mathrm{G} 4>\mathrm{G} 3$

$\mathrm{G} 4>\mathrm{G} 3, \mathrm{G} 1$
G1: LH-LV

\subsection{Matching types and the match between competences and job requirements}

It is interesting to analyse the subjective matching reported by the graduates between their competences and the ones required by their jobs. To clarify this, we asked the participants in the survey: To what extent do your competences match the requirements of your job? The answers were obtained with the following scale:

1. My competences are far below the requirements of my job

2. My competences are a little bit below the requirements of my job

3. My competences match the requirements of my job

4. My competences are a little bit above the requirements of my job

5. My competences are a far above the requirements of my job 
The distribution of the different answers provided by the graduates in each of the job types clearly differs in the matching of their competencies with those required in their job. The subjective perception of an adequate match between the competencies of the graduates and the ones required by the job dramatically increases from G1 (41\% "match") to G4 (81\% "match"). Moreover, the perception of being overqualified ("A little bit above" + "far above") clearly decreases from G1 $(32 \%+17 \%)$ to G4 $(9 \%+2 \%)$. Moreover, the perceptions of underqualification ("a little bit below" + "far below") are lower in G4 double matched jobs (7\% + $1 \%)$ than in the other three groups that have the following under-qualification percentages: G3: 14\%; G2: $17 \%$ and G1: $11 \%$.

Figure 6.16. Matching types and competences-job requirements match

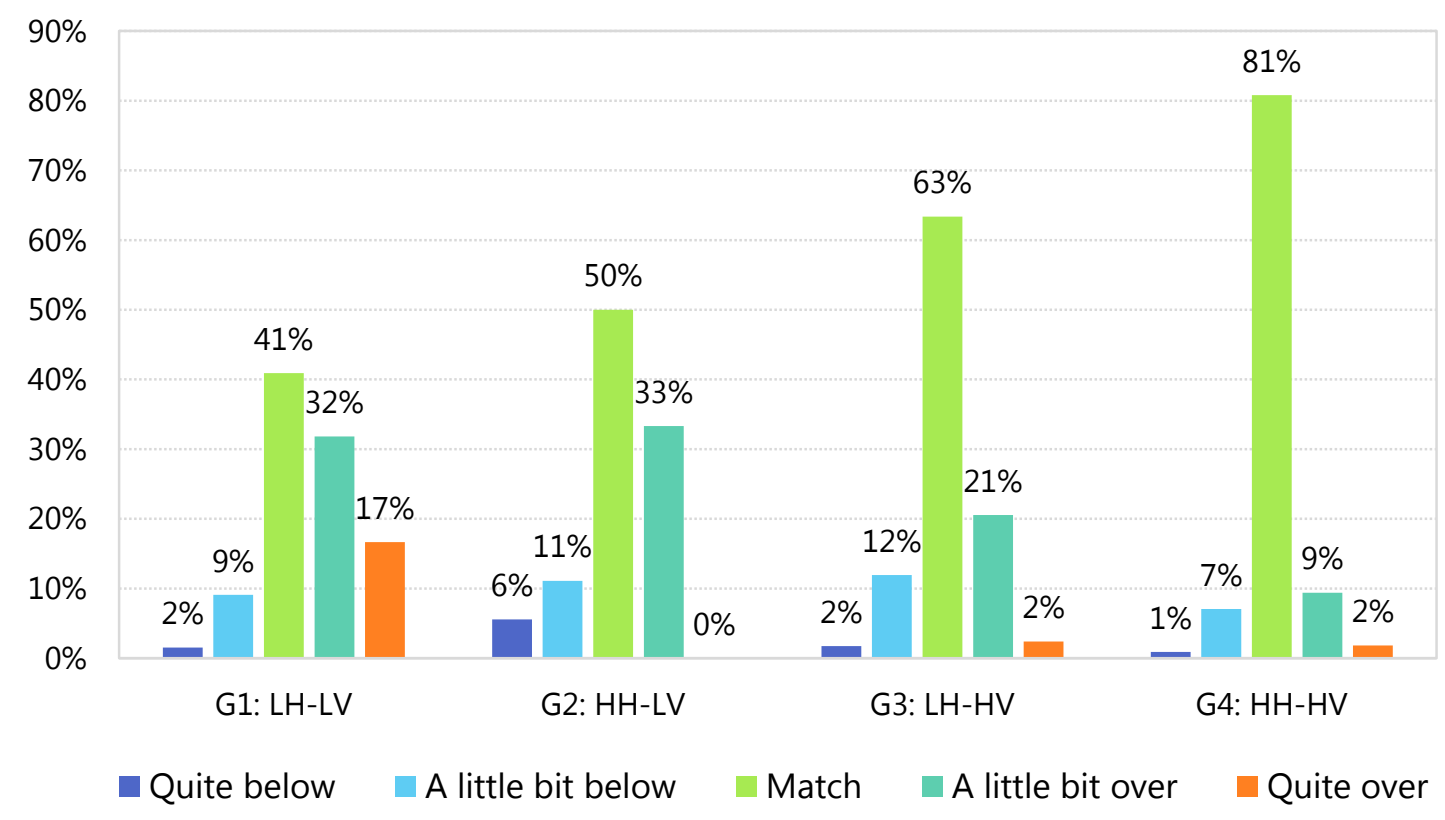

\subsection{Matching types and competence importance}

One relevant aspect that heavily influences employees' job performance is the number and type of competences that the employees have to master when working in that job. 'Competence' has been defined as "a learned ability to adequately perform a task, duty or role" (Roe, 2002; p. 195). From this perspective, "competences are acquired through a process of learning-by-doing, in which knowledge, skills, personal values and attitudes become integrated and connected to a particular task, duty or role" (Lunt, Peiró, Portinga \& Roe, 2014, ch.5). It is important to know what competencies are required in the jobs the University graduates have because this knowledge will provide essential information about the type of education university students should have to receive a preparation that will respond to the demands of the labour market. Given the broad array of majors targeted in this survey, we just focused on soft competencies without asking about the specific competencies for every profession. Soft competencies are required in a large variety of jobs and professions, and they are often not explicitly considered in the curricula of different disciplines and professional groups. Of course, more specific studies 
should also analyse the professional competencies of each degree major aiming to educate a given professional group.

In order to obtain relevant information about the soft competencies required by the employers, we asked the graduates the following question: CJ17. Rate the importance of each of the following factors and competencies for good performance in your current job. To respond to these items, choose one of the options from the following response scale: 1. None; 2. Some; 3. Intermediate; 4. Quite; and 5. Extremely. Then, we presented a long list of competencies that might be required to perform a given job. Those competencies were organized in the following categories: a) Cognitive competencies; b) Management competencies, c) Interpersonal competencies, d) Instrumental competencies; e) Attitudinal competencies. Next, we will present the main results, which show what types of competencies are important in order to perform the four types of jobs that we are considering in this chapter: G1. Low Horizontal match - Low vertical match; G2: High Horizontal match - Low vertical match; G3: Low Horizontal match High vertical match and G4: High Horizontal match - High vertical match. We aim to find out not only the importance of each competence for each group, but also which ones significantly differ among the groups considered. In this way, we will better identify the relationship between the quality of the graduates' jobs and the competencies that are significantly required by these types of jobs.

Cognitive competencies. Regarding the cognitive competencies considered, the survey explored the importance of the following competencies for the job: 1) Critical thinking, 2) Systematic thinking, 3) Problem solving, 4) Creativity, 5) Transferring theory to practice, 6) Continuous learning and 7) Report writing.

Looking at the average score for the importance of each competency for the job performed by the graduate students, it is interesting to highlight that for every competence, graduates in G4 (High horizontal and High Vertical match) report a significantly higher level of importance than the other large group of graduates (G3), who are employed in jobs with a low horizontal match - High vertical match. Moreover, G4 also exceeded the scores obtained by G2 and G1, and G3 also exceeded the scores of $\mathrm{G} 2$ and $\mathrm{G} 1$ on a number of competencies.

A clear conclusion of these results is that every cognitive competence considered should be developed during the education of University students because they are clearly needed, especially in the jobs that the university graduates should aim to hold: jobs that require a university degree and are clearly related to the subject and discipline of their major. Additionally, in the cases where the graduates work in jobs that require a university degree, even if they are not clearly related to the major studied, the importance of the cognitive competencies is higher than in jobs that do not require a university degree ( $G 1$ and G2). In these last two groups, the over-qualification of the graduates represents a waste of effort and investment in their education, given that afterwards their jobs do not require some of those competencies and hardly give them the opportunity to practice and develop them. 
Figure 6.10.a. Matching types and importance of cognitive competences

\begin{tabular}{ll|l|l|}
\hline & $3.6^{3.8}$ & $\mathrm{G} 2>\mathrm{G} 1 ; \mathrm{G} 3>\mathrm{G}$
\end{tabular}

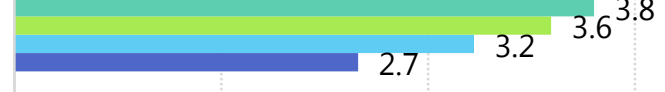

$\mathrm{G} 4>\mathrm{G} 3, \mathrm{G} 2, \mathrm{G} 1$

6. Continuous learning

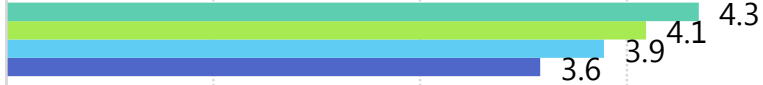

$\mathrm{G} 3>\mathrm{G} 1$

$\mathrm{G} 4>\mathrm{G} 3, \mathrm{G} 2, \mathrm{G} 1$

5. Transfer theory to practice

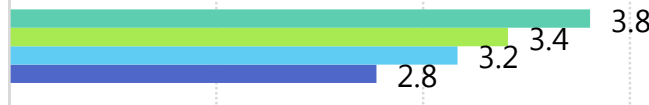

4. Creativity

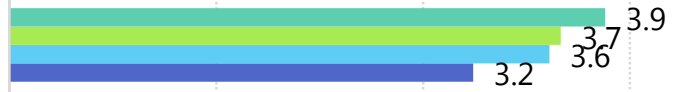

$\mathrm{G} 3>\mathrm{G} 1$

$\mathrm{G} 4>\mathrm{G} 3, \mathrm{G} 2, \mathrm{G} 1$

$\mathrm{G} 3>\mathrm{G} 1$

G4> G3,G1

3. Problem solving

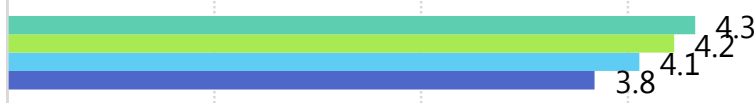

$\mathrm{G} 3>\mathrm{G} 1$

$\mathrm{G} 4>\mathrm{G} 3, \mathrm{G} 1$

2. Systematic thinking

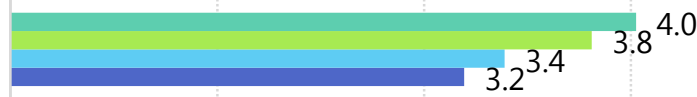

$\mathrm{G} 3>\mathrm{G} 2, \mathrm{G} 1$

1. Critical thinking

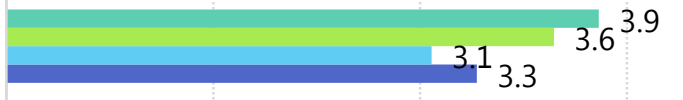

$\mathrm{G} 3>\mathrm{G} 2, \mathrm{G} 1$

1

2

3

4

5

G4: HH-HV

G3: LH-HV

- G2: HH-LV

G1: LH-LV

Management competencies. In the case of management competencies, the survey included the following: 1) Time management, 2) Motivating others, 3) Leadership, 4) Planning, and 5) Decision making. As in the previous block, here again the average score of the importance of every competency in this block for the job performed by the graduates in group 4 (High horizontal and High Vertical match) is significantly higher than the average score of the other large group of graduates (G3), employed in jobs with a low horizontal match - High vertical match. Moreover, the G4 group also exceeded the scores obtained by G2 and G1. In this block, Group 3 also exceeded the scores of G2 and/or G1 on the competencies considered.

Again, the conclusion drawn from these results is that every management competence considered should be developed during the education of University students because they are needed, especially in the jobs that the university graduates should aim to hold: jobs that require a university degree and are clearly related to the subject and discipline of their major. Furthermore, in the cases where the graduates work in jobs that require a university degree, even if they are not clearly related to the major studied, the importance of the management competencies required is higher than in those jobs that do not require a university degree (G1 and G2). 
Figure 6.10.b. Matching types and importance of management competences

5. Decision making

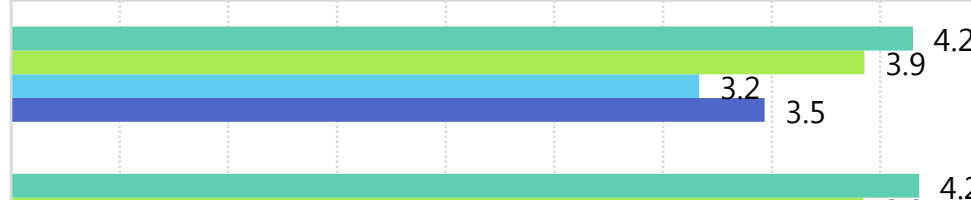

4.2

$G 3>G 2, G 1$

$\mathrm{G} 4>\mathrm{G} 3, \mathrm{G} 2, \mathrm{G} 1$

4. Planning

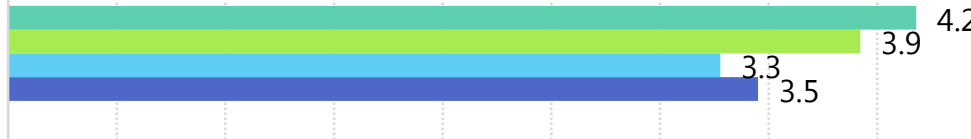

$G 3>G 2, G 1$

$\mathrm{G} 4>\mathrm{G} 3, \mathrm{G} 2, \mathrm{G} 1$

$\mathrm{G} 3>\mathrm{G} 1$

3. Leadership

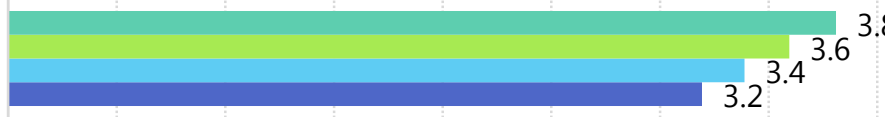

$\mathrm{G} 4>\mathrm{G} 3, \mathrm{G} 1$

$\mathrm{G} 3>\mathrm{G} 1$

2. Motivate others

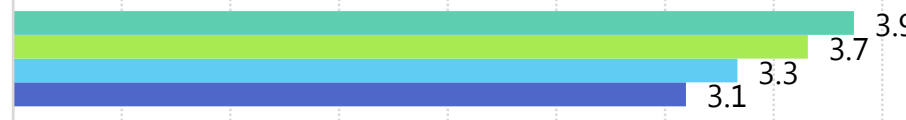

$\mathrm{G} 4>\mathrm{G} 3, \mathrm{G} 2, \mathrm{G} 1$

1. Time management

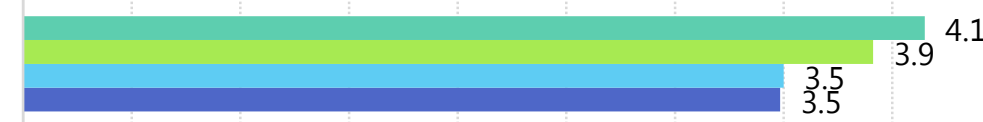

$\mathrm{G} 3>\mathrm{G} 2, \mathrm{G} 1$

$\mathrm{G} 4>\mathrm{G} 3, \mathrm{G} 2, \mathrm{G} 1$

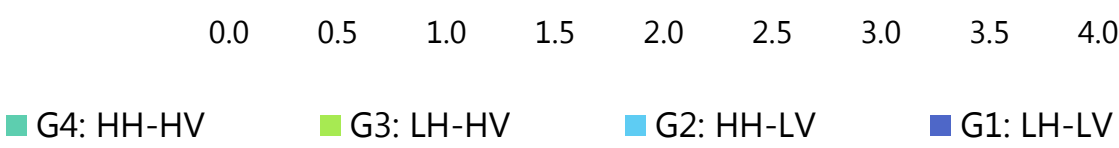

Interpersonal competencies. The third block of competences included in the survey is related to interpersonal relationships. Here we have considered: 1) Conflict solving, 2) Teamwork, 3) Communication skills, 4) Presentation skills, 5) Negotiation skills, 6) Intercultural skills, and 7) Customer relations skills. First, let's note that the average scores obtained in the competence 'Customer relations skills' do not present any significant differences across groups established based on the double (miss)match between the job and the graduate job holder. Moreover, in what concerns with the 'negotiation skills' there are no significant differences about the importance between group 4 and 3 (the two most populated ones). Independently that the job performed present or not an horizontal match, the fact that there is a vertical match already requires high skills of negotiation to perform a good job in both types of work.

For the rest of the competencies in this block, the average score of their importance for the job performed in the G4 (High horizontal and High Vertical match) is significantly higher than the ones obtained by the graduates classified in the other large group (G3 employed in jobs with low horizontal match - High vertical match). Moreover G4 also exceeds the scores obtained by G2 and G1. Moreover, in the case of several competencies, G3 also exceeded the scores presented by graduates in $\mathrm{G} 2$ and/or G1.

Again, the conclusion of these results is that most of the interpersonal competencies should be developed during the education at the University because these competencies are needed, especially in the jobs that require a university degree and that are clearly related to the subject and discipline of their major studies. 
Figure 6.10.c. Matching types and importance of interpersonal competences

7. Customer relationship skills

6. Inter-cultural skills
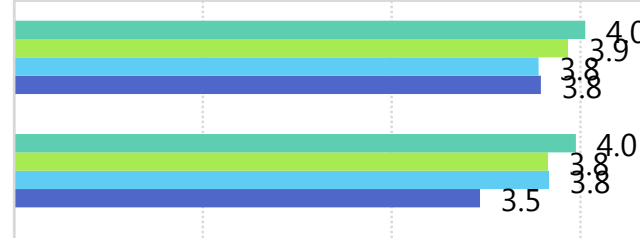

5. Negotiation skills

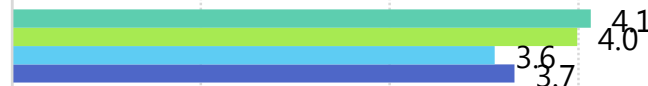

\section{$4.0^{1}$}

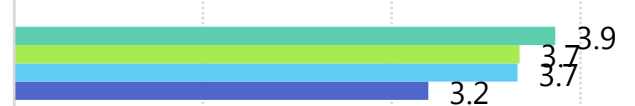

4. Presentation skills

3. Communication skills

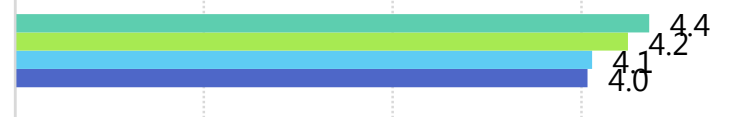

2. Team work

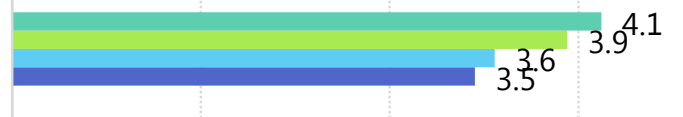

1. Conflict solving

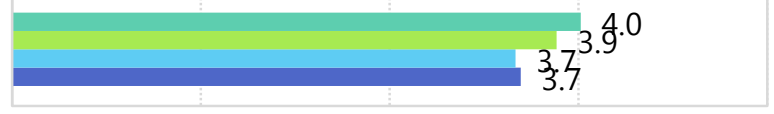

1 2

3

4

NO DIFFS

G3> G1

$\mathrm{G} 4>\mathrm{G} 3, \mathrm{G} 1$

$\mathrm{G} 3>\mathrm{G} 2, \mathrm{G} 1$

$\mathrm{G} 4>\mathrm{G} 2, \mathrm{G} 1$

$\mathrm{G} 3>\mathrm{G} 1$

$\mathrm{G} 4>\mathrm{G} 3, \mathrm{G} 1$

G3> G1

(4)

$\mathrm{G} 3>\mathrm{G} 1$

$\mathrm{G} 4>\mathrm{G} 3, \mathrm{G} 1$

G4: HH-HV

G3: LH-HV

G2: HH-LV

G1: LH-LV

Instrumental competencies. The fourth block of competences considered are Instrumental ones. The ones considered are: 1) Foreign languages, 2) Computer skills, and 3) Office skills. In this case, the average scores obtained in the competence 'Office skills' do not shed significant differences concerning their importance between G4 and G3 (the two most populated ones) although both of them significantly present higher scores that the ones of G2 and G1. Independently that the job performed presents or not horizontal match, the fact that there is a vertical match implies that the office skills are more important for those jobs. For the two other competencies of the block, the average score of each is higher for the jobs performed in the G4 (High horizontal and High Vertical match) than for those performed in the G3 (low horizontal match - High vertical match). Moreover G4 group also exceeds the scores obtained by G2 and/or G1.

Again, the conclusion of these results is that the instrumental competencies should be developed during the education at the University because they are needed, especially in the jobs that require a university degree and are clearly related to the subject and discipline of their major studies. 
Figure 6.10.d. Matching types and importance of instrumental competences

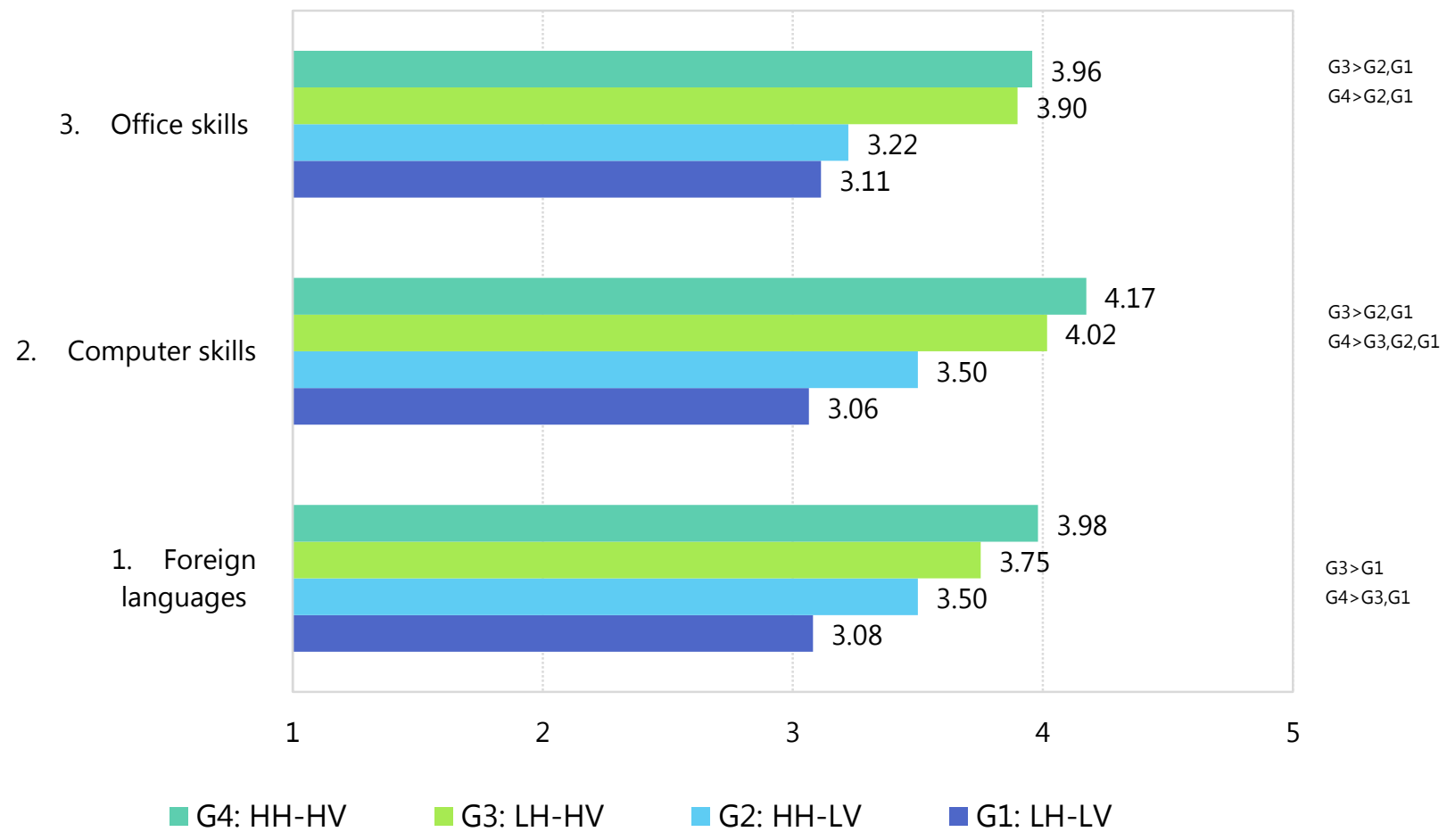

Attitudinal competencies. Every competence integrates the following components: knowledge, skills and attitudes and different ones emphasize one or other component. There are a number of competencies that emphasized affect and attitudes as important component for proper enactment. In our study we have paid attention to a number of competencies in which attitudes are critical: 1) Adaptability, 2) Commitment, 3) Entrepreneurship, 4) Rule Compliance, 5) Punctuality, and 6) Taking responsibility. Looking at the average score of their importance for the performance of the work by the graduate students it is noteworthy to highlight that G4 (High horizontal and High Vertical match) report significant higher score that G3. Thus, if in addition of presenting vertical match the job presents also horizontal match, then the attitudinal competencies considered become more important to perform the work. Of course this is also true when we compare the scores of G4 with G1. Moreover, G3 also exceeds the scores obtained by $\mathrm{G} 1$ in four out of the six competencies considered: Entrepreneurship, Rule Compliance, Punctuality, and Take responsibility. Thus, when a graduate holds a job of the university level, these competencies are more important that when he or she holds a job that is mismatched both horizontally and vertically and so he or she is overqualified for that job. 


\section{Figure 6.10.e. Matching types and importance of attitudinal competences}

\section{Take responsibility}

5. Punctuality

4. Rule compliance

3. Entrepreneurship

2. Commitment

1. Adaptability
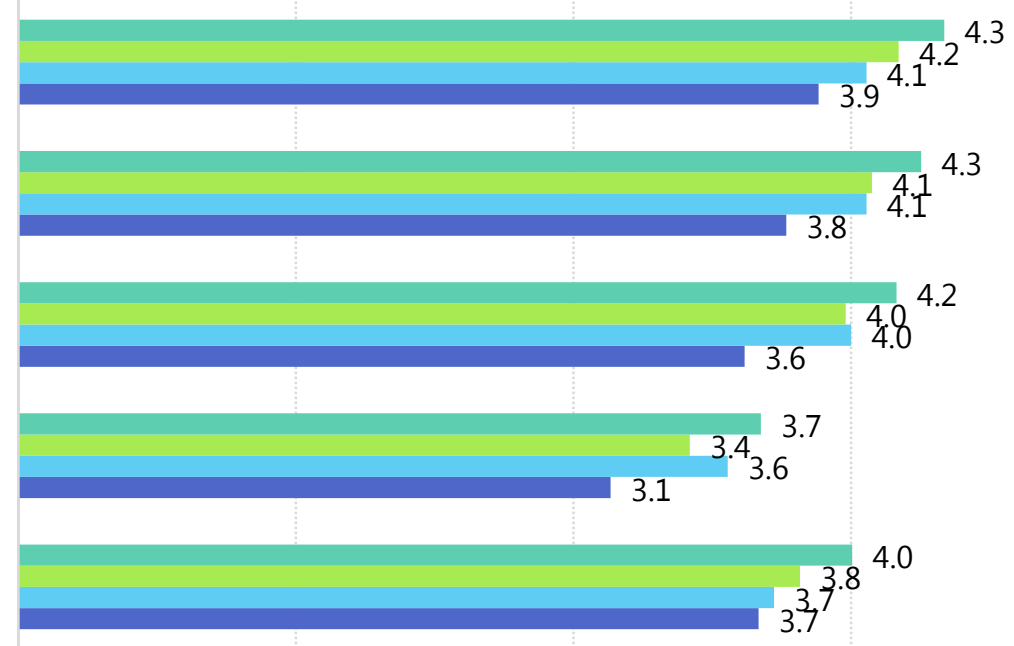

4.0

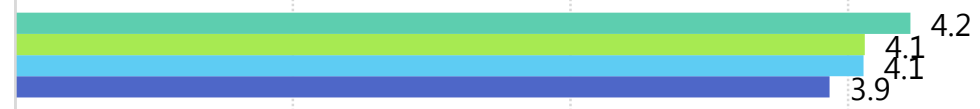

A clear conclusion of these results is that every attitudinal competence considered should be developed during the education of the University students if the aim is to help then to work in jobs according to their education, i.e., jobs that require a university degree and that clearly relate to the subject and discipline of the major studies. Also in the cases, where the graduates work in jobs that require a university degree, even if they are not clearly related to the 'major' degree studied, the importance of the attitudinal competencies still is higher than the ones required by those jobs that do not require a university degree (G1). In these cases, the over-qualification of the graduates represents a waste of efforts and investment on their education, given that as their jobs do not require that much, those competencies, the jobs hardly give them the opportunity to practice the competencies and to further develop them.

\subsection{Summary and conclusions.}

It is important to point out that more than $90 \%$ of the surveyed graduates are included in G4 and G3 when combining the horizontal and vertical mismatch: G4 includes high vertical-high horizontal match jobs and G3 high vertical low horizontal matching jobs. Thus, more than nine out of ten graduates hold a job that requires university level. This is a clear signal of the quality of the jobs. The importance of this grouping displays clearly when considering the differences by groups ( $G 1$ to $G 4)$ in a number of personal, organizational, job and task characteristics.

The characteristic of the graduates, when analysed by groups show that by gender, males concentrate significantly more in G4 (High horizontal- high vertical match) while women concentrate in $\mathrm{G} 3$, holding more frequently jobs just with vertical match but with no horizontal 
match. In what concerns the major of the studies, there are no strong differences by major in G4. However, in G3 the percentage of graduates in Social Sciences and Humanities is higher than the one on Engineering and Sciences. Referring to job search the graduates in G3 and G4 use internet sources more frequently that the ones in the other groups and also look with higher frequency to seek direct contact with employers as a job search strategy. Moreover, the ones in G4 benefit more from their internships and get a job in the company where they did it.

A number of characteristics have been studied concerning the employment and labour market characteristics. Related to the type of employment, the percentage of self-employed is lower in the groups where jobs require an university degree (the G3 and G4) than in those that do not require it, especially in G1. The analysis by sectors of economic activity shows that most of the graduates work in manufacturing, sales and repairs, banking, finance and insurance, and other services. There is no much differences by groups based on matching. However, the banking, finance and insurance sector is more populated by members of the G3 and G4 (jobs requiring university studies). In what refers to graduates' geographical mobility required by the location of their jobs related to the place where their families live, these mobility occurs mostly across the regions of the country, especially among the groups that present partial matching (G2 \& G3) and full matching (G4).

The double matching also shows interesting differences concerning the characteristics of the organizations where the graduates work. The type of company shows that when the matching is high, employment in private companies/organizations decreases (G1: $81 \%$ of the graduates G4: $56 \%$ of the graduates). On the contrary, both graduates holding G3 and G4 jobs are more frequently hired in the FDI companies (G3: $27 \%$ and G4: 24\%). The public companies/organizations hire more often people with high matching. Related to the size of the companies. The matching of jobs and youngsters' preparation according to the size of the company is significant. It tends to be higher in larger companies than in the smaller ones.

The contract and employment features are also influenced by the type of matching. In what concerns the formalization of the contract, when the double matching occurs more than nine out of ten jobs are supported by formal and written contracts (G4), while less than six out of ten (G1) are, when low horizontal and vertical matches occur. Moreover, when considering job duration matching is also a significant antecedent of the rate of permanent jobs. In G4 jobs, the rate of long-term jobs is up to $77 \%$ of the total while in the G1 where no match occurs the same rate only reaches $39 \%$. Full time jobs are held by all (G2) o or nearly all (G3 \& G4) graduates. However, in $\mathrm{G} 1$ only $88 \%$ report this type of jobs. In what relates to hierarchical position, around eight out of ten graduates work as base-employees, although the disaggregation between groups did not yield significant differences. We find clear differences by groups in terms of the monthly income the graduates get paid. In G1, 37\% get paid more than 7 million dongs while in G4 this percentage reaches $61 \%$.

Satisfaction with different job facets differs significantly across the different matching groups of jobs. Double matching is a clear indicator of the quality of the graduates' jobs when 
considering work satisfaction of employees. The group (G4) with high vertical and horizontal matches are significantly more satisfied in all the facets considered: the activities they perform, the income they receive, the working conditions they have, the opportunities for professional development they get in their job and the company as a whole in which they work.

Finally, we paid detailed attention to the competencies required by the jobs in the groups considered. In what concerns the subjective evaluation of the match between competencies available and those required by the job, the perception of an adequate match dramatically increases from G1 till G4. Moreover, the perception of being overqualified clearly decreases from $\mathrm{G} 1$ to $\mathrm{G} 4$ and the perceptions of under-qualification are lower in G4 double matched jobs than in the other three groups $(G 1, G 2, G 3)$.

The importance of different types of soft competencies for the jobs held has been analysed in detail. The results clearly show that double matching (G4) clearly exceeds the other groups (G3 to $\mathrm{G} 1$ ) in the importance of different types of soft characteristics. Also G3 exceeds G1 in a number of competencies. This has been the case for the types of competencies analysed: a) Cognitive competencies; b) Management competencies, c) Interpersonal competencies, d) Instrumental competencies; e) attitudinal competencies. A clear conclusion of these results is that soft competencies should be stronger developed during the education of the University students if the aim is to help them to work in jobs according to their education, that is jobs that require a university degree and clearly related to the subject and discipline of the major studies. In the cases, where the graduates work in jobs that require a university degree, when not clearly related to the 'major' studied, the importance of the soft competencies is still higher than those required by the jobs that do not require a university degree (G1). In these cases, the overqualification of the graduates represent a waste of efforts and investment on their education, given that as their jobs do not require that much, those competencies, the jobs hardly give them the opportunity to practice the competencies and to learn and further develop them. 




\section{CHAPTER 7: DISCUSSION AND CONCLUSIONS}

Previous chapters have reported survey results in overall sample as well as in different subsamples. An integration of these results reveals several key findings that could be inferred from the study. This Chapter presents a synthesis of the results reported in the previous chapters and offer some recommendations to related stakeholders.

\subsection{Synthesis of the results}

Finding \#1: To the vast majority of graduates, finding jobs is not a problem, but finding jobs that matches well with their programs' contents is. As reported, close to $90 \%$ of the graduates in the whole sample got at least a job after 6 months of their graduation, and more than half of them (54\%) got 2 or more jobs. While we do not have formal statistics, our international experts confirm that these numbers were quite impressive. However, finding jobs that match with graduates' acquired knowledge and skills remains a concern. As reported, close to a half of the sample reported a poor match between their jobs' and programs' contents (horizontal match), and nearly one fifth of graduates believed their jobs required lower levels of competencies than what they possessed. Thus, in the context of Vietnam, statistics "having a job" may tell only a small part of the story. Universities should also report on "jobs that match with programs' contents" in their employability reports.

Finding \#2: For a significant proportion of employed graduates, the incomes are not significantly higher than the average of the general workforce, nor is it superior than basic living standards. As reported, about $44 \%$ had a monthly income of less than 7 million dong (about US\$300) and three fourth of employed graduates had a monthly income of less than 10 million dong (about US\$400). Note that 7 million dong is just about the average salary of the whole working population in Vietnam (Chapter 1), and 10 million dong is barely above the basic living standards, especially in Hanoi and HCMC. This is in contrast with the recent sharp increases in total universities' enrolment, raising a question of whether students and their parents carefully considered their future careers when applying to universities.

Finding \#3: Job satisfaction is moderate and the tendency to 'jump' from one job to another is quite high in the first year since graduation. As reported in Chapter 3, employed graduates' satisfaction with the jobs (2.85) is just above the mid-point (2.5 on a scale from 1 to 4). Nearly $55 \%$ have more than one jobs, and the average number of jobs during the first year after graduation is 2.8. These findings suggest a low fit between graduates' expectations and jobs' characteristics. Our focus group discussions with employers suggested that while graduates had a basic understanding of the jobs' technical requirements, they had quite poor understanding of professional values, ethics, and were not well equipped for longer-term career development. This points to the need of career supports where preparation for career development is as critical as job search. 
Finding \#4: A majority of jobs offered by the private sector and foreign direct invested enterprises (FDIs). Jobs from the public sector accounted for $10.6 \%$ of employed sample and self-employed account for only $6 \%$ of the whole sample. These results suggest that universities should have employment strategies with clear which target mostly to the private sector and FDIs. While we support the campaign for starting-up businesses among graduates, we caution universities to be realistic in setting the target as well in equipping graduates with necessary competencies/conditions for starting-up.

Finding \#5: There are notable differences by gender and major in terms of job characteristics, i.e., income, horizontal match, and type of employers. Male graduates have better horizontal match, earn more, and more likely to work in FDIs than female counterparts. Similarly, graduates in science and engineering also earn more, have better horizontal match, more likely to work in FDIs, and are satisfied with the jobs more than those in social science. This implies that universities of social science may need to work harder in linking their graduates with potential employers for better quality jobs. Universities also need to be more attentive to the needs of female graduates who may not be as active as male graduates in looking for help.

Finding \#6: Personal/social network and internet appear to be most frequently used as job search channels, while universities' services were hardly used by graduates. Social networks, internet, and companies' websites were reported as the most frequently used strategies in finding jobs. These channels mostly provide information on job vacancy. How to approach potential employers and apply successfully for vacant jobs may require more focused strategies that help demonstrate the fit between graduates and job requirements. Direct contacts with employers or use of career services may help developing these strategies. However, neither of these strategies were frequently used. As a case in point, less than $5 \%$ of graduates used university employment services, suggesting a great need to promote and improve university employment services to graduates.

Finding \#7: Lack of practical experience and poor understanding of the job contexts are most critical obstacles for job finding. Three of four most critical obstacles for finding jobs, reported by unemployed graduates, related to lack of professional experiences and practices and poor understandings of job contexts. These obstacles were ranked as more critical than job search skills and deficiency in university education. This suggests that universities' programs need to be embedded in the professional contexts to help graduates catch-up with labour markets' movements and requirements. This finding aligns to that on horizontal match (Finding \#1) as well as competencies needed (Finding \#7).

Finding \#8: Problem solving, adaptation, and continuous learning were most important for attaining good performance. These competencies require certain understandings of the contexts and effectively use professional knowledge to solve context-specific problems. This finding further enhances the need to equip graduates with better knowledge of job contexts. Programs that allow experiential learning and have job orientation early are better help students in these respects. 


\subsection{Recommendations}

Based on the study results, we offer some recommendations in order to enhance employability of the graduates, in terms of job access and quality. The recommendations are for universities and MOET.

\section{Recommendations to universities}

Recommendation 1 - Curriculum contents: Review their curriculum design to ensure that genuine experiential learning is incorporated, and job orientation is introduced early in the program. The survey results suggest that graduates lack of professional practice and experience in searching for well-matched jobs. These elements can only be provided via experiential learning where students engaged in solving practical problems, socializing with professionals in their fields, and experiencing the act of working in the fields. Graduates should not only understand and practice the acquired knowledge, they should also 'live and feel' as real professionals. In addition, many universities only let students do internship in later half of the studies, believing that they only have enough knowledge to practice at that time. We believe some practical elements should be introduced even in the first and second years of the study to help students familiarized with their professional fields. These knowledge and feelings will then orient students to study better for future jobs.

Recommendation 2 - Collaboration with industries and potential employers: Intensive collaboration with industries (guest lectures from experts from the field, work visits, internships, joint curriculum development). Universities invite potential employers of their own graduates in curriculum design. By law, employers' participation in curriculum design is required. Many universities have been inviting experts from industries to give lectures or host internships. However, there is a tendency for universities to invite big companies, successful alumni, or representatives from government organizations. As the study shows, most of jobs are offered by SMEs and FDIs. In general, these types of enterprises should be consulted more often in curriculum design. However, each university could have different targets of potential employers for their graduates. We recommend universities to identify potential types of employers and then invite them to participate in curriculum design.

Recommendation 3 - Career services: Provide career services to help students have better knowledge of job contexts and job search skills. Many universities in Vietnam now offer career services to students. Most of the services focus on providing job vacancy information and improving students' job search skills. What is missing is knowledge of job contexts and career identity, i.e., core values, professional ethics, and critical success factors of the jobs. Thus, career services not only help graduates find the jobs, but also prepare them for how to succeed with their career. The services should be easy to access, especially for female students/ graduates.

Recommendation 4 - Tracer study: Conduct tracer studies to provide feedback to curriculum design, career services, and other services to improve employability and success of graduates. Many universities in Vietnam now conduct tracer studies for administrative reasons, i.e., required 
by MOET. The results are for getting enrolment quota and accreditation. These are a very limited use of tracer studies. As demonstrated in this study, results of tracer studies could be used to revise curriculum and services in order to improve graduates' employability and success in their career. We recommend universities to shift the purpose of tracer studies to more long-term benefits for graduates and universities.

Recommendation 5 - Tracer study: Adopt more rigorous methodologies in tracer studies. The methods and process in tracer studies are neither rigorous nor consistent among universities. We recommend universities to adopt more rigorous methods and process, especially in sampling, questionnaire design, and analysis. The methods used in this study could be referenced as a starting point.

\section{Recommendations to Ministry of Education and Training}

Recommendation 6 - Tracer study: Consider using independent employability reports for quality accreditations and enrolment quotas. The current practice of using self-reported employability for quality accreditation and enrolment quotas contains potential conflict of interests. In addition, universities used vastly different approaches and methods in the studies, raising a question of incompatibility in the results. We recommend MOET to conduct or out-source independent tracer studies for universities for that purposes. The studies may be conducted every several years with consistent methods.

Recommendation 7 - Tracer study: Share EVENT's tracer study methodologies to nonparticipant universities. The study's methods and process used in EVENT meets rigorous standards and commonly accepted by international universities. MOET could share the methods to non-participant universities via various channels, such as workshops, web portals, or manuals. 


\section{REFERENCES}

Lunt, I., Peiró, J. M., Poortinga, Y. and Roe, R. (2014). EuroPsy: Standards and quality in education for psychologists. Hogrefe Publishing.

Roe, R. A. (2002). What makes a competent psychologist? European Psychologist, 7(3), 192-202

Tran, C. and Crawford, M. (2015). Vietnamese higher education system: characteristics and challenges. Unpublished manuscript 


\title{
ANNEX. EVENT QUESTIONNAIRE
}

\author{
INTRODUCTION
}

Dear participants,

Your university, in collaboration with a consortium composed of four other Vietnamese Universities (university names) and four European Universities (university names) is conducting a survey about the characteristics of Vietnamese university graduates' employment. The information collected will provide important input to enhance the quality of university education in Vietnam and graduates' employability.

Your participation in this survey is of the utmost importance. You have been randomly selected among the graduates who finished their bachelor's degree in your university one year ago.

We ask you to participate in the survey by responding to the questions you will see below. The information collected will be treated confidentially for research purposes only, and the responses in the data base will be anonymous. Answering the questions on this questionnaire will take around 10 minutes.

Thank you very much for your participation. 


\section{SOCIO-DEMOGRAPHIC DATA}

SD1. First, tell us the University where you obtained your (most recent) bachelor's degree:

1. National Economics University (NEU)

2. Hanoi University of Industry (HAUI)

3. Ho Chi Minh University of Technology (Hutech)

4. Ho Chi Minh City University of Technology and Education (HCMUTE)

5. Hue University (HueUni)

SD2. Tell us the Major of your bachelor degree (the list of options displayed will depend on the University in which the degree was obtained):

1. Major A

2. Major B

3. Major $\mathrm{C}$

4. Etc.

5. Etc.

SD3. What is your gender?

1. Male

2. Female

SD4. How old are you?

SD5. Please tell us the year in which you initiated your bachelor's degree:

\section{SECTION A}

Remember that throughout this questionnaire a JOB is defined as an activity that provides income to make a living. Thus, employed people are those who perform a work activity that provides them with an income to make a living. This definition includes self-employed people, but it excludes voluntary unpaid work.

SA1. How many jobs have you had since you graduated?

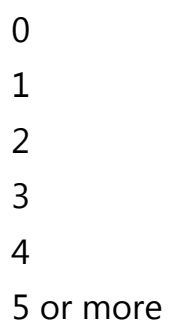


SA2. What is your current employment situation?

1. I have a job now and work for an employer $\rightarrow$ go to SECTION CJ (Current Job)

2. I am self-employed now $\rightarrow$ go to SECTION CJ (Current Job)

3. I am unemployed and looking for a job $\rightarrow$ go to SECTION JS (Job Search)

4. I am unemployed but not looking for a job $\rightarrow$ go to SECTION EIP (Economically Inactive Population)

\section{SECTION CJ}

(This section is only for those who responded 1 or 2 to SA2)

FJ1. Once you got your degree, how long did it take you to find your first paid job after graduation?

1. I already had it. I found it before I graduated.

2. It took me __ months (write the number of months in the gap)

FJ2. How did you find that first paid job after graduation or the job that you already had when you graduated? (choose the 3 most important strategies)

1. Through personal contacts (relatives, friends, ...)

2. Through the practices that I performed in companies or institutions

3. Through social and/or professional Internet networks

4. The employer contacted me

5. By creating my own job, company or business (Self-employment)

6. I contacted the employer on my own initiative

7. By contacting employment agencies

8. Through Internet portals, company websites, and press ads.

9. Through the employment services of my university

10. Other means (Specify)

Please, think of your current job (If now you have more than $\mathbf{1}$ job, think of the best paid job). The following questions refer to your current job. It does not matter whether your current job is the first job you found after graduation or you already had it when you graduated. It is the job you have now. Answer the following questions thinking of your current job.

CJ1. How did you find your current job? (choose the 3 most important strategies)

1. Through personal contacts (relatives, friends, ...)

2. Through the internship I had in companies or institutions

3. Through social and/or professional Internet networks

4. The employer contacted me

5. By creating my own company or business (Self-employment)

6. I contacted the employer on my own initiative 
7. By contacting employment agencies

8. Through Internet portals, company websites, and press advertisement.

9. Through the employment services of my university

10. Other means

CJ2. To what extent is the content of your current job related to the content of your degree?

1. None

2. Little

3. Quite

4. A lot

CJ3. What is the level of education required for your current job?

1. Below high school

2. High school

3. Vocational education

4. College and University degree

5. Master's degree and higher

CJ4. To what extent do your competences match the requirements of your job?

1. My competences are far below the requirements of my job

2. My competences are a little below the requirements of my job

3. My competences match the requirements of my job

4. My competences are a little above the requirements of my job

5. My competences greatly exceed the requirements of my job

CJ5. Is the organization you work for a ...?

1. Public company/organization

2. Private company/organization

3. Public-private venture

4. FDI company

5. Foreign organization

6. NGO

7. Others (specify)

CJ6. What is the sector of economic activity of your organization? Choose the best option.

1. Agriculture, forestry, fishery

2. Mining

3. Manufacturing

4. Electricity, fuel, oil, gas

5. Water supply, waste, and drainage

6. Construction 
7. Wholesale, retail, and repairs

8. Transportation and logistics

9. Food, accommodation services

10. Information and communication

11. Banking, finance, and insurance

12. Real estate activities

13. Professional, science, and technological activities

14. Administration and supportive services

15. Education and training

16. Health and social protection

17. Sport, culture, art, and entertainment

18. Other services

CJ7. In what functional area of the company is your current job included?

1. Sales and marketing

2. Production and/or provision of services

3. General services of the company

4. Administration and finance

5. Computing

6. Human Resources

7. Customer Service

8. General management

9. Quality control

10. Education

11. Research/Research\& Development\& Innovation

12. Health

13. Logistics

14. Do not know

15. Others

CJ8. How many employees does your company have?

1. Up to 10 employees

2. Between 11 and 200

3. Between 201 and 300

4. More than 300 employees

CJ9.Where is your current job located? (choose the most accurate option)

1. In the town where your family lives

2. In the province where your family lives

3. In the region where your family lives

4. In another region of your country.

5. Abroad, in another country. 
CJ10.What is the hierarchical level of your current job?

1. Top manager

2. Manager

3. Middle manager

4. Supervisor

5. Entry-level employee

6. Apprentice

CJ11. Did you sign a formal written employment contract for your current job?

1. Yes

2. No

CJ12. Is your current job ...?

1. A SHORT-TERM job

2. A LONG-TERM job

3. An unidentified-term job.

4. I do not know.

CJ13. Is your current job ...?

1. A part-time job

2. A full-time job

CJ14. Please, give an estimation of your monthly income in your current job:

1. Less than 5 mil. dong/month

2. From 5 mil. dong to $7 \mathrm{mil}$. dong/month

3. From 7 mil. dong to $10 \mathrm{mil}$. dong/month

4. From 10 mil. dong to 15 mil. dong/month

5. More than 15 mil. dong/month

CJ15. What degree of satisfaction or dissatisfaction do you get from each of the following aspects of your job? To respond to these items, choose one of the options from the following response scale:

\begin{tabular}{|l|c|c|c|c|}
\cline { 2 - 4 } \multicolumn{1}{c|}{} & \begin{tabular}{c} 
Very \\
dissatisfied \\
\multicolumn{1}{c|}{}
\end{tabular} & $\begin{array}{c}\text { Dissatisfied } \\
2\end{array}$ & $\begin{array}{c}\text { Satisfied } \\
3\end{array}$ & $\begin{array}{c}\text { Very } \\
\text { satisfied } \\
4\end{array}$ \\
\hline 1. The work you do & & & & \\
\hline 2. The income you receive & & & & \\
\hline 3. Your working conditions & & & & \\
\hline $\begin{array}{l}\text { 4. The opportunities for professional } \\
\text { development }\end{array}$ & & & & \\
\hline 5. Your company as a whole & & & & \\
\hline
\end{tabular}


CJ16. What is the title of your current job? (e.g., accountant, mechanical engineering, primary school teacher, etc.). Write it on the following line:

CJ17. Rate the importance of each of the following factors and competences for good performance in your current job. To respond to these items, choose one of the options from the following response scale:

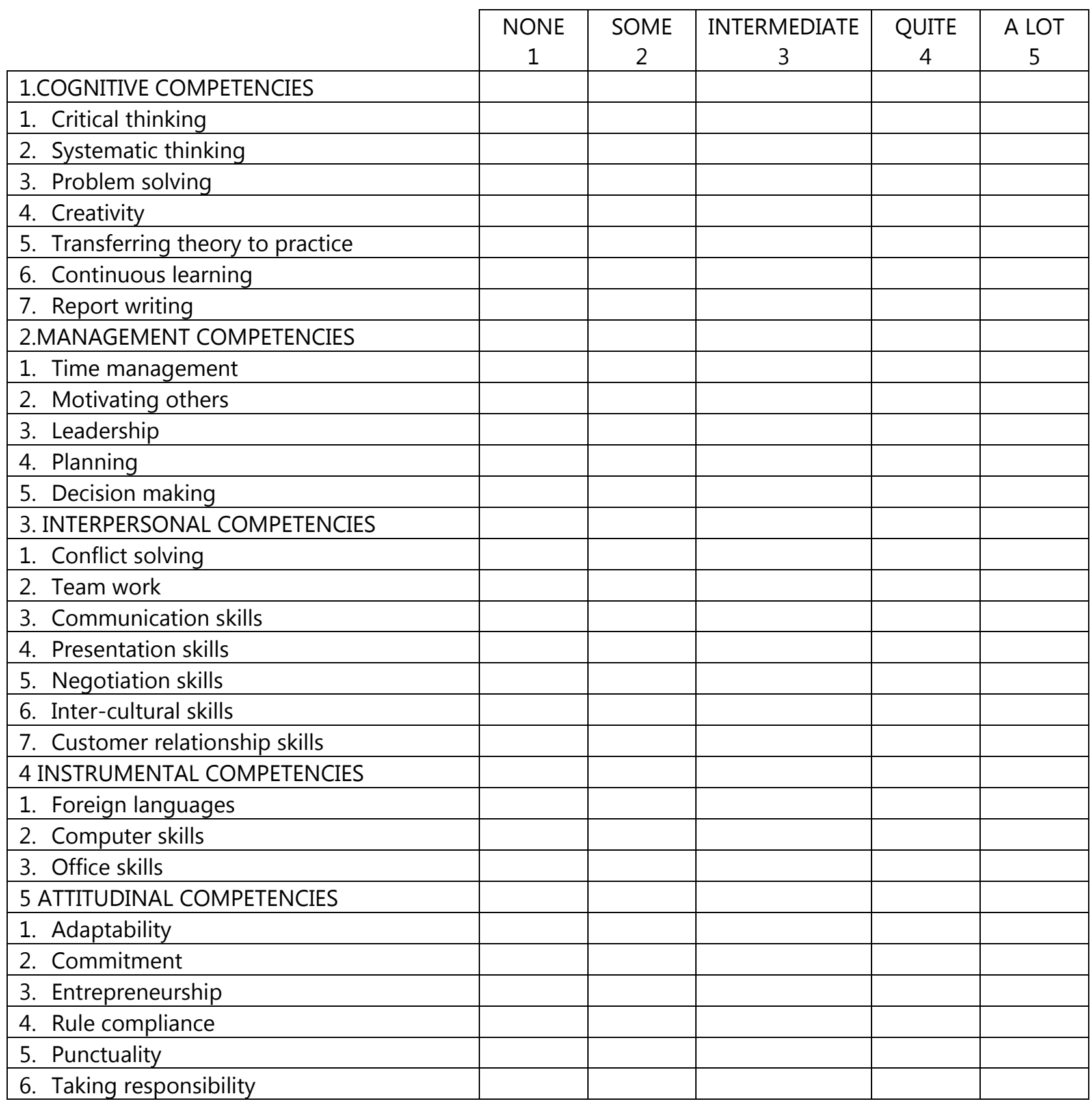




\section{SECTION JS}

(This section is only for those who responded 3 to SA2)

JS1. How long have you been looking for a job? MONTHS

JS2. What are the 3 job search strategies you have used more often?

1. personal contacts (relatives, friends, ...)

2. social and/or professional Internet networks

3. contacting employment agencies

4. Internet portals, company websites, and press ads.

5. Use of the employment services of my university

6. Other strategies

JS.3 Rate the degree of responsibility of each of the following factors in your difficulties in finding a job. To respond to these items, choose one of the options from the following response scale:

\begin{tabular}{|c|c|c|c|c|c|}
\hline & $\begin{array}{c}\text { NONE } \\
1\end{array}$ & $\begin{array}{c}\text { SOME } \\
2\end{array}$ & $\begin{array}{c}\text { INTER- } \\
\text { MEDIATE } \\
3\end{array}$ & $\begin{array}{l}\text { QUITE } \\
4\end{array}$ & $\begin{array}{l}\text { A LOT } \\
5\end{array}$ \\
\hline \multicolumn{6}{|l|}{$\begin{array}{l}\text { 1. Deficiencies in the university education } \\
\text { I received }\end{array}$} \\
\hline \multicolumn{6}{|l|}{$\begin{array}{l}\text { 2. Lack of, or insufficient, professional } \\
\text { practice and experience }\end{array}$} \\
\hline \multicolumn{6}{|l|}{$\begin{array}{l}\text { 3. Lack of knowledge about the labour } \\
\text { market }\end{array}$} \\
\hline \multicolumn{6}{|l|}{ 4. Lack of language skills } \\
\hline \multicolumn{6}{|l|}{ 5. Lack of computer skills } \\
\hline \multicolumn{6}{|l|}{$\begin{array}{l}\text { 6. You do not like the jobs you have been } \\
\text { offered }\end{array}$} \\
\hline \multicolumn{6}{|l|}{$\begin{array}{l}\text { 7. The jobs you have been offered do not } \\
\text { have an adequate wage }\end{array}$} \\
\hline \multicolumn{6}{|l|}{$\begin{array}{l}\text { 8. The jobs you have been offered are not } \\
\text { related to your degree }\end{array}$} \\
\hline \multicolumn{6}{|l|}{$\begin{array}{l}\text { 9. There are personal circumstances that } \\
\text { keep you from working }\end{array}$} \\
\hline \multicolumn{6}{|l|}{ 10. Lack of job search skills } \\
\hline \multicolumn{6}{|l|}{ 11. Saturation of the labour market } \\
\hline \multicolumn{6}{|l|}{$\begin{array}{l}\text { 12. My demographic characteristics } \\
\text { (gender, age, etc.) }\end{array}$} \\
\hline 13. Other (write response: string variable) & & & & & \\
\hline
\end{tabular}

JS4. Do you want the career centre of your university to support you in searching for a job?

1 Yes $\rightarrow$ What kind of support would you like to receive from the career centre of your university? (ask career centre group for response options)

2 No 
JS5. If yes, what do you want the Career Centre to offer?

1. General information on labour market and job opportunities

2. Information about training opportunities

3. Job search consulting services

4. Soft skill training services (communication, teamworking,...

5. Job-hunting skills

6. Hosting job fairs and other events with employers

7. Providing job opportunities for each major

8. Other (specified)

\section{SECTION EIP}

(This section is only for those who responded to SA2 with option 4)

EIP1. Why aren't you looking for a job right now? (choose the most important reason)

1. Because I continue to study

2. Because I have to take care of my family and/or housework

3. Because there are no jobs for people with my degree

4. Because I have lost hope in finding work

5. Because I do not want to work

6. For other reasons 
